\title{
Magnetic resonance imaging and spectroscopy
}

\author{
Citation for published version (APA):
}

van Ewijk, P. A. (2014). Magnetic resonance imaging and spectroscopy: a noninvasive window into lipotoxicity. [Doctoral Thesis, Maastricht University]. Uitgeverij BOXPress. https://doi.org/10.26481/dis.20140701pe

Document status and date:

Published: 01/01/2014

DOI:

10.26481/dis.20140701pe

Document Version:

Publisher's PDF, also known as Version of record

\section{Please check the document version of this publication:}

- A submitted manuscript is the version of the article upon submission and before peer-review. There can be important differences between the submitted version and the official published version of record.

People interested in the research are advised to contact the author for the final version of the publication, or visit the DOI to the publisher's website.

- The final author version and the galley proof are versions of the publication after peer review.

- The final published version features the final layout of the paper including the volume, issue and page numbers.

Link to publication

\footnotetext{
General rights rights.

- You may freely distribute the URL identifying the publication in the public portal. please follow below link for the End User Agreement:

www.umlib.nl/taverne-license

Take down policy

If you believe that this document breaches copyright please contact us at:

repository@maastrichtuniversity.nl

providing details and we will investigate your claim.
}

Copyright and moral rights for the publications made accessible in the public portal are retained by the authors and/or other copyright owners and it is a condition of accessing publications that users recognise and abide by the legal requirements associated with these

- Users may download and print one copy of any publication from the public portal for the purpose of private study or research.

- You may not further distribute the material or use it for any profit-making activity or commercial gain

If the publication is distributed under the terms of Article $25 \mathrm{fa}$ of the Dutch Copyright Act, indicated by the "Taverne" license above, 
Magnetic Resonance Imaging and Spectroscopy:

a noninvasive Window into Lipotoxicity 
(C) Copyright P.A. van Ewijk, Almere 2014

Figures at the cover are from Chapter 5 and Chapter 7

ISBN 978-90-8891-905-3

Published by Uitgeverij BOXPress, 's Hertogenbosch 


\title{
Magnetic Resonance Imaging and Spectroscopy: a noninvasive Window into Lipotoxicity
}

\author{
Proefschrift
}

Ter verkrijging van de graad van doctor aan de Universiteit Maastricht, op gezag van de Rector Magnificus, Prof. dr. L.L.G. Soete, volgens het besluit van het college der Decanen, in het openbaar te verdedigen op dinsdag 1 juli 2014 om 14.00 uur

door

Petronella Adriana van Ewijk

Geboren op 24 december 1984 te Naarden, Nederland 


\section{Promotor:}

Prof. dr. L.P.A.J. Schrauwen

\section{Co-promotores:}

Dr. M.E. Kooi

Dr. V.B. Schrauwen-Hinderling

\section{Beoordelingscommissie:}

Prof. dr. J. Plat (voorzitter)

Prof. dr. S. Heymans

Dr. H.E. Kan, Leids Universitair Medisch Centrum

Prof. dr. F. Mottaghy

Dr. J.J. Prompers, Technische Universiteit Einhoven

The studies presented in this thesis were performed within the NUTRIM School for Nutrition, Toxicology and Metabolism, which participates in the Graduate School VLAG, accredited by the Royal Netherlands Academy of Arts and Sciences.

The research presented in this thesis was performed within the framework of the Center for Translational Molecular Medicine (CTMM), project PREDICCt (grant 01C-104), and supported by the Dutch Heart Foundation, Dutch Diabetes Research Foundation and Dutch Kidney Foundation. 


\section{Table of Contents}

Chapter 1: Introduction 7

Chapter 2: Magnetic Resonance Spectroscopy: a Noninvasive Window into Cardiac Metabolism.

Chapter 3: Geometrical models for cardiac MRI in rodents: comparison of quantification of left ventricular volumes and function by various geometrical models with a full-volume MRI data set in rodents .43

Chapter 4: Lipotoxicity and the role of maternal nutrition..... 63

Chapter 5: Increased cardiac lipid content and postprandial hypertriglyceridemia after early exposure to high-fat feeding

Chapter 6: Hepatic lipid content is unchanged after two hours of cycling exercise in middle-aged overweight men

Chapter 7: Absolute quantification of hepatic $\mathrm{\gamma}$-ATP concentrations using ${ }^{31} \mathrm{P} \mathrm{MR}$ Spectroscopy at a whole body 3T scanner..... 137

Chapter 8: General discussion 159

Summary 171

Samenvatting. 177

Dankwoord 183

Curriculum Vitea 189

List of publications. 193 

Chapter 1

Introduction 


\section{Overweight and obesity}

Worldwide the prevalence of overweight and obesity has increased dramatically. Between 1980 and 2008, the age-standardized prevalence of overweight has increased from $24.6 \%$ to $34.4 \%$ in the adult population (1). The age-standardized prevalence of obesity has nearly doubled; from $6.4 \%$ to $12 \%$ of the adult population between 1980 and 2008 (1). Each year, 2.8 million individuals die as a result of being overweight or obese (2).

Overweight and obesity are known as a strong risk factor for the development of insulin resistance and type 2 diabetes mellitus (T2DM) $(3,4)$, non-alcoholic fatty liver disease (NAFLD) (5), hypertension (6), cardiovascular disease $(7,8)$ and several cancer types (9).

\section{Ectopic lipid accumulation and lipotoxicity}

Although most fat is stored in adipose tissue, small amounts of triglycerides are also stored in other tissues. Next to expansion of adipose tissue mass, overweight and obesity are associated with increased fat deposition in non-adipose tissue at so-called "ectopic" sites, such as heart, liver, pancreas and skeletal muscle. Increased cardiac lipid content is associated with cardiomyopathy and cardiac dysfunction $(10,11)$. Increased fat deposition in the liver, also called hepatic steatosis, and skeletal muscle is associated with insulin resistance (12-14). The adverse effects caused by accumulation of lipids and lipid intermediates in nonadipose tissue are called lipotoxicity (15).

The exact mechanism by which fat accumulation may exert lipotoxic effects is yet unresolved, however, it has been suggested that lipid metabolites ("intermediates"), such as diacylglycerol and ceramides could hamper insulin signaling cascade, thereby hampering insulin sensitivity in skeletal muscle, the liver and the heart (16). Furthermore, some fatty acids can induce apoptosis, which may be of specific importance in cardiac lipotoxicity. Furthermore, highly reactive lipid species (such as peroxidized fatty acids) may damage organelles, hampering cellular function. Especially mitochondrial damage has attained a lot of attention in that respect. Mitochondria are responsible for most of the cellular generation of ATP by oxidizing glucose and fatty acids. Therefore, lipotoxicityinduced mitochondrial damage may reduce the oxidative capacity of cells, thereby reducing the energy producing capacity. A diminished mitochondrial function has been linked to insulin resistance, cardiomyopathy and heart failure (17-19). Importantly, a reduced mitochondrial function may, in turn, also aggravate lipid accumulation, as it has been suggested that a low mitochondrial capacity may favor fat storage over oxidation (20). 
To investigate lipid accumulation and its consequences, in certain cases, biopsy material can be studied. However, invasive biopsies have serious drawbacks such as the risk of complications and the fact that only a limited amount of tissue material can being studied. Therefore, the use of non-invasive techniques, such as Magnetic Resonance Imaging and Spectroscopy, is usually highly preferable.

\section{TECHNIQUES}

Magnetic Resonance Imaging and Spectroscopy

Magnetic Resonance Imaging and Spectroscopy are very attractive techniques, to study in vivo changes in metabolism noninvasively. Since it allows repeated measurement, the effect of interventions can be studied. Lipids can be detected using ${ }^{1} \mathrm{H}-\mathrm{MRS}$ (21) and ${ }^{13} \mathrm{C}-\mathrm{MRS}$ (22), and high energy phosphates such as ATP and $\mathrm{PCr}$ can be detected using ${ }^{31} \mathrm{P}$-MRS (23). Importantly, MRS can be performed in the same session as Magnetic Resonance Imaging (MRI). Using MRI, e.g. cardiac function, structure, perfusion and viability can be determined (24). Additionally (myocardial) fat distribution can be determined using Dixon MRI (25).

The aim of the present thesis was to further investigate the relationship between ectopic fat accumulation and cardiac and hepatic tissue function, using noninvasive magnetic resonance techniques.

\section{OUTLINE OF THIS THESIS}

Magnetic Resonance techniques have proven to be an important tool in noninvasive research on metabolism in humans and experimental animals in vivo. Chapter 2 reviews state-of-the-art MR methods that can be used to assess cardiac metabolism in vivo, namely ${ }^{31} \mathrm{P}-\mathrm{MRS},{ }^{1} \mathrm{H}-\mathrm{MRS}$, hyperpolarized ${ }^{13} \mathrm{C}$ MRS and Dixon MRI. Additionally, various applications of these methods in studying cardiac metabolic disorders are described.

Cardiac MRS can be performed in the same session as cardiac Magnetic Resonance Imaging (CMR). Because of its high temporal and spatial resolution, multiplanar imaging capabilities and high soft tissue contrast, CMR has become an established imaging technique to study myocardial structure, function, perfusion and fibrosis. Multi-slice, short axis cine-MRI of the complete LV is considered gold standard for the assessment of cardiac function in rodent models of cardiac disease. However, this method requires long acquisition times. By using geometrical models that require only up to three cine-MRI slices instead, 
acquisition and post-processing time can be reduced more than 3 -fold, which is described in Chapter 3.

A yet underestimated factor in the etiology of obesity and obesity-related diseases is the early developmental environment, since it is known that developmental conditions exert long-lasting influence. Before application of the described MR techniques in a mouse model of fetal programming, a review on the role of maternal nutrition in the development of lipotoxicity in offspring is given in Chapter 4.

In Chapter 5, various non-invasive MR techniques are used to investigate in a longitudinal study whether early exposure (in utero and during lactation) to a high fat diet in mice, increases the susceptibility for unfavorable (health) effects when consuming a high-fat diet later in life. To this end, we measured glucose tolerance, cardiac function and cardiac-, hepatic- and visceral fat content at several moments in time, and related this to cardiac and hepatic mitochondrial function measured at two points in time.

Whereas early exposure to high-fat feeding may have negative effects on health, exercise training is generally assumed to have beneficial health effects. For example, it has recently been shown that prolonged exercise training lowers hepatic lipid content, and it is well-known that high hepatic lipid content is associated with increased risk of metabolic complications, including insulin resistance and cardiovascular events. However, it is unknown if acute exercise has the same effect. Additionally hepatic ATP content is suggested to be related to insulin resistance and hepatic lipid content. In Chapter 6 we investigated whether acute exercise leads to changes in hepatic lipid content and if these changes are accompanied by changes in hepatic ATP content using ${ }^{1} \mathrm{H}$ - and ${ }^{31} \mathrm{P}$ - MRS.

Changes in hepatic metabolism are generally expressed using metabolite peak ratios (e.g. ATP/Pi ratio or ATP/total phosphor ratio), because it is a fast and robust way of quantification. However, this approach is problematic if the concentration of the reference metabolite varies as well. To overcome this, we implement a protocol for absolute quantification of ${ }^{31} \mathrm{P}$ metabolites in human liver at a whole body 3T MR scanner, which is described in Chapter 7.

Finally, the results of the present thesis are discussed and placed in broader perspective in Chapter 8. 


\section{REFERENCES}

1. Stevens GA, Singh GM, Lu Y, Danaei G, Lin JK, Finucane MM, Bahalim AN, Mclntire RK, Gutierrez HR, Cowan M, Paciorek CJ, Farzadfar F, Riley L, Ezzati M. National, regional, and global trends in adult overweight and obesity prevalences. Popul Health Metr. 2012; 10:22.

2. World Health Organization. Obesity and overweight. Fact sheet $\mathrm{N}^{\circ} 311$. [http://www.who.int/mediacentre/factsheets/fs311/en/]

3. Boden G. Obesity, insulin resistance and free fatty acids. Curr Opin Endocrinol Diabetes Obes. 2011; 18:139-143.

4. Kahn SE, Hull RL, Utzschneider KM. Mechanisms linking obesity to insulin resistance and type 2 diabetes. Nature. 2006; 444:840-846.

5. Rahimi RS, Landaverde C. Nonalcoholic fatty liver disease and the metabolic syndrome: clinical implications and treatment. Nutr Clin Pract. 2013; 28:40-51.

6. Nguyen T, Lau DC. The obesity epidemic and its impact on hypertension. Can J Cardiol. 2012; 28:326333.

7. Hutcheson R, Rocic P. The metabolic syndrome, oxidative stress, environment, and cardiovascular disease: the great exploration. Exp Diabetes Res. 2012; 2012:271028.

8. Berwick ZC, Dick GM, Tune JD. Heart of the matter: coronary dysfunction in metabolic syndrome. J Mol Cell Cardiol. 2012; 52:848-856.

9. Vucenik I, Stains JP. Obesity and cancer risk: evidence, mechanisms, and recommendations. Ann $\mathrm{N} \mathrm{Y}$ Acad Sci. 2012; 1271:37-43.

10. McGavock JM, Victor RG, Unger RH, Szczepaniak LS. Adiposity of the heart, revisited. Ann Intern Med. 2006; 144:517-524.

11. Kankaanpaa M, Lehto HR, Parkka JP, Komu M, Viljanen A, Ferrannini E, Knuuti J, Nuutila P, Parkkola R, Iozzo P. Myocardial triglyceride content and epicardial fat mass in human obesity: relationship to left ventricular function and serum free fatty acid levels. J Clin Endocrinol Metab. 2006; 91:4689-4695.

12. Smith BW, Adams LA. Non-alcoholic fatty liver disease. Crit Rev Clin Lab Sci. 2011; 48:97-113.

13. Takamura T, Misu H, Ota T, Kaneko S. Fatty liver as a consequence and cause of insulin resistance: lessons from type 2 diabetic liver. Endocr J. 2012; 59:745-763.

14. Eckardt K, Taube A, Eckel J. Obesity-associated insulin resistance in skeletal muscle: role of lipid accumulation and physical inactivity. Rev Endocr Metab Disord. 2011; 12:163-172.

15. Schaffer JE. Lipotoxicity: when tissues overeat. Curr Opin Lipidol. 2003; 14:281-287.

16. van Herpen NA, Schrauwen-Hinderling VB. Lipid accumulation in non-adipose tissue and lipotoxicity. Physiol Behav. 2008; 94:231-241.

17. Rector RS, Thyfault JP, Uptergrove GM, Morris EM, Naples SP, Borengasser SJ, Mikus CR, Laye MJ, Laughlin $\mathrm{MH}$, Booth FW, Ibdah JA. Mitochondrial dysfunction precedes insulin resistance and hepatic steatosis and contributes to the natural history of non-alcoholic fatty liver disease in an obese rodent model. J Hepatol. 2010; 52:727-736.

18. Burelle Y, Khairallah M, Ascah A, Allen BG, Deschepper CF, Petrof BJ, Des Rosiers C. Alterations in mitochondrial function as a harbinger of cardiomyopathy: lessons from the dystrophic heart. J Mol Cell Cardiol. 2010; 48:310-321.

19. van Bilsen $M$, van Nieuwenhoven FA, van der Vusse GJ. Metabolic remodelling of the failing heart: beneficial or detrimental? Cardiovasc Res. 2009; 81:420-428.

20. Phielix E, Mensink M. Type 2 diabetes mellitus and skeletal muscle metabolic function. Physiol Behav. 2008; 94:252-258.

21. Szczepaniak LS, Dobbins RL, Metzger GJ, Sartoni-D'Ambrosia G, Arbique D, Vongpatanasin W, Unger R, Victor RG. Myocardial triglycerides and systolic function in humans: in vivo evaluation by localized proton spectroscopy and cardiac imaging. Magn Reson Med. 2003; 49:417-423.

22. Ball DR, Rowlands B, Dodd MS, Le Page L, Ball V, Carr CA, Clarke K, Tyler DJ. Hyperpolarized butyrate: A metabolic probe of short chain fatty acid metabolism in the heart. Magn Reson Med. 2013.

23. Bottomley PA. Noninvasive study of high-energy phosphate metabolism in human heart by depthresolved 31P NMR Spectroscopy. Science. 1985; 229:769-772.

24. Karamitsos TD, Neubauer S. Cardiovascular magnetic resonance in heart failure. Curr Cardiol Rep. 2011; 13:210-219.

25. Goldfarb JW, Roth M, Han J. Myocardial fat deposition after left ventricular myocardial infarction: assessment by using MR water-fat separation imaging. Radiology. 2009; 253:65-73. 

Chapter 2

Magnetic Resonance Spectroscopy: a Noninvasive
Window into Cardiac Metabolism

Petronella A. van Ewijk ${ }^{1,2,5}$, Vera B. Schrauwen-Hinderling ${ }^{1,2,5}$, Sebastiaan C.A.M. Bekkers ${ }^{3}$ Jan F.C Glatz ${ }^{4,6}$, Joachim E. Wildberger ${ }^{2}$ and M. Eline Kooi ${ }^{2,5,6}$

Departments of ${ }^{1}$ Human Biology, ${ }^{2}$ Radiology, ${ }^{3}$ Cardiology and ${ }^{4}$ Molecular Genetics, Maastricht University Medical Centre, Maastricht, the Netherlands, ${ }^{5}$ NUTRIM - School for Nutrition, Toxicology and Metabolism, Maastricht University Medical Centre, Maastricht, the Netherlands, ${ }^{6}$ CARIM - Cardiovascular Research Institute Maastricht, Maastricht University Medical Centre, Maastricht, the Netherlands 


\begin{abstract}
A well-functioning heart requires a constant supply of a balanced mixture of nutrients to be used for the production of adequate amounts of adenosine triphosphate (ATP), which is the main energy source for most cellular functions. Defects in cardiac energy metabolism are linked to several myocardial disorders. Magnetic Resonance Spectroscopy (MRS) can be used to study in vivo changes in cardiac metabolism non-invasively. MR techniques allow repeated measurements, so that disease progression, the response to treatment or to a lifestyle intervention can be monitored. The present review focuses on in vivo MRS to assess cardiac metabolism in experimental animals and in humans. Various magnetic resonance techniques, such as cardiac ${ }^{31} \mathrm{P}$ MRS, ${ }^{1} \mathrm{H}$ MRS, hyperpolarized ${ }^{13} \mathrm{C}$ MRS and Dixon Magnetic Resonance Imaging (MRI), are described. A short overview of current and emerging applications is provided.
\end{abstract}




\section{Cardiac energy metabolism}

The heart is an energy-demanding organ requiring a continuous supply of nutrients and oxygen. A schematic overview of cardiac energy metabolism is presented in Figure 1. To meet this energy-demand, large amounts of long-chain fatty acids (LCFA) and carbohydrates are metabolized to produce adenosine triphosphate (ATP). In the newborn heart, carbohydrates are the major energyproviding substrates (1), while the healthy adult heart obtains $~ 70 \%$ of its energy from LCFA oxidation and the remainder mostly from carbohydrate oxidation.

Uptake of LCFA into cardiomyocytes is facilitated by membrane proteins (CD36, FATP 1 and FATP $_{\mathrm{pm}}$ ), whereafter LCFA are converted into fatty acyl CoAs to be stored as triglycerides (TG) or be degraded into acetyl-CoA, via $\beta$-oxidation, thereby generating reduced nicotinamide adenine dinucleotide (NADH) and reduced flavin adenine dinucleotide $\left(\mathrm{FADH}_{2}\right)$. More NADH and ATP are generated in the tricarboxylic acid (TCA) cycle.

Carbohydrates enter the cardiomyocyte via glucose transporters (GLUT1 and GLUT4). Glucose is converted (via glycolysis) into pyruvate which is produced also from lactate and from alanine. Pyruvate passes the double membrane of the mitochondrion via the pyruvate dehydrogenase (PDH) complex and is converted into acetyl-CoA. Acetyl-CoA enters the TCA cycle or can be converted to acetylcarnitine. During glycolysis also NADH and ATP are produced.

NADH is used for generation of ATP through energy transfer via the electron transport chain (ETC) to ATP synthase. The high energy phosphate bond from ATP can be transferred to creatine $(\mathrm{Cr})$ to form phosphocreatine $(\mathrm{PCr})$ and adenosine diphosphate (ADP). This reaction is catalyzed by the enzyme creatine kinase (CK). $\mathrm{PCr}$ diffuses through the cytosol to places of utilization (e.g. myofibrils, sarcoplasmatic reticulum), where the high energy phosphate from $\mathrm{PCr}$ is transferred to ADP to again form ATP and $\mathrm{Cr}$ again.

Besides LCFA's and carbohydrates, the heart also uses lactate and ketone bodies as an energy source (2).

Under pathophysiological conditions, substrate preference can change as well as TCA cycle activity, that may interfere with cardiac function (3).

\section{Metabolism in cardiac disease}

Various cardiac diseases, both ischemic as well as non-ischemic, but also obesity, diabetes and ageing, have been associated with an altered cardiac energy metabolism $(4,5)$. In ischemic heart disease, substrate metabolism changes in 
relation to the severity of ischemia. In severe ischemia (>70\% reduction in flow), the heart produces lactate that will accumulate, while glycogen and high-energy phosphate levels decline, followed by contractile dysfunction and ultimately cell death. Mild to moderate ischemia (20-60\% reduction in flow) is characterized by a transient lactate production, decreased high-energy phosphate levels and contractile dysfunction (4). Non-ischemic cardiomyopathies are characterized by their increased reliance on glucose, and decreased LCFA uptake and oxidation (5). Obesity and diabetes are associated with increased risk for heart failure $(6,7)$. Here, the increased supply and uptake of LCFA (8-10) may lead to lipid accumulation, which has been associated with metabolic changes, termed 'lipotoxicity' $(11,12)$.

Magnetic Resonance Spectroscopy: a noninvasive window into cardiac metabolism

Because of its high temporal and spatial resolution, multiplanar imaging capabilities and high soft tissue contrast, cardiac MRI has become an established imaging technique to study myocardial structure, function, perfusion and fibrosis (13). Conventional cardiac MRI does not provide information on cardiac metabolism. However, cardiac Magnetic Resonance Spectroscopy (MRS), which enables to study in vivo changes in cardiac metabolism (14), can be combined with MRI. Therefore MRS can provide more insight into changes in cardiac metabolism that are associated with cardiac disease. Because it allows repeated measurements, changes in cardiac metabolism during the development of disease or in response to treatment or life style intervention can be determined. Several metabolites can be detected using Magnetic Resonance Spectroscopy (MRS), as depicted in Figure 1. Metabolites derived from lipid and carbohydrate metabolism can be detected using ${ }^{1} \mathrm{H}-\mathrm{MRS}$ (15) and hyperpolarized ${ }^{13} \mathrm{C}$ MRS (16). Dixon MRI can be used to quantify cardiac lipid content (17). High energy phosphates can be detected using ${ }^{31}$ P-MRS (18). Importantly, cardiac MRS can be performed in the same session as cardiac Magnetic Resonance Imaging. 


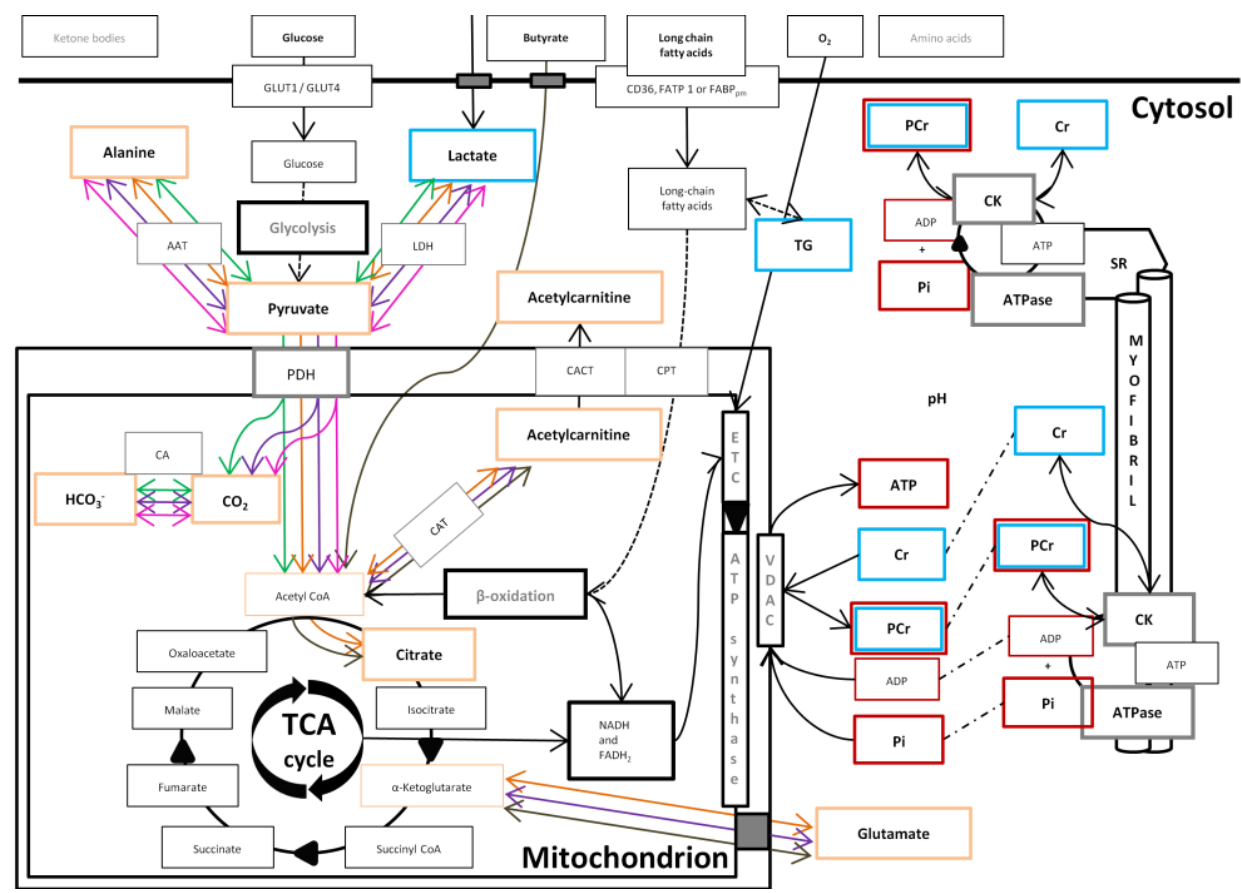

Figure 1. Metabolites which can be detected in cardiomyocytes using MR techniques.

${ }^{1} \mathrm{H}$-MRS can be used for detection of TG's, (total) creatine and lactate, which is indicated by the blue boxes. Additionally, Dixon MRI can be used to detected myocardial TG content.

${ }^{31} \mathrm{P}$-MRS can be used for the detection of ATP, PCr, Pi and ADP, which is indicated by the red boxes. In addition,

${ }^{31} \mathrm{P}-\mathrm{MTS}$ can be used to measure the flux through the CK reaction and the ATP synthesis flux, as well as the intracellular $\mathrm{pH}$ by measuring the chemical shift displacement between $\mathrm{PCr}$ and $\mathrm{Pi}$.

Using hyperpolarized ${ }^{13} \mathrm{C}$-MRS several metabolites as well as fluxes can be determined, dependent on the hyperpolarized substrate used. Green arrows indicate the detectable metabolites from $\left[1-{ }^{13} \mathrm{C}\right]$ pyruvate, orange arrows indicate the detectable metabolites from $\left[2-{ }^{13} \mathrm{C}\right]$ pyruvate, purple arrows indicate the detectable metabolites from $\left[1,2-{ }^{13} \mathrm{C}\right]$ pyruvate, pink arrows indicate the detectable metabolites from $\left[1-{ }^{13} \mathrm{C}\right]$ lactate and some detectable metabolites from [1-13C]butyrate are indicted with brown arrows.

AAT, alanine transaminase; ADP, adenosine diphosphate; ATP, adenosine triphosphate; CA, carbonic anhydrase; CACT, Carnitine-acylcarnitine translocase; CAT, carnitine acetyl transferase; CK, creatine kinase enzyme; CPT, Carnitine palmitoyltransferase; $\mathrm{Cr}$, creatinine; $\mathrm{ETC}$, electron transport chain; $\mathrm{FADH}_{2}$, reduced flavind adenine dinucleotide; $\mathrm{LDH}$, lactate dehydrogenase; $\mathrm{NADH}$, reduced nicotinamide adenine dinucleotide; $\mathrm{PCr}$, phosphocreatine; $\mathrm{PDH}$, pyruvate dehydrogenase complex; SR, sarcoplasmatic reticulum, TCA, tricarboxylic acid cycle; TG, triglyceride; VDAC, voltage-dependent anion channel.

\section{Outline}

The present review focuses on methods that can be used to assess cardiac metabolism in vivo using MRS and Dixon MRI in humans and experimental animals, with a main focus on ${ }^{31} \mathrm{P}-\mathrm{MRS},{ }^{1} \mathrm{H}-\mathrm{MRS},{ }^{1} \mathrm{H}-\mathrm{MRI}$ using the Dixon technique and hyperpolarized ${ }^{13} \mathrm{C}$ MRS. A short overview of current and emerging applications is provided. 
Cardiac MRS and MRI are highly challenging due to cardiac and respiratory motion and field inhomogeneities. Several methods have been developed for cardiac shimming to improve magnetic field homogeneity and to compensate for cardiac and respiratory motion.

\section{$B_{0}$ and $B_{1}$ field homogeneities}

Most human studies are currently performed at a magnetic field $\left(B_{0}\right)$ strength of 1.5 or 3 Tesla (19) while in vivo animal studies are performed at field strengths up to 11.7 Tesla (20). It is well known that cardiac MRI at higher $\mathrm{B}_{0}$-field improves signal-to-noise (SNR) and contrast-to-noise ratios (21). Likewise, cardiac spectroscopy at higher $\mathrm{B}_{0}$-field benefits from improved SNR and improved spectral resolution.

Challenges at higher field strength are increased $T_{1}$ relaxation time, inhomogeneous $B_{0}$ and $B_{1}$ fields, increased specific absorption rate (SAR) and degradation of the ECG. At higher $B_{0}$-field, susceptibility effects increase, leading to stronger field distortions at interfaces between tissue and air, such as in the vicinity of the air-filled lungs to the myocardium (22). In MRS, field inhomogeneities lead to broadened peaks.

Cardiac shimming is complicated by phase shifts caused by cardiac and respiratory motion and blood flow. To overcome this, different shim methods have been developed, i.e. general and cardiac specific shim methods. Shimming can be performed manually, which is time consuming and requires operator experience. Most shimming procedures are currently automated, such as magnetic field mapping ( $B_{0}$-mapping) (23). $B_{0}$-mapping time can be reduced e.g. by using linear projection mapping (24). The first cardiac specific shim method, based on $\mathrm{B}_{0^{-}}$ mapping using chemical-shift imaging (CSI), was introduced by Jaffer et al. (25) The CSI data set was obtained throughout multiple cardiac and respiratory cycles and a time and motion-averaged $\mathrm{B}_{0}$-map of the heart was calculated. Later it was shown that cardiac ECG-triggered and respiratory-gated local linear shimming improves the shim quality (26). More recently, it was shown that $\mathrm{B}_{0}$-mapping using a 3D cardiac-triggered gradient-echo sequence during consecutive breathholds, followed by first-order cardiac phase specific shimming, led to an average gain in field homogeneity of $10 \%$ (27). A drawback is that ECG-triggering during $\mathrm{B}_{0}$-map estimation increases acquisition time. It was shown that low resolution field maps for cardiac shimming can be acquired during a breath-hold of 8-10 seconds without ECG-triggering, yielding negligible temporal variation over the cardiac cycle (28).

Cardiac MRS and MRI at high field ( $\geq 3$ Tesla) not only suffer from increased magnetic field inhomogeneity, but also from transmit radiofrequency field 
$\left(B_{1}\right)$ inhomogeneities. Schär et al. (29) have shown that combined acquisition of $B_{0^{-}}$ and $B_{1}$-maps is feasible using a cardiac-triggered, modified saturated double-angle method (SDAM) (30). Using this method, localized shim, $F_{0}$, and radiofrequency (RF) powers settings can be determined within one single breath-hold (29).

\section{Coils}

The RF coil is an essential component of the MR system, for RF excitation and RF signal reception. RF volume coils are mostly used for signal transmission due to their high $\mathrm{B}_{1}$ field homogeneity and can also be used as a receive coil.

The signal-to-noise ratio can be improved by the use of RF single element surface coils, which are mostly used as a receive coil only. For ${ }^{31} \mathrm{P}$ and ${ }^{13} \mathrm{C}$ MRS studies frequently surface coils are used as a transmit/receive coil, due to the lower MR sensitivity of these nuclei. Since the transmit coil needs to produce a homogeneous $\mathrm{B}_{1}$ field in the volume of interest ( $\mathrm{VOI}$ ) and the exact position of the VOI is usually not known in advance, the size of the surface transmit coil is usually relatively large (31).

Cardiac ${ }^{1} \mathrm{H}$ MRS studies in humans are usually performed using surface receive only coils, while in cardiac ${ }^{1} \mathrm{H}$ MRS animal studies volume coils as well as surface receive coils are currently used.

The diameter of the surface receive coil has to be chosen roughly equal to the depth of the organ of examination (32). Therefore, a surface receive coil of around $10-\mathrm{cm}$ diameter will mostly suffice for cardiac MRS in humans. Careful positioning of the surface coil is important to achieve the highest signal from the organ of interest.

Furthermore dual-tuned coils, such as ${ }^{1} \mathrm{H} /{ }^{13} \mathrm{C}$ coils or ${ }^{1} \mathrm{H} /{ }^{31} \mathrm{P}$ coils, can be used. Dual-tuned coils require two channels and can also be used for indirect detection of low sensitivity nuclei. The advantage of indirect (proton observed) detection is the increased sensitivity of ${ }^{1} \mathrm{H}$ compared to ${ }^{13} \mathrm{C}$ or ${ }^{31} \mathrm{P}$. Furthermore, using indirect detection fractional enrichment can be determined since both the total $\left({ }^{12} \mathrm{C}\right.$ and ${ }^{13} \mathrm{C}$ ) and enriched fraction of a metabolite can be detected.

Finally, using multi-channel coils or phased-array receive coils, SNR can further be improved in cardiac MRS $(33,34)$. However, the number of spectra to be processed is increased by a factor equal to the number of channels used for signal reception. To this end, several automated methods have been developed (35-37), of which more recently whitened singular value decomposition was shown to work in practice (38). Multi-channel coils also enable parallel imaging, thereby reducing scan time, which is beneficial for the generally long cardiac examinations. 


\section{Cardiac and respiratory motion compensation}

To compensate for cardiac motion, cardiac ECG synchronization with prospective triggering is generally used in MRS (39), which requires a predefined time interval between triggering and data acquisition. This can be determined from cine images in order to constrain the acquisition of spectra to end-systole or diastole, when cardiac motion is minimized. For reproducible measurement of cardiac ${ }^{1} \mathrm{H}-\mathrm{MR}$ spectra, it was shown that respiratory motion correction is essential $(40,41)$. Different methods can be used: breath-hold (42), respiratory gating using a pressure belt (15), respiration-related ECG amplitude modulation (43) and respiratory gating based on navigator echo signals (44). Breath-holds limit scantime and are difficult for cardiac patients while long breath-holds often lead to undesirable changes in heart rate. The quality of ECG-based respiratory motion correction is dependent on proper placement of the ECG-electrodes, and the ECG signal is susceptible to interference from RF and gradient pulses. Using navigatorbased respiratory motion compensation, the displacement of the diaphragm is measured and ECG-triggering is allowed in a predefined window of the respiratory cycle. This method improved spectral quality significantly (41). A disadvantage of the navigator technique is that changes in breathing pattern can reduce gating efficiency strongly leading to long scan times. Furthermore, prospective volume tracking based on multiple navigator echoes can be used to compensate for respiratory motion. Using the volume tracking technique an improved spectral quality was found compared to non-navigated reference acquisitions (45).

\section{SPECTROSCOPY OF CARDIAC METABOLISM}

MRS can be used to detect metabolites with ${ }^{31} \mathrm{P},{ }^{1} \mathrm{H}$ or ${ }^{13} \mathrm{C}$ nuclei in the heart, noninvasively. In order to be able to perform MR Spectroscopy on a clinical scanner additional software and, for ${ }^{31} \mathrm{P}$ and ${ }^{13} \mathrm{C}$ MRS, also additional hardware is required. The first in vivo cardiac metabolic investigations were performed using ${ }^{31} \mathrm{P}$ MRS to detected ${ }^{31} \mathrm{P}$-containing metabolites, followed by ${ }^{1} \mathrm{H}-\mathrm{MRS}$ and more recently by ${ }^{13} \mathrm{C}$-MRS. In Table 1 and Table 2 some typical applications of cardiac MRS to study metabolism in cardiac diseases in humans and animals, respectively, are presented.

\section{${ }^{31} P-M R S$}

Cardiac ${ }^{31} \mathrm{P}-\mathrm{MRS}$ is used for the detection of metabolites such as ATP, and PCr. Red boxes are used to indicate metabolites which can be detected using ${ }^{31} \mathrm{P}-\mathrm{MRS}$ in Figure 1. An example of a cardiac phosphorous spectrum is given in Figure 2. Phosphorus spectroscopy is generally used to assess cardiac energy status. The 
PCr/ATP ratio is a measure for cardiac energy status, because any temporary mismatch between ATP demand and supply is met by the breakdown of $\mathrm{PCr}$ catalyzed by the creatine kinase enzyme.

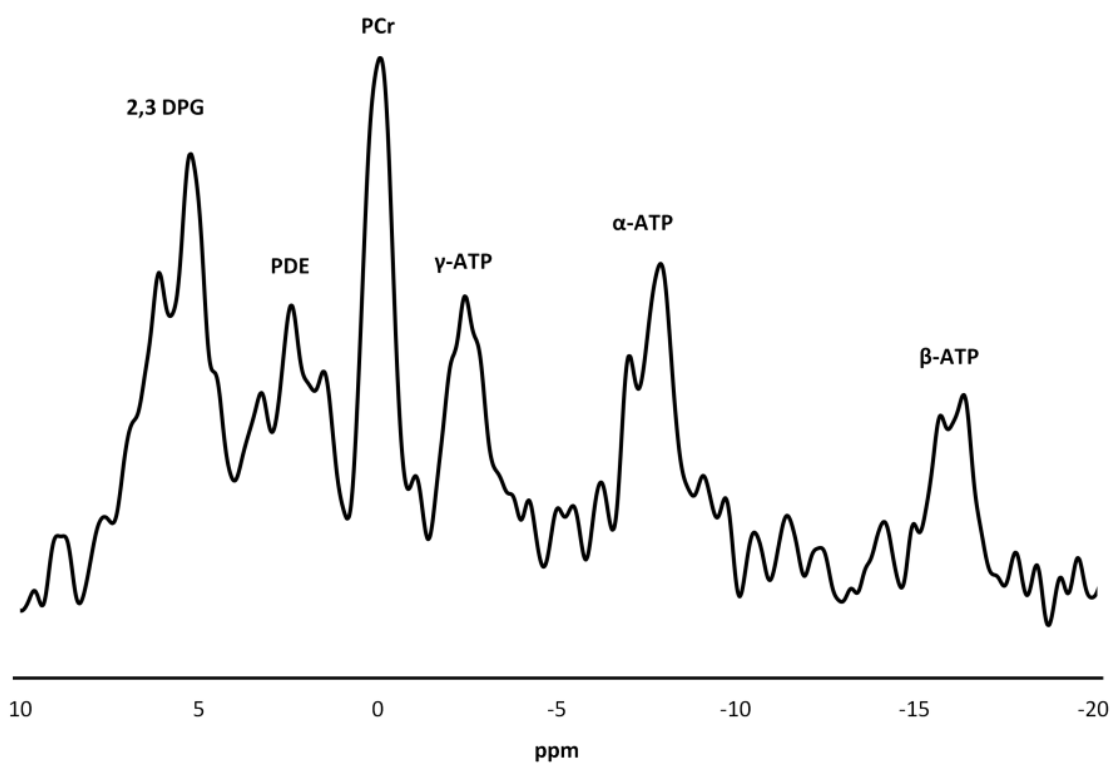

Figure 2: Example of a cardiac phosphorus $\left({ }^{31} \mathrm{P}\right)$ spectrum obtained from a healthy volunteer at a clinical 1.5T scanner. The shimming volume and 3D ISIS volume (TR=3.6 sec, number of averages=192) were placed over the entire left ventricle. ECG-triggering was performed to reduce motion artifacts. As the 3D ISIS volume included the entire left ventricle, a large amount of signal also originates from blood, which is evidenced by the prominent 2,3-DPG peak. The PCr/ATP ratio in this subject was 2.35. The metabolite peaks are indicated in the spectrum. 2,3-DPG, 2,3-diphosphoglycerate; PDE, phosphodiesters; PCr, phosphocreatine; ATP, adenine triphosphate.

The relative MR sensitivity of phosphorus is about fifteen times lower than that of proton. However, there is no dominant signal that needs suppression to detect the peaks-of-interest (such as the water signal in ${ }^{1} \mathrm{H}-\mathrm{MRS}$ ). Cardiac applications of ${ }^{31} \mathrm{P}-\mathrm{MRS}$ require localization of the detected signal to minimize contamination from signal outside the volume of interest, especially from skeletal muscle. Several localization sequences have been developed. Due to short $T_{2}$ relaxation times of most of the phosphorus metabolites, generally Free Induction Decay (FID) localization methods are used, in which the FID is measured immediately after excitation. Localization sequences used for cardiac ${ }^{31} \mathrm{P}-\mathrm{MRS}$ include ImageSelected In-vivo Spectroscopy (ISIS) and Chemical Shift Imaging (CSI). Using 3D ISIS, cubic volumes can be selected by adding and subtracting eight FID MR signals (46), which have been acquired with slice selective inversion pre-pulses along the three Cartesian axes that are switched on and off. The resulting FID signals from outside the cubic volume are canceled out. Localization using ISIS can be hampered by motion, because of disturbance of the differencing scheme. 1D-, 2D- 
and 3D CSI, with phase encoding in one, two, and three dimensions allows the selection of multiple voxels for spectroscopic analysis during a single measurement, at the expense of longer scan times. CSI can be combined with other spatial localization techniques, such as ISIS. At a 1.5 Tesla scanner, it was shown that the PCr/ATP ratios using 3D localization techniques (3D ISIS and a combination of 2D ISIS and 1D CSI) were comparable, while significantly lower $\mathrm{PCr} / \mathrm{ATP}$ ratios were obtained using 1D-CSI (47). The lower PCr/ATP ratio with the less well-defined localization by 1D-CSI may be due to contamination of cardiac spectra by liver. In addition, a reduction in the PCr/ATP ratio may also partly be explained by contamination of blood, which would add ATP signals but no PCr. Blood contamination can be corrected for using the 2,3-diphosphoglycerate (2,3DPG) signal (48). Furthermore, large differences in PCr/ATP ratio were observed between serial examinations (with a time interval of 7 days) for all localization techniques (47). At a 3 Tesla scanner, good reproducibility with a variance of $12 \%$ was found when measuring the PCr/ATP ratio using ISIS volume selection in subjects both on the same day and on different days (49). To allow matching of the shape and size of the sensitive volume to the anatomy of the subject, thereby reducing contamination from adjacent organs and improving sensitivity, Spatial Localization with Optimal Point Spread Function (SLOOP) was developed (50). Compared to CSI, the SNR was improved by 30\% using SLOOP (51).

It is also feasible to determine absolute concentrations of metabolites with cardiac ${ }^{31} \mathrm{P}$ MRS $(52,53)$. Absolute quantification has the advantage that it is unaffected by concentration changes of the reference metabolite. When performing ${ }^{31} \mathrm{P}$ MRS for absolute quantification, one has to correct for partial saturation (54), blood contamination $(48,55)$ and nuclear Overhauser enhancement (56). Under dynamic conditions, partial saturation correction can be affected by chemical exchange $(57,58)$ and may thereby introduce quantification errors. To reduce the quantification error as a result of the use of inaccurate $T_{1}$ times due to chemical exchange, it was suggested to measure $T_{1}$ relaxation times at the beginning and end of an experiment to approximate the saturation factor (59). More recently, the ongoing dual-angle measurement (O-DAM) for correction of partial saturation was introduced and was shown to be superior to conventional approaches (60). Using the O-DAM method, $\mathrm{T}_{1}$ measurements are performed throughout the course of an experiment. For absolute quantification of phosphorus metabolites, one also needs to take coil sensitivity profile $(61,62)$, local flip angle and partial volume effects into account (62). Absolute quantification of phosphorus metabolites can be performed using different methods among which the internal reference method, the external reference method, and the phantom replacement method as reviewed by Jansen et al (63). Nowadays, the phantom replacement method is often used, whereby the VOI needs to be positioned at the same relative position with respect to the coil as in vivo (64). This usually means that for every in vivo measurement, a phantom 
replacement experiment is necessary. Alternatively, one can position the VOI during the in vivo measurement always at exactly the same position with respect to the isocenter of the magnet and the RF coil, so that only one phantom replacement experiment is required (65). However, relative quantification is less time-consuming and less prone to errors, and is therefore still mostly used, e.g. when determining PCr/ATP ratio as measure for cardiac energy status.

PCr/ATP ratio, has been shown to be reduced in dilated cardiomyopathy (48), hypertrophic cardiomyopathy (66), ischemic heart disease (67) and myocardial infarction (68). Also type 2 diabetes mellitus (T2DM) is associated with impaired PCr/ATP ratio in some studies (69) (see Table 1). Inorganic phosphate (Pi) can usually not be determined because of the overlapping resonances from 2,3-DPG originating from blood. However, in some patients with hypertrophic cardiomyopathy decreased $\mathrm{PCr} / \mathrm{Pi}$ ratio was reported (70).

Cardiac energy metabolism has also been studied in small experimental animals in vivo $(71,72)$. Noninvasive ${ }^{31} \mathrm{P}-\mathrm{MRS}$ in small animal models in vivo is challenging because of the high heart rates and respiratory motion, as well as the small size of the heart in general. Nevertheless, several studies were performed in small animal models of disease. In murine hearts with pressure-overload hypertrophy induced by transverse aortic constriction, reductions in PCr/ATP ratio and ATP concentration were found (73). The abnormal energetics in those mice predicts contractile dysfunction and subsequent ventricular remodeling (74). A reduction in PCr/ATP ratio as well as ventricular remodeling is also observed after myocardial infarction. However, in mice supplemented with xantine oxidase inhibitor after myocardial infarction an improvement in ventricular function and a normalization in high-energy phosphate ratio was observed (75). As the $\beta$ oxidation of long-chain fatty acids provides the major energy source of the heart and since mitochondrial very long-chain acyl-CoA dehydrogenase (VLCAD) catalyzes the first step in $\beta$-oxidation, a deficiency in VLCAD reduces myocardial fatty acid $\beta$-oxidation and energy production. It has recently been demonstrated in VLCAD knockout mice that the chronic energy deficiency leads to cardiac dysfunction (76). Long-chain acyl-CoA dehydrogenase (LCAD) knockout mice show a similar phenotype as humans deficient in VLCAD in fasted condition. In the fasted condition, an impairment in myocardial energy status has been demonstrated with ${ }^{31} \mathrm{P}$-MRS (77). Also in rats it was shown that $\mathrm{Cr}$ depletion results in disturbed energy metabolism, comprised left ventricular function and remodeling (78).

\section{${ }^{31}$ P Magnetization Transfer Spectroscopy}

Using magnetization transfer spectroscopy (MTS), reaction rates and fluxes can be measured, i.e. the rate constants of the creatine kinase (CK) reaction which 
multiplied by the PCr concentration gives the (forward) CK flux, and the rate constants of ATP synthase which multiplied with the Pi concentration gives the (forward) ATP synthesis flux. The generation of ATP is largely controlled by the CK and ATP synthase enzymes. The CK enzyme catalyzes the conversion from ADP and PCr to ATP. The ATP synthase enzyme catalyzed the conversion from ADP and Pi to ATP.

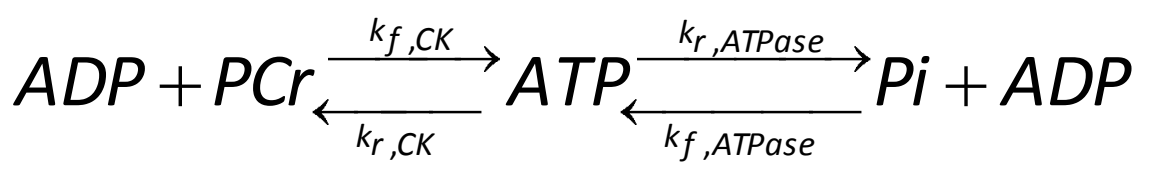

Under most in vivo conditions the forward and reverse fluxes for CK and ATPase are equal (79). In addition, several models have been developed to investigate multisite exchange. It has been shown that the individual rate constants of the three-site exchange model can be investigated by reduction to a two-site exchange model using continuous saturation of one of the molecular subunits (e.g. PCr or $\mathrm{Pi})(80)$.

In MTS, the signal of a target molecular subunit (e.g. $\mathrm{Y}$-ATP) can be saturated by a saturation pulse and transfer of the saturated signal through chemical exchange (e.g. to $\mathrm{PCr}$ or $\mathrm{Pi}$ ) is measured to determine the chemical exchange rate. Saturation transfer is most commonly used, but alternatively magnetization transfer can also be achieved by using a frequency selective inversion pulse. Details on MTS can be found elsewhere (81). ${ }^{31} \mathrm{P}$-MTS suffers from long acquisition times, although a number of methods have been proposed to shorten acquisition times (82).

Decreased in vivo ATP production rates via the CK reaction has been associated with mild-to-moderate heart failure (83), left-ventricular hypertrophy and chronic heart failure (84) in humans (see Table 1).

Using a transgenic mouse model of myocardial creatine-kinase overexpression, the causal relationship between creatine kinase-related energy metabolism and contractile function in heart failure has been demonstrated (85). Therefore, it has been suggested that CK may be a promising target for treatment of heart failure $(85,86)$.

Measurement of $\mathrm{pH}$ using ${ }^{31} \mathrm{P}-\mathrm{MRS}$ is complicated due to overlap from 2,3-DPG originating from blood with the Pi peak and therefore MTS can be used as an alternative (87). The application of a saturation pulse at the $\mathrm{Y}$-ATP resonance frequency will reduce the intensity of the $\mathrm{PCr}$ and $\mathrm{Pi}$ peaks. Subtracting a control spectrum from the saturated spectrum yields a difference spectrum in which only signals from the phosphorus atoms which are in exchange with the $\mathrm{Y}$-ATP pool are visible. Using the difference spectrum, the position of the Pi peak relative to the $\mathrm{PCr}$ peak can be measured to determine $\mathrm{pH}(87)$. 


\section{${ }^{1} H-M R S$}

Cardiac ${ }^{1} \mathrm{H}$-MRS is used mostly for detection of myocardial TG and total creatine, which is indicate metabolites by blue boxes and arrows in Figure 1. A cardiac proton spectrum is shown in Figure 3. The methyl resonance of total creatine (i.e. free $\mathrm{Cr}$ plus $\mathrm{PCr}$ ), with its resonance frequency at $3.03 \mathrm{ppm}(88,89)$, has a lower signal than the protons from the terminal methyl groups and the methylene chain of triglycerides with resonance frequencies at 0.85 and $1.26 \mathrm{ppm}$, respectively $(90,91)$. The most prominent signal is from water at $4.7 \mathrm{ppm}$.

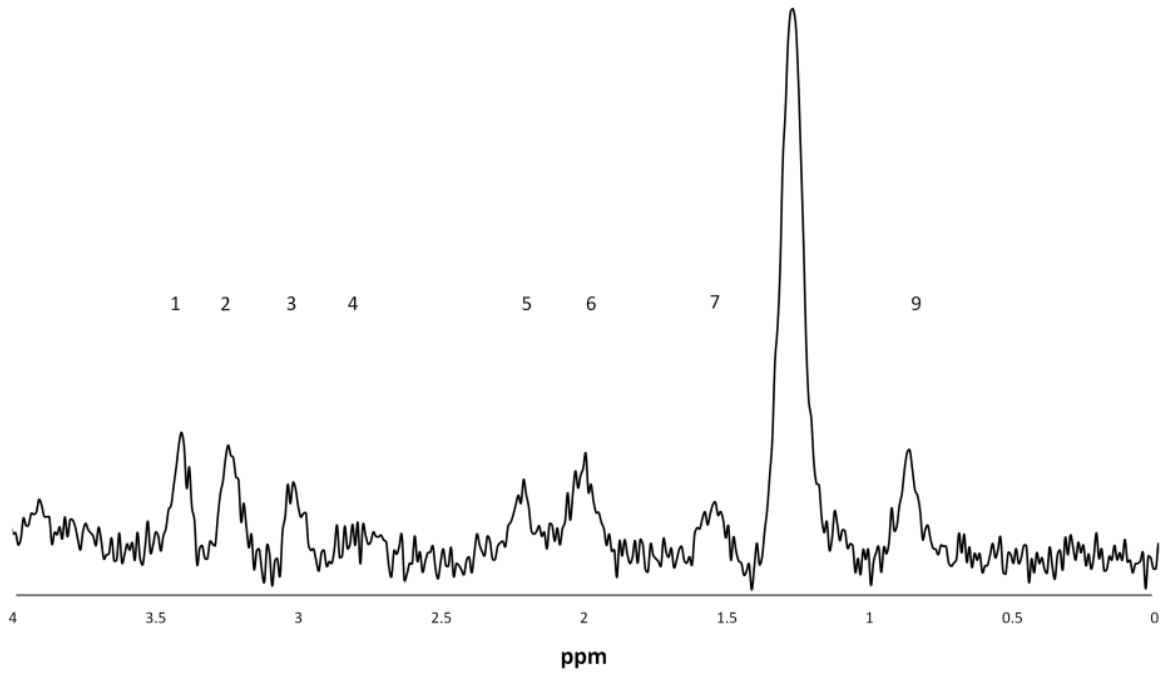

Figure 3: Example of a cardiac proton $\left({ }^{1} \mathrm{H}\right)$ spectrum obtained from a 15 week old wild-type mouse with a 7T animal scanner using a single voxel PRESS pulse sequence. Metabolite peaks are indicated: 1 . Taurine, $3.4 \mathrm{ppm}$; 2. Trimethyl-ammonium compounds, $3.2 \mathrm{ppm}$; 3. Creatine- $\mathrm{CH} 3,3.0 \mathrm{ppm} ; 4$. TG $\mathrm{CH}=\mathrm{CH}-\mathrm{CH} 2-\mathrm{CH}=\mathrm{CH}, 2.7 \mathrm{ppm} ; 5$. TG $\mathrm{C} \alpha \mathrm{H} 2 \mathrm{COO}, 2.2 \mathrm{ppm}$; 6. TG $\mathrm{CH} 2-\mathrm{CH}=\mathrm{CH}-\mathrm{CH} 2,2.0$ ppm; 7. TG $\mathrm{C} \beta \mathrm{H} 2 \mathrm{CH} 2 \mathrm{COO}, 1.6 \mathrm{ppm}$; 8. TG $-(\mathrm{CH} 2) \mathrm{n}-, 1.3 \mathrm{ppm}$ and 9. TG-CH3, $0.9 \mathrm{ppm}$.

In general, ${ }^{1} \mathrm{H}$ metabolites have longer $\mathrm{T}_{2}$ relaxation times compared to ${ }^{31} \mathrm{P} /{ }^{13} \mathrm{C}$ metabolites and therefore spin-echo sequences are generally used for detection of ${ }^{1} \mathrm{H}$-nuclei. The most frequently used single voxel sequences for cardiac ${ }^{1} \mathrm{H}$-MRS are STimulated Echo Acquisition Mode (STEAM) (92) and Point-RESolved Spectroscopy (PRESS) (93). An advantage of the STEAM pulse sequence is that a shorter TE can be achieved than using the PRESS pulse sequence. In addition, the STEAM pulse sequence is less sensitive to $T_{2}$ relaxation, which makes it advantageous for detection of metabolites with short $T_{2}$ relaxation time. $A$ 
disadvantage of using the STEAM pulse sequence is that the amplitude of the acquired stimulated echo is theoretically only $50 \%$ of the amplitude of the spinecho from a PRESS sequence when equal TE is used. This implicates that SNR of STEAM is usually lower compared to PRESS when the number of acquisitions is equal. STEAM enables shorter echo times than PRESS, which can be beneficial for metabolites with a short $\mathrm{T}_{2}$ relaxation time. As during the STEAM and PRESS pulse sequences four unwanted echo signals and three unwanted FID signals are formed, phase cycling and/or crusher gradients are usually applied to remove those signals. However, the performance of phase cycling is affected by motion (94).

To detect myocardial TG and total creatine contents, water suppression is required. A frequently used water suppression technique is chemical shift selective water suppression (CHESS), which consists of 3-6 frequency-selective RF pulses which generate transverse magnetization for all water spins followed by gradient spoiling (95). The duration of CHESS depends on the number of RF pulses and their bandwidth. Implementing CHESS before the localized acquisition can lead to difficulties to fit the acquisition scheme in one cardiac cycle, especially in animal research where the duration between two heartbeats is very short (96). Applying CHESS after the first heartbeat and the localized acquisition after the second heartbeat could lead to partly recovery of the water signal by $T_{1}$ relaxation. Alternatively, a shortened CHESS module can be used and performed immediately before localized acquisition in a single heartbeat.

The metabolite content is generally quantified relative to the water signal. Therefore, two spectra are acquired from the same voxel in the myocardium: a water-suppressed and a water-unsuppressed spectrum. To prevent contamination from epicardial fat, a voxel is generally positioned in the interventricular septum. This means that the voxel size in humans is limited to $6-8 \mathrm{~cm}^{3}(15,97,98)$, while the voxel size in mice is around $2-4 \mathrm{~mm}^{3}(91,96)$. When the voxel size is larger than the wall thickness, the spectrum may also include water signal from blood, which cause an underestimation of metabolite concentrations. However, myocardial fat distribution may be heterogeneous in cardiovascular disease (99), and thus septal TG content may not represent global cardiolipotoxicity severity (100).

CSI could be used for detection of regional differences in myocardial TG and total creatine contents, but the main limitation is the long scan duration. Recently, it was shown that the fast echo-planar spectroscopic imaging (EPSI) sequence could be applied in the heart to measure the regional TG and total creatine content in 12 healthy volunteers (99). In this study, TG and $\mathrm{Cr}$ were measured in six regions of interest located in the midcavity region of the heart and compared results from a single voxel PRESS spectrum obtained from the septal wall region. Results were found to agree well, but some regional variance across the EPSI data was found in the lateral region, which was attributed in part to reduced coil sensitivity and loss 
of spectral resolution as a consequence of line broadening due to $B_{0}$ inhomogeneity close to the posterior vein of the left ventricle.

Disturbances in fatty acid (FA) metabolism can lead to myocardial TG accumulation. Myocardial TG content can be determined using ${ }^{1} \mathrm{H}-\mathrm{MRS}$ in animals and humans in vivo $(15,91)$. Correlation of TG methylene levels determined using ${ }^{1} \mathrm{H}$-MRS with biochemical measurements of total TG in mice was shown to be good ( $r=0.91, P<0.0001)$ (15). Additionally, tissue from human biopsy samples from 10 patients with severe aortic stenosis stained with Oil Red $O$ for lipid staining showed significant correlation with myocardial TG content as measured using ${ }^{1} \mathrm{H}$-MRS in vivo $\left(r_{s}=0.66, P=0.036\right)$ (101). Reproducible assessment of myocardial TG is improved by combined cardiac and respiratory triggering (102). Myocardial TG accumulation as assessed in humans has been associated with aging (97), diabetes (103), and obesity (42) and has been suggested to be an independent predictor of diastolic and systolic dysfunction (42) (see Table 1). Cardiac function was shown to be improved in a group of subjects with obesity (104) and T2DM (105) in interventions reducing cardiac TG content. However, reducing cardiac TG content does not always improve cardiac function (106). It has been shown that ${ }^{1} \mathrm{H}-\mathrm{MRS}$ is sensitive enough to detect changes in myocardial TG content due to fasting and caloric restriction $(107,108)$.

To investigate mechanisms associated with myocardial TG accumulation, also experimental animals are used. Mice deficient for long-chain acyl-CoA dehydrogenase (LCAD), which catalyzed the first step in mitochondrial fatty acid $\beta$-oxidation, show during fasting increased myocardial TG accumulation and impaired left ventricular function (96). Due to the LCAD deficiency also reduced levels of free carnitine are found in LCAD knockout mice. Recently it was shown that carnitine supplementation can be used to normalize total fatty acid content in LCAD knockout mice(109).

In cardiac energy metabolism, the CK system is essential since it is involved in ATP synthesis. Sufficient cardiac creatine levels are important to maintain the capacity of the CK system. Total myocardial creatine levels, i.e. free creatine plus phosphorcreatine, can be determined using ${ }^{1} \mathrm{H}$-MRS. It has been shown that creatine values as obtained with ${ }^{1} \mathrm{H}$-MRS were comparable to creatine values obtained from biopsy assays (110). In humans it has been demonstrated that total myocardial creatine levels are decreased in dilated cardiomyopathy (111), hypertrophic cardiomyopathy (112), ischemic heart disease (98), and chronic heart failure (113). Furthermore, it was found in diseased hearts that lowered total myocardial creatine levels correlate with left ventricular ejection fraction (112) (see Table 1). On the other hand, in a mouse model overexpressing myocardial creatine transporter was shown that a two-fold elevation in total myocardial creatine levels also lead to the development of progressive hypertrophy and heart failure (114) (see Table 2). However, it has recently been shown in failing mouse hearts that overexpression of the myofibrillar isoform of 
CK improves contractile function $(85,86)$, thereby identifying CK as a promising therapeutic target for preventing and treating heart failure.

\section{Dixon MRI}

Chemical shift-encoded fat-water separation with Dixon MRI has been increasingly applied during the last few years. Dixon MRI provides spatial information about fat distribution and in terms of time efficiency is favorable compared to ${ }^{1} \mathrm{H}$-MRS. Fat-water-separated imaging can be used for detection of intramyocardial fat (115), fibrofatty infiltration (17) and delineation of epicardial and pericardial fat $(116,117)$. In the original MR sequence proposed by Dixon, two separate images are acquired with a spin-echo pulse sequence. One image contains the water and fat signals in-phase and the other image contains the water and fat signals with opposite-phase. Using subtraction and addition of the two images, water-only and fat-only images can be generated (118). To achieve fat-water separation the choice of TE's is restricted. In the presence of $B_{0}$-field inhomogeneities this method is sensitive to errors. Therefore, various modifications to the two-point Dixon technique have been proposed, among which three-point Dixon (119), modified Dixon (mDIXON) $(120,121)$, and iterative decomposition of water and fat with echo asymmetry and least-squares estimation (IDEAL) (122). The Dixon techniques have been extensively reviewed elsewhere (123). The three-point Dixon technique was successfully applied in human myocardium and provided a sensitive means of detecting myocardial fat deposition in patients with chronic myocardial infarction (124). Furthermore a relationship between chronic myocardial fat deposition volume and infarction volume and left ventricular volumes was shown (125).

\section{Hyperpolarized ${ }^{13} \mathrm{C}$ MRS}

Metabolic fluxes can be measured with MTS and by using infusion of isotopeenriched substrates. Carbon-13 spectroscopy can be used to study cardiac substrate preference and metabolic activity, thereby adding valuable information about metabolic fluxes in the heart. The natural abundance of ${ }^{13} \mathrm{C}$-nuclei is around $1.1 \%$. To increase the available signal level in MRS and MRI, the hyperpolarization technique can be used to enhance nuclear polarization. The polarization reflects the population difference between spin states. To obtain hyperpolarization different techniques can be applied whereby the signal from a tracer temporarily can be increased by 10,000 -fold or more compared to equilibrium conditions, as previously reviewed (126). For in vivo cardiac applications, mainly dynamic nuclear polarization (DNP) or parahydrogen-induced polarization (PHIP) are used to obtain hyperpolarization. After hyperpolarization, the tracer needs to be 
injected, infused or inhalated. After administration of the hyperpolarized substrate, the substrate is metabolized and the ${ }^{13} \mathrm{C}$-label is transferred to other metabolites, which can be monitored. Different hyperpolarized substrates can be applied, of which hyperpolarized pyruvate is commonly used. Due to the rapid loss of signal enhancement, data must be acquired as fast as possible after administration of the hyperpolarized substrate. Additionally, one must be aware of the unrecoverable loss of the hyperpolarized spin states due to $T_{1}$ relaxation (127), typically in a time span from 1-2 minutes (128). For cardiac hyperpolarized ${ }^{13} \mathrm{C}-\mathrm{MRS}$, cardiac-gated pulse acquire experiments can be performed. A disadvantage of performing a pulse-acquire experiment is that signals are 'localized' to the sensitive volume of the surface coil. It was also demonstrated that CSI can be used for localized cardiac hyperpolarized ${ }^{13} \mathrm{C}-\mathrm{MRI}$ (129). In this study, an elliptical central $k$ space sampling order scheme was applied that is less sensitive to motion and the number of phase encoding steps was reduced to reduce scan time.

Most cardiac in vivo experiments are performed using a form of $\left[{ }^{13} \mathrm{C}\right]$ pyruvate to monitor cardiac oxidative metabolism (130). The metabolic products of hyperpolarized $\left[1-{ }^{13} \mathrm{C}\right]$ pyruvate are $\left[1-{ }^{13} \mathrm{C}\right]$ lactate, $\left[1-{ }^{13} \mathrm{C}\right]$ alanine and ${ }^{13} \mathrm{CO}_{2}$. The conversion of pyruvate to lactate, alanine, or ${ }^{13} \mathrm{CO}_{2}^{-}$is catalyzed by the enzyme lactate dehydrogenase (LDH), alanine transaminase (AAT), and pyruvate dehydrogenase $(\mathrm{PDH}$ ), respectively (Figure 1 , green arrows indicate the detectable metabolites from $\left[1-{ }^{13} \mathrm{C}\right]$ pyruvate). $\mathrm{H}^{13} \mathrm{CO}_{3}{ }^{-}$is in equilibrium with ${ }^{13} \mathrm{CO}_{2}$ under the action of the carbonic anhydrase enzyme. It has been suggested that the mitochondrial conversion of pyruvate to $\mathrm{H}^{13} \mathrm{CO}_{3}{ }^{-}$can be used as a marker for the activity of the PDH complex in vivo (131). Indeed, it was shown that the hyperpolarized MRS measurements of PDH flux correlated significantly with ex vivo measurements of PDH enzyme activity (132). Decreased myocardial PDH flux was observed in a rat model of type 1 diabetes in vivo (130). PDH flux was essentially zero the first 90 seconds of reperfusion after ischemia in isolated rat heart (133). Furthermore, hyperpolarized $\left[1-{ }^{13} \mathrm{C}\right]$ pyruvate can be administrated to measure $\mathrm{pH}$ (134). To calculate $\mathrm{pH}$, signals from both $\mathrm{H}^{13} \mathrm{CO}_{3}^{-}$and ${ }^{13} \mathrm{CO}_{2}$ are required. A drawback is that the ${ }^{13} \mathrm{CO}_{2}$ signal is relatively weak. It was shown that this technique could be applied to measure $\mathrm{pH}$ in the isolated as well as in vivo rat heart (135).

After infusion of hyperpolarized $\left[2-{ }^{13} \mathrm{C}\right]$ pyruvate, the conversion to $\left[2-{ }^{13} \mathrm{C}\right]$ lactate, $\left[1-{ }^{13} \mathrm{C}\right]$ acetylcarnitine, and $\left[1-{ }^{13} \mathrm{C}\right]$ citrate can be followed together with the TCA cycle mediated conversion into $\left[5{ }^{13} \mathrm{C}\right]$ glutamate in the rat heart in vivo (136). The conversion of $\left[2-{ }^{13} \mathrm{C}\right]$ pyruvate to $\left[2-{ }^{13} \mathrm{C}\right]$ lactate provides information about glycolysis, while the conversion to $\left[1-{ }^{13} \mathrm{C}\right]$ acetylcarnitine provides information about the PDH flux (137). Acetylcarnitine is produced by mitochondrial carnitine acetyltransferase, stimulated by acetyl-CoA and carnitine (Figure 1, orange arrows indicate the detectable metabolites from $\left[2{ }^{13} \mathrm{C}\right]$ pyruvate). It was shown that 
acetylcarnitine acts to fine-tune the acetyl-CoA availability in the heart (136). In isolated perfused hearts, it was shown that the production of citrate and glutamate was decreased during post-ischemia, while the production of lactate was elevated. Furthermore, delayed appearance of $\left[1-{ }^{13} \mathrm{C}\right]$ acetylcarnitine was observed (137).

Using dual-labeled hyperpolarized $\left[1,2-{ }^{13} \mathrm{C}_{2}\right]$ pyruvate combined with an interleaved acquisition scheme with selective excitation for ${ }^{13} \mathrm{CO}_{2}$, it is possible to observe metabolites resulting from the PDH and TCA cycle flux, as well as determining the $\mathrm{pH}(138)$ (see also Figure 1 in which purple arrows indicate the detectable metabolites from $\left[1,2-{ }^{13} \mathrm{C}\right]$ pyruvate). A limitation of using dual-labeled hyperpolarized $\left[1,2-{ }^{13} \mathrm{C}_{2}\right]$ pyruvate at field strengths of $\leq 3 \mathrm{~T}$ are the overlapping resonances of $\left[5-{ }^{13} \mathrm{C}\right]$ glutamate with $\left[1-{ }^{13} \mathrm{C}\right]$ lactate and $\left[1-{ }^{13} \mathrm{C}\right]$ acetylcarnitine with $\left[1-{ }^{13} \mathrm{C}\right]$ pyruvate. However, because both $\left[1-{ }^{13} \mathrm{C}\right]$ lactate and $\left[1-{ }^{13} \mathrm{C}\right]$ pyruvate give doublet resonances, the area of the overlapping peaks can be compensated for when no other overlap occurs. Advantages of using dual-labeled hyperpolarized $\left[1,2-{ }^{13} \mathrm{C}_{2}\right]$ pyruvate is the lower dose required to obtain the same $\operatorname{SNR}(138)$.

Using a combination of both $\left[1-{ }^{13} \mathrm{C}\right]$ pyruvate and $\left[2-{ }^{13} \mathrm{C}\right]$ pyruvate, the relationship between pyruvate dehydrogenase complex (PDC)-medicated oxidation of pyruvate and its subsequent incorporation into the TCA cycle can be followed (139). It was shown that a significant pyruvate dehydrogenase kinase (PDK) mediated reduction in PDH flux, which in turn diminishes the contribution of glucose oxidation to energy generation, contributes to the pathology of the hyperthyroid rat heart in vivo (140). In pigs was shown that pyruvate metabolism changes throughout development of dilated cardiomyopathy and that reduced pyruvate oxidation by the PDC also reveals the onset of overt heart failure (141).

In addition to pyruvate, lactate is also an important energy source for the heart (2). The observable metabolic products of hyperpolarized $\left[1-{ }^{13} \mathrm{C}\right]$ lactate were shown to be ${ }^{13} \mathrm{C}$ pyruvate, ${ }^{13} \mathrm{C}$ alanine and ${ }^{13} \mathrm{C}$ bicarbonate (142). It has recently been demonstrated that hyperpolarized $\left[1-{ }^{13} \mathrm{C}\right]$ lactate can also be used to measure cardiac metabolism in rat hearts in vivo (143), thereby providing information about PDH-flux (Figure 1, pink arrows indicate the detectable metabolites from $\left[1-{ }^{13} \mathrm{C}\right]$ lactate). As the physiological concentrations of lactate can be higher than pyruvate (1-10 mM (143) versus 3-6 mM (144), respectively), the use of lactate may represent a viable and potentially safer alternative to pyruvate, since higher concentrations of lactate can be used to achieve an increase in SNR. Furthermore, the feasibility of using hyperpolarized $\left[1-{ }^{13} \mathrm{C}\right]$ butyrate to provide information on metabolism of short chain fatty acid and ketone bodies, has recently been demonstrated in isolated and in vivo rat hearts (145). After infusion, the hyperpolarized $\left[1-{ }^{13} \mathrm{C}\right]$ butyrate is transported into the cell via the monocarboxylate transporter enzyme where it is metabolized to $\beta$-hydroxybutyryl CoA and acetoacetyl CoA before concversion into ketone bodies (acetoacetate and $\beta$-hydroxybutarate) and acetyl-CoA (which enters the TCA cycle). In Figure 1 
some detectable metabolites from $\left[1-{ }^{13} \mathrm{C}\right]$ butyrate are indicated with brown arrows.

Until now, cardiac hyperpolarized ${ }^{13} \mathrm{C}$ imaging and spectroscopy have only been applied in animals in vivo. However, the first study in which hyperpolarized [1${ }^{13} \mathrm{C}$ ]pyruvate was used in patients with prostate cancer, was published recently (146). This study shows that hyperpolarized $\left[1-{ }^{13} \mathrm{C}\right]$ pyruvate can safely be used in humans in vivo and shows promising results for noninvasive cancer diagnosis and treatment monitoring in future clinical trials. Therefore, this study paves the way for other clinical trials in which also cardiac diseases can be studied.

\section{CLINICAL TRANSLATION}

In contrast to cardiac MRI, cardiac metabolic MRS has to overcome several methodological challenges before it can be broadly applied clinically. These challenges include minimizing scan time and increasing SNR. Scan time in MRS is relatively long due to low metabolite concentrations, which require numerous signal averages to obtain sufficient SNR. Advanced shimming algorithms, the use of hyperpolarized nuclei and/or scanning at a higher magnetic field strength, can improve SNR. The ongoing development of multichannel detection coils, RF pulses and pulse sequences will further improve cardiac MRS, thereby increasing its usability for clinical applications. Both cardiac MRS and MRI remain important technologies as they allow a direct translation of findings in experimental animals to the clinical setting.

\section{ACKNOWLEDGEMENT}

This work was performed within the framework of CTMM, the Centre for Translational Molecular Medicine, project PREDICCt (grant number 01C-104), and supported by the Dutch Heart Foundation, Dutch Diabetes Research Foundation and Dutch Kidney Foundation.

Vera Schrauwen-Hinderling is supported by a VENI (grant 91611136) for innovative research from the Netherlands Organization for Scientific Research (NWO). 
Table 1, part 1

Applications of noninvasive cardiac MRS in vivo in myocardial disease: human studies.

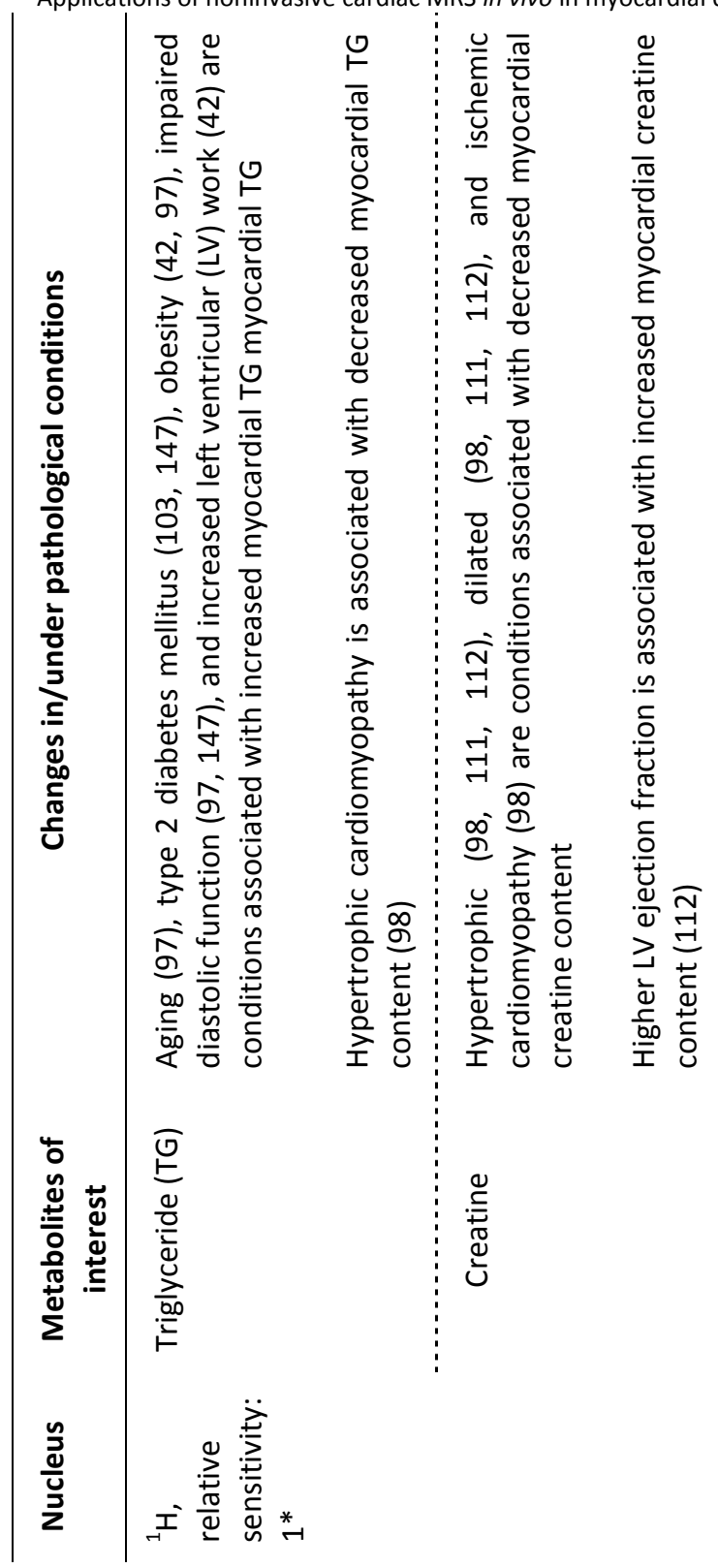

*The relative sensitivity indicates the MR sensitivity multiplied by the natural abundance of the nucleus. TG: triglyceride, CK: creatine kinase. 
Table 1, part 2

Applications of noninvasive cardiac MRS in vivo in myocardial disease: human studies.

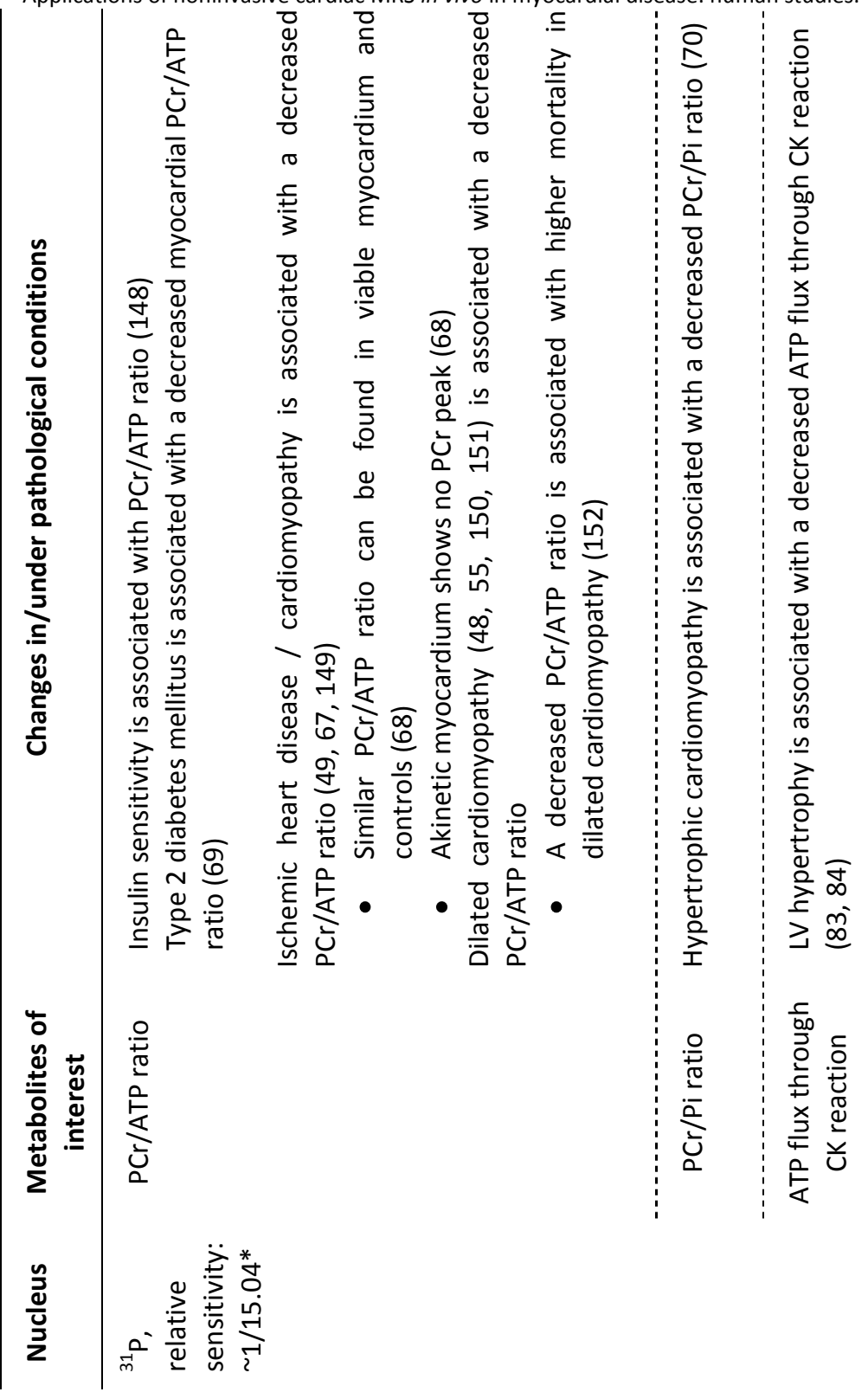

*The relative sensitivity indicates the MR sensitivity multiplied by the natural abundance of the nucleus.

TG: triglyceride, CK: creatine kinase. 


\section{Table 2}

Applications of noninvasive cardiac MRS in vivo in myocardial disease: hamster, rat and mice.

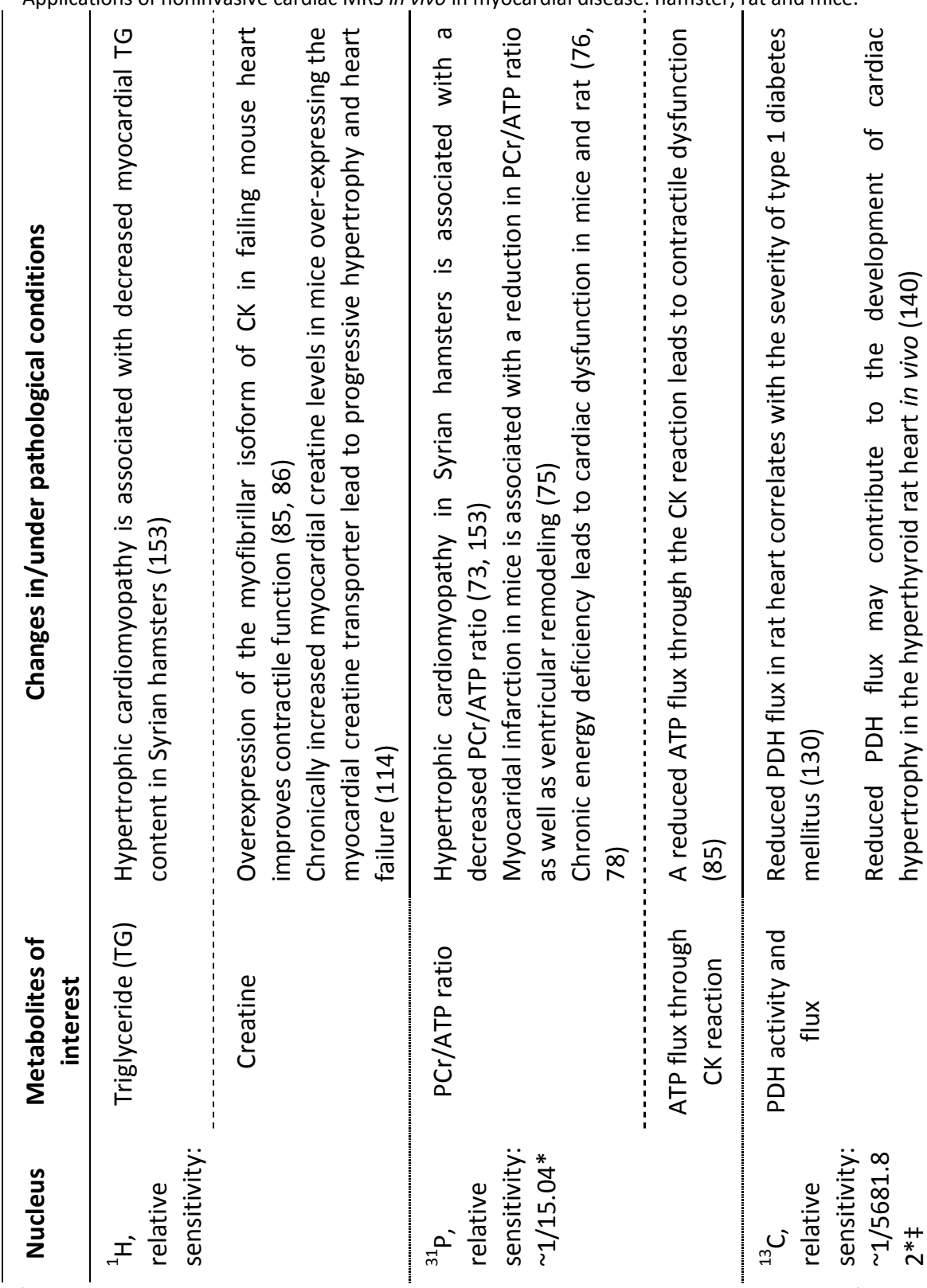

*The relative sensitivity indicates the MR sensitivity multiplied by the natural abundance of the nucleus. $¥$ The low relative sensitivity of ${ }^{13} \mathrm{C}$ is overcome by DNP in the quoted references.

TG: triglyceride and PDH: pyruvate dehydrogenase. 


\section{REFERENCES}

1. Onay-Besikci A. Regulation of cardiac energy metabolism in newborn. Mol Cell Biochem. 2006; 287:111.

2. Taegtmeyer H. Energy metabolism of the heart: from basic concepts to clinical applications. Curr Probl Cardiol. 1994; 19:59-113.

3. Lopaschuk GD, Belke DD, Gamble J, Itoi T, Schonekess BO. Regulation of fatty acid oxidation in the mammalian heart in health and disease. Biochim Biophys Acta. 1994; 1213:263-276.

4. Stanley WC, Lopaschuk GD, Hall JL, McCormack JG. Regulation of myocardial carbohydrate metabolism under normal and ischaemic conditions. Potential for pharmacological interventions. Cardiovasc Res. 1997; 33:243-257.

5. Taha M, Lopaschuk GD. Alterations in energy metabolism in cardiomyopathies. Ann Med. 2007; 39:594-607.

6. Kenchaiah S, Evans JC, Levy D, Wilson PW, Benjamin EJ, Larson MG, Kannel WB, Vasan RS. Obesity and the risk of heart failure. N Engl J Med. 2002; 347:305-313.

7. Nichols GA, Gullion CM, Koro CE, Ephross SA, Brown JB. The incidence of congestive heart failure in type 2 diabetes: an update. Diabetes Care. 2004; 27:1879-1884.

8. Taegtmeyer H, McNulty P, Young ME. Adaptation and maladaptation of the heart in diabetes: Part I: general concepts. Circulation. 2002; 105:1727-1733.

9. Young ME, McNulty P, Taegtmeyer H. Adaptation and maladaptation of the heart in diabetes: Part II: potential mechanisms. Circulation. 2002; 105:1861-1870.

10. Harmancey R, Wilson CR, Taegtmeyer H. Adaptation and maladaptation of the heart in obesity. Hypertension. 2008; 52:181-187.

11. Zhou YT, Grayburn P, Karim A, Shimabukuro M, Higa M, Baetens D, Orci L, Unger RH. Lipotoxic heart disease in obese rats: implications for human obesity. Proc Natl Acad Sci U S A. 2000; 97:1784-1789.

12. Wende AR, Abel ED. Lipotoxicity in the heart. Biochim Biophys Acta. 2010; 1801:311-319.

13. Parsai C, O'Hanlon R, Prasad SK, Mohiaddin RH. Diagnostic and prognostic value of cardiovascular magnetic resonance in non-ischaemic cardiomyopathies. J Cardiovasc Magn Reson. 2012; 14:54.

14. Bottomley PA (ed.): NMR Spectroscopy of the Human Heart. Chichester: John Wiley; 2009.

15. Szczepaniak LS, Dobbins RL, Metzger GJ, Sartoni-D'Ambrosia G, Arbique D, Vongpatanasin W, Unger R, Victor RG. Myocardial triglycerides and systolic function in humans: in vivo evaluation by localized proton spectroscopy and cardiac imaging. Magn Reson Med. 2003; 49:417-423.

16. Schroeder MA, Clarke K, Neubauer S, Tyler DJ. Hyperpolarized magnetic resonance: a novel technique for the in vivo assessment of cardiovascular disease. Circulation. 2011; 124:1580-1594.

17. Kellman P, Hernando D, Shah S, Zuehlsdorff S, Jerecic R, Mancini C, Liang ZP, Arai AE. Multiecho dixon fat and water separation method for detecting fibrofatty infiltration in the myocardium. Magn Reson Med. 2009; 61:215-221.

18. Bottomley PA. Noninvasive study of high-energy phosphate metabolism in human heart by depthresolved 31P NMR Spectroscopy. Science. 1985; 229:769-772.

19. Tyler DJ, Hudsmith LE, Clarke K, Neubauer S, Robson MD. A comparison of cardiac (31)P MRS at 1.5 and 3 T. NMR Biomed. 2008; 21:793-798.

20. Schneider JE, Cassidy PJ, Lygate C, Tyler DJ, Wiesmann F, Grieve SM, Hulbert K, Clarke K, Neubauer S. Fast, high-resolution in vivo cine magnetic resonance imaging in normal and failing mouse hearts on a vertical 11.7 T system. J Magn Reson Imaging. 2003; 18:691-701.

21. Gutberlet M, Noeske R, Schwinge K, Freyhardt P, Felix R, Niendorf T. Comprehensive cardiac magnetic resonance imaging at 3.0 Tesla: feasibility and implications for clinical applications. Invest Radiol. 2006; 41:154-167.

22. Atalay MK, Poncelet BP, Kantor HL, Brady TJ, Weisskoff RM. Cardiac susceptibility artifacts arising from the heart-lung interface. Magn Reson Med. 2001; 45:341-345.

23. Gruetter R. Automatic, localized in vivo adjustment of all first- and second-order shim coils. Magn Reson Med. 1993; 29:804-811.

24. Gruetter RaB, C. Fast, noninteractive shimming of spatially localized signals. J Magn Reson. 1992; 96:323-334.

25. Jaffer FA, Wen H, Balaban RS, Wolff SD. A method to improve the BO homogeneity of the heart in vivo. Magn Reson Med. 1996; 36:375-383.

26. Schär M, Kozerke, S., Harvey, P.A., and Boesiger, P. Local linear shimming for cardiac SSFP imaging at 3T. Proc Intl Soc Mag Reson Med. 2002; 10. 
27. Kubach MR, Bornstedt A, Hombach V, Merkle N, Schar M, Spiess J, Nienhaus GU, Rasche V. Cardiac phase-specific shimming (CPSS) for SSFP MR cine imaging at 3 T. Phys Med Biol. 2009; 54:N467-478.

28. Shah S, Kellman,.P., Greiser, A., Weale, P.J., Zuehlsdorff, S., and Jerecic, R. Rapid fieldmap estimation for cardiac shimming. Proc Intl Soc Mag Reson Med. 2009; 17.

29. Schar M, Vonken EJ, Stuber M. Simultaneous B(0)- and B(1)+-map acquisition for fast localized shim, frequency, and RF power determination in the heart at 3 T. Magn Reson Med. 2010; 63:419-426.

30. Cunningham CH, Pauly JM, Nayak KS. Saturated double-angle method for rapid B1+ mapping. Magn Reson Med. 2006; 55:1326-1333.

31. Giovannetti G, Hartwig, V., Frijia, F., Menichetti, L., Positano, V., Ardenkjaer-Larsen, J.H., Lionetti, V., Donato Aquaro, G., De Marchi, D., Flori, A., Landini, L., Lombardi, M., Santarelli, M.F. Hyperpolarized 13C MRS Cardiac Metabolism Studies in Pigs: Comparison Between Surface and Volume Radiofrequency Coils. Applied Magnetic Resonance. 2012; 42:413-428.

32. Bottomley PA, Lugo Olivieri $\mathrm{CH}$, Giaquinto R. What is the optimum phased array coil design for cardiac and torso magnetic resonance? Magn Reson Med. 1997; 37:591-599.

33. Wright SM, Wald LL. Theory and application of array coils in MR spectroscopy. NMR Biomed. 1997; 10:394-410.

34. Weiss K, Martini N, Boesiger P, Kozerke S. Cardiac proton spectroscopy using large coil arrays. NMR Biomed. 2013; 26:276-284.

35. Sandgren N, Stoica P, Frigo FJ, Selen Y. Spectral analysis of multichannel MRS data. J Magn Reson. 2005; 175:79-91.

36. Brown MA. Time-domain combination of MR spectroscopy data acquired using phased-array coils. Magn Reson Med. 2004; 52:1207-1213.

37. Maril N, Lenkinski RE. An automated algorithm for combining multivoxel MRS data acquired with phased-array coils. J Magn Reson Imaging. 2005; 21:317-322.

38. Rodgers CT, Robson MD. Receive array magnetic resonance spectroscopy: Whitened singular value decomposition (WSVD) gives optimal Bayesian solution. Magn Reson Med. 2010; 63:881-891.

39. Lanzer P, Barta C, Botvinick EH, Wiesendanger HU, Modin G, Higgins CB. ECG-synchronized cardiac MR imaging: method and evaluation. Radiology. 1985; 155:681-686.

40. Felblinger J, Jung B, Slotboom J, Boesch C, Kreis R. Methods and reproducibility of cardiac/respiratory double-triggered (1)H-MR spectroscopy of the human heart. Magn Reson Med. 1999; 42:903-910.

41. van der Meer RW, Doornbos J, Kozerke S, Schar M, Bax JJ, Hammer S, Smit JW, Romijn JA, Diamant M, Rijzewijk LJ, de Roos A, Lamb HJ. Metabolic imaging of myocardial triglyceride content: reproducibility of $1 \mathrm{H}$ MR spectroscopy with respiratory navigator gating in volunteers. Radiology. 2007; 245:251-257.

42. Kankaanpaa M, Lehto HR, Parkka JP, Komu M, Viljanen A, Ferrannini E, Knuuti J, Nuutila P, Parkkola R, lozzo P. Myocardial triglyceride content and epicardial fat mass in human obesity: relationship to left ventricular function and serum free fatty acid levels. J Clin Endocrinol Metab. 2006; 91:4689-4695.

43. Felblinger J, Boesch C. Amplitude demodulation of the electrocardiogram signal (ECG) for respiration monitoring and compensation during MR examinations. Magn Reson Med. 1997; 38:129-136.

44. Schar M, Kozerke S, Boesiger P. Navigator gating and volume tracking for double-triggered cardiac proton spectroscopy at 3 Tesla. Magn Reson Med. 2004; 51:1091-1095.

45. Kozerke S, Schar M, Lamb HJ, Boesiger P. Volume tracking cardiac 31P spectroscopy. Magn Reson Med. 2002; 48:380-384.

46. Ordidge RJ, Connelly, A. and Lohman, J.A.B. Image-selected in vivo spectroscopy (ISIS). A new technique for spatially selective nmr spectroscopy. J Magn Reson. 1986; 66:283-294.

47. Lamb HJ, Doornbos J, den Hollander JA, Luyten PR, Beyerbacht HP, van der Wall EE, de Roos A. Reproducibility of human cardiac 31P-NMR spectroscopy. NMR Biomed. 1996; 9:217-227.

48. Hardy CJ, Weiss RG, Bottomley PA, Gerstenblith G. Altered myocardial high-energy phosphate metabolites in patients with dilated cardiomyopathy. Am Heart J. 1991; 122:795-801.

49. Shivu GN, Abozguia K, Phan TT, Ahmed I, Henning A, Frenneaux M. (31)P magnetic resonance spectroscopy to measure in vivo cardiac energetics in normal myocardium and hypertrophic cardiomyopathy: Experiences at 3T. Eur J Radiol. 2010; 73:255-259.

50. Von Kienlin MaM, R. Spectral localization with optimal pointspread function. J Magn Reson. 1991; 94:268-287.

51. Löffler R, Sauter, R., Kolem, H., Haase, M. and von Kienlin, M. Localized spectroscopy from anatomically matched compartments: improved sensitivity and localization for cardiac 31P MRS in humans. J Magn Reson. 1998; 134:287-299. 
52. Meininger M, Landschütz, W., Beer, M., Seyfarth, T., Horn, M., Pabst, T., Haase, A., Hahn, D., Neubauer, S. and von Kienlin, M. Concentrations of human cardiac phosphorus metabolites determined by SLOOP 31P NMR spectroscopy. Magn Reson Med. 1999; 41:657-663.

53. Yabe T, Mitsunami K, Inubushi T, Kinoshita M. Quantitative measurements of cardiac phosphorus metabolites in coronary artery disease by 31P magnetic resonance spectroscopy. Circulation. 1995; 92:15-23.

54. Bottomley PA, Hardy, C.J., and Weiss, R.G. Correcting human heart 31P NMR spectra for partial saturation. Evidence that saturation factors for PCr/ATP are homogeneous in normal and disease states. J Magn Reson. 1991; 95:341-355.

55. Neubauer S, Krahe T, Schindler R, Horn M, Hillenbrand H, Entzeroth C, Mader H, Kromer EP, Riegger $\mathrm{GA}$, Lackner $\mathrm{K}$, et al. 31P magnetic resonance spectroscopy in dilated cardiomyopathy and coronary artery disease. Altered cardiac high-energy phosphate metabolism in heart failure. Circulation. 1992; 86:1810-1818.

56. Bottomley PA. MR spectroscopy of the human heart: the status and the challenges. Radiology. 1994; 191:593-612.

57. Spencer RGS, Ferretti, J.A., and Weiss, G.H. NMR saturation factors in the presence of chemical exchange. J Magn Reson. 1989; 84:223-235.

58. Galban CJ, Ellis SJ, Spencer RG. Experimental demonstration of quantitation errors in MR spectroscopy resulting from saturation corrections under changing conditions. J Magn Reson. 2003; 161:148-153.

59. Ouwerkerk R, Bottomley PA. On neglecting chemical exchange when correcting in vivo (31)P MRS data for partial saturation: commentary on: "Pitfalls in the measurement of metabolite concentrations using the one-pulse experiment in in Vivo NMR". J Magn Reson. 2001; 149:282-286.

60. Tyler DJ, Lopez O, Cole MA, Carr CA, Stuckey DJ, Lakatta E, Clarke K, Spencer RG. Ongoing dual-angle measurements for the correction of partial saturation in 31P MR spectroscopy. Magn Reson Med. 2010; 64:957-966.

61. Bottomley PA, Atalar E, Weiss RG. Human cardiac high-energy phosphate metabolite concentrations by 1D-resolved NMR spectroscopy. Magn Reson Med. 1996; 35:664-670.

62. Hoffenberg EF, Kozlowski P, Salerno TA, Deslauriers R. Evaluation of cardiac 31P magnetic resonance spectroscopy: reviewing NMR principles. J Surg Res. 1996; 62:135-143.

63. Jansen JFA, Backes, W.H., Nicolay, K. and Kooi, M.E. 1H MR Spectroscopy of the brain: absolute quantification of metabolites. Radiology. 2006; 240:318-332.

64. Laufs A, Livingstone R, Nowotny B, Nowotny P, Wickrath F, Giani G, Bunke J, Roden M, Hwang JH. Quantitative liver $\mathrm{P}$ magnetic resonance spectroscopy at $3 \mathrm{~T}$ on a clinical scanner. Magn Reson Med. 2013.

65. Chmelik M, Schmid Al, Gruber S, Szendroedi J, Krssak M, Trattnig S, Moser E, Roden M. Threedimensional high-resolution magnetic resonance spectroscopic imaging for absolute quantification of 31P metabolites in human liver. Magn Reson Med. 2008; 60:796-802.

66. Beer M, Buchner S, Wirbelauer J, Fuchs J, Machann W, Ritter CO, Beissert M, Darge K, Hahn D, Kostler $H$. [MR imaging and MR spectroscopy for characterization of cardiomyopathies in adolescents preliminary results]. Rofo. 2007; 179:932-937.

67. Weiss RG, Bottomley PA, Hardy CJ, Gerstenblith G. Regional myocardial metabolism of high-energy phosphates during isometric exercise in patients with coronary artery disease. N Engl J Med. 1990; 323:1593-1600.

68. Beer M, Sandstede J, Landschutz W, Viehrig M, Harre K, Horn M, Meininger M, Pabst T, Kenn W, Haase A, von Kienlin M, Neubauer S, Hahn D. Altered energy metabolism after myocardial infarction assessed by 31P-MR-spectroscopy in humans. Eur Radiol. 2000; 10:1323-1328.

69. Scheuermann-Freestone M, Madsen PL, Manners D, Blamire AM, Buckingham RE, Styles P, Radda GK, Neubauer S, Clarke K. Abnormal cardiac and skeletal muscle energy metabolism in patients with type 2 diabetes. Circulation. 2003; 107:3040-3046.

70. Sieverding L, Jung WI, Breuer J, Widmaier S, Staubert A, van Erckelens F, Schmidt O, Bunse M, Hoess T, Lutz O, Dietze GJ, Apitz J. Proton-decoupled myocardial 31P NMR spectroscopy reveals decreased $\mathrm{PCr} / \mathrm{Pi}$ in patients with severe hypertrophic cardiomyopathy. Am J Cardiol. 1997; 80:34A-40A.

71. Chacko VP, Aresta F, Chacko SM, Weiss RG. MRI/MRS assessment of in vivo murine cardiac metabolism, morphology, and function at physiological heart rates. Am J Physiol Heart Circ Physiol. 2000; 279:H2218-2224.

72. Omerovic E, Basetti M, Bollano E, Bohlooly YM, Tornell J, Isgaard J, Hjalmarson A, Soussi B, Waagstein F. In vivo metabolic imaging of cardiac bioenergetics in transgenic mice. Biochem Biophys Res Commun. 2000; 271:222-228. 
73. Gupta A, Chacko VP, Weiss RG. Abnormal energetics and ATP depletion in pressure-overload mouse hearts: in vivo high-energy phosphate concentration measures by noninvasive magnetic resonance. Am J Physiol Heart Circ Physiol. 2009; 297:H59-64.

74. Maslov MY, Chacko VP, Stuber M, Moens AL, Kass DA, Champion HC, Weiss RG. Altered high-energy phosphate metabolism predicts contractile dysfunction and subsequent ventricular remodeling in pressure-overload hypertrophy mice. Am J Physiol Heart Circ Physiol. 2007; 292:H387-391.

75. Naumova AV, Chacko VP, Ouwerkerk R, Stull L, Marban E, Weiss RG. Xanthine oxidase inhibitors improve energetics and function after infarction in failing mouse hearts. Am J Physiol Heart Circ Physiol. 2006; 290:H837-843.

76. Tucci S, Flogel U, Hermann S, Sturm M, Schafers M, Spiekerkoetter U. Development and pathomechanisms of cardiomyopathy in very long-chain acyl-CoA dehydrogenase deficient (VLCAD(-/)) mice. Biochim Biophys Acta. 2014; 1842:677-685.

77. Bakermans AJ, Dodd MS, Nicolay K, Prompers JJ, Tyler DJ, Houten SM. Myocardial energy shortage and unmet anaplerotic needs in the fasted long-chain acyl-CoA dehydrogenase knockout mouse. Cardiovasc Res. 2013; 100:441-449.

78. Lorentzon M, Ramunddal T, Bollano E, Soussi B, Waagstein F, Omerovic E. In vivo effects of myocardial creatine depletion on left ventricular function, morphology, and energy metabolism--consequences in acute myocardial infarction. J Card Fail. 2007; 13:230-237.

79. Bittl JA, Ingwall JS. Reaction rates of creatine kinase and ATP synthesis in the isolated rat heart. A 31P NMR magnetization transfer study. J Biol Chem. 1985; 260:3512-3517.

80. Ugurbil K. Magnetization-Transfer Measurements of Individual Rate Constants in the Presence of Multiple Reactions. J Magn Reson. 1985; 64:207-219.

81. Leibfritz D, Dreher W. Magnetization transfer MRS. NMR Biomed. 2001; 14:65-76.

82. Xiong $Q$, Du F, Zhu X, Zhang P, Suntharalingam P, Ippolito J, Kamdar FD, Chen W, Zhang J. ATP production rate via creatine kinase or ATP synthase in vivo: a novel superfast magnetization saturation transfer method. Circ Res. 2011; 108:653-663.

83. Weiss RG, Gerstenblith G, Bottomley PA. ATP flux through creatine kinase in the normal, stressed, and failing human heart. Proc Natl Acad Sci U S A. 2005; 102:808-813.

84. Smith CS, Bottomley PA, Schulman SP, Gerstenblith G, Weiss RG. Altered creatine kinase adenosine triphosphate kinetics in failing hypertrophied human myocardium. Circulation. 2006; 114:1151-1158.

85. Gupta A, Akki A, Wang Y, Leppo MK, Chacko VP, Foster DB, Caceres V, Shi S, Kirk JA, Su J, Lai S, Paolocci N, Steenbergen C, Gerstenblith G, Weiss RG. Creatine kinase-mediated improvement of function in failing mouse hearts provides causal evidence the failing heart is energy starved. J Clin Invest. 2012; 122:291-302.

86. Gupta A, Rohlfsen C, Leppo MK, Chacko VP, Wang Y, Steenbergen C, Weiss RG. Creatine kinaseoverexpression improves myocardial energetics, contractile dysfunction and survival in murine doxorubicin cardiotoxicity. PLoS One. 2013; 8:e74675.

87. Brindle KM, Rajagopalan B, Williams DS, Detre JA, Simplaceanu E, Ho C, Radda GK. 31P NMR measurements of myocardial pH in vivo. Biochem Biophys Res Commun. 1988; 151:70-77.

88. Ugurbil K, Petein M, Maidan R, Michurski S, Cohn JN, From AH. High resolution proton NMR studies of perfused rat hearts. FEBS letters. 1984; 167:73-78.

89. Griffin JL, Williams HJ, Sang E, Nicholson JK. Abnormal lipid profile of dystrophic cardiac tissue as demonstrated by one- and two-dimensional magic-angle spinning (1)H NMR spectroscopy. Magn Reson Med. 2001; 46:249-255.

90. Chapman D, Morrison A. Physical studies of phospholipids. IV. High resolution nuclear magnetic resonance spectra of phospholipids and related substances. J Biol Chem. 1966; 241:5044-5052.

91. Schneider JE, Tyler DJ, ten Hove M, Sang AE, Cassidy PJ, Fischer A, Wallis J, Sebag-Montefiore LM, Watkins H, Isbrandt D, Clarke K, Neubauer S. In vivo cardiac 1 H-MRS in the mouse. Magn Reson Med. 2004; 52:1029-1035.

92. Frahm J, Merboldt, K.D., and Hanicke, W. Localized proton spectroscopy using stimulated echoes. J Magn Reson. 1987; 72:502.

93. Bottomley PA. Spatial localization in NMR spectroscopy in vivo. Ann N Y Acad Sci. 1987; 508:333-348.

94. De Graaf RA: In vivo NMR spectroscopy: principles and techniques / Robin de Graaf.. - 2nd ed.; 2007.

95. Haase A, Frahm J, Hanicke W, Matthaei D. 1H NMR chemical shift selective (CHESS) imaging. Phys Med Biol. 1985; 30:341-344.

96. Bakermans AJ, Geraedts TR, van Weeghel M, Denis S, Joao Ferraz M, Aerts JM, Aten J, Nicolay K, Houten SM, Prompers JJ. Fasting-induced myocardial lipid accumulation in long-chain acyl-CoA 
dehydrogenase knockout mice is accompanied by impaired left ventricular function. Circ Cardiovasc Imaging. 2011; 4:558-565.

97. van der Meer RW, Rijzewijk LJ, Diamant M, Hammer S, Schar M, Bax JJ, Smit JW, Romijn JA, de Roos A, Lamb HJ. The ageing male heart: myocardial triglyceride content as independent predictor of diastolic function. Eur Heart J. 2008; 29:1516-1522.

98. Nakae I, Mitsunami K, Yoshino T, Omura T, Tsutamoto T, Matsumoto T, Morikawa S, Inubushi T, Horie M. Clinical features of myocardial triglyceride in different types of cardiomyopathy assessed by proton magnetic resonance spectroscopy: comparison with myocardial creatine. J Card Fail. 2010; 16:812822.

99. Weiss K, Martini N, Boesiger P, Kozerke S. Metabolic MR imaging of regional triglyceride and creatine content in the human heart. Magn Reson Med. 2012; 68:1696-1704.

100. Liu CY, Liu YC, Venkatesh BA, Lima JA, Bluemke DA, Steenbergen C. Heterogeneous distribution of myocardial steatosis--an ex vivo evaluation. Magn Reson Med. 2012; 68:1-7.

101. Mahmod M, Bull S, Suttie JJ, Pal N, Holloway C, Dass S, Myerson SG, Schneider JE, De Silva R, Petrou M, Sayeed R, Westaby S, Clelland C, Francis JM, Ashrafian H, Karamitsos TD, Neubauer S. Myocardial steatosis and left ventricular contractile dysfunction in patients with severe aortic stenosis. Circ Cardiovasc Imaging. 2013; 6:808-816.

102. Kreis R, Felblinger J, Jung B, Boesch C. In vivo 1H-MR spectroscopy of the human heart. Magma. 1998; 6:164-167.

103. McGavock JM, Lingvay I, Zib I, Tillery T, Salas N, Unger R, Levine BD, Raskin P, Victor RG, Szczepaniak LS. Cardiac steatosis in diabetes mellitus: a $1 \mathrm{H}$-magnetic resonance spectroscopy study. Circulation. 2007; 116:1170-1175.

104. Schrauwen-Hinderling VB, Hesselink MK, Meex R, van der Made S, Schar M, Lamb H, Wildberger JE, Glatz J, Snoep G, Kooi ME, Schrauwen P. Improved ejection fraction after exercise training in obesity is accompanied by reduced cardiac lipid content. J Clin Endocrinol Metab. 2010; 95:1932-1938.

105. Hammer S, Snel M, Lamb HJ, Jazet IM, van der Meer RW, Pijl H, Meinders EA, Romijn JA, de Roos A, Smit JW. Prolonged caloric restriction in obese patients with type 2 diabetes mellitus decreases myocardial triglyceride content and improves myocardial function. Journal of the American College of Cardiology. 2008; 52:1006-1012.

106. Schrauwen-Hinderling VB, Meex RC, Hesselink MK, van de Weijer T, Leiner T, Schar M, Lamb HJ, Wildberger JE, Glatz JF, Schrauwen P, Kooi ME. Cardiac lipid content is unresponsive to a physical activity training intervention in type 2 diabetic patients, despite improved ejection fraction. Cardiovasc Diabetol. 2011; 10:47.

107. Reingold JS, McGavock JM, Kaka S, Tillery T, Victor RG, Szczepaniak LS. Determination of triglyceride in the human myocardium by magnetic resonance spectroscopy: reproducibility and sensitivity of the method. Am J Physiol Endocrinol Metab. 2005; 289:E935-939.

108. van der Meer RW, Hammer S, Smit JW, Frolich M, Bax JJ, Diamant M, Rijzewijk LJ, de Roos A, Romijn $\mathrm{JA}$, Lamb HJ. Short-term caloric restriction induces accumulation of myocardial triglycerides and decreases left ventricular diastolic function in healthy subjects. Diabetes. 2007; 56:2849-2853.

109. Bakermans AJ, van Weeghel M, Denis S, Nicolay K, Prompers JJ, Houten SM. Carnitine supplementation attenuates myocardial lipid accumulation in long-chain acyl-CoA dehydrogenase knockout mice. J Inherit Metab Dis. 2013; 36:973-981.

110. Bottomley PA, Weiss RG. Non-invasive magnetic-resonance detection of creatine depletion in nonviable infarcted myocardium. Lancet. 1998; 351:714-718.

111. Nakae I, Mitsunami K, Omura T, Yabe T, Tsutamoto T, Matsuo S, Takahashi M, Morikawa S, Inubushi T, Nakamura $Y$, Kinoshita M, Horie M. Proton magnetic resonance spectroscopy can detect creatine depletion associated with the progression of heart failure in cardiomyopathy. Journal of the American College of Cardiology. 2003; 42:1587-1593.

112. Nakae I, Mitsunami K, Matsuo S, Inubushi T, Morikawa S, Tsutamoto T, Koh T, Horie M. Myocardial creatine concentration in various nonischemic heart diseases assessed by $1 \mathrm{H}$ magnetic resonance spectroscopy. Circ J. 2005; 69:711-716.

113. Nakae I, Mitsunami K, Matsuo S, Matsumoto T, Morikawa S, Inubushi T, Koh T, Horie M. Assessment of myocardial creatine concentration in dysfunctional human heart by proton magnetic resonance spectroscopy. Magn Reson Med Sci. 2004; 3:19-25.

114. Phillips D, Ten Hove M, Schneider JE, Wu CO, Sebag-Montefiore L, Aponte AM, Lygate CA, Wallis J, Clarke K, Watkins H, Balaban RS, Neubauer S. Mice over-expressing the myocardial creatine transporter develop progressive heart failure and show decreased glycolytic capacity. J Mol Cell Cardiol. 2010; 48:582-590. 
115. Liu CY, Redheuil A, Ouwerkerk R, Lima JA, Bluemke DA. Myocardial fat quantification in humans: Evaluation by two-point water-fat imaging and localized proton spectroscopy. Magn Reson Med. 2010; 63:892-901.

116. Saranathan M, Glockner J. Three-dimensional dixon fat-water separated rapid breathheld imaging of myocardial infarction. J Magn Reson Imaging. 2013; 38:1362-1368.

117. Nelson AJ, Worthley MI, Psaltis PJ, Carbone A, Dundon BK, Duncan RF, Piantadosi C, Lau DH, Sanders P, Wittert GA, Worthley SG. Validation of cardiovascular magnetic resonance assessment of pericardial adipose tissue volume. J Cardiovasc Magn Reson. 2009; 11:15.

118. Dixon WT. Simple proton spectroscopic imaging. Radiology. 1984; 153:189-194.

119. Glover GH, Schneider E. Three-point Dixon technique for true water/fat decomposition with B0 inhomogeneity correction. Magn Reson Med. 1991; 18:371-383.

120. Berglund J, Ahlstrom H, Johansson L, Kullberg J. Two-point dixon method with flexible echo times. Magn Reson Med. 2011; 65:994-1004.

121. Eggers H, Brendel B, Duijndam A, Herigault G. Dual-echo Dixon imaging with flexible choice of echo times. Magn Reson Med. 2011; 65:96-107.

122. Reeder SB, Pineda AR, Wen Z, Shimakawa A, Yu H, Brittain JH, Gold GE, Beaulieu CH, Pelc NJ. Iterative decomposition of water and fat with echo asymmetry and least-squares estimation (IDEAL): application with fast spin-echo imaging. Magn Reson Med. 2005; 54:636-644.

123. Ma J. Dixon techniques for water and fat imaging. J Magn Reson Imaging. 2008; 28:543-558.

124. Goldfarb JW. Fat-water separated delayed hyperenhanced myocardial infarct imaging. Magn Reson Med. 2008; 60:503-509.

125. Goldfarb JW, Roth M, Han J. Myocardial fat deposition after left ventricular myocardial infarction: assessment by using MR water-fat separation imaging. Radiology. 2009; 253:65-73.

126. Tyler DJ. Cardiovascular Applications of Hyperpolarized MRI. Current cardiovascular imaging reports. 2011; 4:108-115.

127. Mansson S, Johansson E, Magnusson P, Chai CM, Hansson G, Petersson JS, Stahlberg F, Golman K. $13 \mathrm{C}$ imaging-a new diagnostic platform. Eur Radiol. 2006; 16:57-67.

128. Rider OJ, Tyler DJ. Clinical implications of cardiac hyperpolarized magnetic resonance imaging. J Cardiovasc Magn Reson. 2013; 15:93.

129. Golman K, Petersson JS, Magnusson P, Johansson E, Akeson P, Chai CM, Hansson G, Mansson S. Cardiac metabolism measured noninvasively by hyperpolarized 13C MRI. Magn Reson Med. 2008; 59:1005-1013.

130. Schroeder MA, Cochlin LE, Heather LC, Clarke K, Radda GK, Tyler DJ. In vivo assessment of pyruvate dehydrogenase flux in the heart using hyperpolarized carbon-13 magnetic resonance. Proc Natl Acad Sci U S A. 2008; 105:12051-12056.

131. Merritt ME, Harrison C, Storey C, Jeffrey FM, Sherry AD, Malloy CR. Hyperpolarized $13 C$ allows a direct measure of flux through a single enzyme-catalyzed step by NMR. Proc Natl Acad Sci U S A. 2007; 104:19773-19777.

132. Atherton HJ, Schroeder MA, Dodd MS, Heather LC, Carter EE, Cochlin LE, Nagel S, Sibson NR, Radda GK, Clarke K, Tyler DJ. Validation of the in vivo assessment of pyruvate dehydrogenase activity using hyperpolarised 13C MRS. NMR Biomed. 2011; 24:201-208.

133. Merritt ME, Harrison C, Storey C, Sherry AD, Malloy CR. Inhibition of carbohydrate oxidation during the first minute of reperfusion after brief ischemia: NMR detection of hyperpolarized $13 \mathrm{CO} 2$ and H13CO3. Magn Reson Med. 2008; 60:1029-1036.

134. Gallagher FA, Kettunen MI, Brindle KM. Imaging pH with hyperpolarized 13C. NMR Biomed. 2011; 24:1006-1015.

135. Schroeder MA, Swietach P, Atherton HJ, Gallagher FA, Lee P, Radda GK, Clarke K, Tyler DJ. Measuring intracellular $\mathrm{pH}$ in the heart using hyperpolarized carbon dioxide and bicarbonate: a $13 \mathrm{C}$ and 31P magnetic resonance spectroscopy study. Cardiovasc Res. 2010; 86:82-91.

136. Schroeder MA, Atherton HJ, Dodd MS, Lee P, Cochlin LE, Radda GK, Clarke K, Tyler DJ. The cycling of acetyl-coenzyme A through acetylcarnitine buffers cardiac substrate supply: a hyperpolarized $13 \mathrm{C}$ magnetic resonance study. Circ Cardiovasc Imaging. 2012; 5:201-209.

137. Schroeder MA, Atherton HJ, Ball DR, Cole MA, Heather LC, Griffin JL, Clarke K, Radda GK, Tyler DJ. Real-time assessment of Krebs cycle metabolism using hyperpolarized $13 \mathrm{C}$ magnetic resonance spectroscopy. Faseb J. 2009; 23:2529-2538. 
138. Chen AP, Hurd RE, Schroeder MA, Lau AZ, Gu YP, Lam WW, Barry J, Tropp J, Cunningham CH. Simultaneous investigation of cardiac pyruvate dehydrogenase flux, Krebs cycle metabolism and $\mathrm{pH}$, using hyperpolarized [1,2-(13)C2]pyruvate in vivo. NMR Biomed. 2012; 25:305-311.

139. Josan S, Park JM, Hurd R, Yen YF, Pfefferbaum A, Spielman D, Mayer D. In vivo investigation of cardiac metabolism in the rat using MRS of hyperpolarized [1-13C] and [2-13C]pyruvate. NMR Biomed. 2013; 26:1680-1687.

140. Atherton HJ, Dodd MS, Heather LC, Schroeder MA, Griffin JL, Radda GK, Clarke K, Tyler DJ. Role of pyruvate dehydrogenase inhibition in the development of hypertrophy in the hyperthyroid rat heart: a combined magnetic resonance imaging and hyperpolarized magnetic resonance spectroscopy study. Circulation. 2011; 123:2552-2561.

141. Schroeder MA, Lau AZ, Chen AP, Gu Y, Nagendran J, Barry J, Hu X, Dyck JR, Tyler DJ, Clarke K, Connelly $\mathrm{KA}$, Wright $\mathrm{GA}$, Cunningham $\mathrm{CH}$. Hyperpolarized $13 \mathrm{C}$ magnetic resonance reveals early- and late-onset changes to in vivo pyruvate metabolism in the failing heart. Eur J Heart Fail. 2013; 15:130-140.

142. Chen AP, Kurhanewicz J, Bok R, Xu D, Joun D, Zhang V, Nelson SJ, Hurd RE, Vigneron DB. Feasibility of using hyperpolarized [1-13C]lactate as a substrate for in vivo metabolic $13 \mathrm{C} \mathrm{MRSI}$ studies. Magn Reson Imaging. 2008; 26:721-726.

143. Mayer D, Yen YF, Josan S, Park JM, Pfefferbaum A, Hurd RE, Spielman DM. Application of hyperpolarized [1-(1)(3)C]lactate for the in vivo investigation of cardiac metabolism. NMR Biomed. 2012; 25:1119-1124.

144. Moreno KX, Sabelhaus SM, Merritt ME, Sherry AD, Malloy CR. Competition of pyruvate with physiological substrates for oxidation by the heart: implications for studies with hyperpolarized [113C]pyruvate. Am J Physiol Heart Circ Physiol. 2010; 298:H1556-1564.

145. Ball DR, Rowlands B, Dodd MS, Le Page L, Ball V, Carr CA, Clarke K, Tyler DJ. Hyperpolarized butyrate: A metabolic probe of short chain fatty acid metabolism in the heart. Magn Reson Med. 2013.

146. Nelson SJ, Kurhanewicz J, Vigneron DB, Larson PE, Harzstark AL, Ferrone M, van Criekinge M, Chang JW, Bok R, Park I, Reed G, Carvajal L, Small EJ, Munster P, Weinberg VK, Ardenkjaer-Larsen JH, Chen AP, Hurd RE, Odegardstuen LI, Robb FJ, Tropp J, Murray JA. Metabolic imaging of patients with prostate cancer using hyperpolarized [1-(1)(3)C]pyruvate. Sci Transl Med. 2013; 5:198ra108.

147. Rijzewijk L, van der Meer RW, Smit JW, Diamant M, Bax JJ, Hammer S, Romijn JA, de Roos A, Lamb HJ. Myocardial steatosis is an independent predictor of diastolic dysfunction in type 2 diabetes mellitus. Journal of the American College of Cardiology. 2008; 52:1793-1799.

148. Perseghin G, De Cobelli F, Esposito A, Belloni E, Lattuada G, Canu T, Invernizzi PL, Ragogna F, La Torre A, Scifo P, Alberti G, Del Maschio A, Luzi L. Left ventricular function and energy metabolism in middleaged men undergoing long-lasting sustained aerobic oxidative training. Heart. 2009; 95:630-635.

149. Beer M, Spindler M, Sandstede JJ, Remmert H, Beer S, Kostler H, Hahn D. Detection of myocardial infarctions by acquisition-weighted 31P-MR spectroscopy in humans. J Magn Reson Imaging. 2004; 20:798-802.

150. Beer M, Seyfarth T, Sandstede J, Landschutz W, Lipke C, Kostler H, von Kienlin M, Harre K, Hahn D, Neubauer S. Absolute concentrations of high-energy phosphate metabolites in normal, hypertrophied, and failing human myocardium measured noninvasively with (31)P-SLOOP magnetic resonance spectroscopy. Journal of the American College of Cardiology. 2002; 40:1267-1274.

151. Hansch A, Rzanny R, Heyne JP, Leder U, Reichenbach JR, Kaiser WA. Noninvasive measurements of cardiac high-energy phosphate metabolites in dilated cardiomyopathy by using 31P spectroscopic chemical shift imaging. Eur Radiol. 2005; 15:319-323.

152. Neubauer S, Horn M, Cramer M, Harre K, Newell JB, Peters W, Pabst T, Ertl G, Hahn D, Ingwall JS, Kochsiek K. Myocardial phosphocreatine-to-ATP ratio is a predictor of mortality in patients with dilated cardiomyopathy. Circulation. 1997; 96:2190-2196.

153. Toyo-oka T, Nagayama K, Suzuki J, Sugimoto T. Noninvasive assessment of cardiomyopathy development with simultaneous measurement of topical $1 \mathrm{H}$ - and 31P-magnetic resonance spectroscopy. Circulation. 1992; 86:295-301. 

Chapter 3

\section{Geometrical models for cardiac MRI in rodents: comparison of quantification of left ventricular volumes and function by various geometrical models with a full- volume MRI data set in rodents}

Tineke van de Weijer, ${ }^{1,5}$ Petronella A. van Ewijk, ${ }^{1,5}$ H. Reinier Zandbergen, ${ }^{6}$ Jos M. Slenter, ${ }^{3,6}$ Alfons G. Kessels, ${ }^{4}$ Joachim E. Wildberger, ${ }^{3,6}$ Matthijs K. C. Hesselink, ${ }^{2,5}$ Patrick Schrauwen, ${ }^{1,5}$ Vera B. Schrauwen-Hinderling, ${ }^{3,5}$ and Marianne Eline Kooi ${ }^{3,5,6}$

Departments of ${ }^{1}$ Human Biology, ${ }^{2}$ Human Movement Sciences, ${ }^{3}$ Radiology and ${ }^{4}$ Clinical Epidemiology, ${ }^{5}$ Nutrim, School for Nutrition, Toxicology and Metabolism, ${ }^{6}$ Cardiovascular Research Institute Maastricht, Maastricht University Medical Centre, The Netherlands 
MRI has been proven to be an accurate method for non-invasive assessment of cardiac function. One of the current limitations of cardiac MRI is that it is timeconsuming. Therefore various geometrical models are used, which can reduce scan and post-processing time. It is unclear how appropriate their use is in rodents. LV volumes and ejection fraction (EF) were quantified based on 7.0 Tesla cine-MRI in 12 WT mice, 12 adipose triglyceride lipase knockout (ATGL-/-) mice (model of impaired cardiac function) and 11 rats in which we induced cardiac ischemia. The LV volumes and function were either assessed with parallel shortaxis slices covering the full volume of the left ventricle [FV, gold standard), or with various geometrical models (modified Simpson rule (SR), biplane ellipsoid (BP), hemisphere cylinder $(\mathrm{HC})$, single-plane ellipsoid (SP) and modified Teichholz Formula (TF)]. Reproducibility of the different models was tested and results were correlated with the gold standard (FV). All models and the FV data set provided reproducible results for the $\mathrm{LV}$ volumes and $\mathrm{EF}$, with interclass correlation coefficients $\geq 0.87$. All models significantly over- or underestimated $E F$, except for SR. Good correlations were found for all volumes and EF for the SR model when compared to the FV data set $\left(R^{2} \geq 0.90\right.$ for all parameters). The $H C$ model and $B P$ model also predicted EF quite well $\left(R^{2} \geq 0.85\right)$, though proved to be less useful for quantitative analysis. The SP and TF models correlated poorly with the FV data set $\left(R^{2} \geq 0.45\right.$ for $E F$ and $\geq 0.29$ for $E F$, respectively). For the reduction in acquisition and post-processing time, only the SR model proved to be a valuable method for calculating LV volumes, stroke volume and EF. 


\section{INTRODUCTION}

Cardiovascular diseases still are one of the main causes of death in Western countries, and the incidence and prevalence of cardiovascular diseases are still increasing $(1,2)$. Therefore, many studies have focused on the prevention, treatment and etiology of these diseases. Rodent models of cardiac disease have played a critical role in this area of expertise and hence models to assess rodent cardiac function have become increasingly important over the last decades $(3,4)$. MRI has been proven to be an accurate method for non-invasive assessment of cardiac function in rodents (5-7) and has therefore become an important tool in studies of rodent models of cardiac disease $(8,9)$. With MRI, systolic function can be assessed by calculating the Ejection Fraction (EF) from sequential multi-slice short-axis cine MR images covering the complete volume of the left ventricle (5). However, this requires an acquisition of at least 6-8 slices (depending on the size of the heart), which can be quite time consuming, especially in studies requiring high spatial resolution. Also manual or semi-automatic analysis of these slices can demand a substantial amount of time in high-throughput applications (10). Futhermore, it might be desirable to be able to allow quick assessment of the cardiac function, as a secondary parameter, without increasing scan-time too much. The acquisition duration is not only demanding in terms of scan-time but more importantly prolongs the duration of anesthesia and hence increases stress in the animals under investigation $(11,12)$. In specific cardiovascular comprised genotypes, such as the adipose triglyceride lipase knock-out (ATGL-/-) mouse, which was used in our studies (13), prolonged anesthesia can in some cases increase mortality.

To circumvent this, several studies have implemented geometrical models for assessment of cardiac function in rodents, rather than acquiring multiple parallel slices with multi slice cine-MR imaging to determine the full volume of the left ventricle (14-19). These models estimate left ventricular volumes based on single or perpendicular biplane or even triplane slices (20) and therefore allow quick assessment of $\mathrm{LV}$ volumes and $\mathrm{EF}$, as they only require acquisition of one up to three instead of six to eightslices for mice. For rats, due to the larger size of the left ventricle, the reduction in number of slices is even larger, i.e. 1-3 instead of 610 slices. This would substantially reduce total scan time with 10-30 minutes for mice, and even 20-45 minutes for rats. A typical total examination time during which the mice and rats are kept under anesthesia for assessment of cardiac function is $40-45$ and $45-60$ minutes, respectively. Additionally, acquisition of images required for the geometrical models instead of a full volume data set would reduce the number of slices to be segmented to calculate the LV volumes 
and EF with a factor of 2-3 for mice and 2-4 for rats, thereby also reducing time spent on the assessment of cardiac function in rodent models of cardiac disease. Although these models have been compared with ultrasound (21), and the application of these models for cardiac MRI have been investigated in humans (20), to our knowledge no study has determined which of these geometrical models is most accurate in determining cardiac function when compared to the gold standard, i.e. cine-MRI of the complete left ventricle by full volume imaging in rodents. Therefore, the aim of the present study was to evaluate reproducibility and validity of these geometrical models in rodents compared to the gold standard, cine-MRI of the complete left ventricle. After testing the validity of these geometrical models in wild type mice with anticipated normal cardiac function, we tested the applicability of these models in mice with anticipated cardiac failure and in rats in which we induced myocardial infarction. 


\section{Methods}

\section{Animals}

Mice and rats were housed under standard conditions at $25{ }^{\circ} \mathrm{C}$ with a $14: 10 \mathrm{~h}$ light/dark cycle with ad libitum access to water and standard chow diet. The institutional ethics committee on animal welfare approved all experiments. Twelve wild type C57BL/6 mice with anticipated normal cardiac function were imaged for validation of the geometrical models. In addition, we extended the validation to a model of severe cardiac dysfunction by using 12 adipose tritlyceride lipase knock-out mice (ATGL-/-, age 8-12 weeks). ATGL-/- mice were generated on a mixed genetic background (50\% C57BL/6 and 50\% 129/Ola) as previously described (22). The targeted ATGL allele was then backcrossed onto the $\mathrm{C} 57 \mathrm{BL} / 6$ background strain for $>10$ generations. Furthermore, myocardial infarction (MI) was induced in 11 male Wistar-rats (300-500 g) by ligation of the left anterior descending coronary artery using a 6 - 0 Prolene suture, as described previously $(23,24)$. Subsequently, the rats were scanned between 7 and 21 days post-MI.

Before MRI, animals were anesthetized using 1-2\% isoflurane (Abbott Laboratories Ltd, Queensborough, UK) in medical air. Neonatal ECG electrodes (3M, St Paul, MN) were placed on the paws of the right front leg and left hind leg and connected to an MR compatible small animal monitoring system (SA Instruments, Stony Brook, NY). Animals were placed on a warm waterbed. Respiratory rate was continuously monitored.

\section{MRI protocol}

MRI was performed on a 7 Tesla Bruker Biospec 70/30 USR (Bruker Biospin GmbH, Ettlingen, Germany) using the BGA12-S mini-imaging gradient (maximum gradient strength $400 \mathrm{mTm}^{-1}$, slew rate $5000 \mathrm{Tm}^{-1} \mathrm{~s}^{-1}$, linear inductive rise time $5-95 \%$ on all axis; $80 \mu \mathrm{s}$ ), interfaced to an AVANCE II console. First, a bright blood cine image with 10 cardiac phases was recorded in horizontal 4 chamber view $(4 \mathrm{CH})$ using a retrospectively self-gated protocol (IntraGate ${ }^{\mathrm{TM}}$, Bruker Biospin, imaging time: 24 min, for the mice: $2.56 \times 2.56 \mathrm{~cm}^{2}$ field-of-view, $164 \times 164$ matrix size; for the rats: $5.0 \times 5.0 \mathrm{~cm}^{2}$ field-of-view, $128 \times 128$ matrix size see Fig. $1, I$ and $\left.J\right)$. This $4 \mathrm{CH}$ orientation was used to plan a long axis view (LA) perpendicular to the $4 \mathrm{CH}$ view with the same self-gated protocol (Fig. $1, A, B, E$ and $F$ ). The orientation was defined as a sagittal plane through the mitral valve and the apex. Perpendicular to this LA and $4 \mathrm{CH}$ view and the septum, a short axis view (SA) was positioned (see 
Fig. 1, $C, D, G, H, K$ and $L$ ). The slice was planned at half height of the left ventricle, 1-2 $\mathrm{mm}$ below the leaflets of the mitral valve. This image was acquired ECG and respiratory gated, using a bright blood gradient echo sequence with the following parameters for the mice studied: repetition time: $11.6 \mathrm{~ms}$, echo time: $2.5 \mathrm{~ms}$, flip angle: $50^{\circ}$, one slice, $1 \mathrm{~mm}$ thickness, eight signal averages, field of view: $25.6 \times 25.6 \mathrm{~mm}$, matrix-size: $164 \times 164$, resulting in an in-plane resolution: $0.16 \times 0.16$ $\mathrm{mm}^{2}$, acquisition time: $\sim 4$ minutes. The SA images of the rats were acquired with the following parameters: repetition time: $7 \mathrm{~ms}$, echo time: $2.8 \mathrm{~ms}$, flip angle: $50^{\circ}$, 1 slice, $1.263 \mathrm{~mm}$ thickness, one signal average, field of view: 50x50mm, matrixsize: $192 \times 192$, resulting in an in-plane resolution: $0.26 \times 0.26 \mathrm{~mm}^{2}$, acquisition time: $5 \mathrm{~min}$. For image analysis of the complete left ventricular volumes, five to nine additional slices were planned parallel to the short axis slice with a slice thickness of $1 \mathrm{~mm}$ in the mice and $1.2 \mathrm{~mm}$ in the rats, without gap between slices. The slices covered the whole left ventricle, from the apex to the base. The images were acquired using the same pulse sequence. The average time for acquiring a the images need to assess EF with a full volume data set, using eight slices, is 50 min.

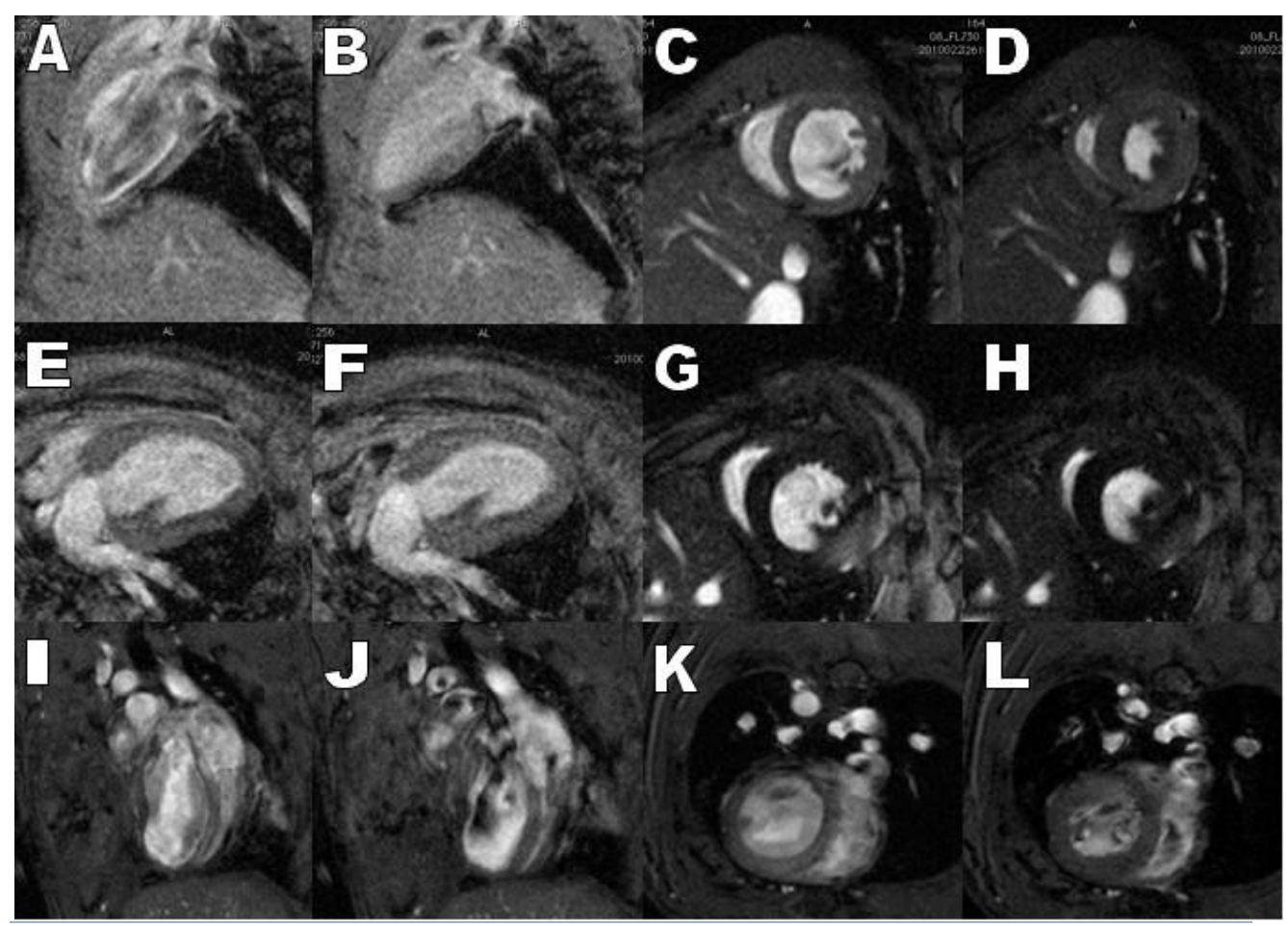

Figure 1. Long axis (LA), 4-chamber view (4CH) and short axis (SA) images of adipose triglyceride lipase knockout mice (ATGL -/-) and wild-type (WT) mice and a rat model of myocardial infarction. Depicted are the LA-plane images of the WT mice. $\boldsymbol{A}$ :. in diastole and $\boldsymbol{B}$ :. in systole. $\boldsymbol{E}$ : LA-plane image in diastole of a ATGL-/- mice. $\boldsymbol{F}$ : LAplane image of a ATGL-/- mice in systole. Here a plane through the mitral valve and the apex was chosen to assess left ventricular (LV) length and volume. I: $4 \mathrm{CH}$ view of a rat heart in diastole. J: $4 \mathrm{CH}$ view of a rat heart in 
diastole, after myocardial infarction. $\boldsymbol{C}$ and $\boldsymbol{D}$ : SA images are depicted in wild-type (WT) mice. $\boldsymbol{G}$ and $\boldsymbol{H}$ : SA images are depicted of a ATGL-/- mice. $\boldsymbol{K}$ and $\mathbf{L}$ : SA images are depicted of a rat heart after myocardial infarction in diastole and systole, respectively. SA view was positioned perpendicular to the LA-plane and 4CH view, for the quantification of LV volumes. Furthermore, in these images an impaired systolic contraction and a dilated and thickened ventricular wall is visible in the ATGL-/- mice (middle), as well as an infracted area in the left ventricle and slight dilatation of the rat heart (bottom).

\section{Image analysis}

All images were analyzed in Osirix (Dicom viewer, version 3.5, Pixmeo, Geneva, Switzerland). The end-diastolic volumes (EDV) and end-systolic volumes (ESV) of the left ventricle were considered the largest and the smallest areas, respectively, of the LV cavity in each slice. For the analysis of cine-MR images, the window width and level were manually adjusted to recognize the internal ventricular morphologic characteristics. For the measurements of LV volumes, the whole LV cavity was selected with semi-automated segmentation parameters in OsiriX. The papillary muscle was excluded from the left ventricular volume during analysis. The diameter $(D)$ of the LV volume on the short axis was measured as the longest distance between the septum and the ventricular wall. Length $(L)$ of the LV on the LA view was defined as the longest distance from the apex to the valves. On average, the time needed to analyze one slice was $3 \mathrm{~min}$.

\section{Data analysis}

In all animals, EDV, ESV, stroke volume (SV = EDV - ESV), and EF (EF = SV/EDV) were calculated from the EDV and ESV volumes based on either the multi-slice short axis cine-images of the complete left ventricle (gold standard) or based on the different geometrical models as described by Dulce et al. 1993 (20). The algorithms and required imaging slices for these models can be found in Fig. 2 . 
Full volume data set (FV)

$\mathrm{LVV}=\mathrm{S}_{1}+\mathrm{S}_{2}+\mathrm{S}_{3}+$.

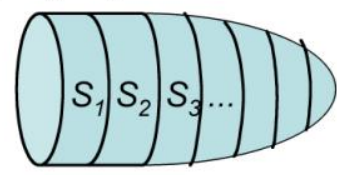

Biplane Ellipsoid model (BP)

$\mathrm{LWV}=\pi / 6 \times L \times\left(4 / \pi \times A_{m} / D\right) \times\left(4 / \pi \times A_{i} / L\right)$

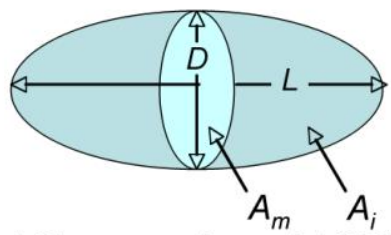

Modified Simpson rule model (SR)

$\operatorname{LVV}=A_{m} \times L / 3+\left(A_{m}+A_{p}\right) / 2 \times L / 3+1 / 3 \times A_{p} \times L / 3$

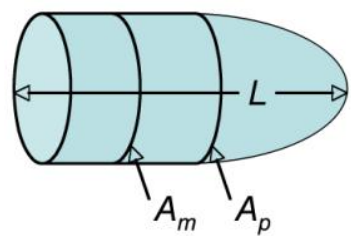

Hemisphere cylinder model (HC)

$L V V=A_{m} \times L / 2+2 / 3 \times A_{m} \times L / 2=5 / 6 \times A_{m} \times L$

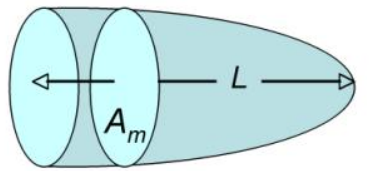

Single-plane Ellipsoid model (SP) $\operatorname{LVV}=\left(8 \times A_{i} \times A_{i}\right) /(3 \pi \times L)=0.85 \times\left(A_{i} \times A_{i}\right) / \mathrm{L}$

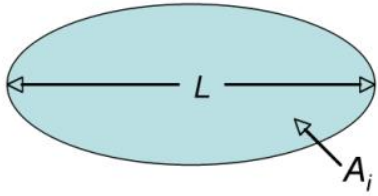

Modified Teichholz Formula (TF)

$\mathrm{LVV}=[7 /(2.4+D)] \times D \times D \times D$

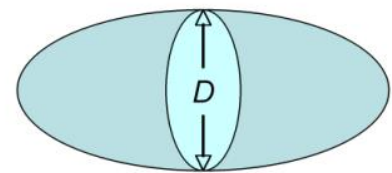

Figure 2.Algorithms and formula's for calculation of LV volumes with a full volume MRI data set of the complete left ventricle or geometrical models based on a few MRI slices.Top: algorithms for full volume data set and the various geometrical models for the determination of LV volumes and ejection fraction (EF) are presented. $A_{i}$, cross-sectional area of LV cavity in the LA plane, $A_{m}$, cross-sectional area of the LV cavity in the SA plane, $\sim 1-2$ $\mathrm{mm}$ below the mitral valve, $A_{p}$, cross-sectional area of the LV cavity in the SA plane, approximately at the base of the papillary muscles, $D$, diameter of the LV cavity in the short axis plane, $\sim 1-2 \mathrm{~mm}$ below the mitral valve, $L$, longest length of LV cavity in the LA plane, LVV, LV volumes [end-diastolic volume (EDV) and end-systolic volume (ESV), respectively]; S1, S2, S3, ..., $1 \mathrm{~mm}$ SA slices from the apex to the base of the left ventricle.

\section{Statistical analysis}

Measurements of $L V$ volumes and $E F$ from cine MR in both the wild type animals and transgenic ATGL-/- mice are presented as mean values \pm SD. The correlations of $\mathrm{LV}$ volumes and $\mathrm{EF}$, as measured with the various geometric models vs. the full volume data set of the left ventricle (gold standard), were assessed by linear regression analysis. $R^{2}, P$ values, and $95 \%$ individual confidence intervals (also known as prediction intervals) are reported for all regression analysis. Differences in LV volumes and EF between the geometric models and the gold standard were analyzed for statistical significance with a one-way ANOVA. Also differences in outcome measures between the different genotypes were assessed with a onwway ANOVA for each model separately. $P$-value $<0.05$ was considered statistically significant. Reproducibility was tested by calculating the interclass correlation for two consecutive measurements for all geometrical models and the gold standard in five wild type mice. For measuring the two consecutive measurements, mice 
were taken out of the scanner in-between the measurements, where after they were repositioned and all preparatory steps (including shimming and scoutimages) were repeated. 


\section{Reproducibility}

The interclass correlation coefficients for each model for the LV volumes and EF are summarized in Table 1. The interclass correlation coefficient was $>0.85$ for all parameters in each model indicating a good reproducibility for all models.

Table 1. Interclass correlation coefficients of LV volumes and ejection fraction in wild type animals

\begin{tabular}{lllll}
\hline \multicolumn{5}{c}{ Wild Type Animals - interclass correlation coefficients } \\
& EDV (\%) & ESV (\%) & SV (\%) & EF (\%) \\
\hline FV & 0.944 & 0.915 & 0.981 & 0.995 \\
BP & 0.991 & 0.994 & 0.986 & 0.975 \\
SR & 0.995 & 0.981 & 0.986 & 0.955 \\
HC & 0.979 & 0.997 & 0.961 & 0.996 \\
SP & 0.997 & 0.989 & 0.976 & 0.939 \\
TF & 0.983 & 0.893 & 0.887 & 0.866 \\
\hline
\end{tabular}

Values were obtained with geometric models and a complete imaging set of the left ventricle (LV) acquired with cine-MRI. Presented are the interclass correlation coefficients of a repeated measurement in 5 mice. EDV and ESV, end-diastolic and end-systolic volume; SV, stroke volume; EF, ejection fraction; FV, full volume data set; $\mathrm{BP}$, biplane ellipsoid model; SR, modified Simpson rule model; HC, hemisphere cylinder model; SP, single plane ellipsoid model; TF, modified Teichholz formula model.

\section{Validation of $L V$ volumes and $E F$}

The values for $\mathrm{LV}$ volumes and $\mathrm{EF}$ in the various animal groups are summarized in Table 2. Only the modified Simpson Rule model gave statistically indifferent values for both the LV volumes and the EF compared with the full volume data set for all study groups. All models could pick up the marked differences in LV volumes and EF found between wild-type and transgenic mice $(P<0.05$, one-way ANOVA test, data not shown).

Table 2. Mean and Standard Deviation of LV volumes and Ejection Fraction

\begin{tabular}{|c|c|c|c|c|}
\hline & $E D V, \mu l$ & ESV, $\mu \mathrm{I}$ & $\mathrm{SV}, \mu \mathrm{l}$ & $E F, \%$ \\
\hline \multicolumn{5}{|c|}{ Wild-type mice $(n=12)$} \\
\hline FV & $52.7 \pm 3.3$ & $14.8 \pm 1.0$ & $37.9 \pm 2.8$ & $71.5 \pm 1.5$ \\
\hline BP & $84.8 \pm 6.0 *$ & $18.0 \pm 1.8(\mathrm{NS})$ & $66.8 \pm 4.6^{*}$ & $79.0 \pm 1.1 *$ \\
\hline SR & $60.3 \pm 2.7$ (NS) & $14.7 \pm 1.4$ (NS) & $45.6 \pm 2.1$ (NS) & $75.9 \pm 1.8$ (NS) \\
\hline $\mathrm{HC}$ & $71.2 \pm 3.6 \S$ & $14.3 \pm 1.4$ (NS) & $56.9 \pm 2.7 *$ & $80.2 \pm 1.3 *$ \\
\hline SP & $58.0 \pm 5.0$ (NS) & $22.2 \pm 2.2$ (NS) & $35.9 \pm 3.7$ (NS) & $61.4 \pm 2.6 *$ \\
\hline TF & $149.5 \pm 15.5 *$ & $45.4 \pm 7.5 *$ & $104.1 \pm 9.6 *$ & $71.1 \pm 3.0$ (NS) \\
\hline
\end{tabular}




\begin{tabular}{|c|c|c|c|c|}
\hline & EDV, $\mu \mathrm{l}$ & ESV, $\mu \mathrm{l}$ & SV, $\mu \mathrm{l}$ & $E F, \%$ \\
\hline \multicolumn{5}{|c|}{ Transgenic mice $(n=12)$} \\
\hline FV & $53.4 \pm 2.7$ & $28.6 \pm 3.3$ & $20.6 \pm 3.8$ & $47.6 \pm 4.2$ \\
\hline BP & $89.3 \pm 4.9 *$ & $41.0 \pm 5.8$ (NS) & $48.3 \pm 3.3 *$ & $55.9 \pm 4.9$ (NS) \\
\hline SR & $55.0 \pm 4.8$ (NS) & $27.1 \pm 4.7$ (NS) & $27.9 \pm 1.6$ (NS) & $53.4 \pm 4.8$ (NS) \\
\hline $\mathrm{HC}$ & $74.2 \pm 5.1$ (NS) & $35.2 \pm 4.9$ (NS) & $39.1 \pm 2.2 *$ & $54.7 \pm 4.2(\mathrm{NS})$ \\
\hline SP & $63.8 \pm 5.7$ (NS) & $48.0 \pm 7.0$ (NS) & $15.8 \pm 2.1$ (NS) & $28.6 \pm 5.2 *$ \\
\hline TF & $180.8 \pm 20.3 *$ & $135 \pm 18.6 *$ & $45.8 \pm 9.6 *$ & $26.8 \pm 4.7 *$ \\
\hline & $\mathrm{EDV}, \mathrm{ml}$ & ESV, ml & SV, ml & $E F, \%$ \\
\hline \multicolumn{5}{|c|}{ Rat ischemic heart model $(n=11)$} \\
\hline FV & $0.36 \pm 0.05$ & $0.23 \pm 0.04$ & $0.13 \pm 0.02$ & $35.2 \pm 5.7$ \\
\hline BP & $0.36 \pm 0.07$ (NS) & $0.24 \pm 0.06$ (NS) & $0.12 \pm 0.04$ (NS) & $33.6 \pm 11.9$ (NS) \\
\hline SR & $0.36 \pm 0.05$ (NS) & $0.23 \pm 0.04$ (NS) & $0.13 \pm 0.03$ (NS) & $36.1 \pm 6.4$ (NS) \\
\hline $\mathrm{HC}$ & $0.33 \pm 0.05 \S$ & $0.21 \pm 0.05$ (NS) & $0.11 \pm 0.03$ (NS) & $35.4 \pm 7.8$ (NS) \\
\hline SP & $0.24 \pm 0.11 *$ & $0.17 \pm 0.11 *$ & $0.07 \pm 0.03 *$ & $34.7 \pm 18.4$ (NS) \\
\hline TF & $0.39 \pm 0.29$ (NS) & $0.23 \pm 0.17$ (NS) & $0.16 \pm 0.16$ (NS) & $41.3 \pm 23.6 \S$ \\
\hline
\end{tabular}

Presented above are the averages and SD of the LV volumes and EF \pm SD per group (wild-type mice, adipose triglyceride lipase knockout mice (ATGL-/-) mice, and rats with cardiac ischemia) and per geometrical model. Values were obtained with geometric models and the complete imaging set of the entire left ventricle acquired with cine-MRI. ${ }^{*} P<0.05 ;+P<0.10$; NS, not significant, when compared with the gold standard (FV).

\section{Linear regression analysis}

The scatter plots with individual regression lines of the EF quantified by the models vs. the gold standard (quantification based on full volume data set) are provided in Fig. 3. Pearson's correlation coefficients $(r)$, individual $95 \%$ confidence intervals and $R^{2}$ can also be found in Fig. 3 . As the modified Simpson rule model was the only model that provided the correct absolute values for EF and LV volumes, we also present the scatter plots of the LV volumes and SV with the full volume data set for this model in Fig.4 (for mice and rats the data are presented separately). 
A

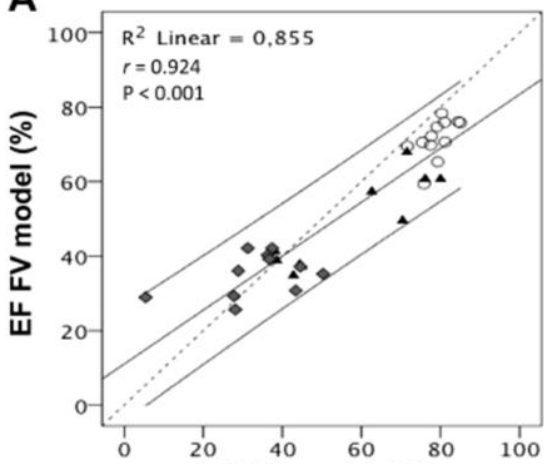

C

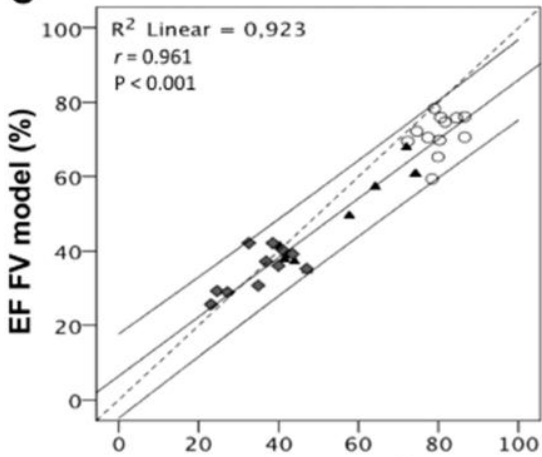

E

EF HC model (\%)

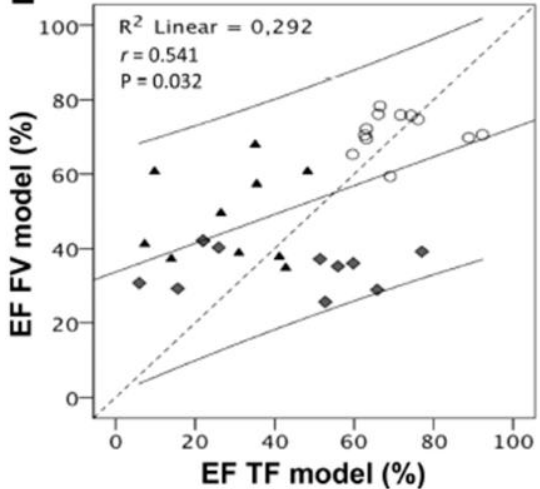

B

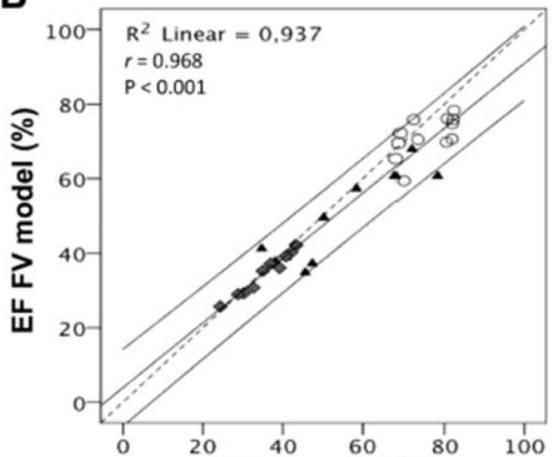

EF SR model (\%)

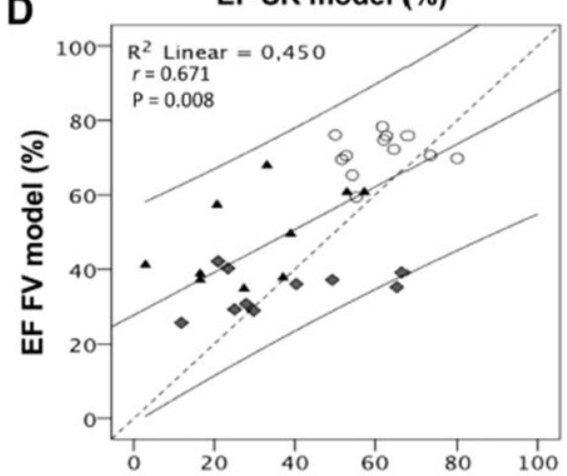

EF SP model (\%)

Wild type mice

ATGL $\%$ mice

ischemic rut mudel

Figure 3. Scatter plots of EF's of the various models vs. full volume data set for A. B: biplane ellipsoid model. C: modified Simpson rule model. D: hemisphere cylinder model. E: single plane ellipsoid model. F: modified Teichholz Formula. In all scatter plots the regression line is given with a $95 \%$ confidence interval. R-squares and Pearson correlation coefficients (with according $P$ values) can also be found in the graph for each fit.

Although all correlations were significant, only the hemisphere cylinder model, the modified Simpson rule model and the biplane ellipsoid model showed a linear regression with a Pearson's correlation coefficient for EF $>0.85$. The other two models showed a poor correlation with correlation coefficients $<0.7$ and R2values $<0.45$. The $95 \%$ confidence interval was smallest for the modified Simpson 
rule model, as the $R 2$ and $r$-values were the highest for this model ( $R 2=0.937$, $r=0.968$ and $P<0.001$ ). The LV volumes and SV, as calculated with the modified Simpson rule model, correlated with the full volume data set both in the mouse models as well as the rat model. However, it should be noticed that the correlations were stronger for the rat model. The R2 values ranged between 0.590.95 with $\mathrm{P}$ values $<0.01$ for all correlations (also see Fig. 4). 

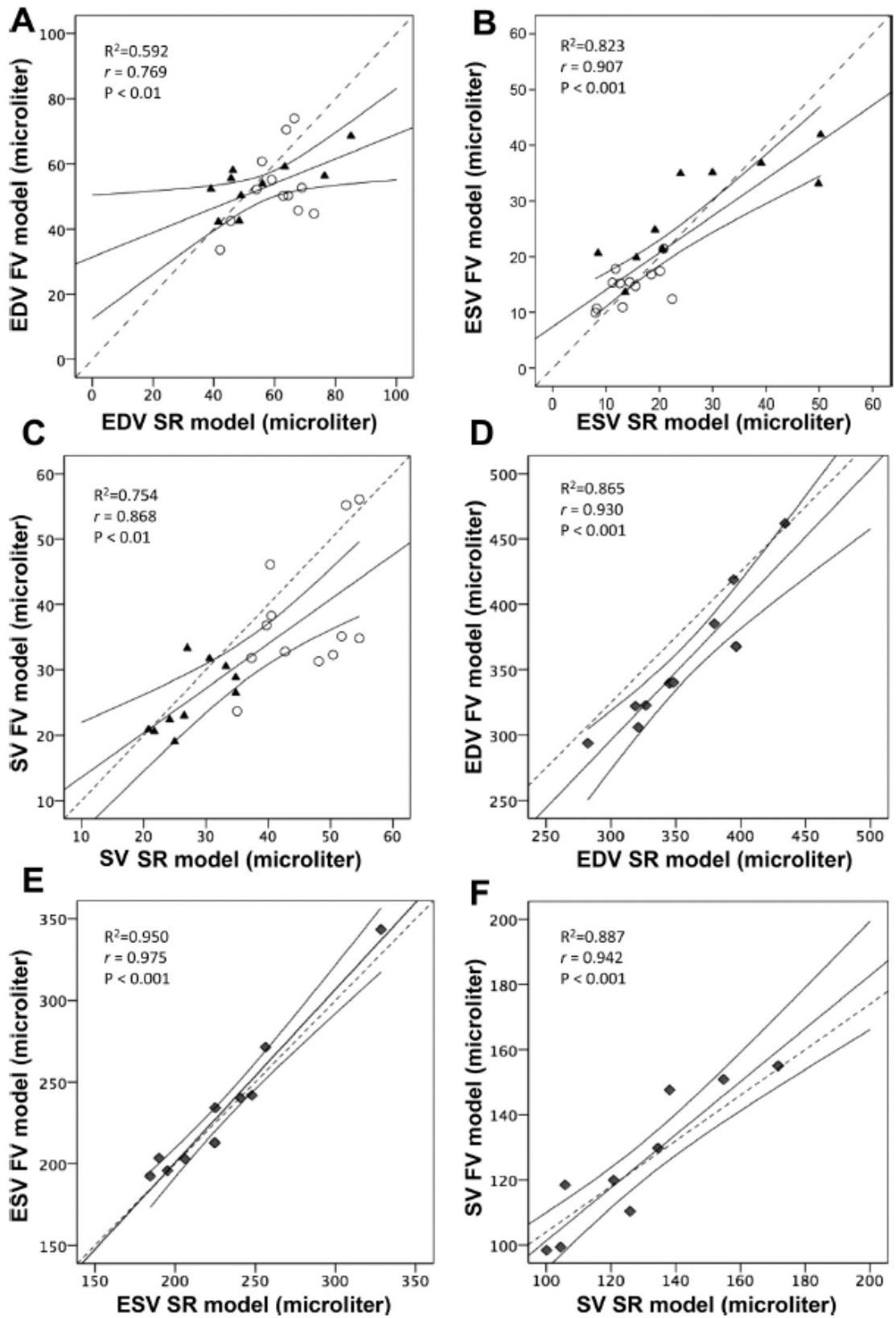

Figure 4. Scatter plots of LV volumes for the modified Simpson rule model (SR) vs. full volume data set. A scatter plot for the EDV in WT $(0)$ and ATGL-/- $(\Delta)$ mice. B scatter plot for the ESV in WT $(0)$ and ATGL-/- $(\Delta)$ mice. C: scatter plot for the stroke volumes in WT (O) and ATGL-/- $(\Delta)$ mice. D: scatter plot for the EDV in rats with myocardial infarction (MI) ( $(0)$. E: scatter plot for the ESV in rats with MI. F: scatter plot for the stroke volumes in rats with MI. In all scatter plots, the regression line is given with a $95 \%$ confidence interval. Dotted line in the graph represents $x=y$. $R$ squares and Pearson correlation coefficients (with according $P$ values) can also be found in the graph for each fit. 


\section{Discussion}

In this study, we aimed to assess the validity of common geometrical models compared to the gold standard, a full volume data set, for quantification of LV volumes and EF with cine-MRI in rodents. We showed that the reproducibility of all models was good, with higher variations in the Teichholz formula model. When the models were compared to the full volume data set, only the modified Simpson rule model showed no significant differences with the gold standard for all the calculated parameters. The values found for the LV volumes, SV, and EF with the modified Simpson rule model correlated well with the full volume data set (gold standard). Also the EF found with the hemisphere cylinder and biplane ellipsoid model showed high correlation coefficients with the full volume data set. The two remaining models were poor predictors of EF.

Although these finding are new for MRI applications, previous research using other imaging modalities already pointed in this direction. For instance, it has been shown that the Teichholz formula model does not give comparable results in MRI compared to ultrasound (21). These results also did not correlate with values found with the modified Simpson rule model in this study either (21). The discrepancy in absolute values compared to the gold standard for all models except the modified Simpson rule points out that care should be taken when cardiac function is compared between studies using different methodology.

By using the modified Simpson rule, one needs to acquire and assess only three imaging planes, thereby reducing total examination time by 10-45 minutes compared with total examination time including positioning of the animal of 3060 minutes in the present study. In addition, segmentation time is reduced by two to three fold (depending on the animal species used). The modified Simpson rule model is only model that divides the heart into three different compartments, based on three imaging planes. This may explain why it is more accurate in estimating the LV volumes, and therefore it might also be more sensitive for nonsymmetrical pathologies (like myocardial infarction, for instance). The other models are based on only one (modified Teichholz formule and single plane ellipsoid model) or two (Hemisphere and biplane ellipsoid models) imaging planes. The most simplified models, using only one plane, showed indeed the poorest correlations, whereas the two plane models did better. Although the EF as determined by these two plane models correlated well with the EF calculated from the full volume data set, they significantly over- or underestimated the real volumes of the left ventricle. Therefore only the modified Simpson rule can be applied in rodent studies of cardiac disease.

For high throughput studies, parallel imaging or simultaneous scanning of multiple animals might be used as an alternative to reduce scan time. These methods will, 
however, not lead to a reduction in segmentation time. Scanning multiple animals simultaneously is still a quite new technique, which requires specific system requirements (25-27). Parallel imaging leads to a reduction of the signal-to-noise ratio and therefore may not always be appropriate (28-31). The Simpson rule model could be a good alternative, and combining parallel imaging with Simpson rule model will even further increase the throughput.

One of the limitations of this study is that the mouse model of transient cardiac disease, namely the ATGL-/- as a model for cardiomyopathy, is quite a rare model. Nonetheless, we choose to use this model as their cardiac function is severely impaired and the progression of their disease is rather extreme (22), which introduces variation in the main outcome parameters as can be found in Table 2 . This variation is not due to a poor reproducibility in this specific group, rather it is due to variation of the disease stage as cardiac function drastically drops with age. A greater variation in the outcome parameters gives a larger spread in the data and makes these data more suited for linear regression analysis. Therefore this model was ideal for looking at correlations in EF. In addition to the ATGL-/- mice, we also included WT mice and rats with myocardial infarction in the present study, since these are more commonly used.

Introducing the rat model of myocardial infarction in this study not only introduced a more common model of cardiac disease but also increased the number of animals for linear regression analysis of EF. One drawback might be that we did handle two different kinds of species in the same analysis. Therefore, we analyzed the correlations between the modified Simpson rule model and full volume data set for the LV volumes and SV for the different animal species separately. The LV volumes seemed to correlate better in the rat model than in the mouse model. The differences in the correlations found are most likely due to the better estimation of the LV volumes in the segmentation analysis of the rat hearts due to relatively higher resolution of the left ventricle (as the LV is quite a bit bigger in rats). In addition, the calculated SV in mice showed more variation compared to the calculated SV in rats. Therefore, one should be careful with the use of the SR model in mice to calculate SV. Also, the spread of the EDV in the rat hearts was greater, resulting in a better spread of the data suitable for regression analysis.

In conclusion, the modified Simpson rule is a good alternative to a full volume data set to measure EF, EDV and ESV and reduces scan and post-processing time. Comparing the absolute values as determined by different geometrical models should be done with caution as they give variable results. 


\section{GRANTS}

This work was supported by the Center for Translational Molecular Medicine and the Netherlands Heart Foundation, Dutch Diabetes Research Foundation and Dutch Kidney Foundation (PREDICCt). V.B. Schrauwen-Hinderling is supported by a VENI grant from the Netherlands Organisation for Scientific Research (NWO).

\section{DISCLOSURES}

No conflicts of interest, financial or otherwise, are declared by the author(s). 


\section{References}

1. Uemura K, Pisa Z. Recent trends in cardiovascular disease mortality in 27 industrialized countries. World Health Stat Q. 1985; 38:142-162.

2. Uemura K, Pisa Z. Trends in cardiovascular disease mortality in industrialized countries since 1950. World Health Stat Q. 1988; 41:155-178.

3. Russell JC, Proctor SD. Small animal models of cardiovascular disease: tools for the study of the roles of metabolic syndrome, dyslipidemia, and atherosclerosis. Cardiovasc Pathol. 2006; 15:318-330.

4. Hasenfuss G. Animal models of human cardiovascular disease, heart failure and hypertrophy. Cardiovasc Res. 1998; 39:60-76.

5. Schneider JE, Cassidy PJ, Lygate C, Tyler DJ, Wiesmann F, Grieve SM, Hulbert K, Clarke K, Neubauer S. Fast, high-resolution in vivo cine magnetic resonance imaging in normal and failing mouse hearts on a vertical 11.7 T system. J Magn Reson Imaging. 2003; 18:691-701.

6. Ruff J, Wiesmann F, Hiller KH, Voll S, von Kienlin M, Bauer WR, Rommel E, Neubauer S, Haase A. Magnetic resonance microimaging for noninvasive quantification of myocardial function and mass in the mouse. Magn Reson Med. 1998; 40:43-48.

7. Ross AJ, Yang Z, Berr SS, Gilson WD, Petersen WC, Oshinski JN, French BA. Serial MRI evaluation of cardiac structure and function in mice after reperfused myocardial infarction. Magn Reson Med. 2002; 47:1158-1168.

8. $\quad$ Epstein FH. MR in mouse models of cardiac disease. NMR Biomed. 2007; 20:238-255.

9. Hiller $\mathrm{KH}$, Waller C, Haase A, Jakob PM. Magnetic resonance of mouse models of cardiac disease. Handb Exp Pharmacol. 2008:245-257.

10. Young AA, Barnes H, Davison D, Neubauer S, Schneider JE. Fast left ventricular mass and volume assessment in mice with three-dimensional guide-point modeling. J Magn Reson Imaging. 2009; 30:514-520.

11. Hanusch C, Hoeger S, Beck GC. Anaesthesia of small rodents during magnetic resonance imaging. Methods. 2007; 43:68-78.

12. Cottrell JE. We care, therefore we are: anesthesia-related morbidity and mortality: the 46th Rovenstine Lecture. Anesthesiology. 2008; 109:377-388.

13. Haemmerle G, Moustafa T, Woelkart G, Buttner S, Schmidt A, van de Weijer T, Hesselink M, Jaeger D, Kienesberger PC, Zierler K, Schreiber R, Eichmann T, Kolb D, Kotzbeck P, Schweiger M, Kumari M, Eder S, Schoiswohl G, Wongsiriroj N, Pollak NM, Radner FP, Preiss-Landl K, Kolbe T, Rulicke T, Pieske B, Trauner M, Lass A, Zimmermann R, Hoefler G, Cinti S, Kershaw EE, Schrauwen P, Madeo F, Mayer B, Zechner R. ATGL-mediated fat catabolism regulates cardiac mitochondrial function via PPAR-alpha and PGC-1. Nat Med. 17:1076-1085.

14. Iltis I, Kober F, Dalmasso C, Cozzone PJ, Bernard M. Noninvasive characterization of myocardial blood flow in diabetic, hypertensive, and diabetic-hypertensive rats using spin-labeling MRI. Microcirculation. 2005; 12:607-614.

15. Oostendorp M, Douma K, Wagenaar A, Slenter JM, Hackeng TM, van Zandvoort MA, Post MJ, Backes WH. Molecular magnetic resonance imaging of myocardial angiogenesis after acute myocardial infarction. Circulation. 2010; 121:775-783.

16. Heijman E, Aben JP, Penners C, Niessen P, Guillaume R, van Eys G, Nicolay K, Strijkers GJ. Evaluation of manual and automatic segmentation of the mouse heart from CINE MR images. J Magn Reson Imaging. 2008; 27:86-93.

17. Shohet RV, Kisanuki YY, Zhao XS, Siddiquee Z, Franco F, Yanagisawa M. Mice with cardiomyocytespecific disruption of the endothelin-1 gene are resistant to hyperthyroid cardiac hypertrophy. Proc Natl Acad Sci U S A. 2004; 101:2088-2093.

18. Franco F, Dubois SK, Peshock RM, Shohet RV. Magnetic resonance imaging accurately estimates LV mass in a transgenic mouse model of cardiac hypertrophy. Am J Physiol. 1998; 274:H679-683.

19. Wiesmann F, Frydrychowicz A, Rautenberg J, Illinger R, Rommel E, Haase A, Neubauer S. Analysis of right ventricular function in healthy mice and a murine model of heart failure by in vivo MRI. Am J Physiol Heart Circ Physiol. 2002; 283:H1065-1071.

20. Dulce MC, Mostbeck GH, Friese KK, Caputo GR, Higgins CB. Quantification of the left ventricular volumes and function with cine MR imaging: comparison of geometric models with three-dimensional data. Radiology. 1993; 188:371-376. 
21. Bunck AC, Engelen MA, Schnackenburg B, Furkert J, Bremer C, Heindel W, Stypmann J, Maintz D. Feasibility of functional cardiac MR imaging in mice using a clinical 3 Tesla whole body scanner. Invest Radiol. 2009; 44:749-756.

22. Haemmerle G, Lass A, Zimmermann R, Gorkiewicz G, Meyer C, Rozman J, Heldmaier G, Maier R, Theussl C, Eder S, Kratky D, Wagner EF, Klingenspor M, Hoefler G, Zechner R. Defective lipolysis and altered energy metabolism in mice lacking adipose triglyceride lipase. Science. 2006; 312:734-737.

23. Kenis $\mathrm{H}$, Zandbergen HR, Hofstra L, Petrov AD, Dumont EA, Blankenberg FD, Haider N, Bitsch N, Gijbels M, Verjans JW, Narula N, Narula J, Reutelingsperger CP. Annexin A5 uptake in ischemic myocardium: demonstration of reversible phosphatidylserine externalization and feasibility of radionuclide imaging. J Nucl Med. 2010; 51:259-267.

24. Palojoki E, Saraste A, Eriksson A, Pulkki K, Kallajoki M, Voipio-Pulkki LM, Tikkanen I. Cardiomyocyte apoptosis and ventricular remodeling after myocardial infarction in rats. Am J Physiol Heart Circ Physiol. 2001; 280:H2726-2731.

25. Bock NA, Konyer NB, Henkelman RM. Multiple-mouse MRI. Magn Reson Med. 2003; 49:158-167.

26. Bock NA, Nieman BJ, Bishop JB, Mark Henkelman R. In vivo multiple-mouse MRI at 7 Tesla. Magn Reson Med. 2005; 54:1311-1316.

27. Bishop J, Feintuch A, Bock NA, Nieman B, Dazai J, Davidson L, Henkelman RM. Retrospective gating for mouse cardiac MRI. Magn Reson Med. 2006; 55:472-477.

28. Roemer PB, Edelstein WA, Hayes CE, Souza SP, Mueller OM. The NMR phased array. Magn Reson Med. 1990; 16:192-225.

29. Jakob PM, Griswold MA, Edelman RR, Manning WJ, Sodickson DK. Accelerated cardiac imaging using the SMASH technique. J Cardiovasc Magn Reson. 1999; 1:153-157.

30. Pruessmann KP, Weiger M, Scheidegger MB, Boesiger P. SENSE: sensitivity encoding for fast MRI. Magn Reson Med. 1999; 42:952-962.

31. Sodickson DK. Tailored SMASH image reconstructions for robust in vivo parallel MR imaging. Magn Reson Med. 2000; 44:243-251. 



\section{Chapter 4}

\section{Lipotoxicity and the role of maternal nutrition}

Maurien G.M. Pruis ${ }^{1}$, Petronella A. van Ewijk ${ }^{2,3}$, Vera B. Schrauwen-Hinderling ${ }^{2}$, Torsten Plösch ${ }^{1}$

1 Department of Pediatrics, Laboratory Medicine, Center for Liver, Digestive and Metabolic Diseases, University Medical Center Groningen, University of Groningen, Groningen, the Netherlands

2 Department of Radiology, Maastricht University Medical Center, Maastricht, the Netherlands 3 Department of Human Biology, Maastricht University Medical Center, Maastricht, the Netherlands 


\begin{abstract}
Intrauterine malnutrition predisposes the offspring towards the development of type 2 diabetes and cardiovascular disease. To explain this association, the Developmental Origins of Health and Disease hypothesis was introduced, meaning that subtle environmental changes during embryonic and foetal development can influence post-natal physiological functions. Different mechanisms, including epigenetics, are thought to be involved in this foetal programming, but the link between epigenetics and disease is missing. There is increasing evidence that ectopic lipid accumulation and/or lipotoxicity is induced by foetal programming. The aim of this review is to provide insights into the mechanisms underlying lipotoxicity through programming, which contributes to the increase in hepatic and cardiac metabolic risk.
\end{abstract}


The prevalence of obesity and the metabolic syndrome is rapidly increasing, paving the way for the development of diabetes and cardiovascular disease. In the etiology of these diseases, fat storage in non-adipose tissue, at so-called ectopic sites, is an important factor (1). Elevated hepatic fat content is strongly linked with insulin resistance, dyslipidemia and all other facets of the metabolic syndrome. Excessive cardiac lipid content is associated with the development of cardiomyopathy and cardiac dysfunction (2).

In spite of all the efforts to promote weight loss and a healthier lifestyle, the prevalence of the metabolic syndrome is still rising. A yet-underestimated factor in the etiology of the metabolic syndrome and related diseases may be the early developmental environment that is known to exert long-lasting influences by socalled 'metabolic programming'. This programming of the foetus to developmental conditions was also called 'developmental programming' $(3,4)$ or 'developmental plasticity' (5), and leads to permanent changes in tissue structure and function. A large number of epidemiological studies have shown the association between impaired foetal nutrition and development of obesity, hypertension, diabetes and cardiovascular disease (6-10). Studies in animal models indicate that maternal overnutrition has similar effects.

While the relationship between early developmental events and adult disease has become evident, the biological mechanisms behind these programming effects have remained largely unclear,although epigenetic modifications and differences in cell type composition may be involved $(11,12)$. The importance of foetal and early postnatal life is currently extensively studied to clarify the physiological and molecular links between events during this developmental period and long-term health. Evidence is accumulating that the ectopic deposition of fat may be mechanistically involved in the long-term programming of disease, thus linking epigenetic effects and physiological outcome. This review highlights the relation between maternal nutrition and hepatic and cardiac lipid metabolism in adult offspring.

\section{COMPLEXITY OF NUTRITIONAL PROGRAMMING}

The investigation of the relationship between maternal diet and lipid metabolism in offspring is complex, as it is influenced by many factors. As the foetus develops at different rates during development, the timing of the insult is important in determining the specificity of programming. Several animal studies have shown the different effects of under- or overnutrition during different stages of pregnancy on programming of the foetus. For example, in a rat study in which dams were exposed to low-protein diets at different time-windows during pregnancy, timing was shown to have differential effects on offspring (13). 
Similarly, the timing of nutrient restriction in sheep was shown to be important for the phenotype of the offspring (14). This exposure effect is also welldocumented in humans. During the Dutch Hunger Winter, the effects of maternal nutrient restriction on the offspring during late- and mid-gestation were especially pronounced $(7,15)$. In addition to exposure timing, nutritional conditions after weaning have been shown to be important for the health effects measured. In sheep exposed to pre- and/or post-natal undernutrition, it was found that a mismatch between pre- and post-natal nutrition leads to unfavourable outcomes (16). Interestingly, pre- and post-natal exposure to a highfat diet did not prevent development of raised blood pressure in a rat model (17). In fact, evidence accumulates that pre-natal exposure to a high-fat diet renders offspring especially sensitive to 'lipotoxic' effects of post-natal high-fat diets (18).

Several studies demonstrated sex-specific effects of developmental exposure to under- or overnutrition (19-21). However, an extensive review on sexual dimorphism and epigenetic programming can be found elsewhere (22).

Programming effects are dependent on specific nutrient deficiency or surplus. At present, an increasing number of animal studies are performed using high-fat diets. Maternal exposure to a high-fat diet rich in saturated fatty acids had detrimental effects in offspring $(19,23)$, while maternal exposure to polyunsaturated fatty acids showed beneficial effects in female rat offspring (24). Ultimately, future research needs to determine which specific signals provoke the programming effects in the target tissues of the foetus. Paradoxically, a general surplus of fatty acids in a high-fat diet may out-compete transport of a single key fatty acid in the placenta, leading to a deficit in the presence of plenty.

\section{THE ROLE OF FOETAL PROGRAMMING IN THE DEVELOPMENT OF NON-ALCOHOLIC FATTY LIVER DISEASE IN EPIDEMIOLOGICAL STUDIES}

Several epidemiological studies implicate an intrauterine contribution to adult liver disease. Although there is little literature about the specific effects of maternal nutrition on birth size in humans, there are many papers highlighting these effects under extreme conditions, like severe starvation (exemplified by the Dutch Hunger Winter, see (25)). It should be noted, however, that intrauterine growth restriction may have a plethora of other (often unknown) causes. Human infants born small-for-gestational-age were found to have reduced liver dimensions, as measured by ultrasonography at birth (26). In addition, low birth size in men, but not women, is associated with increased total cholesterol in blood, which is at least partially regulated by the liver (27). A large Danish prospective record linkage study showed the strongest correlation between measures of birth size and cause-specific mortality for deaths attributed to liver cirrhosis (28). Fraser et al. examined the association of birthweight with adult markers of liver damage and function in a random sample of 2101 British women. 
They found a small but consistent inverse linear association between birthweight and adult age-adjusted levels of alanine aminotransferase (ALT) and gamma glutamyltransferase (GGT) (29). ALT and GGT are liver-specific markers and are considered biomarkers of non-alcoholic fatty liver disease (NAFLD). The inverse association of birthweight with ALT and GGT supports the hypothesis that intrauterine exposure may contribute to the onset of NAFLD.

\section{EVIDENCE OF FOETAL PROGRAMMING IN THE DEVELOPMENT OF NAFLD FROM ANIMAL MODELS}

There are large numbers of well-established animal models that have indicated a link between foetal growth and NAFLD. The first evidence for programming of NAFLD comes from models using nutritionally restricted diets, although the greatest impact is seen in overnourished models. Mouse models of maternal overweight or overnutrition have shown convincing evidence of foetal programming of NAFLD in offspring $(18,30-33)$.

\section{HEPATIC HYPERTROPPHY}

Structural changes have been noted in the liver of offspring from malnourished mothers. Hepatic lobules of protein-restricted rat offspring were described as having double the mean volume of lobules from control livers, without changes in relative liver weight (34). Moreover, several mouse models of maternal malnutrition show hepatic hypertrophy in the offspring $(35,36)$. While not every studies reports hepatic hypertrophy, increases in liver derived enzymes (ALT and AST) are sometimes observed $(32,37,38)$, a change that often accompanies hepatic hypertrophy and may appear in plasma after liver enlargement. Taken together, these results indicate that hepatic hypertrophy is a frequently noted phenomenon accompanying gestational malnutrition. Hepatic hypertrophy can be induced by several factors including altered oxidative status, fatty acid metabolism, energy production and utilization, cell turnover and altered hepatocellular cytoplasmic, and nuclear morphology (39). Several of these factors have been reported in foetal programming of offspring health $(18,34)$.

\section{LIVER FUNCTION}

In addition to structural changes, there have been numerous reports that liver functionality is affected by maternal malnutrition. In rats partially deprived of protein during pregnancy, gluconeogenesis and hepatic glucose handling in offspring are altered compared to controls (34). Glucose output from lactate is increased in maternal low-protein offspring, which is related to the difference in 
glucose handling. One possible mechanism is increased glucogenesis because of the greater absolute phosphoenolpyruvate carboxykinase (PEPCK) activity found in these livers (34). Additionally, several animal models of maternal overnutrition indicate mitochondrial abnormalities in the liver of offspring $(18,40)$. Bruce et al. reported that the activity of the hepatic mitochondrial electron transport chain enzyme complex (I, II/III and IV) is reduced in offspring of high-fat-fed mothers (18). In the progression from NAFLD to non-alcoholic steatohepatitis, inflammatory pathways, which are also affected by foetal programming, are important. In that context, it has recently been reported that offspring from overnourished dams showed increased Kupffer cell numbers with impaired phagocytic function and raised reduced oxygen species synthesis together with reduced natural killer T cells and raised interleukin 12 and interleukin 18 levels (41). Even though many of these animal models use different diets and different strategies, all accumulate fat in the liver and liver functionality seems to be altered in one way or the other (Table 1).

\section{LIPOTOXICITY}

Excessive hepatic fat storage has been shown in many animal models of foetal programming. While hepatic fat accumulation is not necessarily malignant, it is often associated with insulin resistance (42). Models of maternal restriction, overnutrition and glucocorticoid exposure show increased body fat and altered hepatic lipid metabolism in offspring, accompanied by accumulating triglycerides and cholesterol, characteristics of hepatic steatosis $(18,31,33,43)$.

It is still unclear what is underlying the increased lipid accumulation. Impaired oxidative capacity (impaired mitochondrial function) may be of importance; on the other hand, several animal models report a lipogenic transcriptome signature early in the development of the liver $(36,44)$. Non-human primates of overnourished mothers show signs of NAFLD beginning in the early third trimester, including hepatic inflammation, oxidative stress, triglyceride accumulation and gluconeogenic gene activation (44). This is associated with PPAR gamma coactivator 1 alpha (PGC1a) deacetylation and increased hepatocyte nuclear factor 4 alpha (HNF4a) expression in the foetal liver, suggesting an important early mechanism by which excess lipids may reprogram hepatic lipid and glucose metabolism in the liver. In this study, the elevation of hepatic triglyceride levels persisted until adolescence with a twofold increase in per cent body fat. Another study performed in rats found increased per cent liver weight, enlarged hepatocytes and lipid accumulation in livers of offspring at weaning; it is suggested that exposure to maternal overweight programs systemic changes in insulin and adiponectin levels and alteration of genes involved in carbohydrate metabolism, lipid biosynthesis and fatty acid catabolism. Interestingly, sterol regulatory element-binding protein 1 (SREBP1) was increased and identified as a 
common regulator of the altered genes, in addition, a decrease in PPAR-a-AMPK signalling was indicated (36).

In contrast, Krasnow et al. found no differences in triglyceride accumulation and hepatic inflammation in newborn mice (45). However, they reported an increase in fat mass in offspring from mothers fed a high-fat diet.

Currently, most of the research points towards programming of multiple aspects of energy-balance regulation in the offspring during gestational exposure to malnutrition. Therefore, an early change in a lipogenic pathway could be a cause in the development of NAFLD, because the transcriptome is already altered very early in life.

\section{EPIGENETICS}

During the past decade, the role of epigenetics in the pathogenesis of disease has been increasingly recognized. However, the specific role of epigenetics in the pathogenesis of NAFLD is largely unknown. A recent study in human patients showed a tight interaction between the presence of NAFLD and hepatic DNA methylation of PGC1A and mitochondrial transcription factor A promoters (46).

In rodents, numerous studies focus on the consequences of maternal nutrition on the liver epigenome. Promoters of nuclear receptors are relatively well-studied candidates for differential methylation. Lillycrop et al. characterized changes in methylation and expression of the glucocorticoid receptor and peroxisome proliferator-activated receptor (Ppar) alpha $(47,48)$. Van Straten et al. made similar observations for the liver $X$ receptor alpha (LXRa), among 200 other loci (49). It seems plausible that changes in these key factors have long-term consequences for the regulation of metabolism, especially under challenging nutritional conditions.

On the other nutritional extreme, two recent reports showed that maternal highfat diet may alter DNA methylation and gene expression in the offspring. First, maternal high-fat feeding reduces methylation and increased expression of the cyclin-dependent kinase inhibitor $1 \mathrm{~A}(\mathrm{Cdkn1a})$ during neonatal liver development (50). This alteration is responsible for changing hepatic proliferation and liver size, two aspects that are compatible with the development of a fatty liver phenotype (18). The second report demonstrated that in offspring with increased serum glucose and liver triglyceride levels, hepatic Wnt1 (wingless-type MMTV integration site family, member 1) activity is affected through histone modifications (51). 
70 | Chapter 4

Table 1, part 1. Summary of gestational interventions and resulting long-term phenotypes

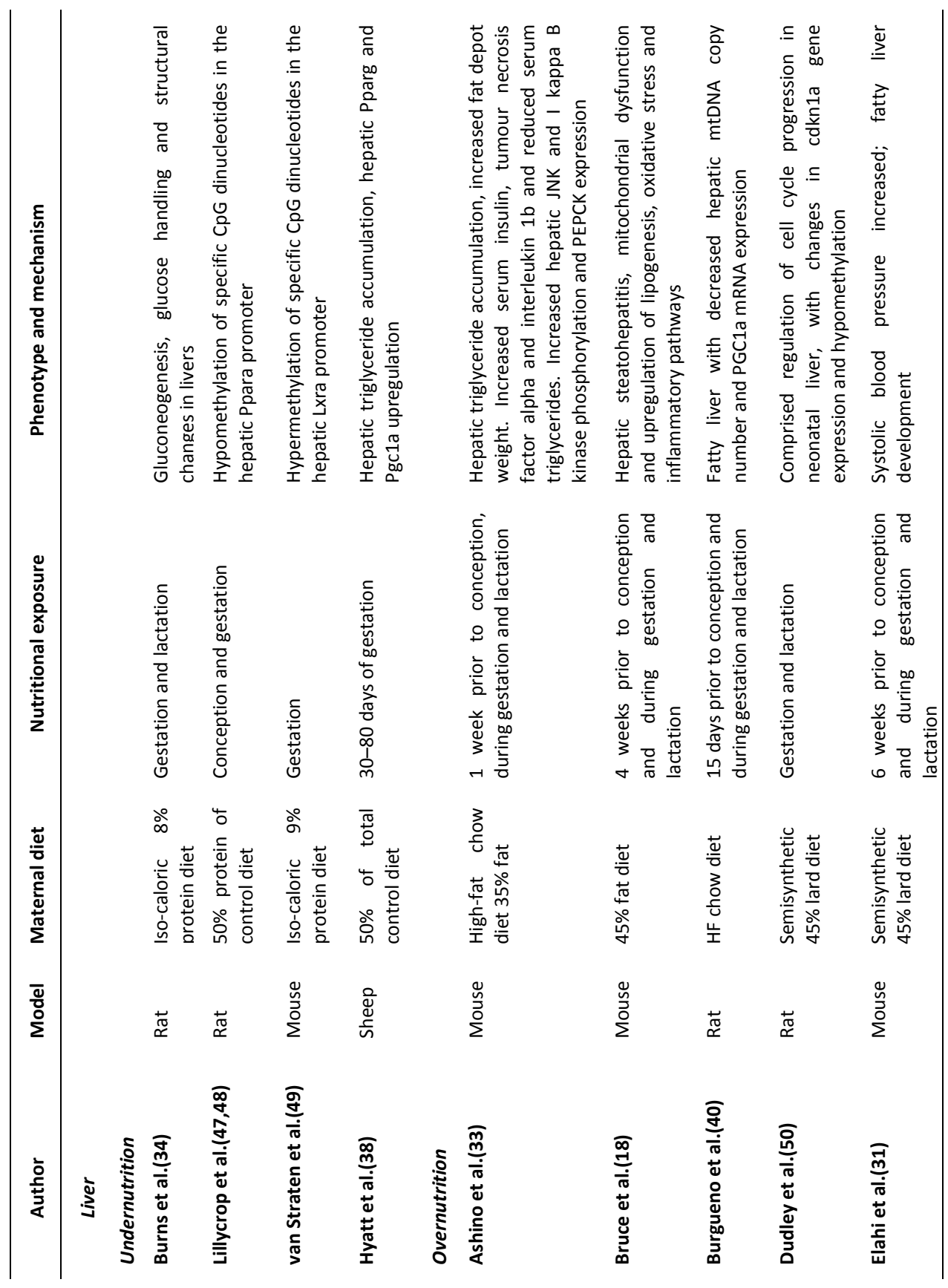


Table 1, part 2. Summary of gestational interventions and resulting long-term phenotypes

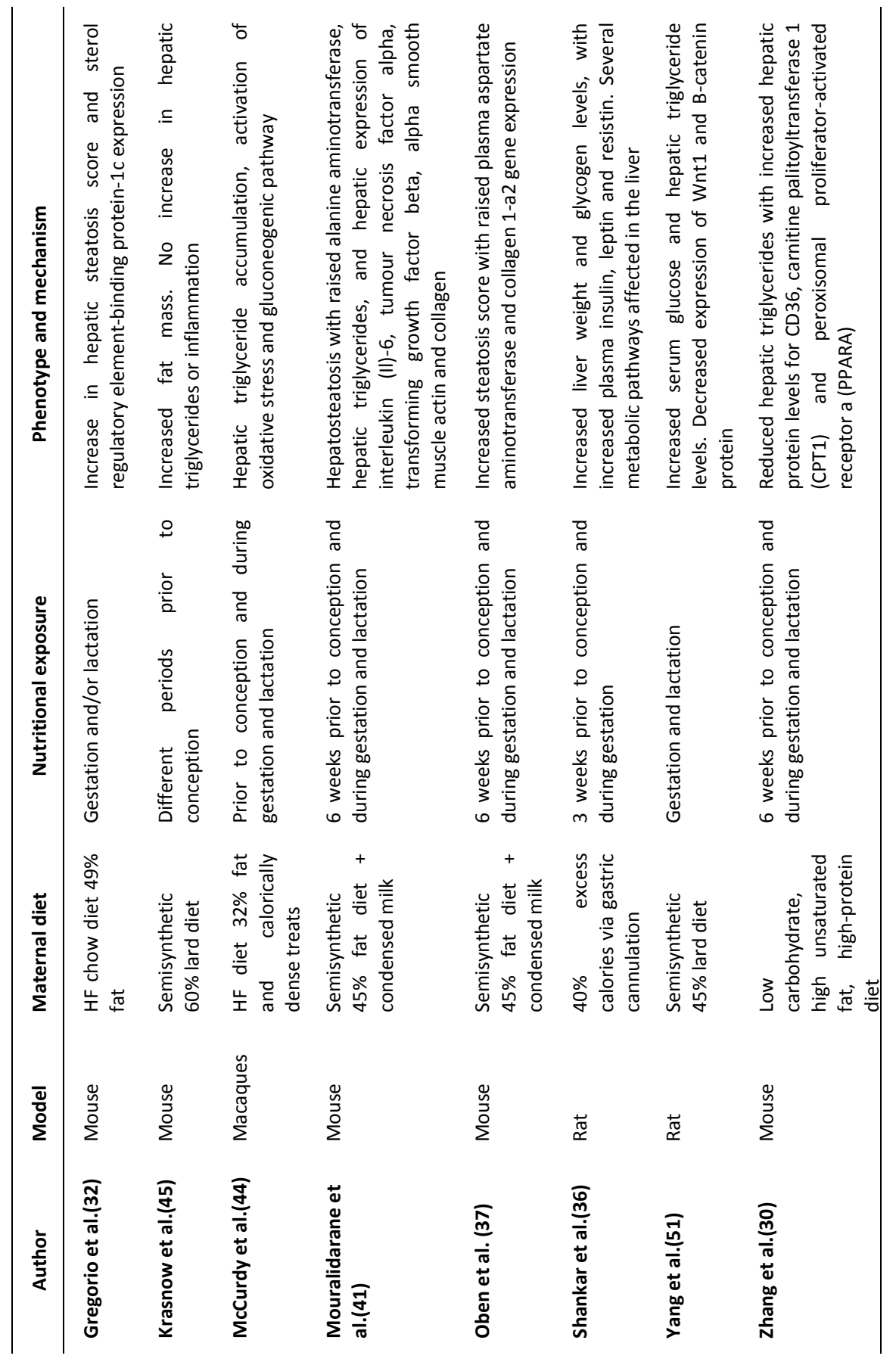


Table 1, part 3. Summary of gestational interventions and resulting long-term phenotypes

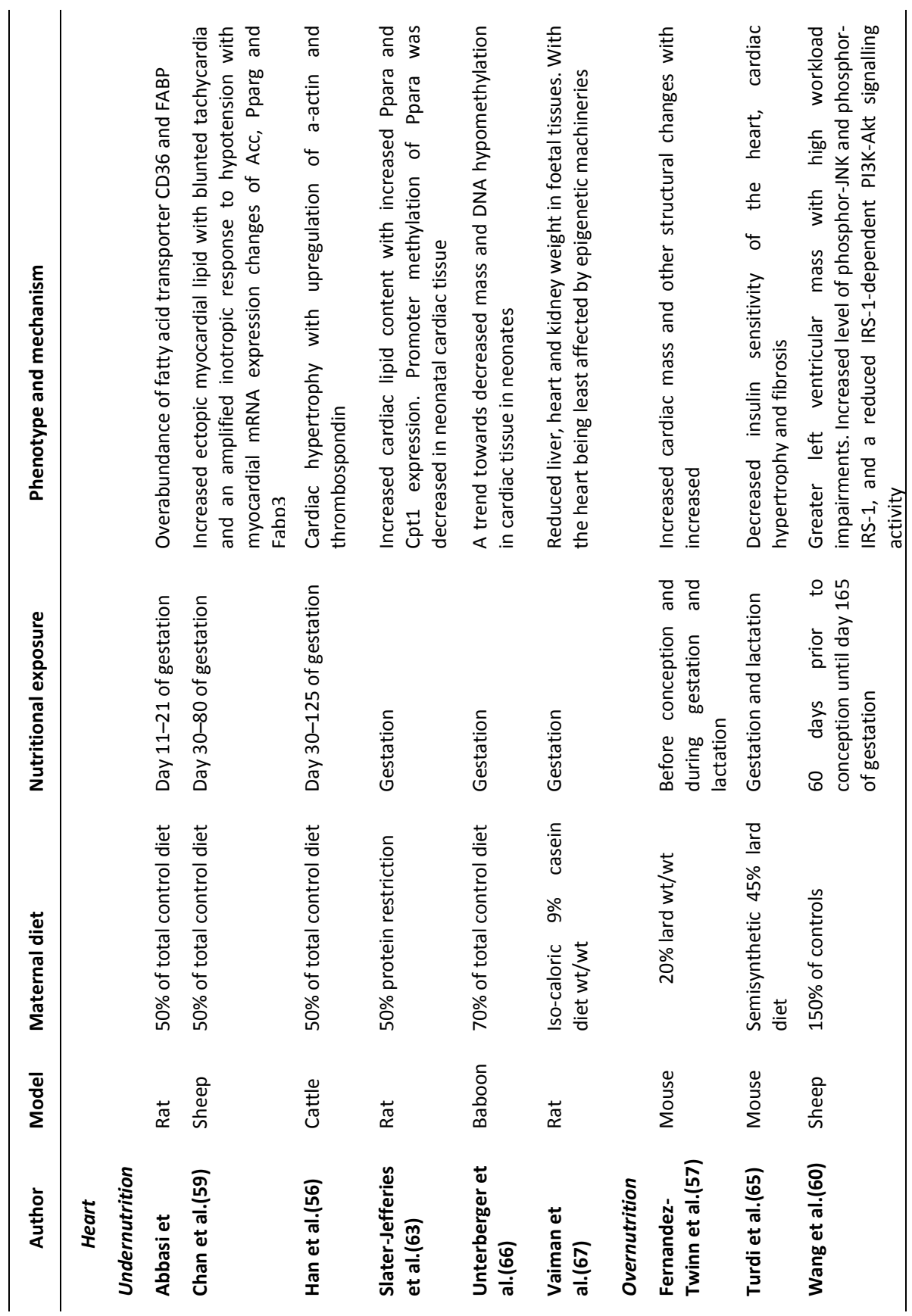

ACC, acetyl-CoA carbocylase; FABP, fatty acid-binding protein; PEPCK, phosphoenolpyruvate carboxykinase; Lxr, liver $X$ receptor; Ppar, peroxisomal proliferator-activator receptor; $\mathrm{Cpt}$, carnitine palitoyltransferase. 


\section{EPIDEMIOLOGICAL EVIDENCE OF FOETAL PROGRAMMING IN THE DEVELOPMENT OF CARDIOVASCULAR DISEASE}

Barker and colleagues were the first to describe an association between maternal health status and mortality of offspring from cardiovascular disease and stroke. The relationship became apparent when investigating regional differences in mortality owing to stroke and cardiovascular disease in England and Wales $(6,52)$. Currently, adverse effects of foetal programming on cardiovascular health are well-documented (4). Many studies report an increased prevalence of hypertension with low birthweight and report inverse correlations between birthweight and blood pressure $(53,54)$. The underlying mechanism of the relation between birthweight and blood pressure is not fully understood. Several mechanisms have been proposed, including reduced nephron number in low birthweight, possibly resulting in hyperfiltration and damage of the remaining nephrons, which favours the development of hypertension. Furthermore, vascular and endothelial dysfunction is associated with low birthweight, contributing to high blood pressure and microvascular structural changes observed in animal models of intrauterine growth restriction. Also, changes in the sympathetic nervous system may be involved in the increased risk to develop hypertension. Additionally, various studies report endocrine changes with high levels of aldosterone and cortisol in low birthweight, which can also influence blood pressure (55). Other systemic risk factors for cardiovascular disease besides blood pressure can be affected: it has been shown that oversupply of substrate during early development leads to changes in plasma metabolites. In that respect, increased plasma high-density lipoprotein cholesterol (HDL-C), triglycerides, apolipoprotein A1 (apoA1) and interleukin 6 (IL-6) concentrations were found in offspring of mothers with large gestational weight gain (9).

\section{THE HEART AS TARGET OF FOETAL PROGRAMMING}

Foetal programming not only influences systemic risk factors for cardiovascular disease but also affects the cardiac muscle directly. This can cause hypertrophy, hamper cardiac function and may modulate cardiac metabolism, lipid oxidation and lipid storage (Table 1).

\section{HYPERTROPHY}

Several animal studies show that both nutrient restriction and oversupply during pre-natal development lead to cardiac hypertrophy in offspring. Cardiac gene expression in the offspring of nutritionally restricted steers showed upregulation of genes that are typically associated with maladaptive cardiac hypertrophy (56). On the other hand, maternal obesity may also lead to hypertrophy in offspring, as 
investigated in mice. Cardiac geometry and gene expression was shown to be affected in offspring of obese mice. These changes are suggested to be owing to the activation of the protein kinase $B$, the extracellular signal-regulated kinase and mammalian target of rapamycin pathway (AKT-ERK-mTOR pathway) (57).

A human study confirms the importance of maternal obesity in developing hypertrophy. The heart weight of 6-month-old infants was investigated by ultrasound and the offspring of the women who gained the greatest weight during pregnancy were characterized by heavier hearts than offspring from women with appropriate weight gain (58).

\section{CARDIAC FUNCTION}

The environment during the early developmental phase seems to have lasting impact on contractile function of the heart with nutritional restriction (59) and oversupply impairing cardiac function in offspring, as shown in a study with an obese sheep model (60). Cardiac function in offspring may be normal at baseline, but impairments may become apparent at high workloads only, as shown in offspring of obese sheep (60). It was shown that plasma levels of tumour necrosis factor alpha (TNF alpha) and leptin are elevated in offspring when ewes were obese and it was suggested that these changes may underlie the negative ionotropic effect on the heart of the offspring $(61,62)$.

\section{LIPOTOXICITY}

Excessive fat storage in the heart is related to cardiac pathology in obesity and diabetes, and is manifested in increased cardiac myocyte apoptosis, myocardial fibrosis, left ventricular chamber expansion, contractile dysfunction and impaired diastolic filling (2). The association between cardiac lipid content and cardiac dysfunction is termed 'cardiac lipotoxicity' and has been described in several genetic rodent models in mice and rats.

In animal models, it was clearly shown that maternal undernutrition or nutrient restriction influences lipid metabolism and increases cardiac fat storage in offspring. The offspring of nutrient-restricted sheep responded differently to an obesogenic diet than the offspring of non-restricted animals, showing a threefold higher increase in myocardial fat deposition. This was accompanied by altered myocardial mRNA expression of acetyl-CoA carbocylase, peroxisome proliferatoractivated receptor gamma (PPARg) and fatty acid-binding protein (FABP) 3 in the animals that were exposed to nutrient restriction during early development (59). Protein restriction during pregnancy in rats was also shown to result in increased cardiac lipid content in the offspring, together with increases in gene expression of PPARa and carnitine palmitoyl transferase 1 (CPT1) (63). 
The exact mechanism by which cardiac lipid content is increased in growthrestricted animal models is not identified. However, a study with intrauterine growth restriction in rats has shown overabundance of the fatty acid transporters CD36 and FABP in the hearts of growth-restricted animals, which may underlie or contribute to cardiac lipid accumulation (64).

As described above, cardiac lipid accumulation occurs in nutrient restriction/intrauteral growth retardation. However, results from animal models suggest that overconsumption of fat during pregnancy has similar effects on the offspring, increasing their susceptibility to the negative effects of a post-natal high-fat diet. Interaction of maternal high-fat diet with post-natal high-fat diet in mice was shown to decrease mitochondrial integrity in the heart and to increase cardiac lipid content. The offspring that were exposed to high-fat diet in utero also showed decreased insulin sensitivity of the heart, decreased cardiac function and was characterized by increased hypertrophy, apoptosis and fibrosis (65).

\section{EPIGENETICS}

Very little is known about the epigenetic mechanisms involved in the changes that occur in the heart because of maternal over- or undernutrition. One of the few studies investigating this issue has been performed in baboons and found a trend towards DNA hypomethylation in cardiac tissue of the offspring that underwent nutrient restriction (66). A more recent study in mice has found that the offspring that had been subjected to protein restriction during gestation were characterized by decreased methylation of the promoter region of PPARa, resulting in changes in mRNA expression (63). However, when investigating epigenetic regulator genes in the offspring of protein-restricted rats, no significant changes could be detected in the heart (67). Clearly, more studies are needed to understand these mechanisms in detail. Future studies will have to address the epigenetic mechanisms that convey the cardiac effects of maternal high-fat feeding and overnutrition to the next generation.

\section{CONCLUSION}

Taken together, there is convincing evidence that prenatal exposure to either dietary shortage or overabundance increases the susceptibility for ectopic lipid accumulation in heart and liver. Furthermore, other metabolic-risk factors also rise owing to a suboptimal environment during early development: blood pressure can increase, cardiac function deteriorates, and plasma lipids and inflammatory markers can increase (Fig. 1). 


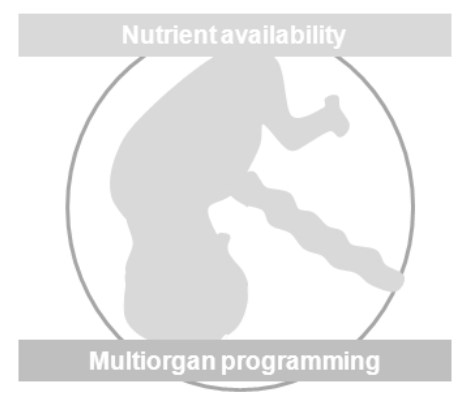

LIPOTOXICITY

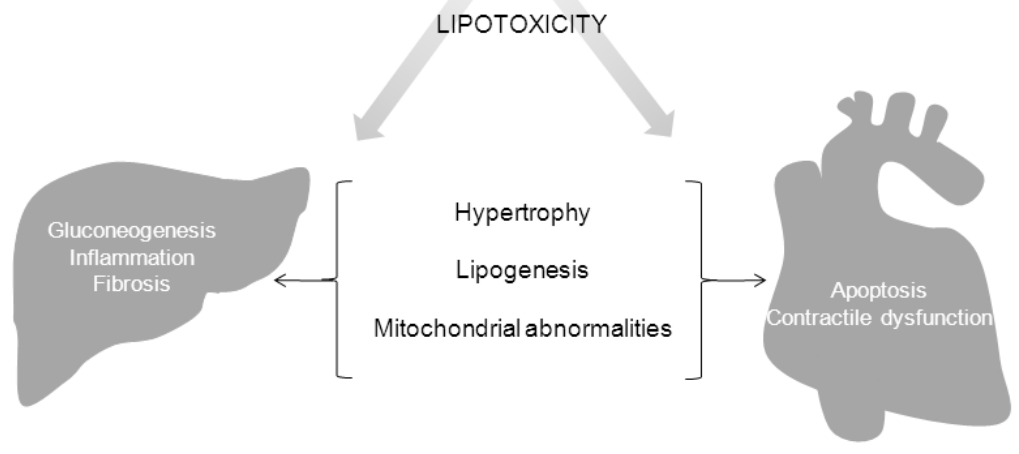

Figure 1. Lipotoxicity as a common pathway of organ dysfunction through fetal programming.

Together, these factors contribute to the phenomenon now known as Developmental Origins of Health and Disease or Barker hypothesis. The molecular mechanisms responsible for the programming of offspring have yet to be fully elucidated. Similar pathways in different organs that lead to the development of metabolic disease owing to programming should be investigated further. So far, in animal studies, it was found that protein restriction during pregnancy alters DNA methylation of the PPARa promoter in heart and liver of the offspring $(48,63)$ among others. Growing evidence supports the concept that epigenetic mechanisms play a role in foetal programming $(12,68)$, which may well be a common mechanism in the development of different organs. Future research will have to unravel the full impact of foetal programming on metabolic disease. The elucidation of underlying mechanisms will support the development of preventive strategies or the early identification of persons-at-risk.

\section{CONFLICT OF INTEREST}

The authors have no conflicts of interest to declare.

This research was performed within the framework of CTMM, the Center for Translational Molecular Medicine (www.ctmm.nl), project PREDICCt (grant 01C-104), and supported by the Dutch Heart 
Foundation, Dutch Diabetes Research Foundation and Dutch Kidney Foundation. Torsten Plösch is supported by the Dutch Heart Foundation (grant 2004T4801), the Netherlands Organization for Scientific Research (TOP ZonMw 40008129811053), and by the Dutch Technology Foundation STW (www.stw.nl), which is part of the Netherlands Organisation for Scientific Research (NWO) and is partly funded by the Ministry of Economic Affairs. Vera Schrauwen-Hinderling is supported by a VENI (grant 91611136) for innovative research from the Netherlands Organization for Scientific Research (NWO). 


\section{References}

1. Cusi K. Role of obesity and lipotoxicity in the development of nonalcoholic steatohepatitis: pathophysiology and clinical implications. Gastroenterology. 2012; 142:711-725 e716.

2. McGavock JM, Victor RG, Unger RH, Szczepaniak LS. Adiposity of the heart, revisited. Ann Intern Med. 2006; 144:517-524.

3. Lucas A. Programming by early nutrition: an experimental approach. J Nutr. 1998; 128:401S-406S.

4. McMillen IC, Robinson JS. Developmental origins of the metabolic syndrome: prediction, plasticity, and programming. Physiol Rev. 2005; 85:571-633.

5. Barker DJ. Developmental origins of adult health and disease. J Epidemiol Community Health. 2004; 58:114-115.

6. Barker DJ, Osmond C. Infant mortality, childhood nutrition, and ischaemic heart disease in England and Wales. Lancet. 1986; 1:1077-1081.

7. Ravelli AC, van der Meulen JH, Michels RP, Osmond C, Barker DJ, Hales CN, Bleker OP. Glucose tolerance in adults after prenatal exposure to famine. Lancet. 1998; 351:173-177.

8. Nohr EA, Vaeth M, Baker JL, Sorensen T, Olsen J, Rasmussen KM. Combined associations of prepregnancy body mass index and gestational weight gain with the outcome of pregnancy. Am J Clin Nutr. 2008; 87:1750-1759.

9. Fraser A, Tilling K, Macdonald-Wallis C, Sattar N, Brion MJ, Benfield L, Ness A, Deanfield J, Hingorani A, Nelson SM, Smith GD, Lawlor DA. Association of maternal weight gain in pregnancy with offspring obesity and metabolic and vascular traits in childhood. Circulation. 2010; 121:2557-2564.

10. Laitinen J, Jaaskelainen A, Hartikainen AL, Sovio U, Vaarasmaki M, Pouta A, Kaakinen M, Jarvelin MR. Maternal weight gain during the first half of pregnancy and offspring obesity at 16 years: a prospective cohort study. Bjog. 2012; 119:716-723.

11. Barnes SK, Ozanne SE. Pathways linking the early environment to long-term health and lifespan. Prog Biophys Mol Biol. 2011; 106:323-336.

12. Jimenez-Chillaron JC, Diaz R, Martinez D, Pentinat T, Ramon-Krauel M, Ribo S, Plosch T. The role of nutrition on epigenetic modifications and their implications on health. Biochimie. 2012; 94:22422263.

13. Langley-Evans SC, Welham SJ, Sherman RC, Jackson AA. Weanling rats exposed to maternal lowprotein diets during discrete periods of gestation exhibit differing severity of hypertension. Clin Sci (Lond). 1996; 91:607-615.

14. Gilbert JS, Lang AL, Grant AR, Nijland MJ. Maternal nutrient restriction in sheep: hypertension and decreased nephron number in offspring at 9 months of age. J Physiol. 2005; 565:137-147.

15. Roseboom TJ, van der Meulen JH, Ravelli AC, van Montfrans GA, Osmond C, Barker DJ, Bleker OP. Blood pressure in adults after prenatal exposure to famine. J Hypertens. 1999; 17:325-330.

16. Cleal JK, Poore KR, Boullin JP, Khan O, Chau R, Hambidge O, Torrens C, Newman JP, Poston L, Noakes $D E$, Hanson MA, Green LR. Mismatched pre- and postnatal nutrition leads to cardiovascular dysfunction and altered renal function in adulthood. Proc Natl Acad Sci U S A. 2007; 104:9529-9533.

17. Khan I, Dekou V, Hanson M, Poston L, Taylor P. Predictive adaptive responses to maternal high-fat diet prevent endothelial dysfunction but not hypertension in adult rat offspring. Circulation. 2004; 110:1097-1102.

18. Bruce KD, Cagampang FR, Argenton M, Zhang J, Ethirajan PL, Burdge GC, Bateman AC, Clough GF, Poston L, Hanson MA, McConnell JM, Byrne CD. Maternal high-fat feeding primes steatohepatitis in adult mice offspring, involving mitochondrial dysfunction and altered lipogenesis gene expression. Hepatology. 2009; 50:1796-1808.

19. Khan IY, Taylor PD, Dekou V, Seed PT, Lakasing L, Graham D, Dominiczak AF, Hanson MA, Poston L. Gender-linked hypertension in offspring of lard-fed pregnant rats. Hypertension. 2003; 41:168-175.

20. McMullen S, Langley-Evans SC. Maternal low-protein diet in rat pregnancy programs blood pressure through sex-specific mechanisms. Am J Physiol Regul Integr Comp Physiol. 2005; 288:R85-90.

21. Samuelsson AM, Matthews PA, Jansen E, Taylor PD, Poston L. Sucrose feeding in mouse pregnancy leads to hypertension, and sex-linked obesity and insulin resistance in female offspring. Front Physiol. 2013; 4:14.

22. Gabory A, Attig L, Junien C. Sexual dimorphism in environmental epigenetic programming. Mol Cell Endocrinol. 2009; 304:8-18. 
23. Khan IY, Dekou V, Douglas G, Jensen R, Hanson MA, Poston L, Taylor PD. A high-fat diet during rat pregnancy or suckling induces cardiovascular dysfunction in adult offspring. American journal of physiology Regulatory, integrative and comparative physiology. 2005; 288:R127-133.

24. Chechi K, Cheema SK. Maternal diet rich in saturated fats has deleterious effects on plasma lipids of mice. Exp Clin Cardiol. 2006; 11:129-135.

25. Ravelli AC, van Der Meulen JH, Osmond C, Barker DJ, Bleker OP. Obesity at the age of $50 \mathrm{y}$ in men and women exposed to famine prenatally. Am J Clin Nutr. 1999; 70:811-816.

26. Latini G, De Mitri B, Del Vecchio A, Chitano G, De Felice C, Zetterstrom R. Foetal growth of kidneys, liver and spleen in intrauterine growth restriction: "programming" causing "metabolic syndrome" in adult age. Acta Paediatr Suppl. 2004; 93:1635-1639.

27. Davies AA, Smith GD, Ben-Shlomo Y, Litchfield P. Low birth weight is associated with higher adult total cholesterol concentration in men: findings from an occupational cohort of 25,843 employees. Circulation. 2004; 110:1258-1262.

28. Andersen AM, Osler M. Birth dimensions, parental mortality, and mortality in early adult age: a cohort study of Danish men born in 1953. Int J Epidemiol. 2004; 33:92-99.

29. Fraser A, Ebrahim S, Smith GD, Lawlor DA. The associations between birthweight and adult markers of liver damage and function. Paediatr Perinat Epidemiol. 2008; 22:12-21.

30. Zhang J, Wang C, Terroni PL, Cagampang FR, Hanson M, Byrne CD. High-unsaturated-fat, high-protein, and low-carbohydrate diet during pregnancy and lactation modulates hepatic lipid metabolism in female adult offspring. Am J Physiol Regul Integr Comp Physiol. 2005; 288:R112-118.

31. Elahi MM, Cagampang FR, Mukhtar D, Anthony FW, Ohri SK, Hanson MA. Long-term maternal high-fat feeding from weaning through pregnancy and lactation predisposes offspring to hypertension, raised plasma lipids and fatty liver in mice. Br J Nutr. 2009; 102:514-519.

32. Gregorio BM, Souza-Mello V, Carvalho JJ, Mandarim-de-Lacerda CA, Aguila MB. Maternal high-fat intake predisposes nonalcoholic fatty liver disease in C57BL/6 offspring. Am J Obstet Gynecol. 2010; 203:495 e491-498.

33. Ashino NG, Saito KN, Souza FD, Nakutz FS, Roman EA, Velloso LA, Torsoni AS, Torsoni MA. Maternal high-fat feeding through pregnancy and lactation predisposes mouse offspring to molecular insulin resistance and fatty liver. J Nutr Biochem. 2012; 23:341-348.

34. Burns SP, Desai M, Cohen RD, Hales CN, lles RA, Germain JP, Going TC, Bailey RA. Gluconeogenesis, glucose handling, and structural changes in livers of the adult offspring of rats partially deprived of protein during pregnancy and lactation. J Clin Invest. 1997; 100:1768-1774.

35. Samuelsson AM, Matthews PA, Argenton M, Christie MR, McConnell JM, Jansen EH, Piersma AH, Ozanne SE, Twinn DF, Remacle C, Rowlerson A, Poston L, Taylor PD. Diet-induced obesity in female mice leads to offspring hyperphagia, adiposity, hypertension, and insulin resistance: a novel murine model of developmental programming. Hypertension. 2008; 51:383-392.

36. Shankar K, Kang P, Harrell A, Zhong Y, Marecki JC, Ronis MJ, Badger TM. Maternal overweight programs insulin and adiponectin signaling in the offspring. Endocrinology. 2010; 151:2577-2589.

37. Oben JA, Mouralidarane A, Samuelsson AM, Matthews PJ, Morgan ML, McKee C, Soeda J, FernandezTwinn DS, Martin-Gronert MS, Ozanne SE, Sigala B, Novelli M, Poston L, Taylor PD. Maternal obesity during pregnancy and lactation programs the development of offspring non-alcoholic fatty liver disease in mice. J Hepatol. 2010; 52:913-920.

38. Hyatt MA, Gardner DS, Sebert S, Wilson V, Davidson N, Nigmatullina Y, Chan LL, Budge H, Symonds ME. Suboptimal maternal nutrition, during early fetal liver development, promotes lipid accumulation in the liver of obese offspring. Reproduction. 2011; 141:119-126.

39. Hall AP, Elcombe CR, Foster JR, Harada T, Kaufmann W, Knippel A, Kuttler K, Malarkey DE, Maronpot RR, Nishikawa A, Nolte T, Schulte A, Strauss V, York MJ. Liver hypertrophy: a review of adaptive (adverse and non-adverse) changes--conclusions from the 3rd International ESTP Expert Workshop. Toxicol Pathol. 2012; 40:971-994.

40. Burgueno AL, Cabrerizo R, Gonzales Mansilla N, Sookoian S, Pirola CJ. Maternal high-fat intake during pregnancy programs metabolic-syndrome-related phenotypes through liver mitochondrial DNA copy number and transcriptional activity of liver PPARGC1A. J Nutr Biochem. 2013; 24:6-13.

41. Mouralidarane A, Soeda J, Visconti-Pugmire C, Samuelsson AM, Pombo J, Maragkoudaki X, Butt A, Saraswati R, Novelli M, Fusai G, Poston L, Taylor PD, Oben JA. Maternal obesity programs offspring nonalcoholic fatty liver disease by innate immune dysfunction in mice. Hepatology. 2013; 58:128-138.

42. Savage DB, Semple RK. Recent insights into fatty liver, metabolic dyslipidaemia and their links to insulin resistance. Curr Opin Lipidol. 2010; 21:329-336. 
43. Drake AJ, Liu L, Kerrigan D, Meehan RR, SeckI JR. Multigenerational programming in the glucocorticoid programmed rat is associated with generation-specific and parent of origin effects. Epigenetics. 2011; 6:1334-1343.

44. McCurdy CE, Bishop JM, Williams SM, Grayson BE, Smith MS, Friedman JE, Grove KL. Maternal highfat diet triggers lipotoxicity in the fetal livers of nonhuman primates. J Clin Invest. 2009; 119:323-335.

45. Krasnow SM, Nguyen ML, Marks DL. Increased maternal fat consumption during pregnancy alters body composition in neonatal mice. Am J Physiol Endocrinol Metab. 2011; 301:E1243-1253.

46. Sookoian S, Rosselli MS, Gemma C, Burgueno AL, Fernandez Gianotti T, Castano GO, Pirola CJ. Epigenetic regulation of insulin resistance in nonalcoholic fatty liver disease: impact of liver methylation of the peroxisome proliferator-activated receptor gamma coactivator 1alpha promoter. Hepatology. 2010; 52:1992-2000.

47. Lillycrop KA, Phillips ES, Jackson AA, Hanson MA, Burdge GC. Dietary protein restriction of pregnant rats induces and folic acid supplementation prevents epigenetic modification of hepatic gene expression in the offspring. J Nutr. 2005; 135:1382-1386.

48. Lillycrop KA, Phillips ES, Torrens C, Hanson MA, Jackson AA, Burdge GC. Feeding pregnant rats a protein-restricted diet persistently alters the methylation of specific cytosines in the hepatic PPAR alpha promoter of the offspring. Br J Nutr. 2008; 100:278-282.

49. van Straten EM, Bloks VW, Huijkman NC, Baller JF, van Meer H, Lutjohann D, Kuipers F, Plosch T. The liver $\mathrm{X}$-receptor gene promoter is hypermethylated in a mouse model of prenatal protein restriction. Am J Physiol Regul Integr Comp Physiol. 2010; 298:R275-282.

50. Dudley KJ, Sloboda DM, Connor KL, Beltrand J, Vickers MH. Offspring of mothers fed a high fat diet display hepatic cell cycle inhibition and associated changes in gene expression and DNA methylation. PLoS One. 2011; 6:e21662.

51. Yang KF, Cai W, Xu JL, Shi W. Maternal high-fat diet programs Wnt genes through histone modification in the liver of neonatal rats. J Mol Endocrinol. 2012; 49:107-114.

52. Barker DJ, Osmond C, Golding J, Kuh D, Wadsworth ME. Growth in utero, blood pressure in childhood and adult life, and mortality from cardiovascular disease. Bmj. 1989; 298:564-567.

53. Huxley RR, Shiell AW, Law CM. The role of size at birth and postnatal catch-up growth in determining systolic blood pressure: a systematic review of the literature. J Hypertens. 2000; 18:815-831.

54. Huxley R, Neil A, Collins R. Unravelling the fetal origins hypothesis: is there really an inverse association between birthweight and subsequent blood pressure? Lancet. 2002; 360:659-665.

55. Edvardsson VO, Steinthorsdottir SD, Eliasdottir SB, Indridason OS, Palsson R. Birth weight and childhood blood pressure. Curr Hypertens Rep. 2012; 14:596-602.

56. Han H, Hansen TR, Berg B, Hess BW, Ford SP. Maternal undernutrition induces differential cardiac gene expression in pulmonary hypertensive steers at high elevation. Am J Physiol Heart Circ Physiol. 2008; 295:H382-389.

57. Fernandez-Twinn DS, Blackmore HL, Siggens L, Giussani DA, Cross CM, Foo R, Ozanne SE. The programming of cardiac hypertrophy in the offspring by maternal obesity is associated with hyperinsulinemia, AKT, ERK, and mTOR activation. Endocrinology. 2012; 153:5961-5971.

58. Geelhoed JJ, L VANO-G, Verburg BO, Steegers EA, Hofman A, Helbing W, Witteman JC, Jaddoe VW. Maternal anthropometrics in pregnancy are associated with left ventricular mass in infancy. The generation R study. Pediatr Res. 2008; 63:62-66.

59. Chan LL, Sebert SP, Hyatt MA, Stephenson T, Budge H, Symonds ME, Gardner DS. Effect of maternal nutrient restriction from early to midgestation on cardiac function and metabolism after adolescentonset obesity. Am J Physiol Regul Integr Comp Physiol. 2009; 296:R1455-1463.

60. Wang J, Ma H, Tong C, Zhang H, Lawlis GB, Li Y, Zang M, Ren J, Nijland MJ, Ford SP, Nathanielsz PW, Li J. Overnutrition and maternal obesity in sheep pregnancy alter the JNK-IRS-1 signaling cascades and cardiac function in the fetal heart. Faseb J. 2010; 24:2066-2076.

61. Oral H, Dorn GW, 2nd, Mann DL. Sphingosine mediates the immediate negative inotropic effects of tumor necrosis factor-alpha in the adult mammalian cardiac myocyte. J Biol Chem. 1997; 272:48364842.

62. Vickers MH. Developmental programming and adult obesity: the role of leptin. Curr Opin Endocrinol Diabetes Obes. 2007; 14:17-22.

63. Slater-Jefferies JL, Lillycrop KA, Townsend PA, Torrens C, Hoile SP, Hanson MA, Burdge GC. Feeding a protein-restricted diet during pregnancy induces altered epigenetic regulation of peroxisomal proliferator-activated receptor-alpha in the heart of the offspring. J Dev Orig Health Dis. 2011; 2:250255 . 
64. Abbasi A, Thamotharan M, Shin BC, Jordan MC, Roos KP, Stahl A, Devaskar SU. Myocardial macronutrient transporter adaptations in the adult pregestational female intrauterine and postnatal growth-restricted offspring. Am J Physiol Endocrinol Metab. 2012; 302:E1352-1362.

65. Turdi S, Ge W, Hu N, Bradley KM, Wang X, Ren J. Interaction between maternal and postnatal high fat diet leads to a greater risk of myocardial dysfunction in offspring via enhanced lipotoxicity, IRS-1 serine phosphorylation and mitochondrial defects. J Mol Cell Cardiol. 2013; 55:117-129.

66. Unterberger A, Szyf M, Nathanielsz PW, Cox LA. Organ and gestational age effects of maternal nutrient restriction on global methylation in fetal baboons. J Med Primatol. 2009; 38:219-227.

67. Vaiman D, Gascoin-Lachambre G, Boubred F, Mondon F, Feuerstein JM, Ligi I, Grandvuillemin I, Barbaux S, Ghigo E, Achard V, Simeoni U, Buffat C. The intensity of IUGR-induced transcriptome deregulations is inversely correlated with the onset of organ function in a rat model. PLoS One. 2011; 6:e21222.

68. Heerwagen MJ, Miller MR, Barbour LA, Friedman JE. Maternal obesity and fetal metabolic programming: a fertile epigenetic soil. Am J Physiol Regul Integr Comp Physiol. 2010; 299:R711-722. 

Chapter 5

\section{Increased cardiac lipid content and postprandial hypertriglyceridemia after early exposure to high-fat feeding}

Petronella A. van Ewijk ${ }^{1,2,6}$, Sabina Paglialunga, $\mathrm{PhD}^{1,6}$, M. Eline Kooi, PhD ${ }^{2,5, \pi}$, Patricia M. Nunes ${ }^{7}$, Anne Gemmink $^{3,6}$, Jos Slenter ${ }^{2}$, Esther Kornips ${ }^{1,6}$, Johanna A. Jörgensen ${ }^{1,6}$, Joris Hoeks, PhD ${ }^{1,6}$, Joachim E. Wildberger, MD, PhD ${ }^{2,5}$, Matthijs K. C. Hesselink, PhD ${ }^{3,6}$, Jan F. C. Glatz, PhD ${ }^{4,5}$, Arend Heerschap, PhD ${ }^{7}$, Sander Kersten, PhD $^{8,9}$, Patrick Schrauwen, PhD $^{1,6}$, and Vera B. Schrauwen-Hinderling, PhD ${ }^{1,2,6}$

Departments of ${ }^{1}$ Human Biology, ${ }^{2}$ Radiology, ${ }^{3}$ Human Movement Sciences, ${ }^{4}$ Molecular Genetics, ${ }^{5}$ CARIM Cardiovascular Research Institute Maastricht and ${ }^{6}$ NUTRIM - School for Nutrition, Toxicology and Metabolism,

Maastricht University Medical Centre, Maastricht, the Netherlands

${ }^{7}$ Department of Radiology, Radboud University Medical Centre, Nijmegen, the Netherlands,

${ }^{8}$ Nutrition, Metabolism and Genomics groups, Division of Human Nutrition, Wageningen University and ${ }^{9}$ Netherlands Nutrigenomics Centre, Top Institute Food and Nutrition, Wageningen, The Netherlands 


\section{ABSTRACT}

Rationale: Fat accumulation in muscle, liver and heart may have detrimental health effects, favoring the progression of metabolic syndrome and cardiovascular disease.

Objective: In a longitudinal study, we used non-invasive Magnetic Resonance (MR) technique to investigate whether exposure to a high fat (HF) diet in mice during gestation and lactation increases the susceptibility to lipotoxic effects of a HF diet consumed later in life.

Methods and Results: Mice were fed HF or a standard chow diet (LF) before conception and throughout gestation and lactation. From weaning onward, all offspring were high-fat fed, generating two experimental groups: HF/HF and LF/HF. Mice were investigated at three time points between age 10 to 28 weeks. Abdominal visceral adipose tissue mass, determined by MRI, was significantly higher in the HF/HF group. At a young age, cardiac lipid content (assessed by ${ }^{1} \mathrm{H}-$ MR Spectroscopy) was higher and hepatic lipid content lower in HF/HF mice compared to LF/HF mice. Triglyceride (TG) tolerance tests revealed severely disturbed lipid clearance and hepatic lipid retention from a lipid load in HF/HF mice. Cardiac and hepatic mitochondrial function was determined by highresolution respirometry at 12 and 28 weeks and showed a tendency for decreased cardiac energy efficiency (state 4 / state 3 respiration) in the HF/HF group.

Conclusion: Early exposure to a high fat diet leads to an unfavourable cardiometabolic risk profile in offspring, characterized by increased visceral adipose tissue and cardiac lipid content and delayed postprandial TG clearance. 


\section{INTRODUCTION}

The prevalence of obesity and metabolic syndrome is rapidly rising (1), thereby increasing the risk of developing diabetes(2) and cardiovascular disease. Fat storage in non-adipose tissue - termed ectopic fat storage - is an important mediator in the development of these diseases. For example, increased fat storage in skeletal muscle is strongly associated with insulin resistance (3) and hepatic fat storage contributes to hepatic insulin resistance, dyslipidemia and many other facets of metabolic syndrome (4). Increased cardiac lipid content has also been suggested to be harmful as it has been linked to the development of cardiomyopathy and cardiac dysfunction (5).

An underestimated factor in the etiology of obesity and related diseases is the early developmental environment that is known to exert long-lasting influences by so-called 'metabolic imprinting'. As first hypothesized by Barker et al (6), adverse environmental conditions may impair growth and development of the fetus and make the adult more susceptible to disease later in life. The original hypothesis was based on data from children of mothers with under-nutrition (7$13)$, but there is increasing evidence that this hypothesis also holds for conditions of over-nutrition (14-18). For instance, positive relationships between maternal pregravid BMI and birth weight (19), fetal insulin resistance (20), and fetal percentage of body fat have been reported (21). Moreover, it was found that children of obese mothers have increased risk to develop metabolic syndrome (14) and congenital heart defects (22). More specifically, in non-human primates it was found that maternal exposure to a high fat diet (31.6 energy \%) resulted in a metabolic syndrome phenotype in $60 \%$ of the offspring and increased the risk for non-alcoholic fatty liver disease (NAFLD) (23). In line with this, it was shown in rodent models that simply increasing the fat content of the diet during pregnancy and lactation suffices to adversely affect the offspring in terms of promoting hepatic lipid storage and inflammation and diminishing markers of mitochondrial function and de novo lipogenesis (24). While these studies suggest that exposure to a high fat (HF) diet during very early development increases the susceptibility for lipotoxic effects of a HF diet later in life, so far no investigations have been performed that have systematically followed the effect of early exposure to a high fat diet on in vivo function of key metabolic organs in time. We hypothesized that early exposure to a HF diet would increase the susceptibility to the negative effects of consuming a HF diet later in life. Here we investigated the effect of early exposure to high-fat diet on muscle, cardiac and hepatic steatosis and function under HF fed conditions using sophisticated non-invasive techniques in a longitudinal study spanning from 10 to 28 weeks of age. We report that early exposure to a HF diet increases visceral adipose tissue mass and cardiac lipid 
$86 \mid$ Chapter 5

content, while hepatic lipid content initially tended to be lower due to delayed postprandial clearance of dietary triglyceride. 
Animal model and study set-up

The Maastricht University Medical Centre Institutional Ethics Committee on Animal Welfare approved all experiments. C57BI/6 mice (breeding couples) were purchased from Charles River (Maastricht, the Netherlands) and housed under standard conditions at $25^{\circ} \mathrm{C}$ with a $12: 12$-h light-dark cycle with ad libitum access to water and diet. Female mice $(n=44)$ and male mice $(n=12)$ were randomly assigned to either a high fat (HF) diet (45\% kcal fat of which $31 \%$ saturated, $36 \%$ mono-unsaturated, $33 \%$ poly-unsaturated fatty acids, $20 \%$ kcal protein, $35 \%$ kcal carbohydrate, Research Diets, New Brunswick, NJ, USA) or standard chow (LF) diet ( $9 \%$ kcal fat, 33\% kcal protein, 58\% kcal carbohydrate, ssniff Spezialdiäten $\mathrm{GmbH}$ ). Both the male and female mice were fed their assigned diets at least 6 weeks before conception and the diet was continued during gestation and lactation. Weight gain and food intake were measured each week. In the Supplementary information, Figure 1 maternal weight gain is presented. At weaning, all offspring were fed the HF diet, generating two experimental groups: HF/HF $(n=33)$ and LF/HF (n=33).

\section{A. Longitudinal Study}

A group of male offspring ( $n=26,13$ from each group) underwent the longitudinal study with minimally invasive measurements which could hence be performed w the same animals on consecutive time points: glucose tolerance test at 12, 18 and 24 weeks of age, and cardiac function and cardiac -, hepatic - and abdominal visceral fat content at 15, 21 and 27 weeks of age. Cardiac and hepatic mitochondrial function were determined at an early time point, at 12 weeks of age, in a parallel group of male offspring ( $n=22, n=11$ in HF/HF group and $n=11$ in LF/HF group) and also in the mice that underwent the longitudinal study when they were killed at 28 weeks of age. See experimental set-up depicted in Figure 1.

\section{B. Postprandial lipid handling and de novo lipogenesis at 10-12 weeks of age} The outcome of the longitudinal investigation suggested the most pronounced differences between the groups to occur at an early age (in terms of cardiac fat content and hepatic mitochondrial function). Therefore, a parallel group of male offspring ( $n=18, n=9$ in HF/HF group and $n=9$ in LF/HF group) underwent a TG tolerance test (see below for experimental details) at 10 weeks of age. At 12 weeks of age cardiac and hepatic lipid retention and hepatic de novo lipogenesis was measured, requiring to sacrifice the mice. See also the experimental set-up depicted in Figure 1. 


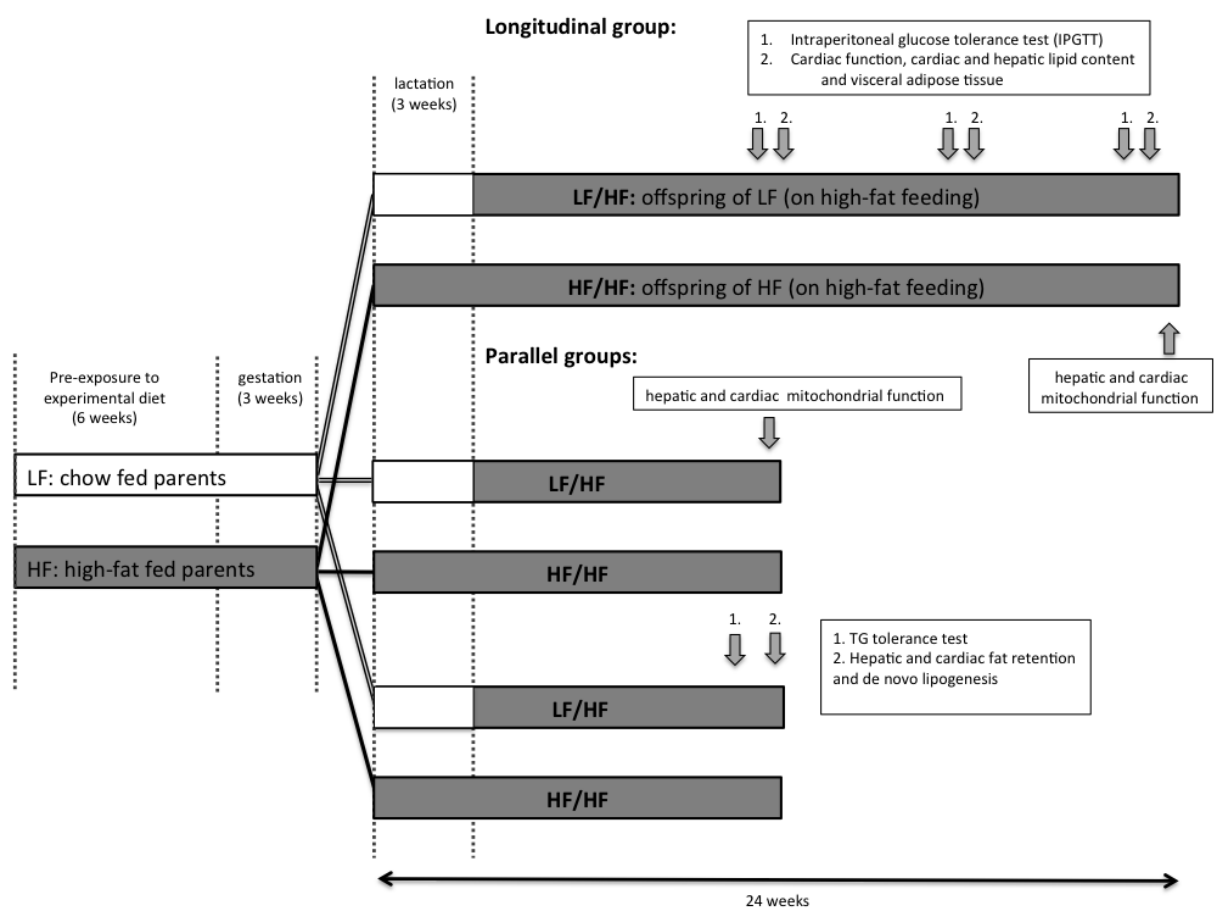

Figure 1: Experimental set-up. Male and female C57BL6 mice were randomly assigned to either a high fat (HF) diet or standard chow (LF) diet. Both the male and female mice were fed their assigned diets at least 6 weeks before conception and continued during gestation and lactation. At weaning, all offspring were fed a high fat diet, generating two experimental groups: HF/HF and LF/HF. Mice of the longitudinal study underwent an intraperitoneal glucose tolerance test (IPGTT) at 12, 18 and 24 weeks of age. Cardiac function, cardiac lipid content, hepatic lipid content and visceral fat content were measured at 15, 21 and 27 weeks of age. At 28 weeks of age, cardiac and hepatic mitochondrial function was measured. Mice of a first parallel group were sacrificed at 12 weeks of age and cardiac and hepatic mitochondrial function was measured. Mice of a second parallel group underwent a TG tolerance test at 10 weeks of age. At 12 weeks of age hepatic and cardiac fat retention after a meal was measured. Also hepatic de novo lipogenesis was measured at 12 weeks of age.

\section{MR imaging and spectroscopy in vivo}

Cardiac function, cardiac, hepatic and abdominal visceral fat content were measured using Magnetic Resonance Imaging (MRI) and Spectroscopy (MRS). Mice were anesthetized with $2 \%$ isoflurane (Abott Laboratories Ltd, Queensboroug, UK) and $0.4 \mathrm{~L} / \mathrm{min}$ of $\mathrm{O}_{2}$. Vital signs were monitored and used for MR gating / triggering by the SA Monitoring \& Gating System (Small Animal Instruments, Stony Brook, NY, USA). ECG electrodes (3M, St Paul, MN) were placed at the right front leg and the left hind leg while respiration was monitored by a sensor balloon was placed under the abdomen. Mice were placed on a warm waterbed to maintain physiological body temperature. Body temperature was monitored with a rectal fiber probe. The mice were laid down supine in a cradle, 
which was positioned horizontally in a 7 Tesla MR System (Bruker Biospin $\mathrm{GmbH}$, Ettlingen, Germany) which was interfaced to a Bruker Avance 2 console and controlled by the ParaVision 5.1 software package. A quadrature volume coil ( $\varnothing 35$ $\mathrm{mm}$, Bruker Biospin) was used for radiofrequency transmission and signal reception.

\section{Visceral fat content}

Coronal T1-weighted spin-echo images were obtained from lungs to anus depending on the size of the mouse. The images covered the kidneys and bladder in all scans. The parameters of the sequence were matrix size: $256^{*} 256$, FOV: 50*50 mm, TE: $9.1 \mathrm{~ms}$, TR: $500 \mathrm{~ms}$, NA: 1, slice thickness: $1 \mathrm{~mm}$. Using in-house developed software visceral adipose tissue (VAT) was determined in the 3dimensional region from half the size of the left kidney to half the size of the bladder. Images were checked visually and manually edited in MRIcron.

\section{Cardiac and hepatic lipid content assessed by 1 H-MRS}

Cardiac ${ }^{1} \mathrm{H}-\mathrm{MR}$ spectroscopy was performed using cardiac-triggered and respiratory-gated point resolved spectroscopy (PRESS with TE=9.1 ms, TR=2000 $\mathrm{ms})$, after volume-selective manual shimming. Spectra were acquired from a $4 \mu \mathrm{l}$ voxel, positioned in the interventricular septum. A water-suppressed spectrum was acquired on resonance on creatine $(N S A=512)$ and a reference spectrum (with non-suppressed water signal) was acquired on resonance on water, while the water suppression module was executed $10 \mathrm{ppm}$ downfield of the water resonance (NSA=64). Water suppression was achieved using the cardiac-triggered and respiratory-gated chemical shift selective (CHESS) module, which consisted of three frequency-selective Gaussian-shaped RF pulses. The duration of the CHESS module was $65 \mathrm{~ms}$. Spectra were fitted using the AMARES fitting algorithm in jMRUI. All spectra were phased and corrected for chemical shift. The watersuppressed spectra were fitted to Gaussian lineshapes after application of line broadening ( $5 \mathrm{~Hz}$ Gaussian apodization). Water spectra were fitted to Lorentzian lineshapes after application of line broadening ( $5 \mathrm{~Hz}$ Lorentzian apodization). Metabolites were assigned according to literature (25). Metabolite concentrations are expressed as percentage of the (unsuppressed) water signal. For quantification of myocardial lipid content the sum of the TG peaks at 1.55, 1.26 and $0.85 \mathrm{ppm}$ was expressed as percentage of the unsuppressed water signal.

Hepatic lipid content was determined as described for cardiac lipid content. The only adjustments include: voxel size of $18 \mu \mathrm{l}$, water-suppressed spectrum (NA=128) and water spectrum (NA=64). 


\section{Cardiac function assessed by MRI}

Bright blood cine images consisting of 8 cardiac phases were recorded in 4 chamber view $(4 \mathrm{CH})$ and long axis view (LA) using a retrospectively self-gated protocol (Intragate ${ }^{\mathrm{TM}}$, Bruker Biospin). Imaging parameters for the $4 \mathrm{CH}$ and LA images were: $30 * 30 \mathrm{~mm}$ field of view (FOV), $256 * 256$ matrix size, echo time (TE) of $2.9 \mathrm{~ms}$, repetition time (TR) of $8 \mathrm{~ms}$, flip angle (FA) of $10^{\circ}$, number of averages (NA) of 150 and $1 \mathrm{~mm}$ slice thickness. Perpendicular to the LA view and the septum, a short axis view (SA) consisting of 2 slices was acquired. The first slice was positioned 1-2 $\mathrm{mm}$ under the mitral valve and the second slice was positioned at the base of the papillary muscle. The images were acquired using the following parameters: $25.6 * 25.6 \mathrm{~mm}$ FOV, $164 * 164$ matrix size, TE of $2.5 \mathrm{~ms}$, TR of $14 \mathrm{~ms}, \mathrm{FA}$ of $60^{\circ}$, NA of 8 and $1 \mathrm{~mm}$ slice thickness. To determine left ventricular volumes, regions of interest (ROIs) were manually drawn in MRIcro. Subsequently, end-diastolic, end-systolic volume and ejection fraction were calculated using the modified Simpson Rule (26).

\section{Glucose tolerance test and plasma metabolites}

Mice were fasted for 6 hours and injected intraperitoneally with glucose $(2 \mathrm{mg} / \mathrm{g}$ body weight in $200 \mu \mathrm{l}$ of sterile solution). Blood samples were taken at $0,15,30$, 60 and 120 minutes after injection by bleeding of the venous sapheous. Blood glucose was measured using a glucose meter (LifeScan, Milpitas, CA, USA) and samples were collected in microtitre tubes (BD, Franklin Lakes, NJ, USA). Plasma was separated by centrifugation for $5 \mathrm{~min}$ at $10,000 \mathrm{~g}$ and stored at $-80^{\circ} \mathrm{C}$.

At 12 and 28 weeks of age, venous blood was collected in EDTA-containing tubes $(1 \mathrm{mg} / \mathrm{ml})$ from mice of after a 5-hour fast. Plasma triacylglycerol and NEFA levels were determined with commercially available kits from Roche (Schlieren, Switzerland) and Wako Chemicals (Neuss, Germany), respectively.

\section{Biochemical TG determination in gastrocnemius}

TG levels in gastrocnemius muscle were measured using the method of Schwartz and Wolins (27).

\section{Mitochondrial isolation and respiration measurements}

Mice were anaesthetized by a mixture of $67 \%$ of $\mathrm{CO}_{2}$ and $33 \%$ of $\mathrm{O}_{2}$ and killed by decapitation. Mitochondria were isolated as previously described with minor modifications (28). Briefly, heart and liver were quickly excised and placed in icecold isolation buffer (Heart Isolation Buffer (HIB): sucrose [100 mmol/l], $\mathrm{KCl}[50$ 
$\mathrm{mmol} / \mathrm{l}]$, TES [20 mmol/l], EDTA [1 mmol/l], 0.2\% fatty acid free BSA [wt/vol], $\mathrm{pH}$ 7.2 and Liver isolation buffer (LIB): sucrose [250 mmol/I], TES [20 mmol/l], EDTA [1 $\mathrm{mmol} / \mathrm{l}], 0.6 \%$ fatty acid free BSA [wt/vol], $\mathrm{pH} \mathrm{7.2).} \mathrm{Both} \mathrm{tissues} \mathrm{were} \mathrm{rinsed} \mathrm{and}$ finely minced on ice. Heart tissue was further digested with an enzymatic treatment (protease, Sigma). Tissue pieces were homogenized in a Potter tube, transferred to a centrifuge tube and then centrifuged at $8500 \mathrm{xg}$ for $10 \mathrm{~min}$ at $4^{\circ} \mathrm{C}$. The resulting pellet was re-suspended in isolation buffer (HIB for heart and LIB without BSA for liver preparations), and centrifuged at $800 \times \mathrm{xg}$ for $10 \mathrm{~min}$ at $4^{\circ} \mathrm{C}$. The supernatant was then centrifuged at $8500 \mathrm{xg}$ for $10 \mathrm{~min}$ at $4^{\circ} \mathrm{C}$, and the final mitochondrial pellet was re-suspended in HIB (for both heart and liver preparations) and homogenized in a small glass homogenizer. Mitochondrial protein content was determined by Fluram assay as previously described.(28) Respiration rates in isolated mitochondria (Heart: $0.1 \mathrm{mg} / \mathrm{mL}$ and Liver: 0.25 $\mathrm{mg} / \mathrm{ml}$ ) were determined at $37^{\circ} \mathrm{C}$ by polarographic oxygen sensors in a twochamber Oxygraph (OROBOROS ${ }^{\circ}$ Instruments, Innsbruck, Austria) using pyruvate $(5 \mathrm{mM})$ plus malate $(3 \mathrm{mM})$ for heart or glutamate $(5 \mathrm{mM})$ plus malate $(3 \mathrm{mM})$ for liver and palmitoyl-coenzyme $\mathrm{A}(\mathrm{COA})(50 \mu \mathrm{M})$ plus carnitine $(2 \mathrm{mM})$ as substrates as previously outlined.(28) ADP-stimulated (state 3) respiration was induced by the addition of ADP $(450 \mu \mathrm{M})$ while state 4 respiration was attained upon the addition of the ATP-synthase inhibitor oligomycin $(1 \mu \mathrm{g} / \mathrm{mL})$.

\section{Mitochondrial DNA and copy number}

The mitochondrial DNA copy number was determined by the ratio of COX2 expression (mitochondrial gene) over UCP2 expression (nuclear gene) as described previously (29). In short, isolated DNA (Nucleospin Tissue kit; Macherey Nagel, Düren, Germany) from heart and liver samples was analyzed by real-time PCR using a sequence detector (ABI 7900; Applied Biosystems, Branchburg, NJ, USA). The program consisted of one cycle at $50^{\circ} \mathrm{C}$ for $2 \mathrm{~min}$, a cycle at $95^{\circ} \mathrm{C}$ for 10 min, followed by 40 cycles at $95^{\circ} \mathrm{C}$ for $15 \mathrm{~s}$ and finally a cycle at $60^{\circ} \mathrm{C}$ for $1 \mathrm{~min}$. Absolute quantification of each gene was performed using a standard curve.

\section{Hepatic de novo lipogenesis}

Fractional contribution of de novo lipogenesis (DNL) to hepatic lipid pool was determined in 12 week old mice, using ${ }^{1} \mathrm{H} /{ }^{2} \mathrm{H}$ NMR spectroscopy of liver extracts. Mice received a bolus of $99.9 \%{ }^{2} \mathrm{H}_{2} \mathrm{O}$ (Sigma-Aldrich, St Louis, MO, USA) to enrich $3 \%$ of their body water. Animals were fed ad libitum and supplied with $3 \%{ }^{2} \mathrm{H}_{2} \mathrm{O}$ enriched drinking water, overnight. Eighteen hours later, mice were sacrificed, livers were excised and rapidly freeze-dried. Blood aliquots were taken to 
determine the absolute plasma ${ }^{2} \mathrm{H}$ enrichment. Lipids from freeze-clamped livers were extracted by the Folch method (30) and dried under a constant $\mathrm{N}_{2}$ flow. Lipids were dissolved in $600 \mu \mathrm{L}$ of chloroform with $1.1 \%$ uniformly ${ }^{2} \mathrm{H}$ enriched pyrazine used as internal reference for NMR analysis (31).

Ex vivo ${ }^{1} \mathrm{H}$ and ${ }^{2} \mathrm{H}$ NMR spectra were acquired on an 11.7 T NMR system (Bruker Instruments, Billerica, MA). Proton-decoupled ${ }^{2} \mathrm{H}-\mathrm{NMR}$ spectra were recorded using a WALTZ-16 pulse sequence. ${ }^{2} \mathrm{H}$ enrichment of the body water was determined by proton decoupled ${ }^{2} \mathrm{H}$ spectra (TR: $10 \mathrm{~s}, \mathrm{NA}: 32$ ), at $25{ }^{\circ} \mathrm{C}$ without field frequency lock as described before (32). ${ }^{2} \mathrm{H}$ enrichment of the hepatic triglyceride (HTG) methyl hydrogens was determined using $T R=4 \mathrm{~s}$ and $2 \mathrm{~K}$ averages. All spectra were processed with NUTS-pro software (Acorn NMR, USA). Total HTG and DNL fraction were quantified against pyrazine. The ratio between ${ }^{2} \mathrm{H}$ enriched body-water and the ${ }^{2} \mathrm{H}$ enrichment of HTG methyl hydrogens determines the contribution of DNL to the total HTG pool (31).

\section{Cardiac and hepatic lipid retention}

To determine the contribution of dietary fat to myocardial and hepatic TG, shortly fasted mice $(4 \mathrm{~h})$ of group 3 were given an oral load of $\left[\mathrm{U}^{13} \mathrm{C}\right]$ algal-lipid mixture (Cambridge Isotope Laboratories, Andover, MA, USA) at dose of $5 \mathrm{~g} \cdot \mathrm{Kg}^{-1}$ body weight. The fatty-acid composition of this algal lipid mixture was $>96 \%$, of which $52 \%$ was palmitic, $23 \%$ oleic, $11 \%$ linoleic, $7 \%$ palmitoleic, $3 \%$ stearic, and $0.2 \%$ was palmitolenic acid. Four hours later, animals were sacrificed and hearts and livers were freeze-clamped. Lipids from freeze-clamped hearts and livers were extracted by the Folch method (30) and dried under a constant $\mathrm{N}_{2}$ flow. Lipids were re-dissolved in deuterated chloroform. Proton-decoupled ${ }^{13} \mathrm{C} N M R$ spectra of cardiac and hepatic lipids were acquired on an 11.7 T NMR system (Bruker Instruments, Billerica, MA) with 30 o pulse and TR of $4 \mathrm{~s}$ and ${ }^{1} \mathrm{H}$ decoupling was achieved with a WALTZ-64 pulse sequence. Absolute ${ }^{13} \mathrm{C}$ enrichment of myocardial and hepatic TG was determined by quantifying the ${ }^{13} \mathrm{C}$ methyl resonances, arising from the $\left[\mathrm{U}-{ }^{13} \mathrm{C}\right]$ lipids, against that of ${ }^{13} \mathrm{C}$ lipids natural abundance $(1.1 \%)$. Due to coupling $J^{13} \mathrm{C}_{-}^{13} \mathrm{C}$ of $\left[\mathrm{U}^{-13} \mathrm{C}\right]$ lipids supplied in the bolus, a doublet is formed around the methyl resonance of ${ }^{13} \mathrm{C}$ natural abundance lipids, which allows the determination of the diet-derived cardiac and hepatic lipids. Dietary lipid absorption to heart or liver (\% of bolus) $=$ total cardiac or hepatic TG $\left(\mu \mathrm{mol} \cdot \mathrm{g}^{-1}\right) \mathrm{x}$ ${ }^{13} \mathrm{C}$ enrichment (\%) $\mathrm{x}$ heart or liver weight $(\mathrm{g}) /$ oral lipid supply ( $\left.\mu \mathrm{mol}\right)$. 


\section{Triglyceride tolerance test}

Mice were shortly fasted (4 hours) and received an oral bolus of olive oil $(11 \mathrm{~g} \cdot \mathrm{kg}$ ${ }^{1}$ ). Plasma triglycerides were then assessed every hour for the next 4 hours with a standard triglyceride meter (Cardiocheck, Belgium).

mRNA expression of LPL and modulators of LPL in hepatic and white adipose tissue

For analyses of mRNAs for LPL, ANGPTL4, GPIHBP1 and PPAR adipose tissue (WAT), as well as mRNAs for Hepatic lipase, ANGPTL4, ANGPTL3, apoE, apoC3 in liver tissue, total RNA was isolated with TRIzol reagent (Invitrogen, Breda, The Netherlands) according to manufacturer's instructions. One $\mu \mathrm{g}$ of total RNA was reverse transcribed using iScript (Bio-Rad, Veenendaal, The Netherlands). cDNA was PCR-amplified with Platinum Taq DNA polymerase (Invitrogen) on a Bio-Rad CFX384 Real Time System using Sensimix (Bioline, GC Biotech, Alphen aan de Rijn, The Netherlands). Ribosomal protein 36B4 mRNA served as control. PCR primer sequences were taken from the PrimerBank and ordered from Eurogentec (Seraing, Belgium). Sequences of the primers used are available upon request.

\section{Statistical analysis}

Results are expressed as means \pm standard error of the mean (SEM). Statistical analysis was performed using IBM SPSS Statistics for Windows, Version 20.0 (Armonk, NY: IBM Corp). To evaluate effects in the longitudinal comparison, repeated measures ANOVA was used to determine the effect of time and the interaction between time and diet. Bonferroni post-test was performed in case ANOVA showed overall significance.

To evaluate effects between the two experimental groups on the measurements performed only at the early time point (e.g. postprandial lipid handling and de novo lipogenesis), a two-tailed Student's t-test was used. Significance was set at $\mathrm{p} \leq 0.05$. 
Body weight, organ weight and visceral fat content

Early exposure to a high-fat diet resulted in a tendency for increased body weight at 12 weeks of age (LF/HF vs. HF/HF: $25.5 \pm 0.7$ vs. $27.3 \pm 0.7 \mathrm{~g}, \mathrm{p}=0.08$ ). Although at 28 weeks of age, body weight was no longer different, fat pad weight was significantly elevated in HF/HF mice compared to LF/HF mice $(1.7 \pm 0.1$ vs. $2.2 \pm 0.2$ g, $p=0.05$, see Table 1 ).

\begin{tabular}{lccc}
\hline & $\begin{array}{r}\text { Age } \\
\text { (weeks) }\end{array}$ & LF/HF & HF/HF \\
\hline Body weight, g & 12 & $25.48 \pm 0.66$ & $27.28 \pm 0.70 \S$ \\
Heart weight, g & 28 & $32.92 \pm 0.70$ & $34.12 \pm 1.19$ \\
Liver weight, g & 12 & $0.19 \pm 0.01$ & $0.18 \pm 0.01$ \\
WAT weight, g & 28 & $0.17 \pm 0.02$ & $0.17 \pm 0.01$ \\
& 12 & $0.96 \pm 0.02$ & $0.94 \pm 0.06$ \\
Plasma TG, mmol/I & 12 & $1.10 \pm 0.03$ & $1.11 \pm 0.03$ \\
& 28 & $0.77 \pm 0.08$ & $1.00 \pm 0.11$ \\
& 12 & $1.70 \pm 0.10$ & $2.18 \pm 0.20 *$ \\
& 28 & $0.86 \pm 0.07$ & $0.82 \pm 0.05$ \\
& 12 & $0.90 \pm 0.08$ & $0.92 \pm 0.08$ \\
& 28 & $0.40 \pm 0.03$ & $0.49 \pm 0.07$ \\
& & $0.32 \pm 0.03$ & $0.35 \pm 0.02$ \\
& & & \\
\hline
\end{tabular}

\footnotetext{
Table 1. Basic characteristics
}

Results are expressed as means \pm SEM for $11 \mathrm{LF} / \mathrm{HF}$ mice and $11 \mathrm{HF} / \mathrm{HF}$ mice. The abbreviations denote WAT, white adipose tissue; TG, triglycerides; NEFA, nonesterified fatty acids. Statistical significance comparing LF/HF vs $\mathrm{HF} / \mathrm{HF}$ is indicated by $\S \mathrm{P} \leq 0.1$ and $* \mathrm{P} \leq 0.05$.

We also determined visceral fat volume, over time, using non-invasive MRI. Visceral fat volume increased with age in both LF/HF (from $582 \pm 34$ to $841 \pm 101$ to $1024 \pm 50 \mu \mathrm{l}$ at $\mathrm{t}=15,21$ and 27 resp., $\mathrm{p}=0.03)$ and in HF/HF mice $(881 \pm 107 \mathrm{vs}$ $1330 \pm 136$ to $1485 \pm 199 \mu \mathrm{l}$ at $t=15,21$ and 27 resp., $p<0.05$, Figure 2). But importantly, visceral fat volume was higher in offspring of mice exposed to HF diet 
during pregnancy and lactation (Figure 2). No difference in heart or liver weight was observed throughout the study.

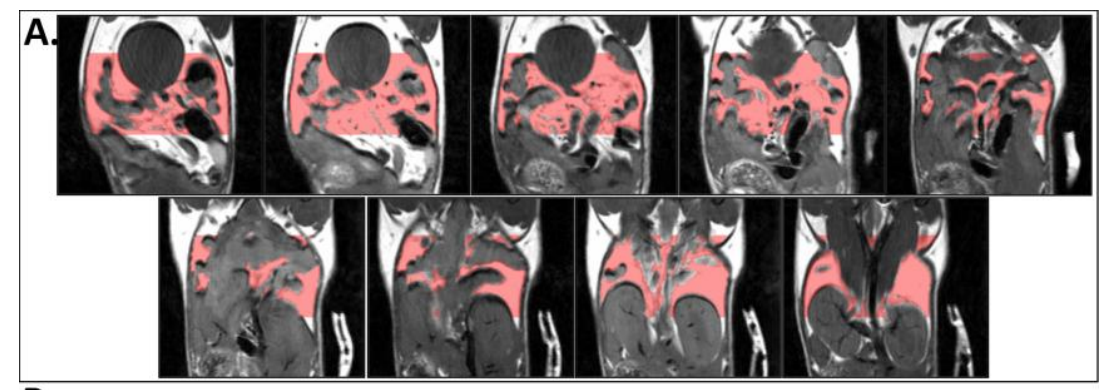

B.

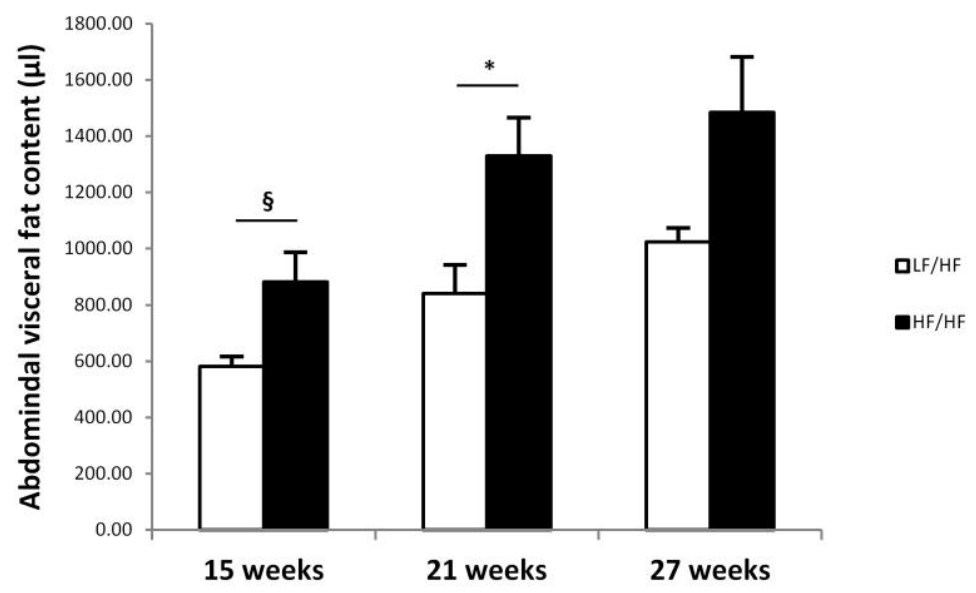

Figure 2: Abdominal visceral adipose tissue (VAT) was determined in the 3-dimensional region from half the size of the bladder to half the size of the left kidney (panel $A$, from left to right, from top to bottom). Mean ( \pm SEM) abdominal visceral fat content $(\mu \mathrm{l})$ at 12,18 and 24 weeks of age. Significant differences between the dietary groups are indicated with $\S P \leq 0.1$ and * $P \leq 0.05$.

\section{Plasma levels and glucose tolerance test}

Fasted plasma glucose, plasma TG and NEFA levels were similar in the two dietary groups at 12 and 28 weeks of age (Table 1). Early exposure to HF diet did not change glucose tolerance from 12 to 24 weeks of age (see Figure 3 ). 
A.

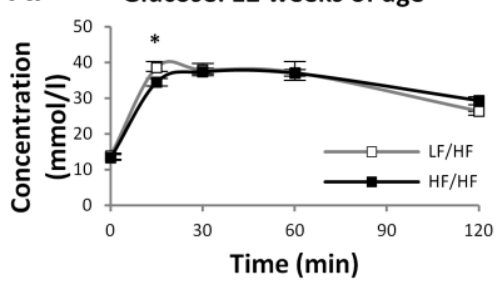

B. Glucose: 18 weeks of age

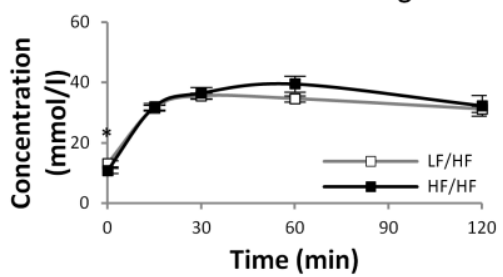

C.

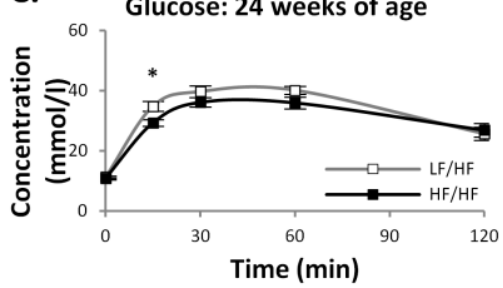

D. AUC Glucose

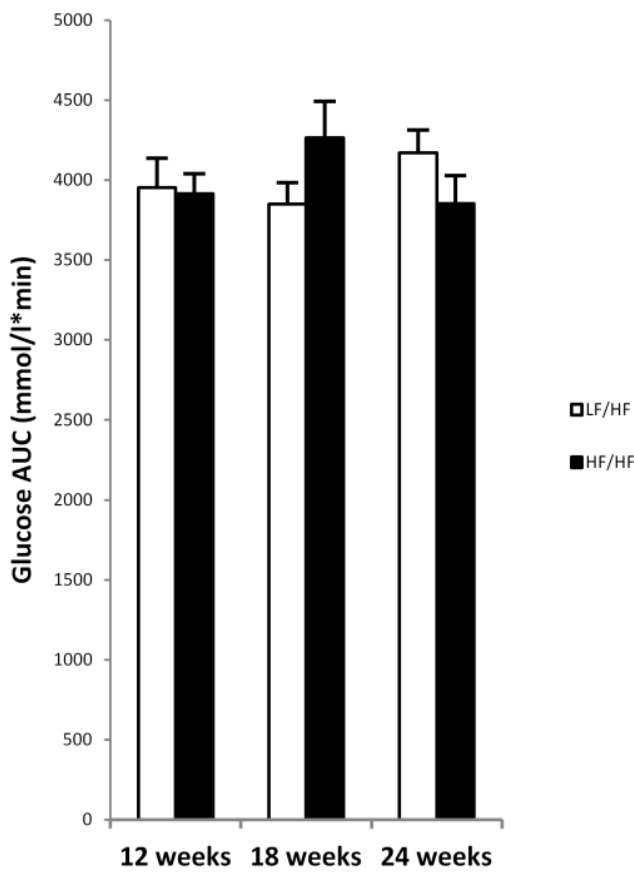

Figure 3: Mean $( \pm$ SEM) plasma glucose $(A, B, C)$ concentrations during the glucose tolerance test at 12,18 and 24 weeks of age, respectively. In panel $D$ also the area under the curve of the glucose concentration during the ipGTT is presented. Glucose clearance was similar for the LF/HF and HF/HF mice.

\section{Skeletal muscle lipid content}

Skeletal muscle lipid content, determined using biochemical lipid quantification in mice killed at week 12 and 28 of age, was not significantly affected by early exposure to a HF diet. In both groups, skeletal muscle lipid content increased with age (LF/HF 12 vs. 28 wk: $0.015 \pm 0.002$ vs. $0.037 \pm 0.009 \mu \mathrm{g} \mathrm{TG} / \mu$ l protein, $\mathrm{p}=0.06$; HF/HF 12 vs. 28 wk: $0.012 \pm 0.002$ vs. $0.034 \pm 0.005 \mu \mathrm{g} \mathrm{TG} / \mu \mathrm{l}$ protein, $p<0.01)$.

\section{Cardiac function, lipid content and mitochondrial respiration}

We next determined cardiac lipid content and cardiac function over time, using non-invasive MRS/MRI (see Figure 4A and 4B). Early exposure to a HF diet resulted in significantly increased cardiac lipid content at 15 weeks of age (LF/HF vs. HF/HF: $1.03 \pm 0.08$ vs. $1.33 \pm 0.07 \%$ of water signal, $p=0.01$ ). Remarkably, cardiac lipid content did not further increase in mice early exposed to HF diet, but rather decreased from 15 to 21 weeks of age (from $1.33 \pm 0.07$ to $0.95 \pm 0.06 \%$ of water 
signal, $\mathrm{p}=0.02$ ). In contrast, mice early exposed to a normal LF diet showed a significant age-related increase in cardiac lipid content between week 21 and 27 of age (1.01 \pm 0.13 vs. $1.66 \pm 0.13 \%$ of water signal, $p=0.003)$.

A.

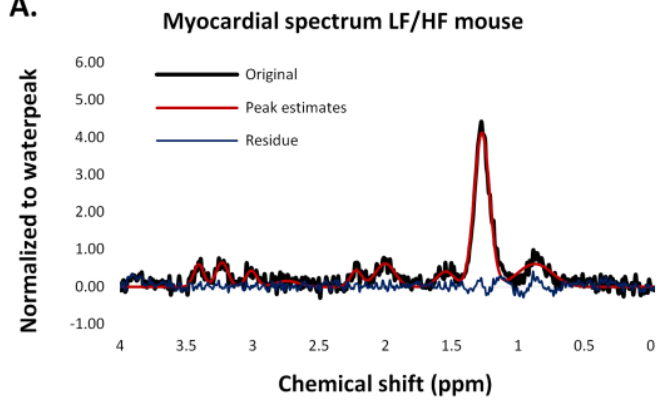

B.

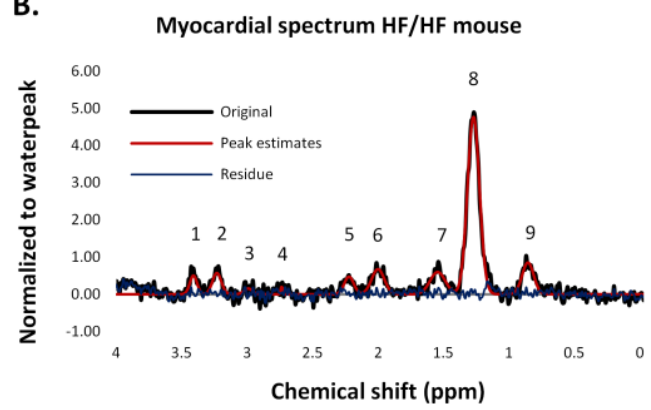

C.
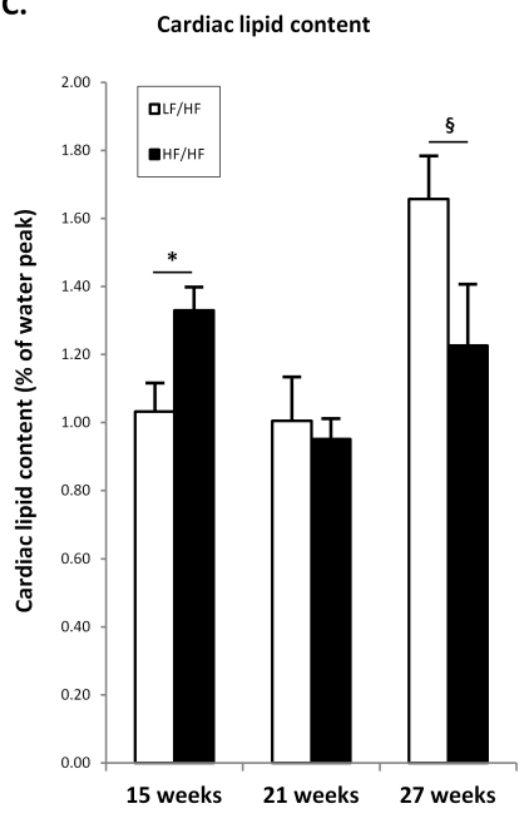

Figure 4: Myocardial ${ }^{1} \mathrm{H}-\mathrm{MR}$ spectra from a 21 weeks old LF/HF mouse (A) and a 15 weeks old HF/HF mouse (B), including peak estimates and residues, as indicated. The graph (C) shows the mean \pm SEM cardiac lipid content of mice from group 2. Metabolite peaks were assigned as described previously $(25,33)$. 1. Taurine, $3.38 \mathrm{ppm} ; 2$. Trimethyl-ammonium compounds, $3.21 \mathrm{ppm}$; 3. Creatine- $\mathrm{CH}_{3}, 2.99 \mathrm{ppm} ; 4$. TG $\mathrm{CH}=\mathrm{CH}-\mathrm{CH}_{2}-\mathrm{CH}=\mathrm{CH}, 2.72 \mathrm{ppm} ; 5$. TG $\mathrm{C}_{\alpha} \mathrm{H}_{2} \mathrm{COO}, 2.20 \mathrm{ppm} ; 6$. TG $\mathrm{CH}_{2}-\mathrm{CH}=\mathrm{CH}-\mathrm{CH}_{2}, 2.0 \mathrm{ppm}$; 7. TG $\mathrm{C}_{\beta} \mathrm{H}_{2} \mathrm{CH}_{2} \mathrm{COO}, 1.55 \mathrm{ppm} ; 8$. TG $-\left(\mathrm{CH}_{2}\right)_{n}-1.26 \mathrm{ppm}$ and 9. TG- $\mathrm{CH}_{3}, 0.85 \mathrm{ppm}$. Significant differences between the dietary groups are indicated with $\S \mathrm{P} \leq 0.1$ and ${ }^{*} \mathrm{P} \leq$ 0.05 .

To investigate if changes in cardiac lipid content were associated with alterations in mitochondrial oxidative capacity, mitochondrial respiration was measured in isolated mitochondria in parallel groups of mice that were killed at 12 and 28 weeks of age. Early exposure to $\mathrm{HF}$ diet did not result in alterations in neither pyruvate nor palmitoylCoA+Carnitine -supported respiration, nor mitochondrial copy number at 12 weeks of age. However, palmitoylCoA+Carnitine -supported respiration tended to be decreased at 28 weeks of age in mice early exposed to $\mathrm{HF}$ diet (State 3: $3309 \pm 229$ vs. $\left.2570 \pm 257 \mathrm{pmol}(\mathrm{s} \times \mathrm{mg})^{-1}, \mathrm{p}=0.06\right)$. State 4 respiration was not different between groups (Table 2), but RCR also tended to be lower in HF/HF mice, indicating reduced mitochondrial efficiency. These alterations in mitochondrial capacity were specific for fatty acids, as no difference in pyruvate-supported respiration was observed. Interestingly, mitochondrial DNA 
copy number was increased in mice early exposed to HF diet at week 28 of age (LF/HF vs. HF/HF: $0.52 \pm 0.03$ vs. $0.62 \pm 0.03, p=0.05$ ), suggesting that the reduction in mitochondrial efficiency might be compensated by increased mitochondrial density.

Heart Age (weeks) LF/HF HF/HF

Pyruvate-supported respiration

\begin{tabular}{llll}
\hline State 3 & 12 & $3502.23 \pm 355.07$ & $3649.58 \pm 222.57$ \\
& 28 & $4158.59 \pm 302.69$ & $4581.62 \pm 410.12$ \\
State 4 & 12 & $667.40 \pm 41.90$ & $691.71 \pm 34.57$ \\
& 28 & $762.32 \pm 41.40$ & $820.87 \pm 56.20$ \\
RCR & 12 & $5.17 \pm 0.34$ & $5.30 \pm 0.26$ \\
& 28 & $5.59 \pm 0.50$ & $5.56 \pm 0.22$ \\
\hline
\end{tabular}

PalmitoylCoA+Carnitine- supported respiration

\begin{tabular}{llll}
\hline State 3 & 12 & $2915.03 \pm 249.06$ & $3218.72 \pm 221.94$ \\
& 28 & $3308.54 \pm 229.25$ & $2569.80 \pm 265.65 \S$ \\
State 4 & 12 & $654.05 \pm 77.60$ & $565.94 \pm 34.40$ \\
& 28 & $514.12 \pm 34.35$ & $542.62 \pm 27.64$ \\
RCR & 12 & $5.03 \pm 0.60$ & $5.83 \pm 0.46$ \\
& 28 & $6.61 \pm 0.66$ & $5.04 \pm 0.53 \S$
\end{tabular}

Table 2. Cardiac mitochondrial respiration levels (pmol $\left.(\mathrm{s} \times \mathrm{mg})^{-1}\right)$

Results are expressed as means \pm SEM for $11 \mathrm{LF} / \mathrm{HF}$ mice and $11 \mathrm{HF} / \mathrm{HF}$ mice. ADP-stimulated (state 3 ) respiration was induced by the addition of ADP, state 4 respiration was attained upon addition of the ATPsynthase inhibitor oligomycin. Additionally, RCR (respiratory control ratio, S3/S4) respiration is presented. Significant differences between the dietary groups are indicated with $\S P \leq 0.1$ and $* P \leq 0.05$.

Next, we tested if these differences in cardiac lipid content and/or mitochondrial efficiency translated into function differences in cardiac function. However, early exposure to HF diet had no (or not yet) effect on cardiac systolic function (enddiastolic volume, end-systolic volume and ejection fraction, see supplementary data, Figure 2). 
Early exposure to a high fat diet affects cardiac lipid content early in life, whereas mitochondrial function was only altered at later time points. To investigate if similar effects are found in liver, we determined hepatic lipid content longitudinally, using non-invasive ${ }^{1} \mathrm{H}-\mathrm{MRS}$. Typical spectra are shown in Figures $5 \mathrm{~A}$ and $5 \mathrm{~B}$. In contrast to the elevated lipid content in the heart, hepatic fat content tended to be reduced in mice early exposed to HF at 15 weeks of age (LF/HF vs. HF/HF: $4.50 \pm 0.43$ vs. $3.64 \pm 0.18 \%$ of water signal, $p=0.07)$. These results were confirmed by ex vivo analysis of hepatic fat content in a parallel group of mice sacrificed at 12 weeks of age (LF/HF vs. HF/HF: $271.67 \pm 49.21$ vs. $169.07 \pm 16.18$ $\mu \mathrm{mol} / \mathrm{g}$ of liver, $\mathrm{p}=0.06)$. Hepatic lipid content increased with age in both groups, although this increase was more pronounced in the HF/HF group (from: $3.64 \pm 0.18$ to $5.06 \pm 0.56$ to $6.09 \pm 0.68 \%$ of water signal, at $t=15,21$ and 27 weeks of age respectively, $\mathrm{p}=0.08$ for $\mathrm{t}-15$ vs. 27 , see Figure 5 ) and as a result, the reduction in hepatic lipid content observed at a young age did not remain when mice got older.

A.

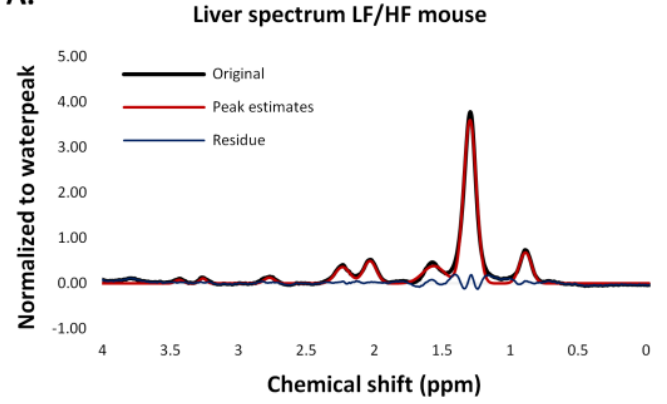

B.

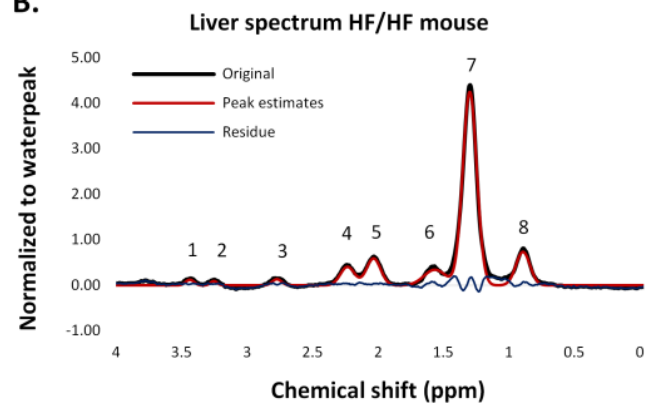

C.

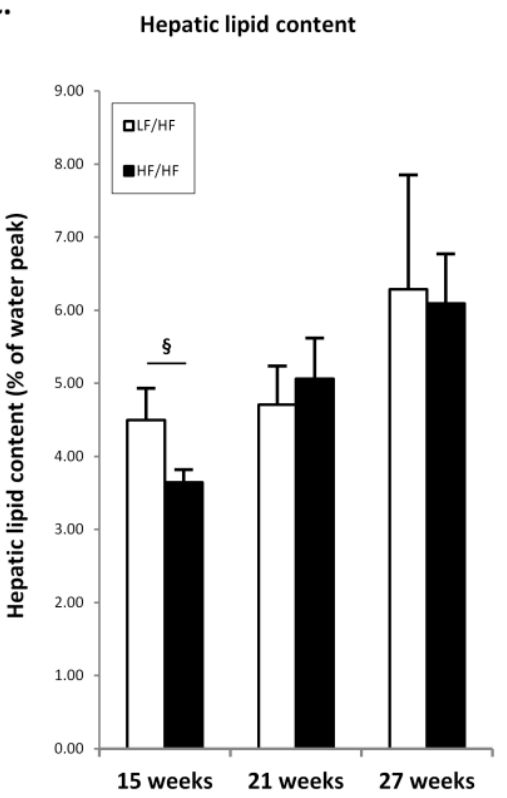

Figure 5: Hepatic ${ }^{1} \mathrm{H}-\mathrm{MR}$ spectra from a 21 weeks old LF/HF mouse (A) and a 21 weeks old HF/HF mouse (B), including peak estimates and residues, as indicated. The graph (C) shows the mean \pm SEM hepatic content of mice from group 2. Metabolite peaks were 1. Taurine, $3.38 \mathrm{ppm} ; 2$. Trimetyl-ammonium compounds, $3.21 \mathrm{ppm}$; 3. TG $\mathrm{CH}=\mathrm{CH}-\mathrm{CH}_{2}-\mathrm{CH}=\mathrm{CH}, 2.72 \mathrm{ppm}$; 4. TG $\mathrm{C}_{\alpha} \mathrm{H}_{2} \mathrm{COO}, 2.20 \mathrm{ppm}$; 5. TG $\mathrm{CH}_{2}-\mathrm{CH}=\mathrm{CH}-\mathrm{CH}_{2}, 2.0 \mathrm{ppm}$; 6 . TG $\mathrm{C}_{\beta} \mathrm{H}_{2} \mathrm{CH}_{2} \mathrm{COO}, 1.55 \mathrm{ppm} ; 7$. TG $-\left(\mathrm{CH}_{2}\right)_{n}-1.26 \mathrm{ppm}$ and 8. TG- $\mathrm{CH}_{3}, 0.85 \mathrm{ppm}$. Significant differences between the dietary groups are indicated with $\S \mathrm{P} \leq 0.1$ and $* \mathrm{P} \leq 0.05$. 
Despite the reduced hepatic fat content in young mice, mitochondrial respiration on glutamate was significantly reduced in mice early exposed to HF diet at 12 weeks of age (State 3: $1125 \pm 96$ vs. $902 \pm 41$ pmol(s x mg) $\left.)^{-1}, p=0.05\right)$, an effect that diminished at the later time point. No differences in mitochondrial respiration with palmitoylCoA as a substrate were observed between groups, and mitochondrial DNA copy number was not affected by early exposure to HF diet (Table 3).

\begin{tabular}{lccc}
$\frac{\text { Liver }}{4 \text { Glutamate-supported respiration }}$ & \multicolumn{1}{c}{ LF/HF } & HF/HF \\
\hline State 3 & 12 & $1124.51 \pm 95.52$ & $901.76 \pm 40.69 *$ \\
& 28 & $1863.66 \pm 219.05$ & $1999.23 \pm 134.78$ \\
State 4 & 12 & $254.88 \pm 21.53$ & $217.27 \pm 14.06$ \\
& 28 & $364.12 \pm 20.71$ & $410.19 \pm 20.45$ \\
RCR & 12 & $4.46 \pm 0.22$ & $4.24 \pm 0.23$ \\
& 28 & $5.13 \pm 0.53$ & $5.00 \pm 0.50$
\end{tabular}

PalmitoyICoA+Carnitine- supported respiration

\begin{tabular}{llll}
\hline State 3 & 12 & $585.26 \pm 82.73$ & $570.94 \pm 82.41$ \\
& 28 & $699.92 \pm 72.77$ & $879.69 \pm 136.72$ \\
State 4 & 12 & $262.90 \pm 42.12$ & $223.17 \pm 15.87$ \\
& 28 & $323.76 \pm 74.42$ & $289.78 \pm 24.88$ \\
RCR & 12 & $2.28 \pm 0.22$ & $2.46 \pm 0.20$ \\
& 28 & $2.51 \pm 0.32$ & $2.96 \pm 0.31$
\end{tabular}

Table 3. Hepatic mitochondrial respiration levels (pmol (s x mg) $)^{-1}$ )

Results are expressed as means \pm SEM for $11 \mathrm{LF} / \mathrm{HF}$ mice and $11 \mathrm{HF} / \mathrm{HF}$ mice. ADP-stimulated (state 3) respiration was induced by the addition of ADP, state 4 respiration was attained upon addition of the ATPsynthase inhibitor oligomycin. Additionally, RCR (respiratory control ratio, S3/S4) respiration is presented. Significant differences between the dietary groups are indicated with $\S \mathrm{P} \leq 0.1$ and $* \mathrm{P} \leq 0.05$.

Postprandial lipid handling and de novo lipogenesis at 12 weeks of age

To further investigate the mechanism underlying the increased lipid content in heart and decreased content in liver, respectively, at 12 weeks of age, we performed additional experiments at this time point. As both cardiac and hepatic 
lipid content may be affected by dietary fat handling, we first investigated cardiac and hepatic dietary lipid retention. To this end, mice were given an oral load of $\left[\mathrm{U}-{ }^{13} \mathrm{C}\right]$ algal-lipid mixture and were killed 4 hours postprandially. Cardiac lipid absorption from this lipid bolus was similar in the two groups (LF/HF vs. HF/HF: $0.21 \pm 0.06$ vs. $0.20 \pm 0.07 \%$ of bolus, NS, Figure $6 \mathrm{~A}$ ). However, early exposure to a $\mathrm{HF}$ diet resulted in a marked 3.1 fold reduction of hepatic lipid absorption after a meal (LF/HF vs. HF/HF: $2.73 \pm 0.85$ vs. $0.89 \pm 0.26 \%$ absorption form bolus, $p=0.04$, Figure $6 \mathrm{~B})$. These results are consistent with a reduction in plasma TG clearance upon a lipid load in HF/HF mice, compared to LF/HF mice and therefore elevated postprandial TG levels $\left(6753 \pm 2213 \mathrm{mmol} / \mathrm{I}^{*} \mathrm{~min}\right.$ vs $14367 \pm 1978, \mathrm{p}=0.01$, see Figure 7). We also determined the contribution of de novo lipogenesis, traced by $2 \mathrm{H} 2 \mathrm{O}$ to the hepatic lipid content of these mice. In the HF/HF group, DNL to the hepatic lipid content tended to be higher in the HF/HF group (LF/HF vs. HF/HF: $4.24 \pm 0.82$ vs. $7.59 \pm 1.38 \%, p=0.06$, Figure $6 C$ ).

A.

$\left[\mathrm{U}-{ }^{13} \mathrm{C}\right]$ lipid absorption in

heart

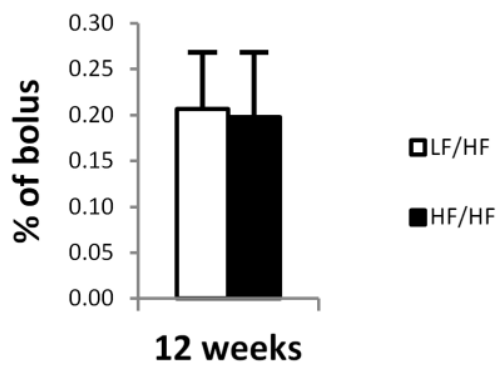

B.

$\left[\mathrm{U}-{ }^{13} \mathrm{C}\right]$ lipid absorption in liver

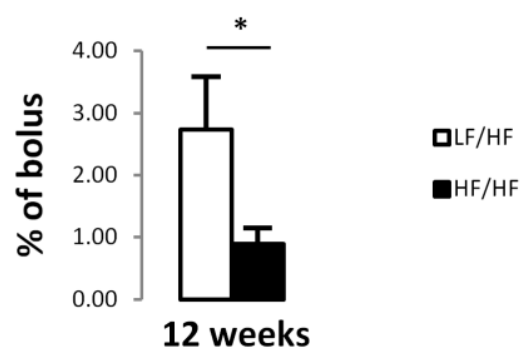

C.

\section{Contribution of DNL to hepatic TG content}

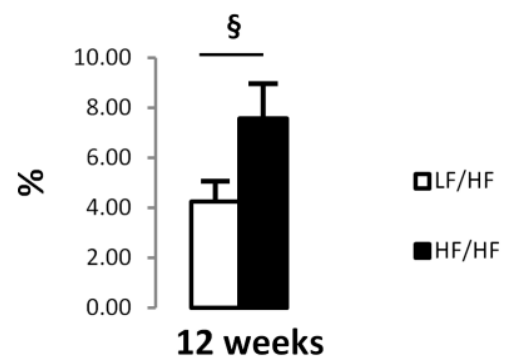

Figure 6: Mean \pm SEM of cardiac and hepatic $\left[\mathrm{U}^{13} \mathrm{C}\right]$ lipid absorption and contribution of de novo lipogenesis to hepatic TG content. No difference in cardiac lipid absorption after a meal was found, but HF/HF mice show significantly reduced hepatic lipid absorption after a meal $(p=0.04)$ compared to the $L F / H F$ at 12 weeks of age. A 
trend $(p=0.06)$ for elevated contribution of DNL to hepatic TG content was found in the HF/HF group compared to the LF/HF group. Significant differences between the dietary groups are indicated with $\S P \leq 0.1$ and ${ }^{*} P \leq 0.05$.

A.

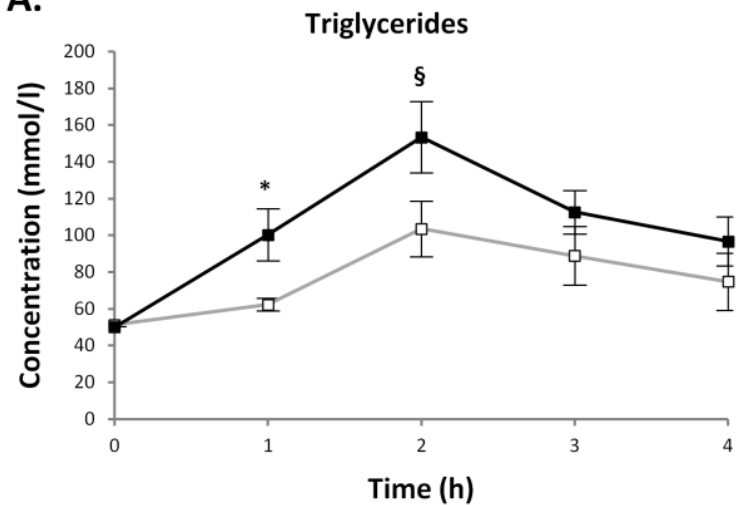

B.

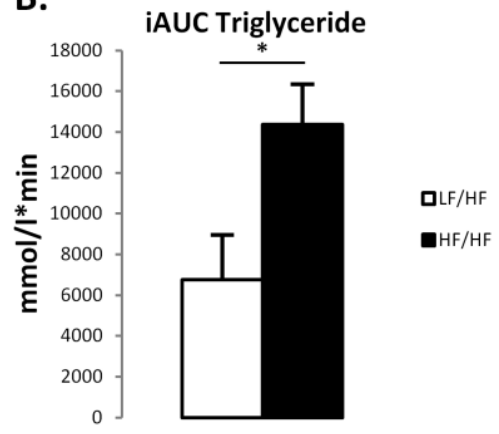

Figure 7: One hour after administration of the bolus a significant difference in plasma TG concentrations was found between the HF/HF and LF/HF group during the TG tolerance test, performed at 12 weeks of age (A). Additionally, the incremental area under the curve is significantly higher $(P=0.01)$ in the HF/HF mice compared to the LF/HF mice (B). Significant differences between the dietary groups are indicated with $\S \mathrm{P} \leq 0.1$ and ${ }^{*} \mathrm{P} \leq 0.05$.

\section{Expression of LPL and modulators of LPL activity}

The reduced dietary lipid retention in the liver can be due a reduced capacity of the liver to take up dietary lipids or to a reduced clearance in LPL-rich tissue such as adipose tissue. Therefore, we investigated expression of genes involved in these processes in liver and adipose tissue No difference in hepatic Angtpl4, Angptl3, ApoE and ApoC3 mRNA expression levels was found between LF/HF and $\mathrm{HF} / \mathrm{HF}$ mice. However, hepatic lipase showed a trend towards lower expression in mice early exposed to HF diet compared to control mice (HF/HF vs. LF/HF: $0.89 \pm 0.08$ vs. $1.08 \pm 0.06, p=0.08$ ). The expression of $L P L$, Angtpl4, Gpihbp1 and PPARY in WAT was similar in the two groups. See also supplementary data, Table 1. 


\section{Discussion}

It is generally accepted that the consumption of fat-rich diets favors the development of obesity and cardiovascular disease, often accompanied by accumulation of ectopic lipids and impaired postprandial lipid handling. An underestimated factor in the development of this phenotype may be the longlasting influence of the exposure to a high-fat diet during very early development (in utero and during lactation). The goal of the present study was to investigate whether exposure to a HF diet during early development increases the susceptibility for unfavorable health effects when consuming a high-fat diet later in life. Here, we investigated in a unique longitudinal study, the effect of early exposure to a high fat diet on glucose tolerance, visceral, hepatic and cardiac fat and cardiac function in an age span from 10 to 28 weeks of age. Mitochondrial function was also determined at 12 and 28 weeks and effects on postprandial lipid handling were investigated. We found that early exposure to a HF diet resulted in major disturbances in dietary lipid handling with increased postprandial plasma triglyceride concentrations and elevated visceral fat content. Since it is well established that postprandial hypertriglyceridemia and visceral fat content are risk factors for cardiovascular disease (34), exposure to a HF diet during early development may be an important risk factor for morbidity and mortality later in life. It is important to note that fasted triglyceride plasma concentrations were similar in the two groups, showing the added value of postprandial plasma sampling in investigating metabolic disturbances.

Early exposure of mice to a HF diet resulted in a reduced hepatic lipid content at week 12 of age. In general, elevated hepatic lipid content is recognized to be a determinant in the development of insulin resistance and diabetes, and a reduced liver fat content would be considered a beneficial adaption. However, the reduction in hepatic fat was associated with a disturbed triglyceride clearance as well as severely decreased hepatic lipid retention from a meal in the HF/HF group at 12 weeks. Moreover, the contribution of hepatic de novo lipogenesis to hepatic fat content tended to be higher in these animals. De novo lipogenesis is known to be elevated in animal models of non-alcoholic fatty liver disease (NAFLD) and in humans with NAFLD, and may significantly contribute to the development of a fatty liver on the long term. In a study investigating the origin of hepatic fat in non-alcoholic steatohepatitis (NASH) patients DNL accounted for $20-30 \%$ of fatty acids in the liver (35). Together with the impaired TG clearance, these results indicate that early exposure to a HF diet resulted in altered lipid metabolism favoring the development of the metabolic syndrome.

In addition to hepatic lipase, the triglyceride uptake in the liver also largely depends on the clearance of chylomicron particles by LPL in adipose tissue or 
skeletal muscle. To investigate the origin of the impaired TG clearance, we explored mRNA-expression of PPAR- $\gamma$ and LPL as well as known LPL modulators such as Angpt14, Gpihbp1 in white adipose tissue and expression of liver-specific LPL modulators (angiopoietin-like proteins Angtpl3, Angtpl4 and apolipoproteins ApoE, ApoC3) as well as hepatic lipase. We found a tendency for reduced mRNA expression of hepatic lipase in HF/HF mice, which may partially underlie the decreased uptake of dietary lipid during a meal and may contribute to the elevated plasma TG concentrations after an oral lipid load in HF/HF mice.

Next to the disturbances in postprandial lipid metabolism, which represent a cardiovascular risk factor, non-invasive MR imaging revealed that early exposure to a HF diet resulted in elevated visceral fat content. It is known that visceral adiposity is associated with and even predicts the development of coronary heart disease (36), hypertension (36) and type 2 diabetes (37), further suggesting that early exposure to a HF diet results in a less preferable metabolic phenotype. The fact that the fat content of the maternal diet is a strong determinant for later metabolic health, is of particular relevance as the typical western diet contains high amounts of fat and is widely consumed, also by women of child-bearing age. Future research should further investigate the mechanism underlying the identified derangements in postprandial lipid partitioning in order to be able to prevent the development of postprandial hypertriglyceridemia induced by early exposure to high fat diet.

Contrary to the liver, cardiac lipid content was significantly increased at week 12 of age. It is well known that cardiac tissue is able to take up circulating TG via the action of cardiac LPL. Therefore, the increased cardiac lipid content most likely is due to the elevated plasma TG levels observed postprandially. Moreover, it has been suggested that cardiac lipid accumulation may hamper cardiac function by so-called lipotoxic mechanisms (38). Although mitochondrial respiration was not impaired at the early time point, early exposure to a HF diet resulted in reduced fat oxidative capacity and reduced mitochondrial efficiency at week 28 of age. Despite these changes in cardiac lipid content and mitochondrial function, cardiac systolic function was not (yet) compromised. It is important to note that the increment in cardiac lipid content in the current study is modest when compared to genetic animal models where cardiac lipid content is often severely manipulated, which is then associated with cardiac dysfunction (39-41). The outcome of the present study is in line with earlier findings in rat (42) and men $(43,44)$, showing that a moderate, but physiological change in cardiac fat content is not a strong determinant of cardiac function.

In summary, in the current study, despite similar glucose tolerance, early exposure to a high fat diet caused metabolic changes that are considered pathophysiological, such as increased cardiac lipid content and delayed 
postprandial TG clearance. Impaired TG clearance may in turn be underlying the modest hepatic lipid retention from a meal in the HF/HF mice. Future studies are needed also in the human setting, opening new avenues to combat postprandial hypertriglyceridemia caused by early high-fat exposure. 
106 | Chapter 5

\section{SUPPLEMENTAL MATERIAL}

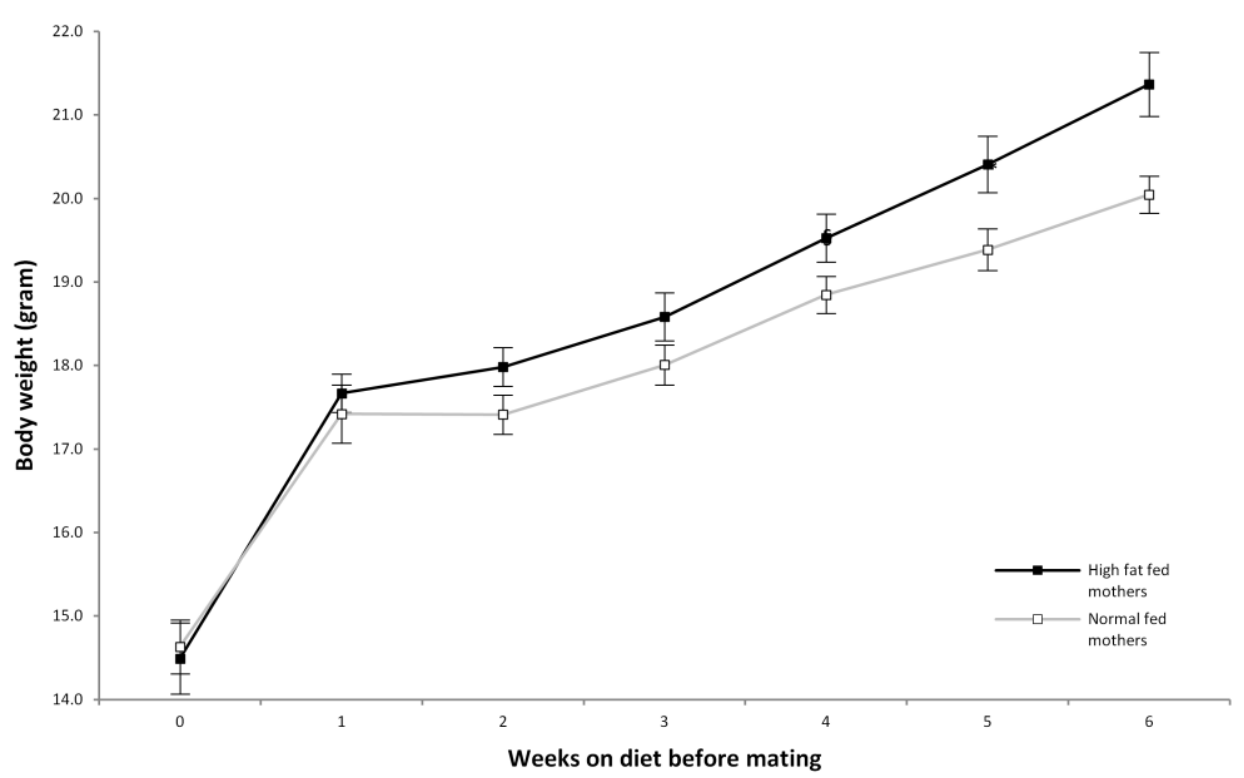

Suppl. Figure 1: Weight gain was measured each week in the damns from the start of the diet till mating. Mean \pm SEM weight per group is presented and statistical significance is indicated by $\S \mathrm{P} \leq 0.1$ and * $\mathrm{P} \leq 0.05$. 
A.

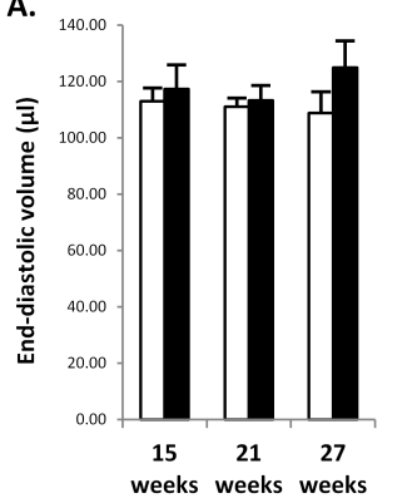

B.

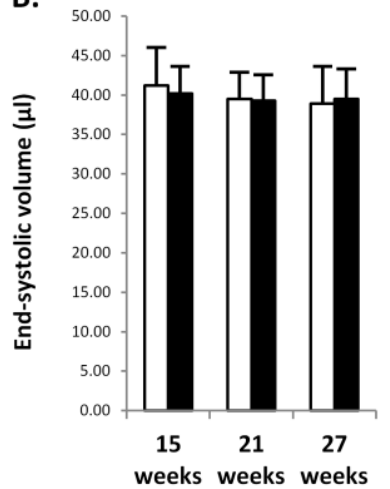

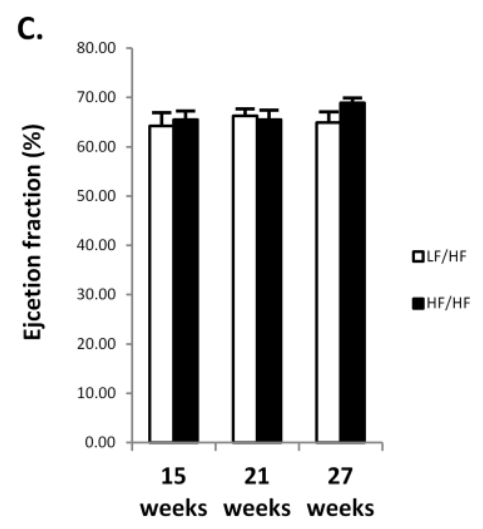

Suppl. Figure 2: End-diastolic volume (A) and end-systolic volume (B) were similar at 15, 21 and 27 weeks of age, as determined by cardiac MR imaging. The calculated ejection fraction (C) was also similar in the two groups. Mean \pm SEM per group per time point is presented. 


\begin{tabular}{l|ccc} 
Liver & Age (weeks) & LF/HF & HF/HF \\
\hline Hepatic lipase & 12 & $1.08 \pm 0.06$ & $0.89 \pm 0.08 \S$ \\
& 28 & $1.03 \pm 0.06$ & $1.04 \pm 0.06$ \\
Angpt|4 & 12 & $1.09 \pm 0.07$ & $0.90 \pm 0.11$ \\
& 28 & $0.87 \pm 0.05$ & $0.92 \pm 0.05$ \\
Angptl3 & 12 & $0.78 \pm 0.05$ & $0.86 \pm 0.07$ \\
& 28 & $1.08 \pm 0.04$ & $1.07 \pm 0.08$ \\
ApoE & 12 & $0.77 \pm 0.05$ & $0.83 \pm 0.03$ \\
& 28 & $0.88 \pm 0.03$ & $0.97 \pm 0.04 \S$ \\
ApoC3 & 12 & $0.78 \pm 0.06$ & $0.74 \pm 0.05$ \\
& 28 & $0.84 \pm 0.03$ & $0.95 \pm 0.06$
\end{tabular}

\begin{tabular}{l|ccc}
\multicolumn{1}{c|}{ WAT } & Age (weeks) & LF/HF & HF/HF \\
\hline LPL & 12 & $0.93 \pm 0.09$ & $1.13 \pm 0.09$ \\
& 28 & $1.01 \pm 0.09$ & $1.08 \pm 0.11$ \\
Angpt|4 & 12 & $0.96 \pm 0.10$ & $1.09 \pm 0.07$ \\
& 28 & $1.10 \pm 0.13$ & $1.03 \pm 0.10$ \\
Gpihbp1 & 12 & $0.94 \pm 0.10$ & $1.05 \pm 0.09$ \\
& 28 & $0.90 \pm 0.07$ & $0.91 \pm 0.09$ \\
PPARY & 12 & $0.27 \pm 0.03$ & $0.30 \pm 0.04$ \\
& 28 & $0.26 \pm 0.04$ & $0.21 \pm 0.05$ \\
\hline
\end{tabular}

Suppl. Table 1. Relative mRNA levels of LPL and modulators of LPL activity in liver and white adipose tissue (WAT).

Results are expressed as means \pm SEM for $8 \mathrm{LF} / \mathrm{HF}$ and HF/HF mice per group at 12 weeks of age and $11 \mathrm{LF} / \mathrm{HF}$ and HF/HF mice per group at 28 weeks of age. Statistical significance was evaluated by a two-tailed Students ttest, comparing LF/HF vs HF/HF, where $\S \mathrm{P} \leq 0.1$ and * $\mathrm{P} \leq 0.05$. 


\section{References}

1. World Health Statistics 2012. In.: World Health Organization (WHO); 2012.

2. Deckelbaum RJ, Williams CL. Childhood obesity: the health issue. Obes Res. 2001; 9 Suppl 4:239S243S.

3. Machann J, Haring H, Schick F, Stumvoll M. Intramyocellular lipids and insulin resistance. Diabetes Obes Metab. 2004; 6:239-248.

4. Rasouli N, Molavi B, Elbein SC, Kern PA. Ectopic fat accumulation and metabolic syndrome. Diabetes Obes Metab. 2007; 9:1-10.

5. Wende AR, Abel ED. Lipotoxicity in the heart. Biochim Biophys Acta. 2010; 1801:311-319.

6. Barker DJ, Winter PD, Osmond C, Margetts B, Simmonds SJ. Weight in infancy and death from ischaemic heart disease. Lancet. 1989; 2:577-580.

7. Barker DJ. Fetal origins of coronary heart disease. Br Heart J. 1993; 69:195-196.

8. Barker DJ, Gluckman PD, Godfrey KM, Harding JE, Owens JA, Robinson JS. Fetal nutrition and cardiovascular disease in adult life. Lancet. 1993; 341:938-941.

9. Barker DJ. Maternal and fetal origins of coronary heart disease. J R Coll Physicians Lond. 1994; 28:544551.

10. Barker DJ. Fetal origins of coronary heart disease. Bmj. 1995; 311:171-174.

11. Barker DJ. Fetal nutrition and cardiovascular disease in later life. Br Med Bull. 1997; 53:96-108.

12. Barker DJ. Maternal nutrition, fetal nutrition, and disease in later life. Nutrition. 1997; 13:807-813.

13. Barker DJ. Developmental origins of adult health and disease. J Epidemiol Community Health. 2004; 58:114-115.

14. Boney CM, Verma A, Tucker R, Vohr BR. Metabolic syndrome in childhood: association with birth weight, maternal obesity, and gestational diabetes mellitus. Pediatrics. 2005; 115:e290-296.

15. Hillier TA, Pedula KL, Schmidt MM, Mullen JA, Charles MA, Pettitt DJ. Childhood obesity and metabolic imprinting: the ongoing effects of maternal hyperglycemia. Diabetes Care. 2007; 30:2287-2292.

16. Fraser A, Tilling K, Macdonald-Wallis C, Sattar N, Brion MJ, Benfield L, Ness A, Deanfield J, Hingorani A, Nelson SM, Smith GD, Lawlor DA. Association of maternal weight gain in pregnancy with offspring obesity and metabolic and vascular traits in childhood. Circulation. 2010; 121:2557-2564.

17. Sullivan EL, Grove KL. Metabolic imprinting in obesity. Forum Nutr. 2010; 63:186-194.

18. Tounian P. Programming towards childhood obesity. Ann Nutr Metab. 2011; 58 Suppl 2:30-41.

19. Surkan PJ, Hsieh CC, Johansson AL, Dickman PW, Cnattingius S. Reasons for increasing trends in large for gestational age births. Obstet Gynecol. 2004; 104:720-726.

20. Catalano PM, Presley L, Minium J, Hauguel-de Mouzon S. Fetuses of obese mothers develop insulin resistance in utero. Diabetes Care. 2009; 32:1076-1080.

21. Reynolds RM, Osmond C, Phillips DI, Godfrey KM. Maternal BMI, parity, and pregnancy weight gain: influences on offspring adiposity in young adulthood. J Clin Endocrinol Metab. 2010; 95:5365-5369.

22. Mills JL, Troendle J, Conley MR, Carter T, Druschel CM. Maternal obesity and congenital heart defects: a population-based study. Am J Clin Nutr. 2010; 91:1543-1549.

23. McCurdy CE, Bishop JM, Williams SM, Grayson BE, Smith MS, Friedman JE, Grove KL. Maternal highfat diet triggers lipotoxicity in the fetal livers of nonhuman primates. J Clin Invest. 2009; 119:323-335.

24. Bruce KD, Cagampang FR, Argenton M, Zhang J, Ethirajan PL, Burdge GC, Bateman AC, Clough GF, Poston L, Hanson MA, McConnell JM, Byrne CD. Maternal high-fat feeding primes steatohepatitis in adult mice offspring, involving mitochondrial dysfunction and altered lipogenesis gene expression. Hepatology. 2009; 50:1796-1808.

25. Schneider JE, Tyler DJ, ten Hove M, Sang AE, Cassidy PJ, Fischer A, Wallis J, Sebag-Montefiore LM, Watkins $\mathrm{H}$, Isbrandt D, Clarke K, Neubauer S. In vivo cardiac $1 \mathrm{H}-\mathrm{MRS}$ in the mouse. Magn Reson Med. 2004; 52:1029-1035.

26. van de Weijer T, van Ewijk PA, Zandbergen HR, Slenter JM, Kessels AG, Wildberger JE, Hesselink MK, Schrauwen P, Schrauwen-Hinderling VB, Kooi ME. Geometrical models for cardiac MRI in rodents: comparison of quantification of left ventricular volumes and function by various geometrical models with a full-volume MRI data set in rodents. Am J Physiol Heart Circ Physiol. 2012; 302:H709-715.

27. Schwartz DM, Wolins NE. A simple and rapid method to assay triacylglycerol in cells and tissues. J Lipid Res. 2007; 48:2514-2520. 
28. Hoeks J, Briede JJ, de Vogel J, Schaart G, Nabben M, Moonen-Kornips E, Hesselink MK, Schrauwen P. Mitochondrial function, content and ROS production in rat skeletal muscle: effect of high-fat feeding. FEBS letters. 2008; 582:510-516.

29. Sparks LM, Xie H, Koza RA, Mynatt R, Hulver MW, Bray GA, Smith SR. A high-fat diet coordinately downregulates genes required for mitochondrial oxidative phosphorylation in skeletal muscle. Diabetes. 2005; 54:1926-1933.

30. Folch J, Lees M, Sloane Stanley GH. A simple method for the isolation and purification of total lipides from animal tissues. J Biol Chem. 1957; 226:497-509.

31. Delgado TC, Pinheiro D, Caldeira M, Castro MM, Geraldes CF, Lopez-Larrubia P, Cerdan S, Jones JG. Sources of hepatic triglyceride accumulation during high-fat feeding in the healthy rat. NMR Biomed. 2009; 22:310-317.

32. Jones JG, Merritt M, Malloy C. Quantifying tracer levels of $(2) \mathrm{H}(2) \mathrm{O}$ enrichment from microliter amounts of plasma and urine by (2)H NMR. Magn Reson Med. 2001; 45:156-158.

33. Griffin JL, Williams HJ, Sang E, Nicholson JK. Abnormal lipid profile of dystrophic cardiac tissue as demonstrated by one- and two-dimensional magic-angle spinning (1)H NMR spectroscopy. Magn Reson Med. 2001; 46:249-255.

34. Nordestgaard BG, Benn M, Schnohr P, Tybjaerg-Hansen A. [Non-fasting triglycerides and risk of for myocardial infarction and death among women and men]. Ugeskr Laeger. 2007; 169:3865-3868.

35. Donnelly KL, Smith Cl, Schwarzenberg SJ, Jessurun J, Boldt MD, Parks EJ. Sources of fatty acids stored in liver and secreted via lipoproteins in patients with nonalcoholic fatty liver disease. J Clin Invest. 2005; 115:1343-1351.

36. Fujimoto WY, Bergstrom RW, Boyko EJ, Chen KW, Leonetti DL, Newell-Morris L, Shofer JB, Wahl PW. Visceral adiposity and incident coronary heart disease in Japanese-American men. The 10-year followup results of the Seattle Japanese-American Community Diabetes Study. Diabetes Care. 1999; 22:1808-1812.

37. Boyko EJ, Fujimoto WY, Leonetti DL, Newell-Morris L. Visceral adiposity and risk of type 2 diabetes: a prospective study among Japanese Americans. Diabetes Care. 2000; 23:465-471.

38. Kankaanpaa M, Lehto HR, Parkka JP, Komu M, Viljanen A, Ferrannini E, Knuuti J, Nuutila P, Parkkola R, lozzo P. Myocardial triglyceride content and epicardial fat mass in human obesity: relationship to left ventricular function and serum free fatty acid levels. J Clin Endocrinol Metab. 2006; 91:4689-4695.

39. Finck BN, Han X, Courtois M, Aimond F, Nerbonne JM, Kovacs A, Gross RW, Kelly DP. A critical role for PPARalpha-mediated lipotoxicity in the pathogenesis of diabetic cardiomyopathy: modulation by dietary fat content. Proc Natl Acad Sci U S A. 2003; 100:1226-1231.

40. Haemmerle G, Lass A, Zimmermann R, Gorkiewicz G, Meyer C, Rozman J, Heldmaier G, Maier R, Theussl C, Eder S, Kratky D, Wagner EF, Klingenspor M, Hoefler G, Zechner R. Defective lipolysis and altered energy metabolism in mice lacking adipose triglyceride lipase. Science. 2006; 312:734-737.

41. Chiu HC, Kovacs A, Ford DA, Hsu FF, Garcia R, Herrero P, Saffitz JE, Schaffer JE. A novel mouse model of lipotoxic cardiomyopathy. J Clin Invest. 2001; 107:813-822.

42. Axelsen LN, Lademann JB, Petersen JS, Holstein-Rathlou NH, Ploug T, Prats C, Pedersen HD, Kjolbye AL. Cardiac and metabolic changes in long-term high fructose-fat fed rats with severe obesity and extensive intramyocardial lipid accumulation. Am J Physiol Regul Integr Comp Physiol. 2010; 298:R1560-1570.

43. Bilet L, van de Weijer T, Hesselink MK, Glatz JF, Lamb HJ, Wildberger J, Kooi ME, Schrauwen P, Schrauwen-Hinderling VB. Exercise-induced modulation of cardiac lipid content in healthy lean young men. Basic Res Cardiol. 2011; 106:307-315.

44. Schrauwen-Hinderling VB, Meex RC, Hesselink MK, van de Weijer T, Leiner T, Schar M, Lamb HJ, Wildberger JE, Glatz JF, Schrauwen P, Kooi ME. Cardiac lipid content is unresponsive to a physical activity training intervention in type 2 diabetic patients, despite improved ejection fraction. Cardiovasc Diabetol. 2011; 10:47. 




\section{Chapter 6}

\section{Hepatic lipid content is unchanged after two hours of cycling exercise in middle-aged overweight men}

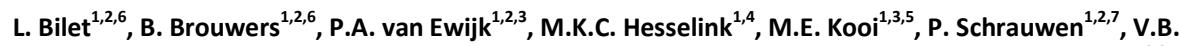
Schrauwen-Hinderling ${ }^{1,2,3,7}$

${ }^{1}$ NUTRIM, School of Nutrition, Toxicology and Metabolism, Departments of ${ }^{2}$ Human Biology, ${ }^{3}$ Radiology, ${ }^{4}$ Human Movement Sciences, ${ }^{5}$ CARIM, Cardiovascular Research Institute Maastricht, MUMC, Maastricht, The Netherlands, ${ }^{6,7}$ These authors contributed equally to this work 


\section{ABSTRACT}

Background \& Aims: Elevated hepatic lipid content (IntraHepatic Lipid, IHL) markedly increases the risk of metabolic complications, including insulin resistance and cardiovascular events. Although prolonged exercise training has been shown to lower IHL, it is unknown if acute exercise has the same effect. Next to IHL, hepatic ATP content may be related to insulin resistance and IHL. Therefore, we aimed to investigate if acute exercise leads to changes in IHL and if these changes are accompanied by changes in hepatic ATP content.

Methods: Twenty-one overweight middle-aged men with a wide range of IHL (age $54.8 \pm 7.2$ years, BMI $29.7 \pm 2.2 \mathrm{~kg} / \mathrm{m}^{2}$ ) performed a $2 \mathrm{~h}$ cycling protocol, once while staying fasted and once while ingesting glucose. IHL was measured by proton magnetic resonance spectroscopy $\left({ }^{1} \mathrm{H}-\mathrm{MRS}\right)$ at baseline, directly after exercise and again $4 \mathrm{~h}$ post-exercise. Additionally hepatic ATP content was measured by ${ }^{31} \mathrm{P}$ MRS at baseline and $4 \mathrm{~h}$ post-exercise.

Results: IHL was unchanged directly post-exercise in both the fasted and the glucose-supplemented condition. However, in the fasted condition IHL was elevated $4 \mathrm{~h}$ post-exercise compared with baseline (from $8.3 \pm 1.8$ to $8.7 \pm 1.8 \%, p=0.010$ ), while it did not change when glucose was supplemented (from8.3 \pm 1.9 to $8.3 \pm 1.9 \%, \mathrm{p}=0.789$ ).

Conclusions: Acute exercise when performed in the fasted state increased rather than decreased IHL in overweight middle-aged men. These data suggest that plasma FA concentrations play an important role in determining $\mathrm{IHL}$, and that a single bout of exercise may not be able to lower IHL, not even in a population with elevated IHL. 


\section{INTRODUCTION}

Worldwide, the number of individuals suffering from type 2 diabetes mellitus is rising steadily (1). As a consequence, a dramatic increase in diabetes-related morbidity and mortality can be expected over the next few decades. Accordingly, a concerted effort aimed at reducing diabetes rates and towards effective diabetes management is needed.

One of the earliest hallmarks of type 2 diabetes is resistance of the peripheral tissues liver and muscle to the action of insulin. Development of insulin resistance is strongly promoted by obesity. In fact, obesity is the major risk factor for insulin resistance, and $80 \%$ of all type 2 diabetic patients are overweight or obese. Specifically, the accumulation of fat within peripheral tissues (called steatosis or ectopic fat accumulation) is strongly associated with the development of insulin resistance. Indeed, type 2 diabetic patients and their first-degree relatives are characterized by excessive accumulation of fat in skeletal muscle (2). Similarly, a fatty liver is very common in patients with type 2 diabetes and obesity (3-6). Nonalcoholic fatty liver disease (NAFLD) increases the risk on metabolic complications, including insulin resistance and cardiovascular events (7).

Regular exercise has beneficial effects on metabolic risk factors associated with type 2 diabetes $(8,9)$. Recent studies have suggested that prolonged exercise training reduces liver fat content and may thereby contribute to the beneficial effects of exercise on metabolic risk (10-13). Results from exercise training studies in animals revealed that the effect of exercise on hepatic lipid content (IntraHepatic Lipid, IHL) strongly depends on the diet and that exercise is more effective in reducing IHL under conditions that favor liver fat accretion, such as when animals are fed a high-fat diet (14). Interestingly, human data also revealed that exercise training appears to be more potent in reducing $\mathrm{IHL}$ in subjects with increased baseline IHL. Thus, the exercise-mediated reduction in IHL is more pronounced in subjects with NAFLD, type 2 diabetes, or in elderly (15), than in healthy normal weight and young subjects. Furthermore, like with exercise training, acute bouts of exercise also appear to improve insulin sensitivity (16-18). The acute effects of exercise on IHL, however, have not yet been intensively studied. As yet, only one study has examined the effect of acute exercise on IHL. This study was performed in young trained males in which liver fat is usually rather low (19), which would complicate detecting exercise-mediated reductions in IHL. To circumvent this, the subjects consumed a high-fat diet or a mixed diet for $67 \mathrm{~h}$ before exercise. Thereafter their IHL was measured (with ${ }^{1} \mathrm{H}-\mathrm{MRS}$ ) before and after 90 minutes of moderate intensity cycling. It was found that IHL was unchanged directly after exercise, irrespective of the dietary condition. Hence it was concluded that acute exercise does not lower liver fat in young healthy men. A clinically more relevant question, however, would be if acute exercise lowers 
liver fat in a middle-aged overweight subject population who are prone to the development of fatty liver or may already have elevated IHL (NAFLD), but such information is presently lacking.

A potentially biasing complication when measuring $\mathrm{IHL}$ post-exercise is the increase in plasma FA that goes along with exercise in the fasted state (originating from exercise-mediated increase in adipose tissue lipolysis) $(20,21)$. Plasma FA is an important source for hepatic triglyceride (22) and therefore high levels of plasma FA during or post-exercise might mask a potential exercise-lowering effect. To circumvent this bias, we here investigated the effect of acute exercise on IHL in middle-aged overweight sedentary subjects with a wide range of liver fat content under conditions with high and low plasma FA concentrations.

Next to IHL, hepatic ATP concentrations, a measure for liver energy status, have also been suggested to be related to insulin resistance and hepatic lipid accumulation (23). Therefore, we also studied if changes in IHL are accompanied by changes in hepatic ATP concentration. To this end, we employed ${ }^{1} \mathrm{H}-\mathrm{MRS}$ to determine $\mathrm{IHL}$ before and after exercise performed with and without glucose ingestion to suppress FFA levels, as well as $4 \mathrm{~h}$ post exercise. ${ }^{31} \mathrm{P}$-MRS was employed before exercise and $4 \mathrm{~h}$ post exercise to determine hepatic ATP concentrations. 


\section{Subjects}

Twenty-one middle-aged overweight men with a wide range of liver fat content participated in this study. None of the subjects participated in competitive sports and subjects with unstable body weight (> $3 \mathrm{~kg}$ change in preceding six months) were excluded from the study. The study protocol conforms to the ethical guidelines of the 1975 Declaration of Helsinki as reflected in a priori approval by the institution's human research committee and written informed consent was obtained from all participants.

\section{Study protocol}

Before the start of the study, body composition and maximal aerobic capacity were determined in all subjects. The experimental trial comprised two separate test days separated by at least one week and performed in random order. Subjects refrained from physical activity two days prior to the test days. Furthermore, subjects were instructed to consume a standardized meal the evening prior to the test days and stayed fasted from $10 \mathrm{pm}$ onwards. On the test days, subjects reported to the laboratory at 7:00 am after an overnight fast. IHL was investigated by proton magnetic resonance spectroscopy $\left({ }^{1} \mathrm{H}-\mathrm{MRS}\right)$. After this, a teflon canula was inserted into an antecubital forearm vein for sampling of blood and subjects rested for 30 minutes. Immediately after drawing the first blood sample, subjects ingested either $1.4 \mathrm{~g} / \mathrm{kg}$ body weight of glucose (dissolved in water to a $20 \%$ solution and flavoured with $1 \mathrm{ml}$ lemon juice) or the same amount of water. After this, subjects started exercising on a stationary bike at 50 $\%$ of their pre-determined maximal power output ( $\mathrm{Wmax}$ ) ( $\mathrm{t}=0$ minute) for two hours. During exercise, blood samples were drawn and substrate oxidation was measured by indirect calorimetry (Omnical, Maastricht, The Netherlands) every 30 minutes (at $\mathrm{t}=30,60,90$ and 120 minutes) while heart rate was constantly measured. Immediately after cessation of exercise, a second ${ }^{1} \mathrm{H}-\mathrm{MRS}$ measurement was performed. Subsequently, subjects bed-rested for three hours, followed by a third ${ }^{1} \mathrm{H}$-MRS scan four hours post exercise. Additionally, in a subgroup of eight subjects, ATP content was measured by phosphorous magnetic resonance spectroscopy $\left({ }^{31} \mathrm{P}-\mathrm{MRS}\right)$ at baseline as well as four hours post exercise. During the 4-hour post exercise period, blood samples were drawn and substrate oxidation was measured for 15 minutes every hour (at $t=180,240,300$ and 360 minutes) in all subjects. The experimental design is depicted in Figure 1. 


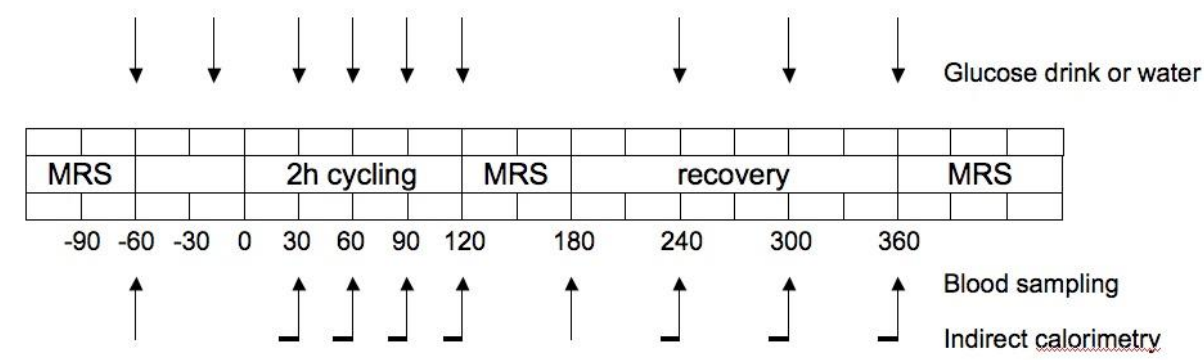

Figure 1. The experimental design of the study. All subjects performed the protocol twice, one time in the fasted state consuming water and one time with glucose supplementation. MRS: hepatic magnetic resonance spectroscopy.

\section{Measurements prior to test days}

A routine incremental cycling test on a stationary bike was used to determine maximal exercise capacity as described previously (24) and a hydrostatic weighing with simultaneous measurement of lung volume was used to determine body composition. The equation of Siri (25) was used to calculate fat percentage, fat mass and fat-free mass.

Blood sample analysis

Blood samples were collected in EDTA-containing tubes and immediately spun at high speed and frozen in liquid nitrogen and subsequently stored at $-80^{\circ} \mathrm{C}$ until assayed. Plasma free fatty acids, triglycerides, and glucose were measured with enzymatic assays automated on a Cobas Fara/Mira (FA: Wako Nefa C test kit; Wako Chemicals, Neuss, Germany) (glucose: hexokinase method; Roche, Basel, Switzerland) (triglycerides: $A B X$ Pentra $C P$ reagens, Horiba $A B X$ Diagnostics, Montpellier, France) (glycerol: Enzytec ${ }^{T M}$ glycerol kit, R-Biopharm, Germany). The liver enzymes Gamma-GT, ASAT and ALAT were routinely measured during the screening visit and analysed in the clinical chemistry department in the hospital.

\section{${ }^{1} H-M R S$}

IHL was determined in vivo by ${ }^{1} \mathrm{H}-\mathrm{MRS}$ as reported previously (26). An $18 \mathrm{~cm}^{3}$ Volume of Interest (VOI) was placed within the lower right hepatic lobe (point resolved spectroscopy (PRESS), repetition time $(T R)=4 \mathrm{~s}$, Echo time $(T E)=23 \mathrm{~ms}$, bandwidth $(\mathrm{BW})=1000 \mathrm{~Hz}, \mathrm{n}=1024$ points, number of signal averages $(\mathrm{NSA})=$ 64). To minimize motion artifacts, subjects were asked to breathe in the rhythm of the measurement and to be at end-expiration during acquisition of spectra. Water 
signal was suppressed using frequency-selective prepulses. Spectra without water suppression were acquired with identical settings (NSA=16) and all spectra were fitted with AMARES (27) in the jMRUI software (28). The $\mathrm{T}_{2}$-corrected ratios of the $\mathrm{CH}_{2}$ peak, relative to the unsuppressed $\mathrm{T}_{2}$-corrected water resonance was calculated and converted to a tissue fat percentage (weight/weight) by assuming a water content of $71.1 \%$, a $\mathrm{CH}_{2}$-proton density of triglycerides of $60.2 \mathrm{~mol}^{-1}$, a proton density of water of $2 \mathrm{~mol}^{-1}$, a molecular weight of triglycerides and water of $860 \mathrm{~g} / \mathrm{mol}$ and $18 \mathrm{~g} / \mathrm{mol}$, respectively. Three subjects had to be excluded from the IHL analysis due to poor quality of spectra.

\section{${ }^{31} P-M R S$}

In a subgroup of eight subjects ATP content was determined at baseline and four hours post exercise in both the fasted and the glucose-supplemented condition. Measurements were performed on a whole body scanner (1.5T, Intera, Philips Healthcare, Best, The Netherlands). Subjects were positioned in supine position with a 10-cm diameter transmit/receive surface coil positioned at the level of the liver. MRI scout images were acquired during a breath hold and one-dimensional spectroscopic imaging $(\mathrm{SI})$ was performed with 8 phase-encoding steps and SI slice thickness of $30 \mathrm{~mm}$ ( $T R=4 \mathrm{~s}, \mathrm{n}=512$ points, $B W=4000 \mathrm{~Hz}, \mathrm{NSA}=16)$. At least one slice was planned to be exclusively in liver tissue. To minimize motion artifacts, subjects were asked to breathe in the rhythm of the measurement and to be at end-expiration during acquisition of spectra. All spectra were fitted with the AMARES algorithm (27) in the jMRUI software package (28). The ?-ATP resonance was quantified and expressed as ratio of the ?-ATP to total phosphorus signal in the -25 to $25 \mathrm{ppm}$ frequency region.

\section{Statistics}

Data are presented as mean \pm SE. Hepatic lipid content was not normally distributed and therefore a non-parametric Friedman test was performed to test if there was an overall effect on IHL. Thereafter a pairwise comparison was performed with a Bonferroni correction for multiple comparisons. A two-way repeated measures ANOVA was performed to compare the mean differences between conditions for ATP, substrate oxidation and plasma values of FA, triglycerides, and glucose. All statistics were performed using SPSS 16.0 for Mac and $\mathrm{P}<0.05$ was considered statistically significant. 
RESULTS

\section{Basic characteristics}

Twenty-one middle-aged overweight men participated in this study. The subject characteristics of the entire group are shown in Table 1 . The subjects had a wide variety of liver fat content (see figure $3 a$ for basal liver fat content per subject). Of these subjects, eleven subjects met the clinical criteria for NAFLD (>5.6\% liver fat) (29), while in ten subjects hepatic fat content was within the normal physiological range $(<5.6 \%$ liver fat). There were no differences in body weight, BMI, whole body fat percentage and fasting plasma glucose levels between subjects that would qualify as NAFLD and subjects with a normal liver fat content, but the NAFLD subjects were somewhat younger than the subjects with normal liver fat content ( $51.7 \pm 5.4$ years vs $58.2 \pm 7.7$ years) and had a lower diastolic blood pressure. As expected, clinical parameters that associate with fatty liver, such as plasma levels of TG and the liver enzymes gamma-GT, ASAT and ALAT were all significantly higher in subjects with a high (>5.6\%) liver fat content compared to the subjects with normal liver fat content. However, despite these clinical differences, liver fat content responded similarly in subjects with low and high liver fat content and hence all subjects are treated as one group in the data presented below. 
Table 1. Subject characteristics.

\begin{tabular}{|l|l|l|l|}
\hline Mean \pm SD & Liver fat $<5.6 \%$ & Liver fat $>5.6 \%$ & $\begin{array}{l}\text { All subjects } \\
\text { (pooled) }\end{array}$ \\
\hline Age, $\mathrm{yr}$ & $58.2 \pm 7.7$ & $51.7 \pm 5.4^{*}$ & $54.8 \pm 7.2$ \\
\hline Height, $\mathrm{m}$ & $1.79 \pm 0.05$ & $1.79 \pm 0.03$ & $1.79 \pm 0.04$ \\
\hline Weight, $\mathrm{kg}$ & $92.6 \pm 9.1$ & $97.5 \pm 8.6$ & $95.2 \pm 9.0$ \\
\hline $\mathrm{BMI}, \mathrm{kg} / \mathrm{m}^{2}$ & $28.7 \pm 1.8$ & $30.4 \pm 2.3$ & $29.6 \pm 2.2$ \\
\hline Fat \% & $27.5 \pm 6.2$ & $28.5 \pm 3.1$ & $27.9 \pm 4.9$ \\
\hline $\mathrm{VO}_{2 \mathrm{max}} / \mathrm{kg}, \mathrm{ml} \times \mathrm{min}^{-1} \times \mathrm{kg}^{-1}$ & $30.3 \pm 5.7$ & $29.1 \pm 6.1$ & $29.7 \pm 5.8$ \\
\hline $\mathrm{SBP}(\mathrm{mmHg})$ & $135.7 \pm 16.5$ & $144.7 \pm 12.6$ & $140.4 \pm 15.0$ \\
\hline DBP $(\mathrm{mmHg})$ & $83.3 \pm 12.0$ & $95.1 \pm 6.7^{*}$ & $89.5 \pm 11.1$ \\
\hline Glucose (mmol/L) & $5.3 \pm 0.8$ & $5.6 \pm 0.4$ & $5.4 \pm 0.6$ \\
\hline Gamma-GT (U/L) & $27.6 \pm 9.4$ & $55.5 \pm 26.2^{*}$ & $42.2 \pm 24.2$ \\
\hline ASAT (U/L) & $18.0 \pm 4.5$ & $25.9 \pm 6.6^{*}$ & $22.1 \pm 6.9$ \\
\hline ALAT (U/L) & $25.4 \pm 8.8$ & $44.6 \pm 11.0^{*}$ & $35.5 \pm 13.9$ \\
\hline Triglycerides (mmol/L) & $1.1 \pm 0.3$ & $2.0 \pm 0.5^{*}$ & $1.5 \pm 0.6$ \\
\hline Liver fat (\%) & $2.7 \pm 1.5$ & $13.1 \pm 6.7^{*}$ & $8.1 \pm 7.2$ \\
\hline
\end{tabular}

Data are means \pm SD. BMI, Body Mass Index; SBP, Systolic Blood Pressure; DBP, Diastolic Blood Pressure. ${ }^{*} \mathrm{P}<$ 0.05 compared with subjects having less than $5.6 \%$ liver fat. 


\section{Energy expenditure and substrate oxidation}

No significant differences in energy expenditure between the glucose-fed and the fasted state were found at baseline, during exercise or post exercise (see table 2). During exercise, there was a significant time $(p<0.001)$ and treatment $(p<0.001)$ effect, without a time*treatment interaction $(p<0.132)$ effect for respiratory quotient (RQ). RQ was significantly higher at all time points, except for at baseline, in the glucose-fed state compared with the fasted state $(p<0.01)$ (see figure $2 a$ ), reflecting a higher carbohydrate oxidation in the glucose-fed state compared with the fasted state $(p<0.01)$ and a higher fat oxidation in the fasted state compared with the glucose-fed state (see table 2 for whole body glucose- and fat oxidation). $R Q$ dropped between $t=30$ and $t=120 \mathrm{~min}(p<0.001)$ in both conditions. In the post-exercise period, a significant treatment effect $(p<0.001)$ was observed, with $\mathrm{RQ}$ remaining significantly higher in the glucose-fed state compared with the fasted state at all time points $(p<0.001)$. Data presented above is acquired from 17 subjects, data from four subjects had to be excluded from the analysis due to missing or poor quality of data.

Table 2. Energy expenditure and fat and carbohydrate oxidation during and after exercise in glucosesupplemented and fasted state.

\begin{tabular}{|c|c|c|c|c|}
\hline & \multicolumn{3}{|l|}{ Glucose } \\
\hline Treatment & Time, $\min$ & $E E, \mathrm{~kJ} / \mathrm{min}$ & $\begin{array}{l}\text { Fat oxidation, } \\
\mathrm{mg} / \mathrm{min}\end{array}$ & $\begin{array}{l}\mathrm{CHO} \text { oxidation, } \\
\mathrm{mg} / \mathrm{min}\end{array}$ \\
\hline \multirow[t]{4}{*}{ Exercise } & 30 & $36 \pm 4$ & $342 \pm 108 \#$ & $1442 \pm 273 \#$ \\
\hline & 60 & $37 \pm 4$ & $512 \pm 133 \#$ & $1077 \pm 362 \#$ \\
\hline & 90 & $36 \pm 5$ & $534 \pm 114 \#$ & $942 \pm 326 \#$ \\
\hline & 120 & $35 \pm 4$ & $548 \pm 135 \#$ & $891 \pm 329 \#$ \\
\hline \multirow[t]{5}{*}{ Post exercise } & 240 & $5 \pm 1$ & $54 \pm 43 \#$ & $231 \pm 107 \#$ \\
\hline & 300 & $5 \pm 1$ & $45 \pm 20 \#$ & $238 \pm 54 \#$ \\
\hline & 360 & $5 \pm 1$ & $45 \pm 18 \#$ & $240 \pm 45 \#$ \\
\hline & & \multicolumn{3}{|l|}{ Fasted } \\
\hline & & $E E, \mathrm{~kJ} / \mathrm{min}$ & $\begin{array}{l}\text { Fat oxidation, } \\
\mathrm{mg} / \mathrm{min}\end{array}$ & $\begin{array}{l}\mathrm{CHO} \text { oxidation, } \\
\mathrm{mg} / \mathrm{min}\end{array}$ \\
\hline \multirow[t]{4}{*}{ Exercise } & 30 & $36 \pm 5$ & $457 \pm 139$ & $1125 \pm 337$ \\
\hline & 60 & $37 \pm 5$ & $592 \pm 162$ & $854 \pm 396$ \\
\hline & 90 & $36 \pm 5$ & $646 \pm 174$ & $666 \pm 424$ \\
\hline & 120 & $36 \pm 6$ & $672 \pm 164$ & $600 \pm 438$ \\
\hline \multirow[t]{3}{*}{ Post exercise } & 240 & $6 \pm 1$ & $107 \pm 21$ & $79 \pm 45$ \\
\hline & 300 & $5 \pm 1$ & $108 \pm 22$ & $72 \pm 45$ \\
\hline & 360 & $6 \pm 1$ & $114 \pm 21$ & $70 \pm 45$ \\
\hline
\end{tabular}

Data are means $\pm \mathrm{SEM}, \mathrm{n}=17$. $\mathrm{EE}$, energy expenditure; $\mathrm{CHO}$, carbohydrate. \# $\mathrm{P}<0.01$ compared with fasted treatment. 


\section{Plasma concentrations}

There was a significant time $(p<0.0001)$, treatment $(p<0.0001)$ and time*treatment interaction $(p<0.0001)$ effect for plasma FA concentrations. Plasma FA concentrations were substantially higher at the end of 2 hours of exercise and 4 hours post-exercise in the fasted state $(p<0.0001)$ compared with the glucose-fed state (Fig 2b). Moreover, plasma FA concentrations increased with time during exercise and recovery from exercise in the fasted state, with a significant higher plasma FA concentration at the end of exercise $(t=120)$ and 4 hours post-exercise $(t=360)$ compared with before exercise $(t=-60)(p<0.0001)$, whereas plasma FA concentrations decreased over time in the glucose-fed state $(\mathrm{p}=0.002)$.

Plasma glucose concentrations showed a significant time $(p<0.0001)$, treatment $(p<0.0001)$ and time*treatment interaction $(p<0.0001)$ effect. Thus, plasma glucose concentrations were higher at the end of 2 hours of exercise and 4 hours post-exercise in the glucose-supplemented state $(p<0.0001)$ compared with the fasted state (Fig 2c). Moreover, plasma glucose concentrations increased with time during exercise and recovery from exercise in the glucose-supplemented state, with a significant higher plasma glucose concentration at the end of exercise $(t=120)$ and 4 hours post-exercise $(t=360)$ compared with before exercise $(t=-60)(p=0.0001)$, whereas plasma glucose concentrations decreased over time in the fasted state $(p=0.0001)$.

Plasma triglyceride concentrations showed a significant time $(p<0.0001)$ and time*treatment interaction $(p<0.0001$ ) effect in the fasted condition (Fig $2 d)$. Plasma triglyceride concentrations decreased with time from baseline $(t=-60)$ to post-recovery $(t=360)$ in the fasted state, whereas it did not change when glucose supplementation was given. 
124 Chapter 6

Figure 2

a)

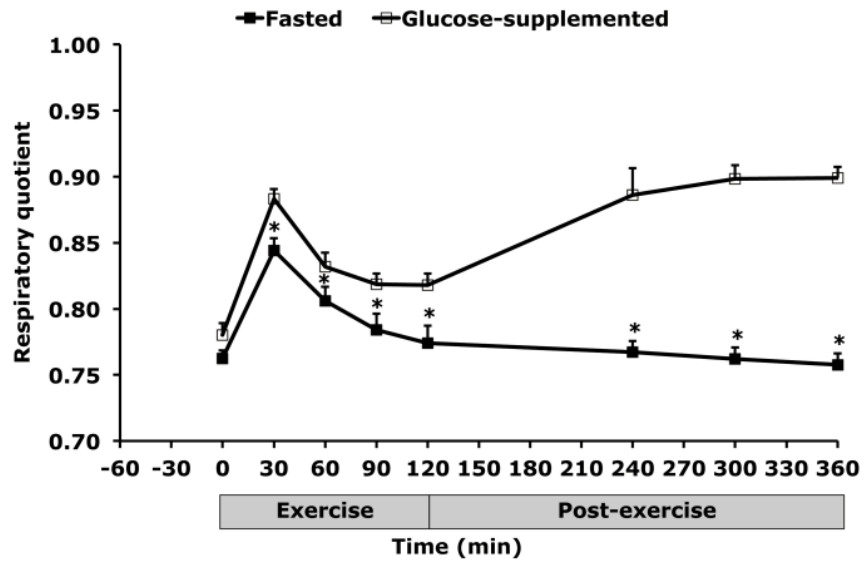

b)

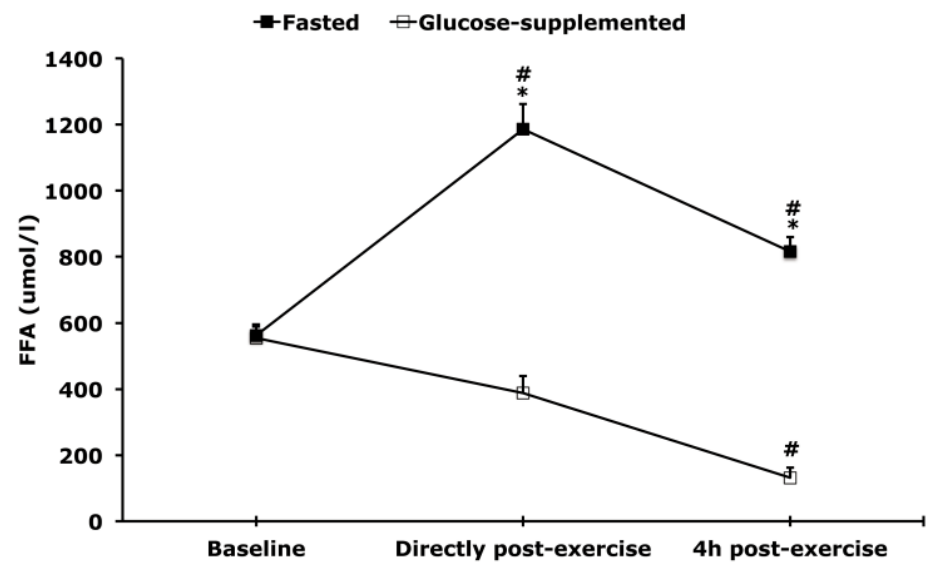


c)

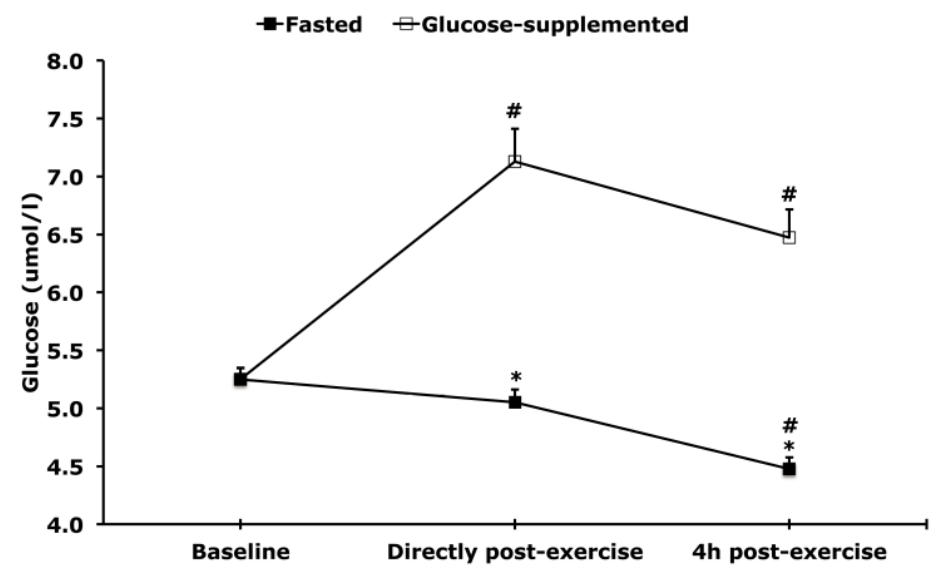

d)

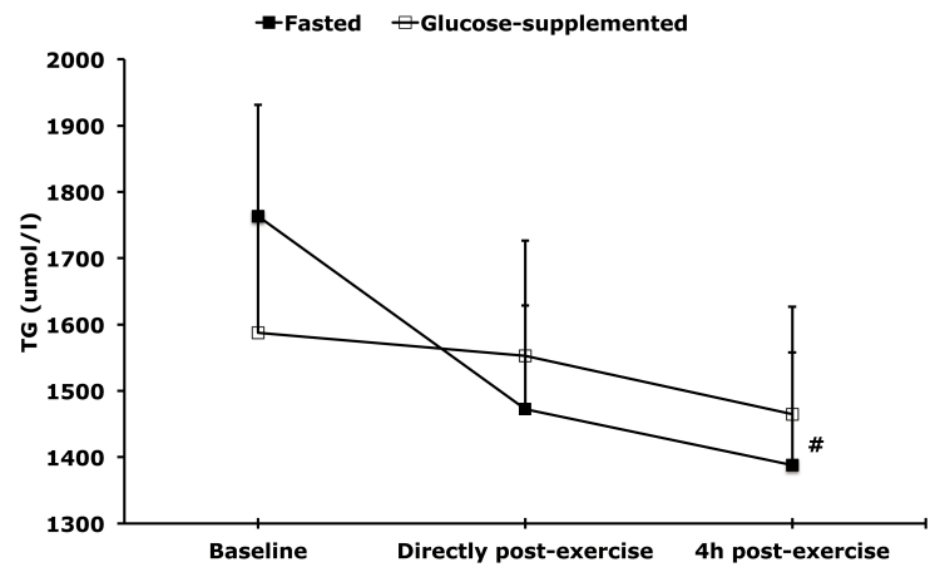

Figure 2. (A) Respiratory quotient during and after $2 \mathrm{~h}$ of cycling at $50 \%$ of maximal power output (Wmax) ( $\mathrm{n}=17)$ and plasma concentrations of (B) fatty acids (FA), (C) glucose, (D) and triglycerides (TG), with (open square) and without (filled square) glucose supplementation. ${ }^{*} \mathrm{P}<0.05$ compared with glucose-supplemented condition. \# $\mathrm{P}$ $<0.05$ compared with baseline $(t=-60)$. Data are mean $\pm \mathrm{SE}$. 
Hepatic lipid content

A typical hepatic ${ }^{1} \mathrm{H}-\mathrm{MR}$ spectrum is shown in Figure $3 \mathrm{~b}$. In the fasted condition at baseline, the IHL resonance was $8.3 \pm 1.8 \%$ of the water resonance and increased to $8.7 \pm 1.8 \%$ of the water resonance 4 h post-exercise, $(p=0.010)$, whereas in the glucose-supplemented condition the $\mathrm{IHL}$ resonance remained unchanged at $8.3 \pm$ $1.9 \%$ of the water resonance, ( $p=0.789$ ) (Fig $3 c$ ).

$\mathrm{IHL}$ did not change directly with exercise in either condition (IHL resonance was $8.3 \pm 1.9 \%$ of the water resonance in the fasted condition and $8.4 \pm 1.8 \%$ in the glucose-supplemented condition, $p>0.05$ ). When looking at subjects with low and high liver fat content separately we see the same effect as when pooling the data, with $\mathrm{IHL}$ being increased $4 \mathrm{~h}$ post-exercise in the fasted condition compared with baseline, $p=0.011$ for subjects with liver fat $<5.6 \%$ and $p=0.051$ for subjects with liver fat $>5.6 \%$. Furthermore, the increase in IHL $4 \mathrm{~h}$ post-exercise was similar for both groups $(p=0.630)$ (see delta increase in figure $3 d)$.

\section{Figure 3}

a)

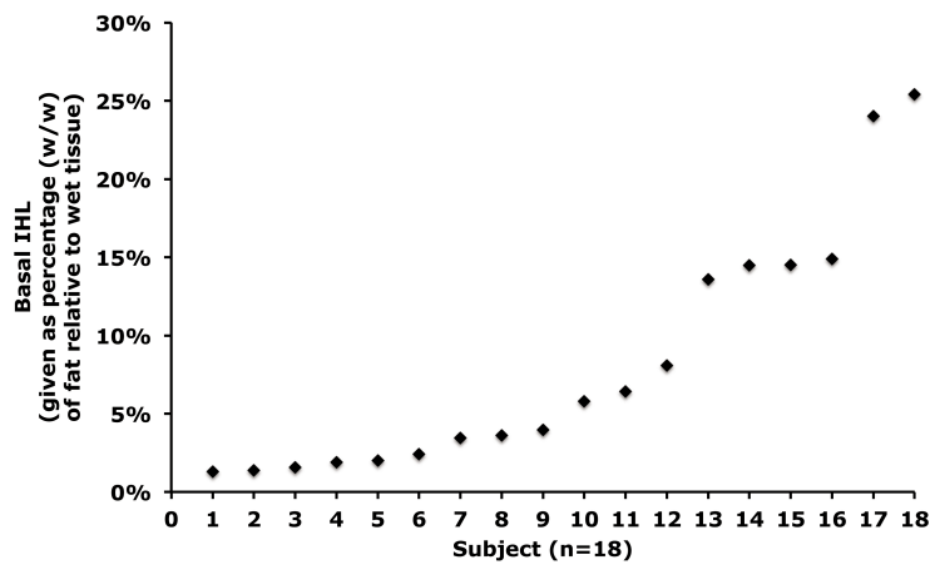


b)

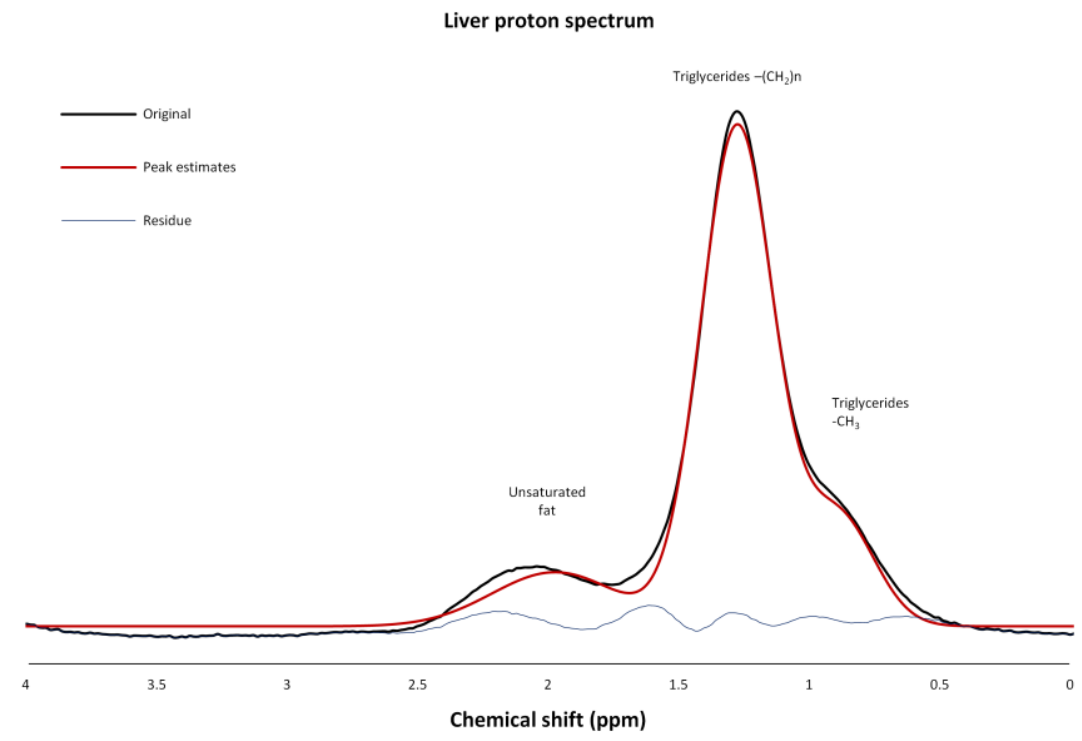

c)

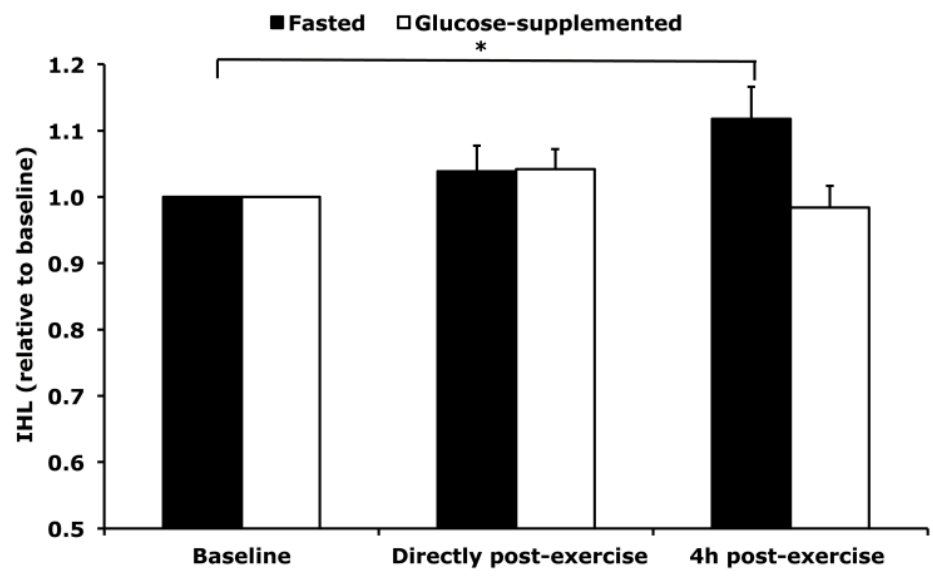


d)

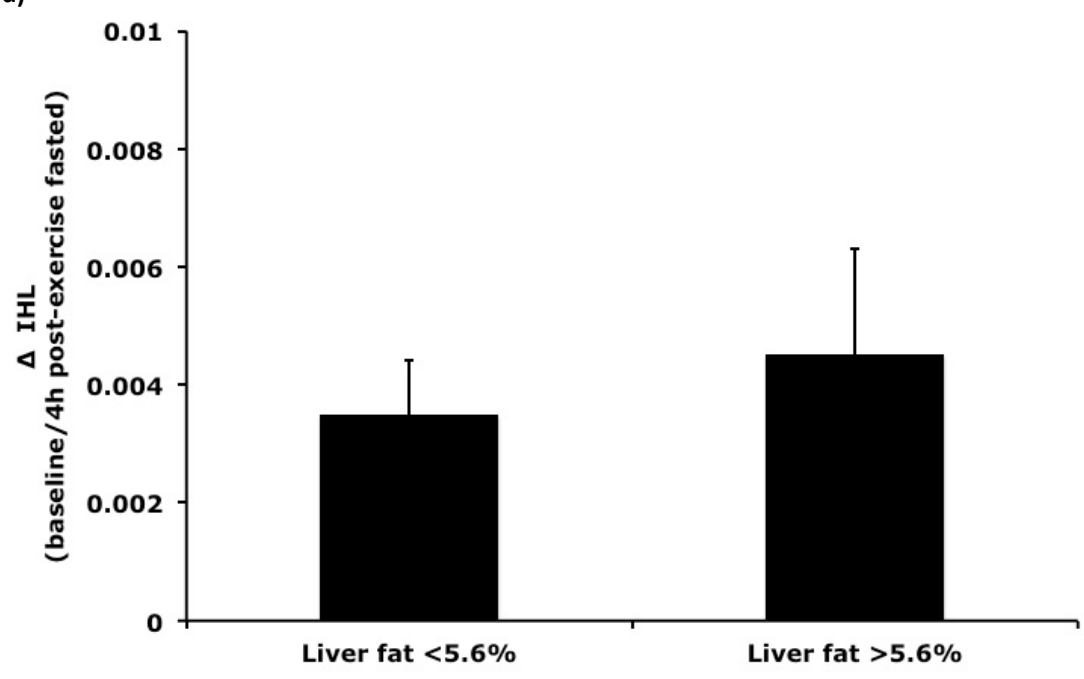

Figure 3. (A) Hepatic lipid content at baseline for each individual subject given as percentage $(w / w)$ of fat relative to wet tissue, $n=21$. (B) Typical ${ }^{1} \mathrm{H}-\mathrm{MR}$ spectrum obtained in the fasted condition at baseline. The peak estimates as well as the residue are shown in the spectrum, as indicated. (C) Hepatic lipid content directly post-exercise and $4 \mathrm{~h}$ post-exercise, (because the subjects had a wide variety of liver fat content data was normalized to baseline values), $n=18$, and (D) delta $(\Delta) \mathrm{IHL}$ between baseline and $4 \mathrm{~h}$ post-exercise in the fasted condition in subjects with low $(<5.6 \%)$ and high $(>5.6 \%)$ liver fat content $* P<0.05$. Data are mean $\pm S E$.

Hepatic ATP content

A typical hepatic ${ }^{31}$ P-MR spectrum is shown in Figure 4a. There was a trend for a decrease in hepatic ATP content four hours post exercise compared with baseline $(p=0.086)$ in the fasted state (Fig $4 b)$. In six out of eight subjects hepatic ATP content decreased with $16.9 \pm 3.3 \%$ four hours post-exercise, whereas it did not change when glucose supplementation was given $(p=0.582)$ (See individual data in figure $4 \mathrm{c}$ and d). No correlation was found between IHL and hepatic ATP content in this subgroup of eight subjects. 
Figure 4

a)

Liver phosphorus spectrum

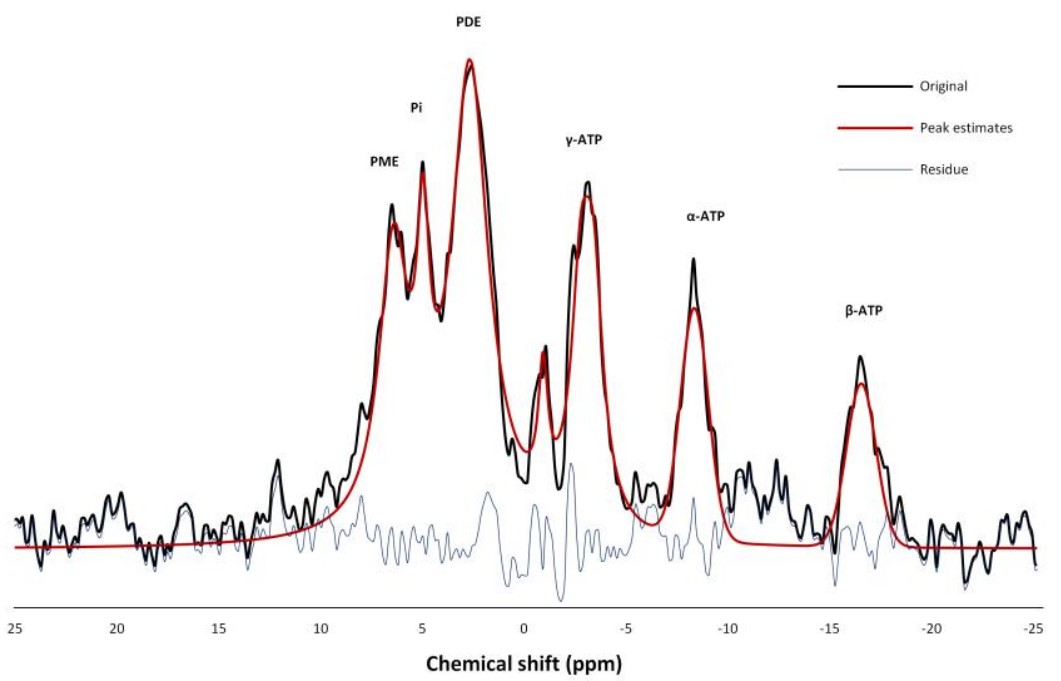

b)

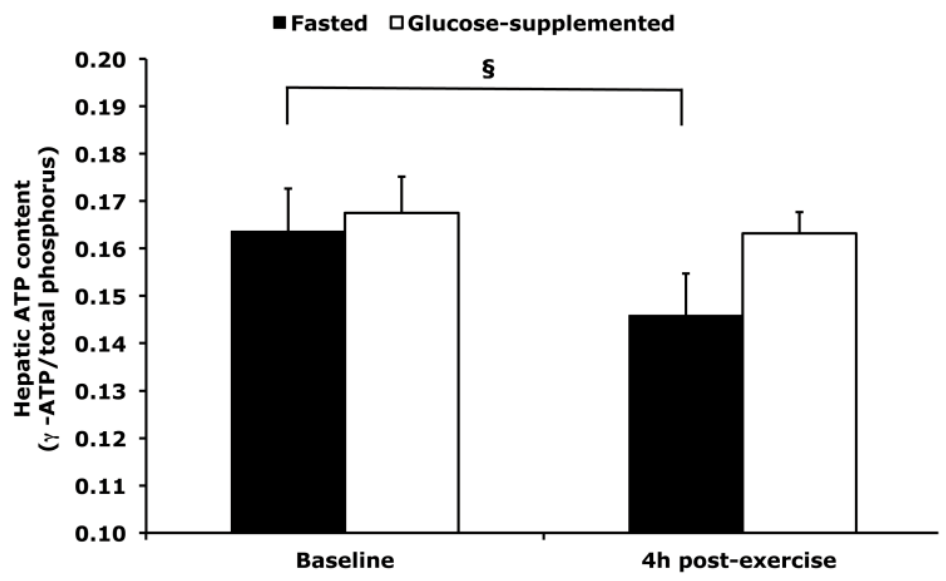


c)

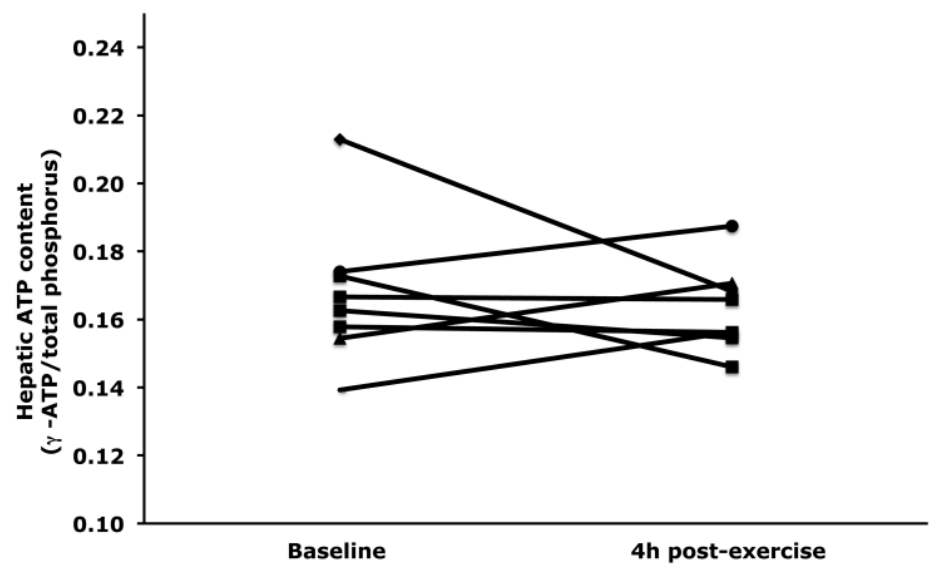

d)

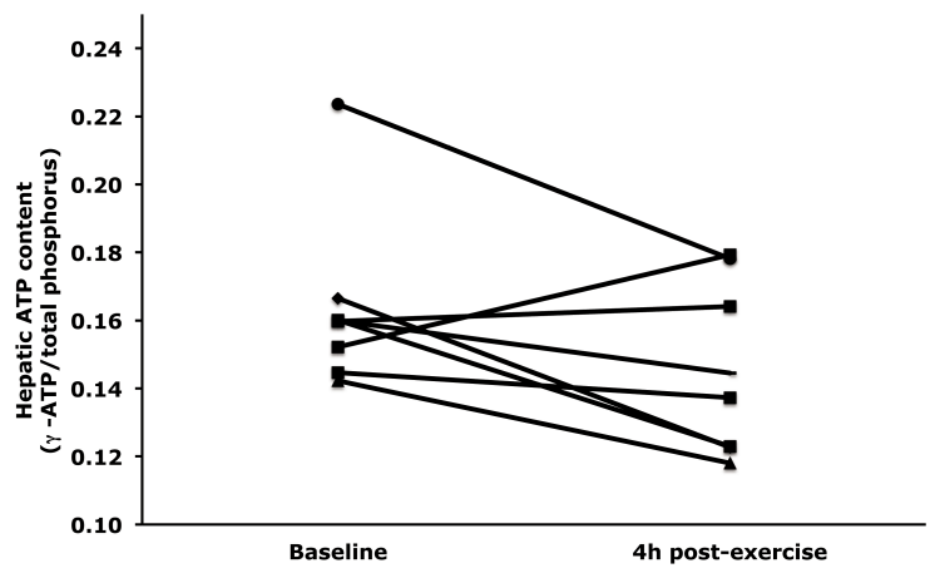

Figure 4. (A) Typical ${ }^{31} \mathrm{P}$ MR-spectrum obtained in the fasted condition at baseline. The peak estimates as well as the residue are shown in the spectrum, as indicated. Hepatic ATP content at baseline and $4 \mathrm{~h}$ post-exercise as (B) group average and individual data with (C) and without (D) glucose supplementation. Hepatic ATP concentrations are expressed as the relative amount of total phosphorous in the liver. $\S \mathrm{P}<0.10$ compared with baseline $(\mathrm{t}=-60)$. 


\section{Discussion}

Recent evidence suggests that prolonged exercise training might have a lowering effect on IHL (10-13). Here, we examined the effect of an acute bout of exercise on the IHL in middle-aged overweight men with a wide range of liver fat content. The data show that an acute bout of exercise does not result in a decrease in IHL in this population. Instead, the IHL increased rather than decreased upon exercise when exercise was performed in the fasting state. In the fasted state, circulatory FA levels are profoundly increased during and after exercise (in contrast to the glucose fed condition). The increase in plasma FA levels in the fasted state may deliver fatty acids to the liver with increased IHL as a consequence. The results of the present study indicate that in spite of strongly stimulated whole body fat oxidation during exercise, an acute bout of exercise is not enough to decrease IHL in this population.

There is an increasing prevalence of obesity worldwide, and obesity is associated with excessive storage of lipids (triglycerides) not only in adipose tissue, but also in non-adipose tissues, such as skeletal muscle and liver. Excessive lipid accumulation in the liver is associated with insulin resistance and type 2 diabetes. Life style interventions like exercise training revealed that hepatic fat can be lowered by prolonged exercise training, hence preventing complications associated with hepatic fat accumulation (10-13), with patients with high liver fat content showing the greatest reduction following physical activity training. Until now there are no studies investigating the acute effects of exercise on hepatic fat accumulation in an overweight middle-aged population at risk of developing fatty liver or with NAFLD already being present. We show here that an acute bout of exercise does not decrease IHL, neither in a fasted nor in a glucose-supplemented condition. To our knowledge this is the first study to show that an acute bout of exercise is not leading to lower IHL in overweight middle-aged men, and that the long term effects of physical activity training cannot simply be explained by an additive effect of acute exercise bouts. Performing exercise while staying fasted leads to a large increase in plasma FA concentrations $(20,21)$. Our results suggest that a high flux of FA into the liver may exceed the capacity of the liver to oxidize and/or export FA and therefore subsequently results in an accumulation of triglycerides in the liver. Although it is generally believed that the majority of fat that enters the liver in obese people is FA released into the portal vein from visceral adipose tissue (30), there is evidence that the peripheral plasma FFA pool is a major contributor to hepatic lipid accumulation as well $(22,31)$. Also during exercise it is shown that the increase in arterial FFA levels more than compensate for the reduction in hepatic blood flow so that splanchnic inflow of FFA and its uptake by the splanchnic bed rises compared with resting state (32). Although our results suggests that elevated plasma FFA concentrations are underlying hepatic 
lipid accumulation, it is important to note that also de novo lipogenesis, which is an insulin- and glucose-dependent process (33), is considered as an important contributing factor (34). Thus, in the current study, higher plasma glucose levels and possibly plasma insulin levels (not measured) (35) in the glucosesupplemented condition compared with the fasted condition, might also, next to the changes in plasma FFA, affect liver fat content. Interestingly, our finding that elevated plasma FA leads to hepatic lipid accumulation is to some extent in accordance with observations in skeletal muscle and heart $(21,36)$. Thus, we have previously shown that using a similar exercise protocol, acute exercise performed in the fasted (i.e. with high FFA) state results in a net accumulation of lipids in non-exercising muscle, and in the heart. Together these findings suggest that - like in muscle and heart - elevation of circulating FFA levels coincides with a - most likely temporally - increase in IHL.

In parallel to the increased IHL 4 hours post-exercise in the fasted condition, we observed a tendency to a lower hepatic ATP content in a sub group of eight subjects. It has been suggested that hepatic ATP levels are decreased in conditions such as insulin resistance and type 2 diabetes mellitus $(23,37)$, and that hepatocellular ATP is negatively correlating with liver fat in human subjects, suggesting lipotoxicity. In agreement with these data the current study reports a trend to decreased ATP levels along with increased IHL, although no correlation between hepatic lipid content and hepatic ATP levels was found. Interestingly, a recent study investigating the energy charge in the liver of mice after one single bout of exercise found a clear increase of AMP and a strong decrease of ATP in the liver (38), suggesting that the reduction in ATP levels after exercise is a direct consequence of exercise. In the current study we did not observe a decrease in ATP after exercise in the glucose-supplemented condition, which suggests that the elevation of IHL upon exercise instead of exercise per se - may be responsible for the reduced hepatic energy status of the liver. However, investigation of larger subject groups will have to determine to what extent the decrease in ATP is related to increase in $\mathrm{IHL}$.

In summary, acute exercise when performed in the fasted state increased rather than decreased IHL in overweight middle-aged men. The increase in hepatic lipid content upon exercise was absent when exercise was performed in the glucosefed state, thereby blunting the elevation of plasma FA in response to exercise. These data suggest that plasma FA concentrations play an important role in determining $\mathrm{IHL}$, and that a single bout of exercise may not be able to lower $\mathrm{IHL}$, not even in a population with elevated IHL. 


\section{References}

1. Mokdad AH, Ford ES, Bowman BA, Dietz WH, Vinicor F, Bales VS, Marks JS. Prevalence of obesity, diabetes, and obesity-related health risk factors, 2001. Jama. 2003; 289:76-79.

2. Perseghin G, Scifo P, De Cobelli F, Pagliato E, Battezzati A, Arcelloni C, Vanzulli A, Testolin G, Pozza G, Del Maschio A, Luzi L. Intramyocellular triglyceride content is a determinant of in vivo insulin resistance in humans: a $1 \mathrm{H}-13 \mathrm{C}$ nuclear magnetic resonance spectroscopy assessment in offspring of type 2 diabetic parents. Diabetes. 1999; 48:1600-1606.

3. Leevy CM. Fatty liver: a study of 270 patients with biopsy proven fatty liver and review of the literature. Medicine (Baltimore). 1962; 41:249-276.

4. Stone BG, Van Thiel DH. Diabetes mellitus and the liver. Semin Liver Dis. 1985; 5:8-28.

5. Foster KJ, Griffith AH, Dewbury K, Price CP, Wright R. Liver disease in patients with diabetes mellitus. Postgrad Med J. 1980; 56:767-772.

6. Silverman JF, Pories WJ, Caro JF. Liver pathology in diabetes mellitus and morbid obesity. Clinical, pathological, and biochemical considerations. Pathol Annu. 1989; 24 Pt 1:275-302.

7. Marchesini G, Brizi M, Bianchi G, Tomassetti S, Bugianesi E, Lenzi M, McCullough AJ, Natale S, Forlani G, Melchionda N. Nonalcoholic fatty liver disease: a feature of the metabolic syndrome. Diabetes. 2001; 50:1844-1850.

8. Dela F. Other adaptations to training/inactivity in type 2 diabetics and other groups with insulin resistance: emphasis on prevention of CHD. Applied physiology, nutrition, and metabolism = Physiologie appliquee, nutrition et metabolisme. 2007; 32:602-606.

9. Gordon BA, Benson AC, Bird SR, Fraser SF. Resistance training improves metabolic health in type 2 diabetes: a systematic review. Diabetes research and clinical practice. 2009; 83:157-175.

10. Sullivan S, Kirk EP, Mittendorfer B, Patterson BW, Klein S. Randomized trial of exercise effect on intrahepatic triglyceride content and lipid kinetics in nonalcoholic fatty liver disease. Hepatology. 2012; 55:1738-1745.

11. Hallsworth K, Fattakhova G, Hollingsworth KG, Thoma C, Moore S, Taylor R, Day CP, Trenell MI. Resistance exercise reduces liver fat and its mediators in non-alcoholic fatty liver disease independent of weight loss. Gut. 2011; 60:1278-1283.

12. Finucane FM, Sharp SJ, Purslow LR, Horton K, Horton J, Savage DB, Brage S, Besson H, De Lucia Rolfe E, Sleigh A, Martin HJ, Aihie Sayer A, Cooper C, Ekelund U, Griffin SJ, Wareham NJ. The effects of aerobic exercise on metabolic risk, insulin sensitivity and intrahepatic lipid in healthy older people from the Hertfordshire Cohort Study: a randomised controlled trial. Diabetologia. 2010; 53:624-631.

13. Chen SM, Liu CY, Li SR, Huang HT, Tsai CY, Jou HJ. Effects of therapeutic lifestyle program on ultrasound-diagnosed nonalcoholic fatty liver disease. J Chin Med Assoc. 2008; 71:551-558.

14. Magkos F. Putative factors that may modulate the effect of exercise on liver fat: insights from animal studies. Journal of nutrition and metabolism. 2012; 2012:827417.

15. Magkos F. Exercise and fat accumulation in the human liver. Current opinion in lipidology. 2010; 21:507-517.

16. Rogers MA. Acute effects of exercise on glucose tolerance in non-insulin-dependent diabetes. Medicine and science in sports and exercise. 1989; 21:362-368.

17. Frank P, Katz A, Andersson E, Sahlin K. Acute exercise reverses starvation-mediated insulin resistance in humans. American journal of physiology. 2013; 304:E436-443.

18. Mackenzie R, Maxwell N, Castle P, Elliott B, Brickley G, Watt P. Intermittent exercise with and without hypoxia improves insulin sensitivity in individuals with type 2 diabetes. The Journal of clinical endocrinology and metabolism. 2012; 97:E546-555.

19. Johnson NA, van Overbeek D, Chapman PG, Thompson MW, Sachinwalla T, George J. Effect of prolonged exercise and pre-exercise dietary manipulation on hepatic triglycerides in trained men. European journal of applied physiology. 2011; 112:1817-1825.

20. Schrauwen P, Hesselink MK, Vaartjes I, Kornips E, Saris WH, Giacobino JP, Russell A. Effect of acute exercise on uncoupling protein 3 is a fat metabolism-mediated effect. American journal of physiology. 2002; 282:E11-17.

21. Bilet L, van de Weijer T, Hesselink MK, Glatz JF, Lamb HJ, Wildberger J, Kooi ME, Schrauwen P, Schrauwen-Hinderling VB. Exercise-induced modulation of cardiac lipid content in healthy lean young men. Basic research in cardiology. 2010; 106:307-315. 
22. Donnelly KL, Smith Cl, Schwarzenberg SJ, Jessurun J, Boldt MD, Parks EJ. Sources of fatty acids stored in liver and secreted via lipoproteins in patients with nonalcoholic fatty liver disease. The Journal of clinical investigation. 2005; 115:1343-1351.

23. Szendroedi J, Chmelik M, Schmid Al, Nowotny P, Brehm A, Krssak M, Moser E, Roden M. Abnormal hepatic energy homeostasis in type 2 diabetes. Hepatology. 2009; 50:1079-1086.

24. Kuipers H, Verstappen FT, Keizer HA, Geurten P, van Kranenburg G. Variability of aerobic performance in the laboratory and its physiologic correlates. Int J Sports Med. 1985; 6:197-201.

25. Siri WE. The gross composition of the body. Adv Biol Med Phys. 1956; 4:239-280.

26. van Herpen NA, Schrauwen-Hinderling VB, Schaart G, Mensink RP, Schrauwen P. Three weeks on a high-fat diet increases intrahepatic lipid accumulation and decreases metabolic flexibility in healthy overweight men. The Journal of clinical endocrinology and metabolism. 2011; 96:E691-695.

27. Vanhamme L, van den Boogaart A, Van Huffel S. Improved method for accurate and efficient quantification of MRS data with use of prior knowledge. J Magn Reson. 1997; 129:35-43.

28. Naressi A, Couturier C, Devos JM, Janssen M, Mangeat C, de Beer R, Graveron-Demilly D. Java-based graphical user interface for the MRUI quantitation package. Magma (New York, NY. 2001; 12:141-152.

29. Szczepaniak LS, Nurenberg P, Leonard D, Browning JD, Reingold JS, Grundy S, Hobbs HH, Dobbins RL. Magnetic resonance spectroscopy to measure hepatic triglyceride content: prevalence of hepatic steatosis in the general population. American journal of physiology. 2005; 288:E462-468.

30. Klein S. Is visceral fat responsible for the metabolic abnormalities associated with obesity?: implications of omentectomy. Diabetes Care. 2010; 33:1693-1694.

31. Teusink B, Voshol PJ, Dahlmans VE, Rensen PC, Pijl H, Romijn JA, Havekes LM. Contribution of fatty acids released from lipolysis of plasma triglycerides to total plasma fatty acid flux and tissue-specific fatty acid uptake. Diabetes. 2003; 52:614-620.

32. Wahren J, Sato Y, Ostman J, Hagenfeldt L, Felig P. Turnover and splanchnic metabolism of free fatty acids and ketones in insulin-dependent diabetics at rest and in response to exercise. The Journal of clinical investigation. 1984; 73:1367-1376.

33. Hellerstein MK. De novo lipogenesis in humans: metabolic and regulatory aspects. European journal of clinical nutrition. 1999; 53 Suppl 1:S53-65.

34. Ferre P, Foufelle F. Hepatic steatosis: a role for de novo lipogenesis and the transcription factor SREBP-1c. Diabetes, obesity \& metabolism. 2010; 12 Suppl 2:83-92.

35. Stellingwerff $\mathrm{T}$, Boon $\mathrm{H}$, Gijsen AP, Stegen $\mathrm{JH}$, Kuipers $\mathrm{H}$, van Loon LJ. Carbohydrate supplementation during prolonged cycling exercise spares muscle glycogen but does not affect intramyocellular lipid use. Pflugers Archiv : European journal of physiology. 2007; 454:635-647.

36. Schrauwen-Hinderling VB, van Loon L, Koopman R, Nicolay K, Saris WH, Kooi ME. Intramyocellular lipid content is increased after exercise in nonexercising human skeletal muscle. J Appl Physiol. 2003; 95:2328-2332.

37. Schmid Al, Szendroedi J, Chmelik M, Krssak M, Moser E, Roden M. Liver ATP synthesis is lower and relates to insulin sensitivity in patients with type 2 diabetes. Diabetes Care. 2011; 34:448-453.

38. Camacho RC, Donahue EP, James FD, Berglund ED, Wasserman DH. Energy state of the liver during short-term and exhaustive exercise in C57BL/6J mice. American journal of physiology. 2006; 290:E405-408. 


Chapter 7

\section{Absolute quantification of hepatic $\gamma$-ATP concentrations using ${ }^{31} \mathrm{P}$ MR Spectroscopy at a whole body $3 \mathrm{~T}$ scanner}

Petronella A. van Ewijk ${ }^{1,2,4}$, M. Eline Kooi ${ }^{2,4,5}$, Bram Brouwers ${ }^{1,4}$, Lena Bilet ${ }^{1,4}$, Friso den Heijer ${ }^{1}$, Kevin van Lieshout $^{1}$, Joachim E. Wildberger ${ }^{2}$, Matthijs K. Hesselink ${ }^{3,4}$, Patrick Schrauwen ${ }^{1,4}$, and Vera B. Schrauwen-

Hinderling ${ }^{1,2,4}$

Departments of ${ }^{1}$ Human Biology, ${ }^{2}$ Radiology, ${ }^{3}$ Human Movement Sciences, ${ }^{4}$ NUTRIM - School for Nutrition, Toxicology and Metabolism, ${ }^{5}$ CARIM - Cardiovascular Research Institute Maastricht, Maastricht University Medical Centre, Maastricht, the Netherland 


\section{ABSTRACT}

Purpose: The aim of this study was to investigate whether absolute quantification of hepatic ATP concentrations is feasible using a single phantom-replacement method with correction by a 3D sensitivity map for small deviations in voxel position.

Method: Absolute quantification of hepatic ATP concentrations with a single phantom replacement method was performed in 10 volunteers using ${ }^{31} \mathrm{P}$ magnetic resonance spectroscopy after acquisition of a 3D sensitivity map to account for small deviations in voxel position. The method was validated in a series of phantoms with known concentrations. Additionally, the stability of the calibration phantom measurement was tested and validity of coil load correction was investigated. Finally, reproducibility of the measurement was assessed in vivo.

Results: Validation of the method showed an average deviation of $6.8 \pm 1.7 \%$ of the measured compared to the known concentrations. The stability of the calibration phantom measurement over a period of 491 days, showed a deviation between the first and subsequent measurements of $9.42 \%$ (after 313 days), $4.52 \%$ (after 447 days) and $4.49 \%$ (after 491 days), respectively. The correction for coil-load induced variation in signal intensity was not complete with a remaining variation of $\pm 11.8 \%$. The reproducibility of the measurement was shown to be good (CoV of $3.5 \%)$.

Conclusion: Absolute quantification of hepatic ATP concentrations is feasible using a single phantom-replacement method with correction by a 3D sensitivity map for small deviations in voxel position. 


\section{INTRODUCTION}

The prevalence of obesity and the metabolic syndrome is rapidly increasing (1) which are both strongly associated with the development type 2 diabetes mellitus (T2DM) (2). In many populations, hyperinsulinemia and insulin resistance predict the development of $\operatorname{T2DM}(3,4)$. It has been demonstrated that increased fat storage in the liver is strongly correlated with insulin resistance $(5,6)$, but the underlying mechanism is yet unclear. In a rat model of high-fat diet-induced obesity and insulin resistance, a reduced mitochondrial function was observed in liver which was suggested to lead to the development of metabolic diseases such as obesity, T2DM and nonalcoholic steatohepatitis (7). Patients with T2DM indeed showed lower hepatic ATP and Pi concentrations in the liver compared to BMImatched controls as well as a fatty liver, suggesting a role for impaired hepatic energy metabolism in the development of hepatic steatosis (8). However, the exact determinants of hepatic mitochondrial function and consequently ATP concentration are still unknown. In skeletal muscle, it is well known that exercise training improves mitochondrial function and thereby energy metabolism. In patients with T2DM, it was shown that a 12 weeks exercise-training program had beneficial effects on skeletal muscle mitochondrial function and insulin sensitivity (9). It is unknown whether exercise-training also has beneficial effects on hepatic metabolism.

Phosphorous Magnetic Resonance Spectroscopy ( ${ }^{31} \mathrm{P}$ MRS) can be used to assess non-invasively hepatic high-energy phosphate metabolism in vivo. Using ${ }^{31} \mathrm{P} M R S$ phosphomonoesters (PME), inorganic phosphate (Pi), phosphodiesters (PDE), adenine triphosphate (ATP), nicotinamide adenine dinucleotide phosphate (NADPH) and uridine diphosphoglucose (UDPG) can be detected. Reduced energy metabolism could be due to mitochondrial dysfunction, reduction in mitochondrial content as well as loss of functional hepatocytes (10). Hepatic phosphorus metabolites can be quantified relative to a reference metabolite (e.g. ATP/Pi ratio, or ATP/total phosphorus ratio) or in absolute concentration. Relative quantification is fast and robust. However, this approach is problematic if the concentration of the reference metabolite might change, too. For absolute quantification of phosphorus metabolites, a phantom replacement method is often used, whereby the volume of interest (VOI) needs to be positioned at the same relative position with respect to the coil as in vivo (11). This usually means that for every in vivo measurement, a phantom replacement experiment is necessary. Alternatively, one can position the VOI during the in vivo measurement at exactly the same position with respect to the RF coil, so that only one phantom replacement experiment is necessary (12). However, due to differences in anatomy, this approach alone is difficult when a single voxel technique is used and small deviations in voxel position are likely, due to differences in patient's 
geometry. To correct for such small differences in geometry, a sensitivity map can be acquired and could be used to correct for positional differences. In the present study, this third option will be evaluated using a series of phantom measurements. To assess the feasibility of the method, the implemented protocol is subsequently applied to measure hepatic ATP concentrations in healthy control subjects, in patients diagnosed with type 2 diabetes mellitus (T2DM) and in patients with non-alcoholic fatty liver disease (NAFLD) before and after a 12-week exercise-training program. 


\section{$M R$ Imaging and Spectroscopy in volunteers}

Measurements were performed on a 3T whole-body scanner (Philips Achieva 3Tx, Best, The Netherlands). Subjects were positioned in a supine position. A $14-\mathrm{cm}$ diameter circular ${ }^{31} \mathrm{P}$ receive and transmit surface coil was positioned at the level of the liver and secured in place using velcro bands. Six vitamin E capsules were fixed on the surface coil to visualize its position on the MR images. A small reference phantom giving a detectable signal with a frequency shift of $1670 \mathrm{~Hz}$ with respect to the $\mathrm{PCr}$ resonance was located in the centre of the surface coil. Before spectroscopic acquisition, fifteen axial, coronal and sagittal ${ }^{1} \mathrm{H}$ MR images in each direction (slice thickness $=10 \mathrm{~mm}$, field of view $=450 * 450 \mathrm{~mm}$, matrix size $=192 * 96, \mathrm{TE}=1.82 \mathrm{msec}, \mathrm{TR}=3.8 \mathrm{msec}$ ) from the liver region were acquired using a gradient-echo sequence during one breath hold. Additionally, a slice was planned crossing the vitamin E capsules to define the plane parallel to the coil. Using the MR images, a three-dimensional VOI with a dimension of $6 \times 6 \times 6 \mathrm{~cm}$ was positioned within the liver. The VOI was positioned parallel to the coil at a distance of $5 \mathrm{~cm}$ from the center of the coil. Manual tuning and matching of the ${ }^{31} \mathrm{P}$-surface transmit-receive coil was performed to adjust for different coil loadings. Pencil bean shimming was performed in the VOI using the proton signal detected by the body coil. Localized phosphorus spectra were obtained using Image Selected In Vivo Spectroscopy (ISIS). Sequence parameters were repetition time (TR): 5500 msec, number of single acquisitions (NSA): 128, number of sample points: 1024 and spectral bandwidth: $3000 \mathrm{~Hz}$. The carrier frequency was chosen to match the resonance frequency of y-ATP. Adiabatic pulses were used to achieve inversion and excitation. Furthermore, a non-localized spectrum was obtained by detecting the free induction decay signal using the following parameters TR: 7000 msec, NSA: 56, number of sample points: 2048 and spectral bandwidth: $6000 \mathrm{~Hz}$. The carrier frequency was set on resonance on $1670 \mathrm{~Hz}$. This signal from the small reference phantom observed in the unlocalized spectrum was used to compensate for differences in coil load between phantoms and in vivo measurements.

\section{Phantom calibration experiment}

A calibration experiment was performed using a calibration phantom containing 5 $\mathrm{mM} \mathrm{KH} \mathrm{PO}_{4}, 154 \mathrm{mM} \mathrm{NaCl}, 5 \mathrm{ml}$ Gadovist $(1 \mathrm{mmol} / \mathrm{ml})$ dissolved in 8 I water (MiliQ). The measurement protocol with identical position of the VOI relative to 
the coil as during the in vivo measurements was performed in the calibration phantom. Scan parameters were TR: $3000 \mathrm{msec}$, NSA: 112, number of sample points: 4096 and spectral bandwidth: $3000 \mathrm{~Hz}$. The non-localized spectrum was obtained, with scan parameters TR: $7000 \mathrm{msec}$, NSA: 56, number of sample points: 2048 and spectral bandwidth: $3000 \mathrm{~Hz}$.

Additionally, $\mathrm{T}_{1}$ relaxation time was determined by an inversion recovery experiment (TR: $3000 \mathrm{msec}, \mathrm{IR}: 300 \mathrm{msec}$ intervals ranging from $35-2735 \mathrm{msec}$, NSA: 8). $T_{1}$ relaxation was fitted using a Least Square algorithm in Matlab (The MathWorks, Inc., Natick, Massachusetts, United States).

Metabolite concentrations were determined using the following equation (as described before by Chmelik et al (12)):

$$
c_{(\ll, y, z)}=c_{p} \frac{I_{([, y, z)}}{\left.I_{p \ll, y, z}\right)} \times \frac{S_{p}}{S} \times \frac{I_{\text {ref }, p}}{I_{\text {ref }}}
$$

Where $c_{\varangle, y, z}$ is the metabolite concentration of the voxel at position $(x, y, z)$ in the liver, $c_{p}$ is the metabolite concentration in the calibration phantom, $l_{\varepsilon, y, z}$-is the signal integral of the $\gamma$-ATP peak from the voxel at position $(x, y, z), I_{p<, y, z}$-is the signal integral of the from the metabolite peak in the calibration phantom at position $(x, y, z), S$ and $S_{p}$ the saturation factors calculated from the measured $T_{1}$ relaxation time in the calibration phantom and the reported $\mathrm{T}_{1}$ relaxation time of $\gamma$-ATP in vivo (13), $I_{\text {ref }}$ and $I_{\text {ref }, p}$ the signal integral from the small reference phantom in the surface coil.

\section{Coil load and signal intensity}

The coil load can vary between subjects and depends on the position of the coil, the electrical properties of the coil and tissue. Variation in coil load leads to a decrease in signal intensity. To correct for differences in coil load between subjects and during the calibration phantom measurement, the signal of a small reference phantom (inside the coil) was acquired after each in vivo measurement. To investigate whether the load correction indeed reduces (load induced) interscan variation and thereby improves quantification, the calibration phantom was measured with varying load (as shown in Figure 1) either by bringing a saturated saline solution $(100 \mathrm{ml})$ close to the coil (increasing load) or by using spacers between the coil and the phantom (decreasing coil load). The signal intensities in the phantom with varying coil loads were compared to investigate whether the load correction by the signal intensity of the small phantom could reduce the variation in load-induced variability in signal intensity. 
A.

COIL

with small REFERENCE PHANTOM
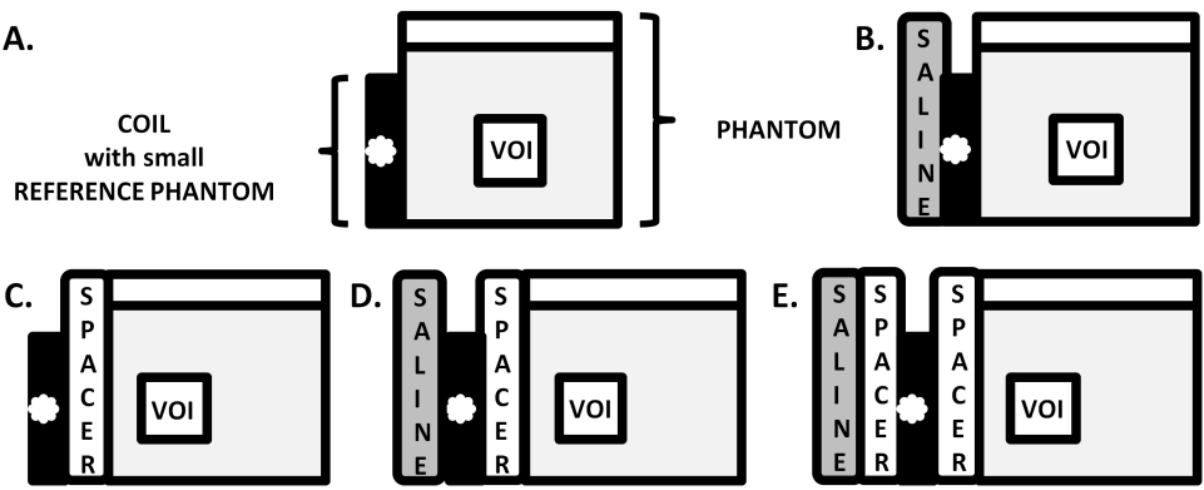

E.

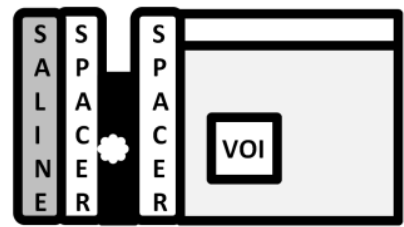

Figure 1: To investigate how differences in coil load affect signal intensity, the calibration phantom was measured with varying load by using a saturated saline solution $(100 \mathrm{ml})$ and spacers. In the default coil setup (coil setup A), no saline solution or spacers were added. In coil setup B, only saline solution was added thereby increasing coil load. In setup C, only a spacer was added thereby decreasing coil load. In setup $D$, saline solution and one spacer were added, while in setup $\mathrm{E}$ also another spacer was added.

\section{Validation and reproducibility}

First, to validate the measurements of absolute concentrations, a series of phantoms with known concentrations of 5, 10 of $20 \mathrm{mM} \mathrm{KH}_{2} \mathrm{PO}_{4}$ were measured. Scan parameters of the localized measurements were TR: $3000 \mathrm{msec}$, NSA: 112, number of sample points: 4096 and spectral bandwidth: $3000 \mathrm{~Hz}$. The calibration phantom was used to calculate the concentrations of the phantom series.

Second, it may be difficult to use a single calibration measurement to calculate concentrations of measurements acquired during a prolonged period of time due to system instability. Therefore, the stability of the calibration phantom measurement was assessed at three different points in time (in a time span from 0-491 days) and the coefficient of variation (CV) was calculated.

Third, reproducibility of the in vivo determination of absolute ATP concentrations was tested in two healthy volunteers by performing the measurement twice, while the subject left the scanner table between the measurements.

\section{D intensity mapping in a phantom}

For the absolute quantification of hepatic phosphorus metabolites, a phantom experiment using the same scan parameters as the in vivo experiment needs to be performed. To compensate for deviations in position, a three-dimensional

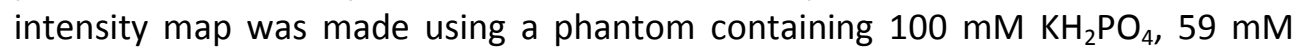
$\mathrm{NaCl}, 7.5 \mathrm{ml}$ Gadovist $(1 \mathrm{mmol} / \mathrm{ml}$ ) dissolved in 8 I water (MiliQ). Scan parameters of the localized scans were slightly adjusted based on observed signal, to minimize scan time and optimize signal intensity. Scan parameters were TR: $3000 \mathrm{msec}$, 
NSA: 8, number of sample points: 4096 and spectral bandwidth: $3000 \mathrm{~Hz}$. A series of scans were made at different positions with deviations from the optimal / central position, ranging from $0-10 \mathrm{~mm}$ in coronal (right-left, $\mathrm{RL}$ ), and $\pm 0-30 \mathrm{~mm}$ in axial (anterior-posterior, AP) and sagittal (feed-head, FH) direction. The central position is defined as the position where the voxel is at a distance of $5 \mathrm{~cm}$ exactly parallel and centered to the coil, i.e. the position with the following geometry parameters: $\mathrm{RL}=0, \mathrm{AP}=0, \mathrm{FH}=0$. Based on the acquired signal at different positions, a three-dimensional quadratic polynomial function was fitted in Matlab (The MathWorks, Inc., Natick, Massachusetts, United States). The deduced equation describes the relative intensity at a certain position in the phantom with respect to the intensity at the central position. The central position in every phantom has a reference value of 1 , regardless of its concentration. So, to calculate the signal intensity at a non-central position in the phantom, the relative intensity at this position is multiplied with the signal integral at the central position. Using this equation, the relative signal change, due to small deviations in voxel placement can thus be determined.

\section{Validation of correction method for deviation in voxel position}

The equation was tested on a phantom with the same concentration $\mathrm{KH}_{2} \mathrm{PO}_{4}$, and in a phantom with a concentration of $4.6 \mathrm{mM} \mathrm{KH}_{2} \mathrm{PO}_{4}$. The scans were made at different positions, ranging from 0-15 $\mathrm{mm}$ in coronal (RL), $\pm 0-30 \mathrm{~mm}$ in axial (AP) and sagittal (FH) direction regarding to the central position. The deviation between the measured and calculated signal intensity was assessed as a percentage.

\section{Data analysis}

The localized spectra were fitted using the AMARES fitting algorithm in jMRUI. All spectra were corrected manually for zero-order phase differences and $5 \mathrm{~Hz}$ Gaussian apodization was performed. Spectra were fitted to Gaussian lineshapes. The PME, Pi, PDE, PCr, $\gamma^{-}, \alpha$ - and $\beta$-ATP peaks were assigned according to literature (14). Unlocalized spectra were integrated using NUTS (Acorn NMR, Palo Alto, CA, USA). Spectra were phased manually, baseline correction and spectral apodization were performed. The peak integral was calculated from $\pm 2 \mathrm{ppm}$ starting from the centre of the peak, such that always the whole peak was integrated. For absolute quantification equation [1] was used, when necessary in combination with the equation derived from the 3D-intensity map. In case of in vivo measurements, $T_{1}$-correction was performed using $T_{1}$-values obtained from literature (13). To correct for $T_{1}$-relaxation in phantoms, measured $T_{1}$-relaxation times were used. Correction for muscular ATP signal contamination was 
performed and was based on quantifying $\mathrm{PCr}$ in the liver spectra and assuming a skeletal muscle PCr concentration of $34 \pm 1 \mathrm{mM}$ and ATP concentration of $8.1 \pm 0.2$ $\mathrm{mM}$ and therefore PCr/ATP ratio of 4.198 (15).

Subjects participating in the 12 week exercise and endurance-training program

The Medical Ethical Committee of the Maastricht University Medical Centre approved all experiments. Experiments were performed after written informed consent was obtained from all participants. Ten overweight to obese subjects, of which two were healthy (age: $52.5 \pm 4.7$ years; $\mathrm{BMI}: 29.2 \pm 0.1 \mathrm{~kg} / \mathrm{m}^{2}$ ), six were diagnosed with T2DM (age: $59.7 \pm 1.8$ years; BMI: $31.0 \pm 0.6 \mathrm{~kg} / \mathrm{m}^{2}$ ) and two were diagnosed with NAFLD (age: $47.5 \pm 1.5$ years; BMI: $31.2 \pm 0.4 \mathrm{~kg} / \mathrm{m}^{2}$ ), participated in a 12 weeks exercise-training program. The 12 weeks training intervention consisted of a combination of aerobic and resistance exercise. Aerobic exercise was performed twice a week for half an hour at $70 \%$ of maximal aerobic capacity. Resistance training was performed once a week and consisted of 3 series of 10 repetitions at $60 \%$ of maximum voluntary contraction. Before onset of the training program, participants underwent Phosphorous Magnetic Resonance Spectroscopy $\left({ }^{31} \mathrm{P} \mathrm{MRS}\right)$ to determine hepatic ATP concentration. After the 12 week of exercisetraining program, spectroscopic measurements were repeated.

Results are expressed as means \pm standard error of the mean (SEM). To evaluate effects between the two experimental conditions, a two-tailed Student's t-test was used. Significance was set at $p \leq 0.05$. 


\section{RESULTS}

\section{Validation of the calibration phantom measurement}

The calculated concentrations for the phantoms with known concentration are shown in Table 1 and Figure 2. The calculated concentration differed from the known concentration of 5,10 and $20 \mathrm{mM}$ with $-3.5 \%, 8.2 \%$ and $-8.7 \%$ respectively.

Table 1: Results validation experiment

\begin{tabular}{c|c|c}
\hline Known concentration (mM) & $\begin{array}{c}\text { Calculated concentration } \\
(\mathbf{m M})\end{array}$ & Deviation (\%) \\
\hline 5.0 & 4.8 & -3.5 \\
\hline 10.0 & 10.8 & 8.2 \\
\hline 20.0 & 18.3 & -8.7 \\
\hline
\end{tabular}

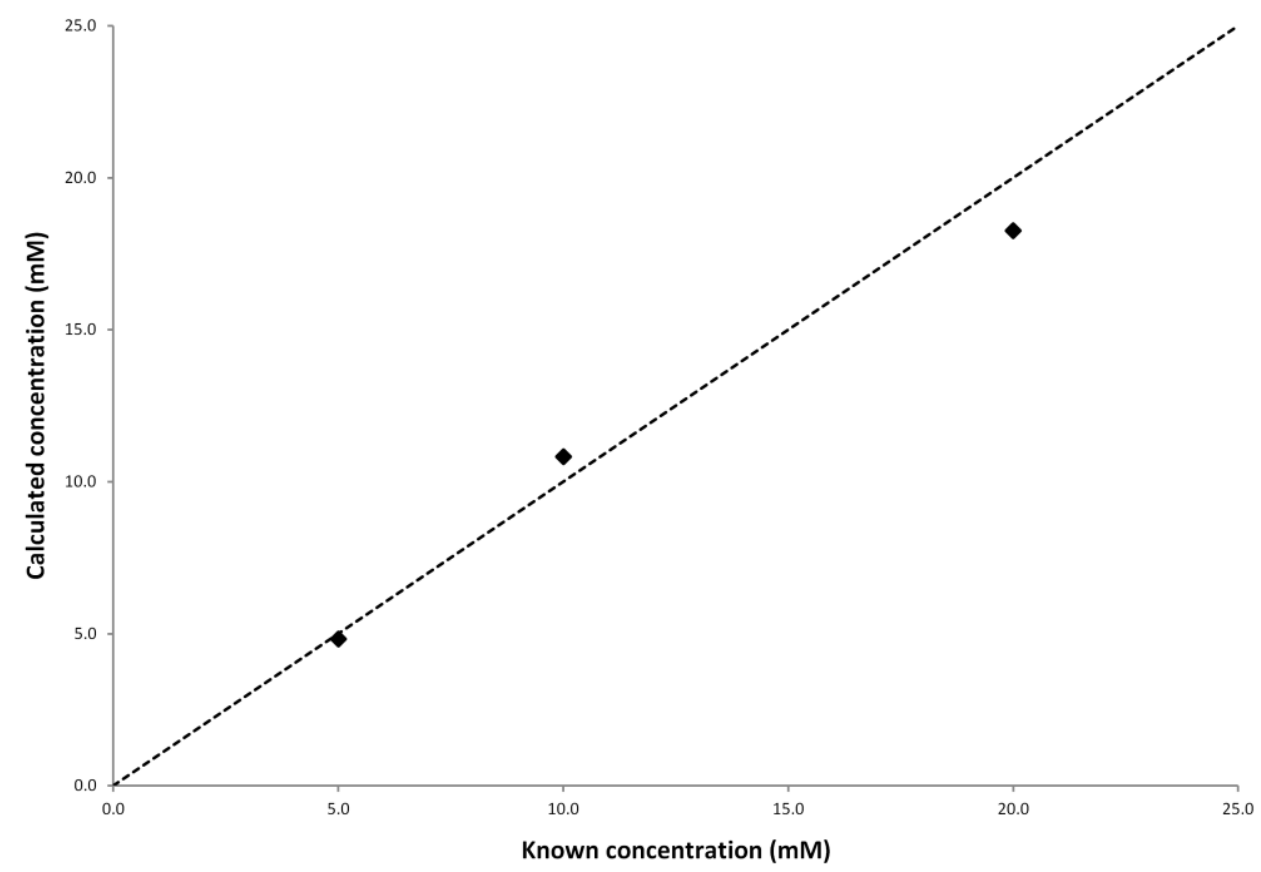

Figure 2: To validate the usability of the calibration phantom for assessing absolute concentrations, a series of phantoms with known concentrations of 5, 10 of $20 \mathrm{mM} \mathrm{KH}_{2} \mathrm{PO}_{4}$ were measured. The calibration phantom was used to calculate the concentrations of the phantom series. In the graph are the calculated concentrations plotted against the known concentrations of the phantoms (dotted line, identity line). 


\section{Stability of calibration measurement}

The stability of the calibration measurement in time was tested four times in a time span from 0-491 days. The average signal intensity as determined in the calibration phantom and external reference phantom was $2.36 * 10^{-3} \pm 1.04 * 10^{-4}$ and $7.53 \pm 1.89 * 10^{-1}$ a.u., respectively. The signal intensity measured in the calibration phantom was divided by the signal intensity measured in the external reference phantom resulting in an average signal ratio of $3.13 * 10^{-4} \pm 8.55 * 10^{-6}$ (which was set equal to 1 , as shown Figure 3 ). The variation between the first and subsequent measurements was $9.42 \%$ (after 313 days), $4.52 \%$ (after 447 days) and $4.49 \%$ (after 491 days), respectively.

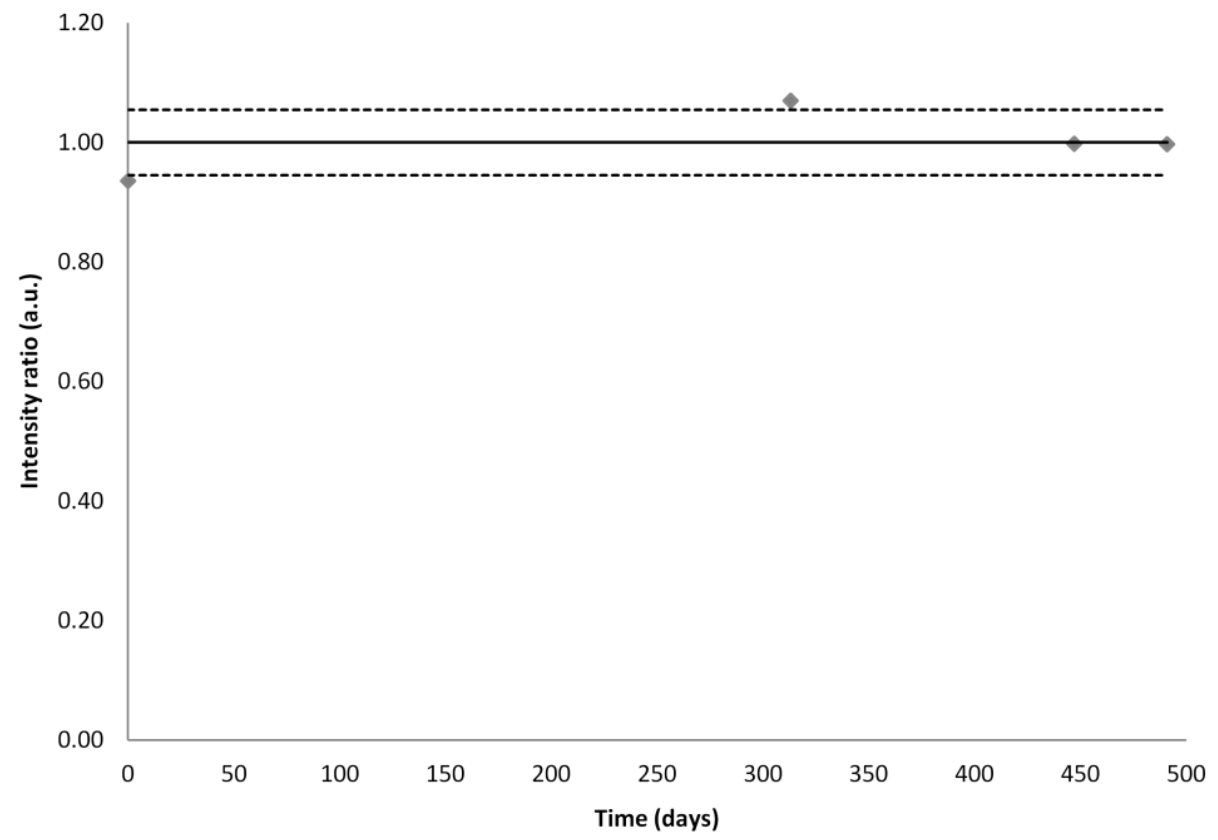

Figure 3: The stability of the calibration measurement in time was tested four times, in a time span from 0-491 days. The intensity ratio value, which resulted from the measured signal intensity of the calibration phantom and external reference phantom, is presented in gray points. The average intensity ratio (black line) and standard deviation (dotted line) are also presented.

\section{Influence of coil load}

Intensities measured with varying coil load are given in Figure 3. The variation in coil load resulted in variation in signal intensities of $24.4 \%$. The intensities of the small reference phantom showed a similar pattern. When differences in coil load 
were corrected using the small reference phantom (Figure 4), the resulting coefficient of variation was $11.8 \%$.

A.

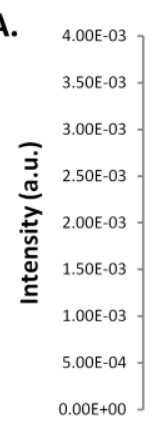

Signal intensity VOI in phantom

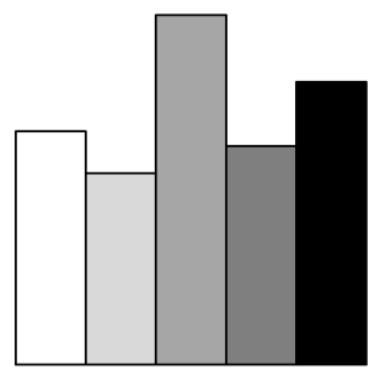

B.

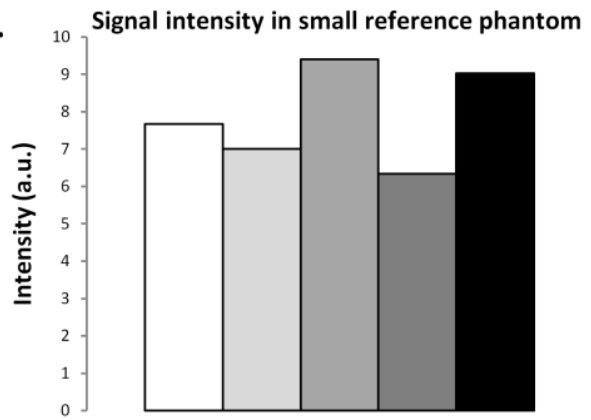

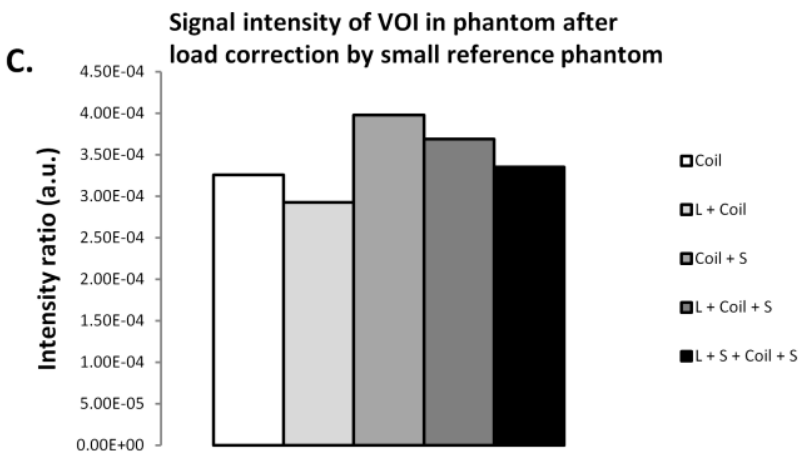

Figure 4: To investigate how differences in coil load affect signal intensity, the calibration phantom and small reference phantom were measured with varying load by using a saturated saline solution (L) and spacers (S). In panel A the signal intensities are presented as measured in the calibration phantom. Panel B presents the signal intensities from the external reference phantom. To correct for differences in coil load, signal intensity is generally normalized to the signal from the external reference phantom. Panel $\mathrm{C}$ shows the variation in intensity ratio.

\section{D intensity mapping in a phantom}

In Figure 5A a two-dimensional heat-map is presented. It is shown how signal intensity decreases with increasing distance from the central position $(R L=0, F H=0$, $A P=0)$ at $5 \mathrm{~cm}, 5.5 \mathrm{~cm}$ and $6 \mathrm{~cm}$ distance with respect to the coil. Figure $5 B$ shows some data as line-graphs. An equation describing the signal decrease from the central position in the intensity map was fitted in Matlab (The MathWorks, Inc., Natick, Massachusetts, United States) using polynomial function. The equation is: 


$$
\begin{aligned}
& I F_{p(y, z)}= \\
& 1 \\
& + \\
& \left(\left(7.02 E^{-4}\right) \times A P\right)+\left(\left(1.45 E^{-4}\right) \times A P^{2}\right) \\
& + \\
& \left(\left(-1.37 E^{-3}\right) \times F H\right)+\left(\left(-1.95 E^{-4}\right) \times F H^{2}\right) \\
& + \\
& \left.\left(\left(-4.7 E^{-2}\right) \times R L\right)+\left(1.4 E^{-3}\right) \times R L^{2}\right)
\end{aligned}
$$

Where $I F_{p(y, z}$ is the factor describing the decrease in signal intensity from the voxel at position $(x, y, z)$ in the calibration phantom with respect to the central position, $\mathrm{RL}, \mathrm{AP}$ and $\mathrm{FH}$ are given in $\mathrm{mm}$ distance from the central position.

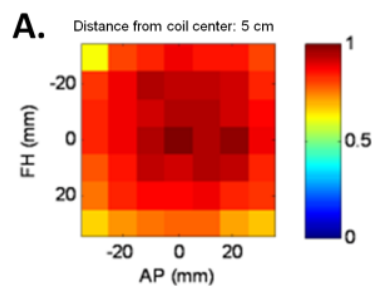

B.

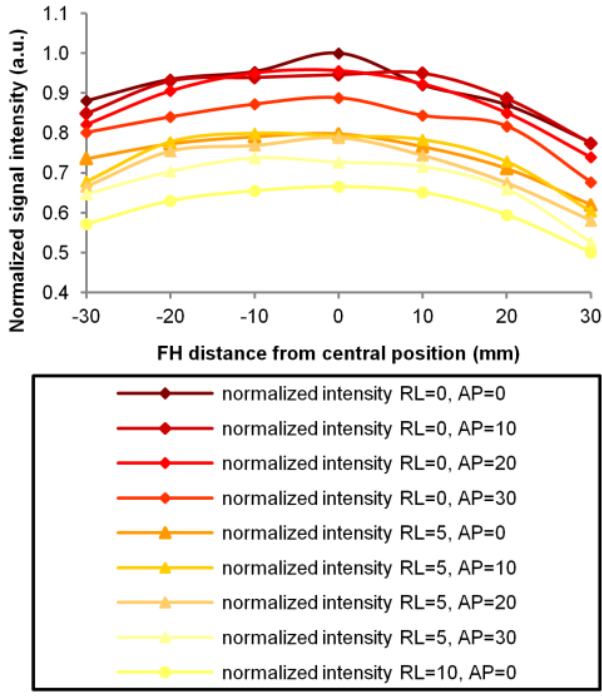

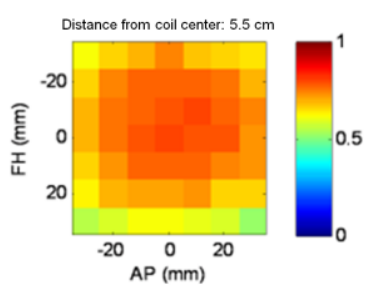

C.
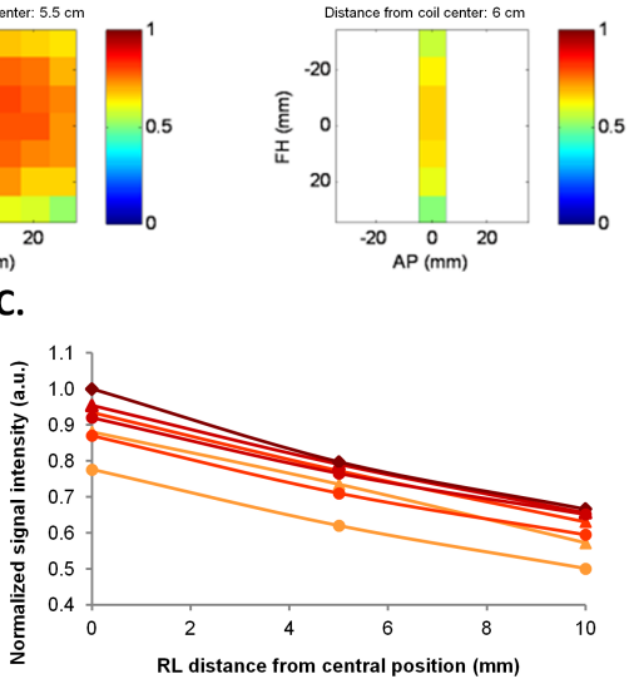

$\mathrm{RL}$ distance from central position $(\mathrm{mm})$

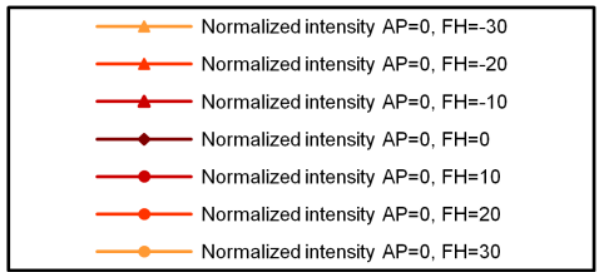

Figure 5: In panel A a two-dimensional intensity map is shown. Colors are used to indicate intensity (a.u.). Panel $\mathrm{B}$ and $\mathrm{C}$ show signal differences in signal intensity at the indicated positions. 


\section{Validation of equation describing intensity profile}

The equation was tested on a phantom with the same concentration $\mathrm{KH}_{2} \mathrm{PO}_{4}$, and in a phantom with a concentration of $4.6 \mathrm{mM} \mathrm{KH}_{2} \mathrm{PO}_{4}$. At different positions in the phantom, signal intensity was measured and also calculated using equation 2 . The deviation between the measured and calculated signal intensity was assessed in percent.

In Figure 6 and Figure 7, a two-dimensional heat-map is presented showing the measured intensity, the calculated intensity and the deviation in measured and calculated signal intensity in percent in a phantom containing $100 \mathrm{mM} \mathrm{KH}_{2} \mathrm{PO}_{4}$ and $4.6 \mathrm{mM} \mathrm{KH} 2 \mathrm{PO} 4$, respectively. It is shown that the deviation is generally lower than $5 \%$, when the voxel position is shifted less than $20 \mathrm{~mm}$ shifted from the central position ( $L R=0, F H=0, A P=0)$.
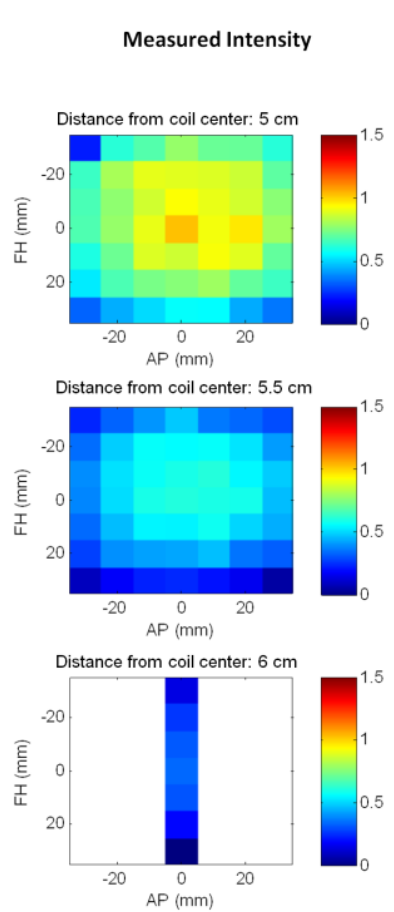
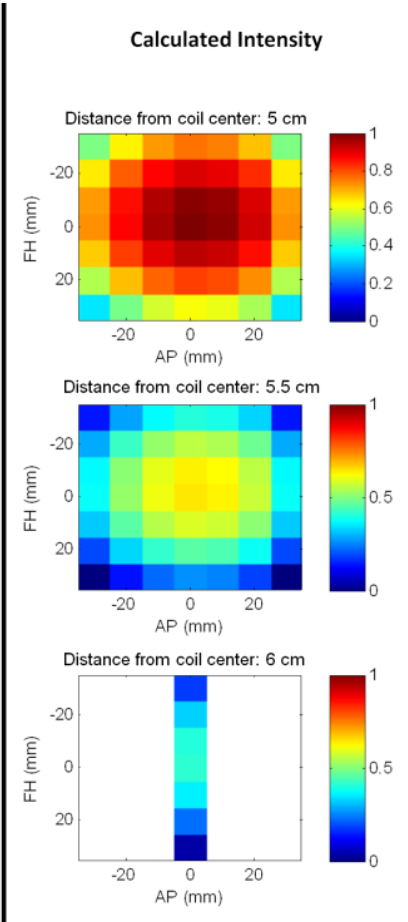
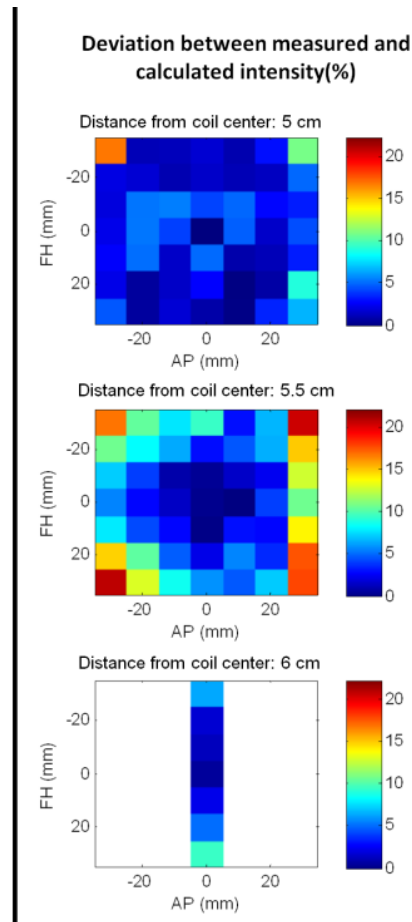

Figure 6: The figure shows the deviation from the measured, calculated and deviation between measured and calculated intensity. The measurements were performed using in a phantom containing $100 \mathrm{mM} \mathrm{KH}_{2} \mathrm{PO}_{4}$, at least at 5 locations with respect to the center of the coil. The measured and normalized intensity is shown in the left panel, the calculated intensity is shown in the middle panel and the deviation between the measured and calculated signal intensity is shown in the right panel. 

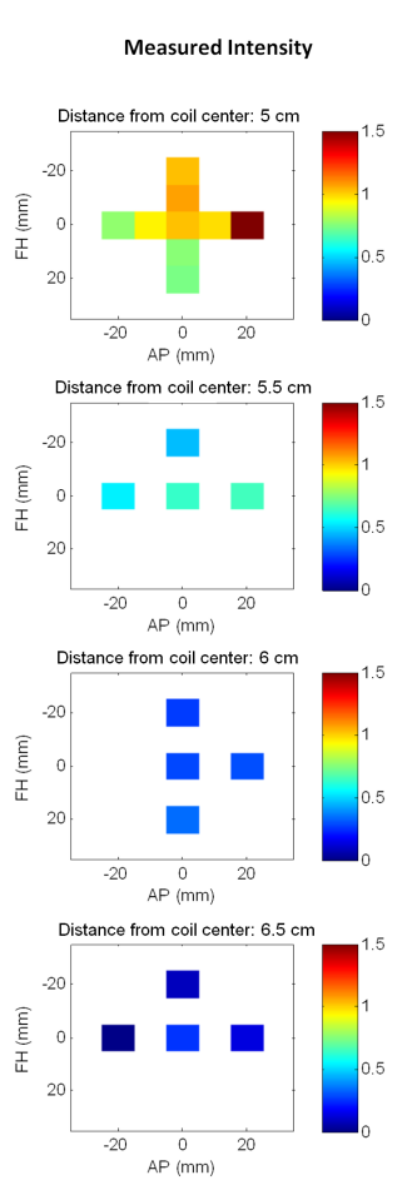
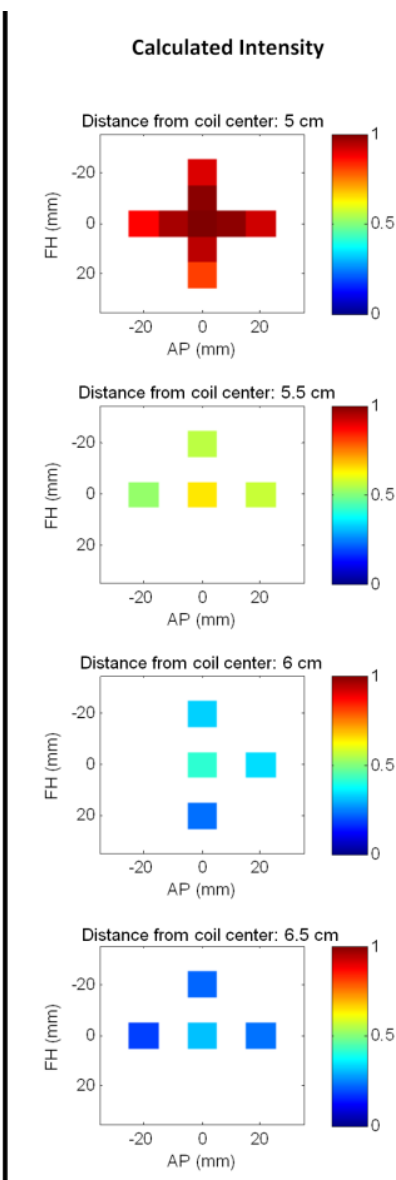

Deviation between measured and calculated intensity(\%)
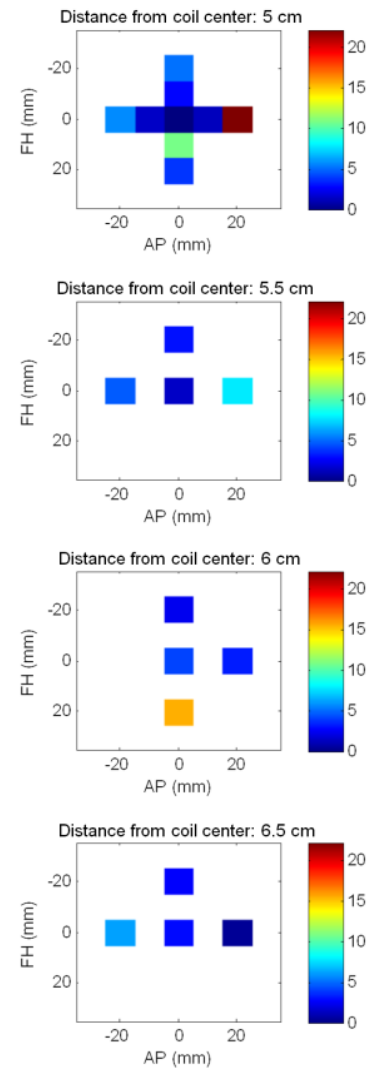

Figure 7: The figure shows the deviation from the measured, calculated and deviation between measured and calculated intensity. The measurements were performed using in a phantom containing $4.6 \mathrm{mM} \mathrm{KH}_{2} \mathrm{PO}_{4}$, at least at 5 locations with respect to the center of the coil. However, due to the low concentrations not all spectral fits were reliable and some data points were removed. The measured and normalized intensity is shown in the left panel, the calculated intensity is shown in the middle panel and the deviation between the measured and calculated signal intensity is shown in the right panel.

\section{Reproducibility}

Reproducibility of the method in vivo yielded an average coefficient of variation of $4.93 \pm 1.51 \%$. In the first volunteer a $\gamma$-ATP a concentration of 3.01 and $2.85 \mathrm{mM}$ was measured, respectively, corresponding to a concentration difference of $5.31 \%$. In the second volunteer a $y$-ATP concentration of 4.18 and $3.84 \mathrm{mM}$ was measured, respectively, corresponding to a concentration difference of $8.13 \%$. 
A typical image of a patient's liver indicating also the voxel position for ${ }^{31} \mathrm{P} M R S$ is displayed in Figure 8. Additionally, an example of a spectrum is shown in Figure 8B in which the peaks originating from PME, Pi, PDE, ATP, NADPH and UDPG can be distinguished. The low phosphocreatine $(\mathrm{PCr})$ signal at $0 \mathrm{ppm}$, indicates that there is negligible contamination from skeletal muscle.
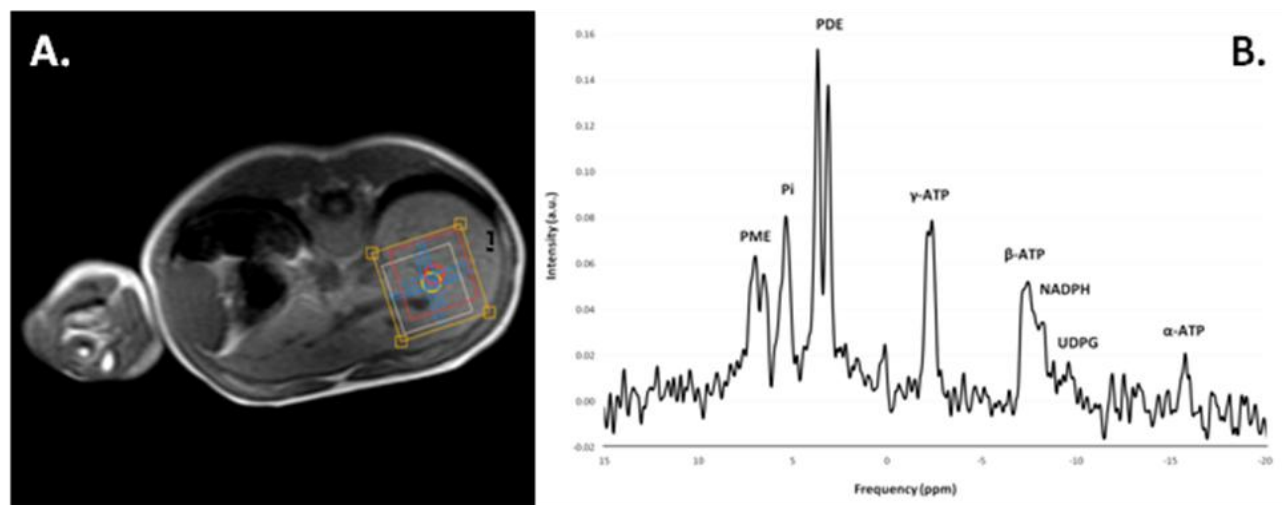

Figure 8: In panel A, a screenshot of the voxel planning in the liver is shown. The yellow voxel indicates the size of the shim volume, the red voxel indicates the position where the $\gamma$-ATP (on-resonance) will be detected and the white voxel indicates the position where other metabolites (off-resonance) are detected. Both voxel are positioned in the liver. In panel B, a typical phosphorus spectrum is shown. The following peaks are indicated: PME, phosphomonoesters; Pi, inorganic phosphate; PDE, phosphodiesters; ATP, adenine triphosphate; NADPH, nicotinamide adenine dinucleotide phosphate; UDPG, uridine diphosphoglucose.

The mean y-ATP concentrations before and after 12-weeks exercise intervention are presented in Figure 9. The measured mean hepatic ATP concentrations before and after training intervention were $3.75 \pm 0.31$ and $3.36 \pm 0.14$, respectively. These ATP concentrations are well in accordance with reported values in literature (16). 


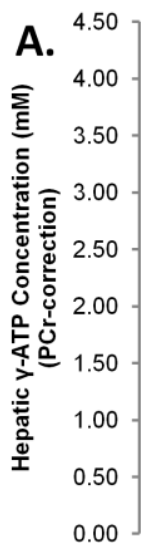

口Baseline

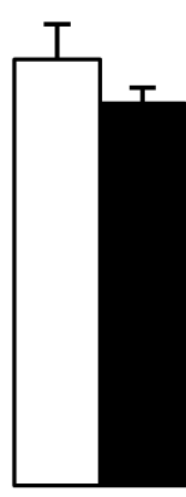

Dost-intervention
B.

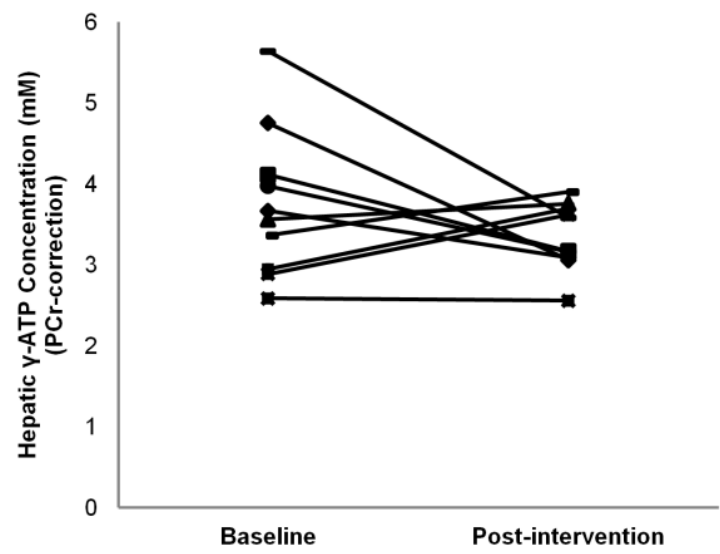

Figure 9: In panel A the mean \pm SEM hepatic ATP content from all subjects (total ten overweight to obese subjects, of which two were healthy, six were diagnosed with T2DM and two were diagnosed with NAFLD) before (white bars) and after (black bars) a 12-week endurance-training intervention. Panel B, shows the individual data. 


\section{Discussion}

In the present study, we have shown that absolute quantification of hepatic ATP concentrations is feasible using a single phantom-replacement method with correction by a 3D sensitivity map for small deviations in voxel position. First, validation of the method with $a$ in a series of phantoms with known concentrations showed an average deviation of $\pm 6.8 \pm 1.7 \%$ of the measured compared to the known concentrations. It is noteworthy that for the $5 \mathrm{mM}$ measurement, which is close to the normal ATP concentration (around 2 to $4 \mathrm{mM}$ $(8,11,12,16))$, the deviation was smaller and was only $3.5 \%$. Second, calibration phantom measurements showed that the system was stable in a time span of more than one year, yielding a deviation of $4.49 \%$ after 491 days. Third, we confirmed that the correction for coil load, based on a small external phantom, improved the quantification since the load-induced variation of signal intensity of $\pm 24.4 \%$ was considerably reduced by the normalization with the signal from the small external reference phantom, although the correction was not complete with a remaining variation of $\pm 11.8 \%$. The saline-induced variation in coil load in this experiment $( \pm 16.6 \%)$ was about twice as high the variation observed in vivo $( \pm 7.9 \%)$. Therefore, the load-induced error of ATP concentration measured in vivo will be smaller. Finally, the reproducibility of the measurement as assessed in two healthy volunteers was shown to be good ( $\mathrm{CoV}$ of $3.5 \%$ ) and the calculated ATP concentrations are well in accordance with reported values in literature (16).

A limitation of this study is that only $\gamma$-ATP was quantified, because measurements were performed on the resonance frequency of $\gamma$-ATP. For quantification of other metabolites, ideally additional spectra on resonance should be acquired, or at least the pulse profile needs to be determined to be able to correct for pulse profile.

When using the phantom replacement method for absolute quantification, it is important to use the same protocol with identical geometry as the in vivo measurements. Due to variations in liver size and geometry between various patients, it is not always possible to position the voxel at the same position with respect to the coil. We showed that by acquiring a three-dimensional intensity map of the phantom, one can correct for minor changes in voxel position. The equation was shown to perform well when small deviations in position with respect to the coil were taken into account, yielding acceptable deviation in calculated versus measured intensity. The small deviations in voxel position were well in accordance with variation in voxel position observed during the in vivo experiment. Due to possible time effects in system (in)stability (e.g. due to eddy currents), it is necessary to repeat the calibration measurement periodically. In a time span of 491 days we observed a variation in signal intensity $5.5 \%$, and the variation between the first and last measurement was $4.49 \%$. 
Unlike Chmelik et al. (12) we have chosen to use a single voxel approach to minimize total scan time. A disadvantage of the single voxel approach is that no information is obtained about the spatial distribution of metabolites. However, multivoxel magnetic resonance spectroscopic imaging is time demanding which is disadvantageous in a clinical setting, and is more susceptible for respiratory motion artifacts. The duration of our spectroscopy protocol was $\sim 17$ minutes.

The feasibility of the method was evaluated by performing several in vivo measurements. Reliable hepatic ATP concentrations were obtained, and a 12 week exercise and endurance training did not show to have an effect on absolute hepatic ATP concentrations. However, the training intervention lead to the expected changes in physical fitness (maximal aerobic capacity was significantly increased, as well as muscle strength -data not shown-) and changes in body fat (body fat percentage was decreased - data not shown-), suggesting that the training was effective.

In summary, the present study shows the feasibility of absolute quantification using a single voxel phantom replacement method at a $3 T$ clinical scanner. Additionally, three-dimensional signal intensity mapping enabled us to calculated absolute ATP concentrations from a single calibration experiment, even when voxel position during phantom replacement slightly deviated from the in vivo measurement.

The feasibility of the measurement was demonstrated in 10 overweight to obese subjectsbefore and after a 12 week training intervention.

\section{ACKNOWLEDGEMENTS}

MEK is supported by Aspasia (grant 015.008.047) from the Netherlands Organisation for Scientific Research (NWO).

VS is supported by a veni grant (grant 91611136) from the Netherlands Organization for Scientific Research (NWO). 


\section{REFERENCES}

1. World Health Statistics 2012. In.: World Health Organization (WHO); 2012.

2. Deckelbaum RJ, Williams CL. Childhood obesity: the health issue. Obes Res. 2001; 9 Suppl 4:239S2435 .

3. Hanley AJ, D'Agostino R, Jr., Wagenknecht LE, Saad MF, Savage PJ, Bergman R, Haffner SM. Increased proinsulin levels and decreased acute insulin response independently predict the incidence of type 2 diabetes in the insulin resistance atherosclerosis study. Diabetes. 2002; 51:1263-1270.

4. Weyer C, Bogardus C, Mott DM, Pratley RE. The natural history of insulin secretory dysfunction and insulin resistance in the pathogenesis of type 2 diabetes mellitus. J Clin Invest. 1999; 104:787-794.

5. Fabbrini E, Magkos F, Mohammed BS, Pietka T, Abumrad NA, Patterson BW, Okunade A, Klein S. Intrahepatic fat, not visceral fat, is linked with metabolic complications of obesity. Proc Natl Acad Sci U S A. 2009; 106:15430-15435.

6. Sanyal AJ, Campbell-Sargent C, Mirshahi F, Rizzo WB, Contos MJ, Sterling RK, Luketic VA, Shiffman ML, Clore JN. Nonalcoholic steatohepatitis: association of insulin resistance and mitochondrial abnormalities. Gastroenterology. 2001; 120:1183-1192.

7. Raffaella C, Francesca B, Italia F, Marina P, Giovanna L, Susanna I. Alterations in hepatic mitochondrial compartment in a model of obesity and insulin resistance. Obesity (Silver Spring). 2008; 16:958-964.

8. Szendroedi J, Chmelik M, Schmid Al, Nowotny P, Brehm A, Krssak M, Moser E, Roden M. Abnormal hepatic energy homeostasis in type 2 diabetes. Hepatology. 2009; 50:1079-1086.

9. Meex RC, Schrauwen-Hinderling VB, Moonen-Kornips E, Schaart G, Mensink M, Phielix E, van de Weijer T, Sels JP, Schrauwen P, Hesselink MK. Restoration of muscle mitochondrial function and metabolic flexibility in type 2 diabetes by exercise training is paralleled by increased myocellular fat storage and improved insulin sensitivity. Diabetes. 2010; 59:572-579.

10. Szendroedi J, Roden M. Ectopic lipids and organ function. Curr Opin Lipidol. 2009; 20:50-56.

11. Laufs A, Livingstone R, Nowotny B, Nowotny P, Wickrath F, Giani G, Bunke J, Roden M, Hwang JH. Quantitative liver $\mathrm{P}$ magnetic resonance spectroscopy at 3T on a clinical scanner. Magn Reson Med. 2013.

12. Chmelik M, Schmid Al, Gruber S, Szendroedi J, Krssak M, Trattnig S, Moser E, Roden M. Threedimensional high-resolution magnetic resonance spectroscopic imaging for absolute quantification of 31P metabolites in human liver. Magn Reson Med. 2008; 60:796-802.

13. Schmid Al, Chmelik M, Szendroedi J, Krssak M, Brehm A, Moser E, Roden M. Quantitative ATP synthesis in human liver measured by localized 31P spectroscopy using the magnetization transfer experiment. NMR Biomed. 2008; 21:437-443.

14. Malloy CR, Cunningham CC, Radda GK. The metabolic state of the rat liver in vivo measured by 31PNMR spectroscopy. Biochim Biophys Acta. 1986; 885:1-11.

15. Kemp GJ, Meyerspeer M, Moser E. Absolute quantification of phosphorus metabolite concentrations in human muscle in vivo by 31P MRS: a quantitative review. NMR Biomed. 2007; 20:555-565.

16. Tosner Z, Dezortova M, Tintera J, Hajek M. Application of two-dimensional CSI for absolute quantification of phosphorus metabolites in the human liver. Magma. 2001; 13:40-46. 


Chapter 8

General discussion 
The prevalence of obesity is very high and still growing, thereby increasing the relative risk of cardiovascular disease $(1,2)$ and diabetes $(3-5)$, although it is incompletely understood what the underlying mechanisms are. Obesity is defined as a pronounced expansion of adipose tissue. However, in obesity, lipid accumulation in the liver and heart are also increased, a phenomenon which has been implicated in metabolic changes in these tissues, such as hepatic and cardiac insulin resistance. In the case of the liver, increased lipid content is associated with increased risk for the development of type 2 diabetes mellitus (6) and in the case of the heart, cardiomyopathy and decreased cardiac function were reported (7). Increased lipid content in these tissues is also termed steatosis and in the liver, it is usually diagnosed with the clinical term of non-alcoholic fatty liver disease (NAFLD) $(8,9)$ if the lipid accumulation is not caused by exaggerated alcohol consumption. Investigation of ectopic lipid accumulation in heart and liver in humans is strongly dependent on the use of non-invasive techniques such as Magnetic Resonance Imaging (MRI) and Magnetic Resonance Spectroscopy (MRS). The aim of the present thesis was to further investigate the relationship between ectopic fat accumulation and cardiac and hepatic tissue function, using noninvasive magnetic resonance techniques. In this chapter, the results of the present thesis are discussed and put in broader perspective.

\section{QUANTIFICATION OF ECTOPIC LIPID CONTENT}

${ }^{1} \mathrm{H}-\mathrm{MRS}$ is currently the most reliable noninvasive method to determine cardiac fat content in vivo $(10,11)$. Validity and reliability of cardiac ${ }^{1} \mathrm{H}$-MRS was tested using in vitro biochemical measurement of fat content in rodent heart as reference and was shown to be good (10, 12-14).

For quantification of hepatic lipid content, several techniques can be used (15). To diagnose the severity of NAFLD, liver biopsy is currently the gold standard to distinguish between simple steatosis and steatohepatitis (NASH) (16). However, it is well known that taking a liver biopsy increases the risk for complications, and this method has also several limitations: the liver is a heterogeneous tissue (17), and one small biopsy is not representative for the whole organ. Additionally, taking a liver biopsy is painful (18) and associated with a albeit small mortality risk (19). Liver biopsy is therefore not appropriate to be used for repeated measurements. To this end, noninvasive techniques are required.

Ultrasound is commonly used in clinical practice for detection of fatty liver due to its low cost and wide availability. Several studies have been performed to determine the sensitivity and specificity of the method. The sensitivity ranges from $60-94 \%$ and the specificity from $84-95 \%$ (20-22), but in the presence of obesity the sensitivity and specificity of the method was shown to be decreased to $49 \%$ and $75 \%$, respectively, possible due to technical problems in performing ultrasound in obese subjects (23). However, due to the operator dependency of 
the method and its inability to precisely quantify (small changes in) hepatic lipid content, ultrasonography can be considered mostly as a qualitative method instead of a quantitative method and is therefore less useful for longitudinal studies (15).

Noncontrast-enhanced computerized tomography (CT) is a suitable method for diagnosis of hepatic lipid accumulation. To determine hepatic steatosis the absolute hepatic attenuation value (in Hounsfield units) can be used (24), as well as the difference in attenuation between liver and spleen (25). However, due to wide interpatient and interscanner variation in liver CT attenuation values, measurement of absolute liver attenuation is thought to be less accurate (25). Additionally, during a CT-scan, the subject is exposed to ionizing radiation which makes CT less useful for application in longitudinal studies.

Fat selective MRI, such as Dixon Magnetic Resonance Imaging can be used to quantify intra-organ lipid content, by acquisition of water- and fat-images (26). Using this technique, also spatial information about fat distribution can be obtained. Initially, the two-point Dixon method was developed. However, without phase information it is not possible to distinguish whether the water or fat fraction is dominant, and $T_{1}$ and $T_{2}{ }^{*}$ relaxation could influence quantification. Therefore, several modifications to the two-point Dixon method have been developed, among which three-point Dixon (27), modified Dixon (mDIXON) (28, 29) and iterative decomposition of water and fat with echo asymmetry and leastsquares estimation (IDEAL) (30). Despite good correlation between ${ }^{1} \mathrm{H}-\mathrm{MRS}$ and Dixon-based methods, an overestimation of the fat fraction in heart (31) and liver(32) was found using two-point Dixon as well as mDixon, respectively. Additionally, it was also shown that the apparent hepatic fat fraction as determined by two-point Dixon and IDEAL can significantly vary, which may limit the clinical application (33).

Alternatively, ${ }^{1} \mathrm{H}-\mathrm{MRS}$ can be used to measure hepatic lipid content noninvasively. The method is reproducible (34-36) and closely coincides with biopsy-derived triglyceride concentrations (34). In contrast to the qualitative and semiquantitative measures from ultrasound and CT respectively, MRS provides quantitative measures (37). Furthermore, MRS does not use ionizing radiation and can therefore safely be applied in longitudinal studies, although subjects identified with contra-indications for MRI cannot be scanned. Additionally, ${ }^{1} \mathrm{H}$ MRS might be a promising technique to measure also fibrosis severity by determining lipid composition index, as shown in patients with hepatitis C (38). Newer techniques in which liver stiffness is assessed (using ultrasound or magnetic resonance elastography) may also be promising for detecting liver inflammation and fibrosis (39). Thus, cardiac and hepatic ${ }^{1} \mathrm{H}$-MRS allow repeated measurements, for instance to study disease progression and to monitor response to treatment and intervention. Since ${ }^{1} \mathrm{H}-\mathrm{MRS}$ can be combined with MR imaging and 31-Phosphorous $\left({ }^{31} \mathrm{P}\right) \mathrm{MRS}$, organ function (e.g. cardiac function) can be 
determined in the same session. ${ }^{31} \mathrm{P}$ MRS is generally used to assess tissue energy status by determining the PCr/ATP ratio (in the heart) or ATP concentration (in the liver), while cardiac Magnetic Resonance Imaging is an established imaging technique for the study of myocardial structure, function, perfusion, and fibrosis (40).

\section{ECTOPIC LIPID ACCUMULATION AND ORGAN FUNCTION}

Ectopic lipid accumulation is generally not found in a single organ only, but affects several organs simultaneously and may together contribute to organ dysfunction. In this thesis, we focused on heart and liver.

\section{Heart}

Obesity is well known to increase blood pressure and dyslipidemia, thereby increasing cardiovascular risk $(1,2)$. In addition, in human and animal models of obesity, changes in cardiac function have been reported, which may result from hypertension $(41,42)$, mitochondrial dysfunction (43), but also from ectopic lipid accumulation $(44,45)$. However, to what extent the observed cardiac changes are due to cardiac fat storage is not fully understood. Therefore, to investigate the relationship between ectopic lipid accumulation and cardiac function, we performed in this thesis a longitudinal study in mice in which ectopic lipid accumulation was facilitated by (early) exposure to a high fat (HF) diet already in utero and during lactation. As described in Chapter 5, cardiac lipid content was indeed increased in 15-week old offspring which were already exposed to a HF diet during development in utero and during lactation. However, no changes in cardiac mitochondrial function and cardiac systolic function were observed. Additionally, glucose tolerance was unaffected, however, triglyceride clearance was diminished.

Our results obtained at the first time point (12-15 weeks of age) are at first glance inconsistent with previous findings, where cardiac lipid accumulation was correlated with metabolic disturbances such as impaired glucose tolerance and insulin resistance in obese subjects, and patients with impaired glucose tolerance and $\operatorname{T2DM}(11,46)$, and with mitochondrial dysfunction in humans and animal models of disease $(43,47)$. Whether cardiac lipid accumulation is a cause or consequence of myocardial insulin resistance is still under debate (48). However, it is known that during insulin resistance, myocardial glucose uptake is impaired and the heart has an increased reliance on fatty acid (FA) oxidation $(49,50)$. The increased FA oxidation can also lead to accumulation of lipid intermediates and raised production of reactive oxygen species (ROS) (50). Together, this may lead to mitochondrial dysfunction, which in turn leads to cardiac dysfunction (51) and even cell death (52-54). However, in our study, we did not find an effect of cardiac lipid accumulation and/or mitochondrial dysfunction on the development of 
cardiac systolic dysfunction. In some studies a correlation was found between cardiac lipid accumulation and cardiac contractile or systolic dysfunction $(7,10)$. It should be noted that the model used here induced only a mild increase in lipid content as compared to genetic animal models where cardiac lipid content is often severely manipulated, which is then associated with cardiac dysfunction (55-57). Furthermore, the early exposure to a HF diet might have lead initially to an adaptive response such that mitochondrial function and cardiac systolic function first stayed unaffected, as previously observed in rat offspring from HF fed mothers which did not develop endothelial dysfunction or reduced heart rate, when receiving the same diet as their mothers $(58,59)$.

In the longitudinal mouse study however, we found at 28 weeks of age a reduced mitochondrial respiration in mice early exposed to a HF diet while cardiac lipid content stayed equally high in time, but even tended to be lower than in mice exposed to a HF diet only after weaning. Cardiac systolic function and glucose tolerance were unaffected in both groups. This result is consistent with data from a recent study in which it was shown that exposure to HF feeding of sufficient duration results in reduced mitochondrial respiration, together with increased ROS production (60). Due to the reduced mitochondrial respiration in mice exposed to the HF diet during their whole lifetime, we also expected a further increase in cardiac lipid accumulation, unless the heart protects itself by switching substrate preference. Hypertrophied hearts are characterized by an increased reliance on glucose metabolism and an overall reduction in oxidative metabolism (61). Whether this also happens in mice early exposed to a HF diet needs further investigation.

\section{Liver}

A wide variety of underlying factors may contribute to the development of NAFLD, of which mitochondrial dysfunction (62), increased hepatic de novo lipogenesis (DNL) $(62,63)$, increased lipolysis in adipose tissue and dyslipidemia (64).

In our longitudinal mouse study, we investigated how these factors are affected by early exposure to a high fat diet and furthermore, how postprandial fatty acid retention from a meal is affected. As described in Chapter 5, early exposure to a $\mathrm{HF}$ diet did not lead to hepatic lipid accumulation in offspring at 12 weeks of age, but in fact lowered hepatic fat content. The reduction in liver fat was not due to the contribution of hepatic DNL as this tended to be higher after early exposure to a HF diet. This is in line with an earlier reported increase in (indicators of) DNL in animal models of NAFLD (62) and in humans with NAFLD (63). Triglyceride clearance was disturbed and lipid retention from a meal was severely decreased after early exposure to HF and could therefore explain the unexpected lowered hepatic fat content. Whether the reduction in hepatic lipid content in mice early exposed to a HF diet is also caused by adaptive mechanisms needs further investigation. However, whether the disturbed lipid metabolism on the longer 
term may contribute to the development of fatty liver, needs further investigation.

Given that high hepatic lipid content is associated with an increased risk for metabolic complications, such as insulin resistance and cardiovascular events (65), efforts to reduce hepatic lipid content are desirable. It has recently been shown that prolonged exercise training lowers hepatic lipid content (66-69). As described in Chapter 6, we investigated whether acute exercise has the same effect on hepatic lipid content. We showed that hepatic lipid content increased rather than decreased upon exercise when performed in the fasting state, in overweight subjects with and without NAFLD. As it has been shown in other studies that performing exercise during fasting leads to increased free fatty acid concentrations $(70,71)$ and the plasma free fatty acids are a major contributor to hepatic lipid accumulation $(72,73)$, the increased hepatic lipid content can most likely be explained by increased fatty acid flux to the liver in the fasted state.

\section{FUTURE PERSPECTIVES}

In this thesis, it was shown in a longitudinal mouse study that cardiac ectopic lipid accumulation may lead to mitochondrial dysfunction in time, while no changes in systolic function were found. Myocardial lipid accumulation has been associated with systolic (10) and diastolic dysfunction (74-76), probably via mitochondrial dysfunction. Changes in diastolic function generally precede changes in systolic function and parameters of diastolic function might therefore indicate early changes and it might take longer for systolic dysfunction to develop. Therefore, one of the future aims would be to establish whether cardiac diastolic and systolic dysfunction develops later in life when early exposed to a HF (older than 28 weeks of age).

Additionally, a higher contribution of DNL to hepatic lipid content, which also has been shown in animal models $(62,77)$ and humans $(63)$ with NAFLD, may contribute to hepatic lipid accumulation on the longer term. Therefore, another future aim would be to determine whether steatosis develops later in life when early exposed to HF (older than 28 weeks of age).

Several studies have shown that early exposure to different types of dietary fat has also different effects on health in offspring $(59,78-80)$. Hence, it would be interesting to investigate which specific dietary lipids are responsible for ectopic lipid accumulation and organ dysfunction and whether the negative health effects can be prevented by specific dietary lipid supplementation.

In this thesis, it was shown in mice that early exposure to a HF diet leads to an unfavorable cardiometabolic risk profile in offspring. As the prevalence of obesity is rising, also in woman of child-bearing age, the question is whether the results are also applicable to the human situation. This needs further investigation, whereby the use of non-invasive techniques is essential, for instance to measure 
cardiac function, cardiac and hepatic lipid metabolism, energy status as well as body fat volume at several points in time in obese parents and their child(ren). In conclusion, noninvasive Magnetic Resonance techniques have proven to be helpful in determining the relationship between ectopic fat accumulation and tissue function, in mice and man. It has been shown that the relationship between ectopic fat accumulation and organ function is complicated and depends on the organ of interest, the time point at which the measurement is performed and several other factors. Although the application of Magnetic Resonance techniques is more challenging in mice due to their small size, high heart rate and fast breathing rhythm. Still, it is worth investing in this technique, because repeated measurements are possible whereby the number of animals needed for investigations are reduced. So, also in small animal models MR techniques can be valuable and help in understanding the mechanisms and development of metabolic diseases. 


\section{References}

1. Wilson PW, D'Agostino RB, Sullivan L, Parise H, Kannel WB. Overweight and obesity as determinants of cardiovascular risk: the Framingham experience. Arch Intern Med. 2002; 162:1867-1872.

2. Strazzullo P, D'Elia L, Cairella G, Garbagnati F, Cappuccio FP, Scalfi L. Excess body weight and incidence of stroke: meta-analysis of prospective studies with 2 million participants. Stroke. 2010; 41:e418-426.

3. Boyko EJ, Fujimoto WY, Leonetti DL, Newell-Morris L. Visceral adiposity and risk of type 2 diabetes: a prospective study among Japanese Americans. Diabetes Care. 2000; 23:465-471.

4. Fletcher B, Gulanick M, Lamendola C. Risk factors for type 2 diabetes mellitus. J Cardiovasc Nurs. 2002; 16:17-23.

5. Hossain P, Kawar B, El Nahas M. Obesity and diabetes in the developing world--a growing challenge. N Engl J Med. 2007; 356:213-215.

6. Cusi K. The role of adipose tissue and lipotoxicity in the pathogenesis of type 2 diabetes. Curr Diab Rep. 2010; 10:306-315.

7. Sharma S, Adrogue JV, Golfman L, Uray I, Lemm J, Youker K, Noon GP, Frazier OH, Taegtmeyer H. Intramyocardial lipid accumulation in the failing human heart resembles the lipotoxic rat heart. Faseb J. 2004; 18:1692-1700.

8. Cusi K. Role of obesity and lipotoxicity in the development of nonalcoholic steatohepatitis: pathophysiology and clinical implications. Gastroenterology. 2012; 142:711-725 e716.

9. Ibrahim SH, Kohli R, Gores GJ. Mechanisms of lipotoxicity in NAFLD and clinical implications. J Pediatr Gastroenterol Nutr. 2011; 53:131-140.

10. Szczepaniak LS, Dobbins RL, Metzger GJ, Sartoni-D'Ambrosia G, Arbique D, Vongpatanasin W, Unger R, Victor RG. Myocardial triglycerides and systolic function in humans: in vivo evaluation by localized proton spectroscopy and cardiac imaging. Magn Reson Med. 2003; 49:417-423.

11. McGavock JM, Lingvay I, Zib I, Tillery T, Salas N, Unger R, Levine BD, Raskin P, Victor RG, Szczepaniak LS. Cardiac steatosis in diabetes mellitus: a $1 \mathrm{H}$-magnetic resonance spectroscopy study. Circulation. 2007; 116:1170-1175.

12. Reingold JS, McGavock JM, Kaka S, Tillery T, Victor RG, Szczepaniak LS. Determination of triglyceride in the human myocardium by magnetic resonance spectroscopy: reproducibility and sensitivity of the method. Am J Physiol Endocrinol Metab. 2005; 289:E935-939.

13. Bakermans AJ, Geraedts TR, van Weeghel M, Denis S, Joao Ferraz M, Aerts JM, Aten J, Nicolay K, Houten SM, Prompers JJ. Fasting-induced myocardial lipid accumulation in long-chain acyl-CoA dehydrogenase knockout mice is accompanied by impaired left ventricular function. Circ Cardiovasc Imaging. 2011; 4:558-565.

14. O'Connor RD, Xu J, Ewald GA, Ackerman JJ, Peterson LR, Gropler RJ, Bashir A. Intramyocardial triglyceride quantification by magnetic resonance spectroscopy: In vivo and ex vivo correlation in human subjects. Magn Reson Med. 2011; 65:1234-1238.

15. Mehta SR, Thomas EL, Bell JD, Johnston DG, Taylor-Robinson SD. Non-invasive means of measuring hepatic fat content. World J Gastroenterol. 2008; 14:3476-3483.

16. Lupsor M, Badea R. Imaging diagnosis and quantification of hepatic steatosis: is it an accepted alternative to needle biopsy? Rom J Gastroenterol. 2005; 14:419-425.

17. Jungermann K, Kietzmann T. Zonation of parenchymal and nonparenchymal metabolism in liver. Annu Rev Nutr. 1996; 16:179-203.

18. Castera L, Negre I, Samii K, Buffet C. Pain experienced during percutaneous liver biopsy. Hepatology. 1999; 30:1529-1530.

19. Grant A, Neuberger J. Guidelines on the use of liver biopsy in clinical practice. British Society of Gastroenterology. Gut. 1999; 45 Suppl 4:IV1-IV11.

20. Joseph AE, Saverymuttu SH, al-Sam S, Cook MG, Maxwell JD. Comparison of liver histology with ultrasonography in assessing diffuse parenchymal liver disease. Clin Radiol. 1991; 43:26-31.

21. Debongnie JC, Pauls C, Fievez M, Wibin E. Prospective evaluation of the diagnostic accuracy of liver ultrasonography. Gut. 1981; 22:130-135.

22. Saverymuttu SH, Joseph AE, Maxwell JD. Ultrasound scanning in the detection of hepatic fibrosis and steatosis. Br Med J (Clin Res Ed). 1986; 292:13-15.

23. Mottin CC, Moretto M, Padoin AV, Swarowsky AM, Toneto MG, Glock L, Repetto G. The role of ultrasound in the diagnosis of hepatic steatosis in morbidly obese patients. Obes Surg. 2004; 14:635637. 
24. Kodama Y, Ng CS, Wu TT, Ayers GD, Curley SA, Abdalla EK, Vauthey JN, Charnsangavej C. Comparison of CT methods for determining the fat content of the liver. AJR Am J Roentgenol. 2007; 188:13071312.

25. Park SH, Kim PN, Kim KW, Lee SW, Yoon SE, Park SW, Ha HK, Lee MG, Hwang S, Lee SG, Yu ES, Cho EY. Macrovesicular hepatic steatosis in living liver donors: use of CT for quantitative and qualitative assessment. Radiology. 2006; 239:105-112.

26. Dixon WT. Simple proton spectroscopic imaging. Radiology. 1984; 153:189-194.

27. Glover GH, Schneider E. Three-point Dixon technique for true water/fat decomposition with B0 inhomogeneity correction. Magn Reson Med. 1991; 18:371-383.

28. Berglund J, Ahlstrom H, Johansson L, Kullberg J. Two-point dixon method with flexible echo times. Magn Reson Med. 2011; 65:994-1004.

29. Eggers H, Brendel B, Duijndam A, Herigault G. Dual-echo Dixon imaging with flexible choice of echo times. Magn Reson Med. 2011; 65:96-107.

30. Reeder SB, Pineda AR, Wen Z, Shimakawa A, Yu H, Brittain JH, Gold GE, Beaulieu CH, Pelc NJ. Iterative decomposition of water and fat with echo asymmetry and least-squares estimation (IDEAL): application with fast spin-echo imaging. Magn Reson Med. 2005; 54:636-644.

31. Liu CY, Redheuil A, Ouwerkerk R, Lima JA, Bluemke DA. Myocardial fat quantification in humans: Evaluation by two-point water-fat imaging and localized proton spectroscopy. Magn Reson Med. 2010; 63:892-901.

32. Livingstone RS, Begovatz P, Kahl S, Nowotny B, Strassburger K, Giani G, Bunke J, Roden M, Hwang JH. Initial clinical application of modified Dixon with flexible echo times: hepatic and pancreatic fat assessments in comparison with H MRS. Magma. 2013.

33. Kim H, Taksali SE, Dufour S, Befroy D, Goodman TR, Petersen KF, Shulman GI, Caprio S, Constable RT. Comparative MR study of hepatic fat quantification using single-voxel proton spectroscopy, two-point dixon and three-point IDEAL. Magn Reson Med. 2008; 59:521-527.

34. Cowin GJ, Jonsson JR, Bauer JD, Ash S, Ali A, Osland EJ, Purdie DM, Clouston AD, Powell EE, Galloway GJ. Magnetic resonance imaging and spectroscopy for monitoring liver steatosis. J Magn Reson Imaging. 2008; 28:937-945.

35. Machann J, Thamer C, Schnoedt B, Stefan N, Haring HU, Claussen CD, Fritsche A, Schick F. Hepatic lipid accumulation in healthy subjects: a comparative study using spectral fat-selective MRI and volumelocalized 1H-MR spectroscopy. Magn Reson Med. 2006; 55:913-917.

36. Szczepaniak LS, Nurenberg P, Leonard D, Browning JD, Reingold JS, Grundy S, Hobbs HH, Dobbins RL. Magnetic resonance spectroscopy to measure hepatic triglyceride content: prevalence of hepatic steatosis in the general population. Am J Physiol Endocrinol Metab. 2005; 288:E462-468.

37. Schwenzer NF, Springer F, Schraml C, Stefan N, Machann J, Schick F. Non-invasive assessment and quantification of liver steatosis by ultrasound, computed tomography and magnetic resonance. J Hepatol. 2009; 51:433-445.

38. Cobbold JF, Patel JH, Goldin RD, North BV, Crossey MM, Fitzpatrick J, Wylezinska M, Thomas HC, Cox IJ, Taylor-Robinson SD. Hepatic lipid profiling in chronic hepatitis C: an in vitro and in vivo proton magnetic resonance spectroscopy study. J Hepatol. 2010; 52:16-24.

39. Cobbold JF, Patel D, Taylor-Robinson SD. Assessment of inflammation and fibrosis in non-alcoholic fatty liver disease by imaging-based techniques. J Gastroenterol Hepatol. 2012; 27:1281-1292.

40. Parsai C, O'Hanlon R, Prasad SK, Mohiaddin RH. Diagnostic and prognostic value of cardiovascular magnetic resonance in non-ischaemic cardiomyopathies. J Cardiovasc Magn Reson. 2012; 14:54.

41. Nguyen T, Lau DC. The obesity epidemic and its impact on hypertension. Can J Cardiol. 2012; 28:326333.

42. Landsberg L, Aronne LJ, Beilin LJ, Burke V, Igel LI, Lloyd-Jones D, Sowers J. Obesity-related hypertension: pathogenesis, cardiovascular risk, and treatment: a position paper of The Obesity Society and the American Society of Hypertension. J Clin Hypertens (Greenwich). 2013; 15:14-33.

43. Bugger $\mathrm{H}$, Abel ED. Molecular mechanisms for myocardial mitochondrial dysfunction in the metabolic syndrome. Clin Sci (Lond). 2008; 114:195-210.

44. Montani JP, Carroll JF, Dwyer TM, Antic V, Yang Z, Dulloo AG. Ectopic fat storage in heart, blood vessels and kidneys in the pathogenesis of cardiovascular diseases. Int J Obes Relat Metab Disord. 2004; 28 Suppl 4:S58-65.

45. Shimabukuro M, Kozuka C, Taira S, Yabiku K, Dagvasumberel M, Ishida M, Matsumoto S, Yagi S, Fukuda D, Yamakawa K, Higa M, Soeki T, Yoshida H, Masuzaki H, Sata M. Ectopic fat deposition and global cardiometabolic risk: new paradigm in cardiovascular medicine. J Med Invest. 2013; 60:1-14. 
46. Iozzo P, Lautamaki R, Borra R, Lehto HR, Bucci M, Viljanen A, Parkka J, Lepomaki V, Maggio R, Parkkola R, Knuuti J, Nuutila P. Contribution of glucose tolerance and gender to cardiac adiposity. J Clin Endocrinol Metab. 2009; 94:4472-4482.

47. Zhou YT, Grayburn P, Karim A, Shimabukuro M, Higa M, Baetens D, Orci L, Unger RH. Lipotoxic heart disease in obese rats: implications for human obesity. Proc Natl Acad Sci U S A. 2000; 97:1784-1789.

48. Gastaldelli A, Morales MA, Marraccini P, Sicari R. The role of cardiac fat in insulin resistance. Curr Opin Clin Nutr Metab Care. 2012; 15:523-528.

49. Carley AN, Severson DL. Fatty acid metabolism is enhanced in type 2 diabetic hearts. Biochim Biophys Acta. 2005; 1734:112-126.

50. Dirkx E, Schwenk RW, Glatz JF, Luiken JJ, van Eys GJ. High fat diet induced diabetic cardiomyopathy. Prostaglandins Leukot Essent Fatty Acids. 2011; 85:219-225.

51. Tsutsui H, Kinugawa S, Matsushima S. Mitochondrial oxidative stress and dysfunction in myocardial remodelling. Cardiovasc Res. 2009; 81:449-456.

52. Chen L, Knowlton AA. Mitochondria and heart failure: new insights into an energetic problem. Minerva Cardioangiol. 2010; 58:213-229.

53. Gray S, Kim JK. New insights into insulin resistance in the diabetic heart. Trends Endocrinol Metab. 2011; 22:394-403.

54. Belke DD, Betuing S, Tuttle MJ, Graveleau C, Young ME, Pham M, Zhang D, Cooksey RC, McClain DA, Litwin SE, Taegtmeyer H, Severson D, Kahn CR, Abel ED. Insulin signaling coordinately regulates cardiac size, metabolism, and contractile protein isoform expression. J Clin Invest. 2002; 109:629-639.

55. Finck BN, Han X, Courtois M, Aimond F, Nerbonne JM, Kovacs A, Gross RW, Kelly DP. A critical role for PPARalpha-mediated lipotoxicity in the pathogenesis of diabetic cardiomyopathy: modulation by dietary fat content. Proc Natl Acad Sci U S A. 2003; 100:1226-1231.

56. Haemmerle G, Lass A, Zimmermann R, Gorkiewicz G, Meyer C, Rozman J, Heldmaier G, Maier R, TheussI C, Eder S, Kratky D, Wagner EF, Klingenspor M, Hoefler G, Zechner R. Defective lipolysis and altered energy metabolism in mice lacking adipose triglyceride lipase. Science. 2006; 312:734-737.

57. Chiu HC, Kovacs A, Ford DA, Hsu FF, Garcia R, Herrero P, Saffitz JE, Schaffer JE. A novel mouse model of lipotoxic cardiomyopathy. J Clin Invest. 2001; 107:813-822.

58. Khan I, Dekou V, Hanson M, Poston L, Taylor P. Predictive adaptive responses to maternal high-fat diet prevent endothelial dysfunction but not hypertension in adult rat offspring. Circulation. 2004; 110:1097-1102.

59. Khan IY, Dekou V, Douglas G, Jensen R, Hanson MA, Poston L, Taylor PD. A high-fat diet during rat pregnancy or suckling induces cardiovascular dysfunction in adult offspring. American journal of physiology Regulatory, integrative and comparative physiology. 2005; 288:R127-133.

60. Yu L, Fink BD, Herlein JA, Oltman CL, Lamping KG, Sivitz WI. Dietary fat, fatty acid saturation and mitochondrial bioenergetics. J Bioenerg Biomembr. 2013.

61. Kolwicz SC, Jr., Tian R. Glucose metabolism and cardiac hypertrophy. Cardiovasc Res. 2011; 90:194201.

62. Bruce KD, Cagampang FR, Argenton M, Zhang J, Ethirajan PL, Burdge GC, Bateman AC, Clough GF, Poston L, Hanson MA, McConnell JM, Byrne CD. Maternal high-fat feeding primes steatohepatitis in adult mice offspring, involving mitochondrial dysfunction and altered lipogenesis gene expression. Hepatology. 2009; 50:1796-1808.

63. Donnelly KL, Smith Cl, Schwarzenberg SJ, Jessurun J, Boldt MD, Parks EJ. Sources of fatty acids stored in liver and secreted via lipoproteins in patients with nonalcoholic fatty liver disease. J Clin Invest. 2005; 115:1343-1351.

64. Chatrath H, Vuppalanchi R, Chalasani N. Dyslipidemia in patients with nonalcoholic fatty liver disease. Semin Liver Dis. 2012; 32:22-29.

65. Gaggini M, Morelli M, Buzzigoli E, DeFronzo RA, Bugianesi E, Gastaldelli A. Non-alcoholic fatty liver disease (NAFLD) and its connection with insulin resistance, dyslipidemia, atherosclerosis and coronary heart disease. Nutrients. 2013; 5:1544-1560.

66. Sullivan S, Kirk EP, Mittendorfer B, Patterson BW, Klein S. Randomized trial of exercise effect on intrahepatic triglyceride content and lipid kinetics in nonalcoholic fatty liver disease. Hepatology. 2012; 55:1738-1745.

67. Hallsworth K, Fattakhova G, Hollingsworth KG, Thoma C, Moore S, Taylor R, Day CP, Trenell MI. Resistance exercise reduces liver fat and its mediators in non-alcoholic fatty liver disease independent of weight loss. Gut. 2011; 60:1278-1283. 
68. Finucane FM, Sharp SJ, Purslow LR, Horton K, Horton J, Savage DB, Brage S, Besson H, De Lucia Rolfe E, Sleigh A, Martin HJ, Aihie Sayer A, Cooper C, Ekelund U, Griffin SJ, Wareham NJ. The effects of aerobic exercise on metabolic risk, insulin sensitivity and intrahepatic lipid in healthy older people from the Hertfordshire Cohort Study: a randomised controlled trial. Diabetologia. 2010; 53:624-631.

69. Chen SM, Liu CY, Li SR, Huang HT, Tsai CY, Jou HJ. Effects of therapeutic lifestyle program on ultrasound-diagnosed nonalcoholic fatty liver disease. J Chin Med Assoc. 2008; 71:551-558.

70. Bilet L, van de Weijer T, Hesselink MK, Glatz JF, Lamb HJ, Wildberger J, Kooi ME, Schrauwen P, Schrauwen-Hinderling VB. Exercise-induced modulation of cardiac lipid content in healthy lean young men. Basic research in cardiology. 2010; 106:307-315.

71. Schrauwen P, Hesselink MK, Vaartjes I, Kornips E, Saris WH, Giacobino JP, Russell A. Effect of acute exercise on uncoupling protein 3 is a fat metabolism-mediated effect. American journal of physiology. 2002; 282:E11-17.

72. Donnelly KL, Smith Cl, Schwarzenberg SJ, Jessurun J, Boldt MD, Parks EJ. Sources of fatty acids stored in liver and secreted via lipoproteins in patients with nonalcoholic fatty liver disease. The Journal of clinical investigation. 2005; 115:1343-1351.

73. Teusink B, Voshol PJ, Dahlmans VE, Rensen PC, Pijl H, Romijn JA, Havekes LM. Contribution of fatty acids released from lipolysis of plasma triglycerides to total plasma fatty acid flux and tissue-specific fatty acid uptake. Diabetes. 2003; 52:614-620.

74. Hammer S, van der Meer RW, Lamb HJ, Schar M, de Roos A, Smit JW, Romijn JA. Progressive caloric restriction induces dose-dependent changes in myocardial triglyceride content and diastolic function in healthy men. J Clin Endocrinol Metab. 2008; 93:497-503.

75. van der Meer RW, Rijzewijk LJ, Diamant M, Hammer S, Schar M, Bax JJ, Smit JW, Romijn JA, de Roos A, Lamb HJ. The ageing male heart: myocardial triglyceride content as independent predictor of diastolic function. Eur Heart J. 2008; 29:1516-1522.

76. Rijzewijk L, van der Meer RW, Smit JW, Diamant M, Bax JJ, Hammer S, Romijn JA, de Roos A, Lamb HJ. Myocardial steatosis is an independent predictor of diastolic dysfunction in type 2 diabetes mellitus. Journal of the American College of Cardiology. 2008; 52:1793-1799.

77. Elahi MM, Cagampang FR, Mukhtar D, Anthony FW, Ohri SK, Hanson MA. Long-term maternal high-fat feeding from weaning through pregnancy and lactation predisposes offspring to hypertension, raised plasma lipids and fatty liver in mice. Br J Nutr. 2009; 102:514-519.

78. Khan IY, Taylor PD, Dekou V, Seed PT, Lakasing L, Graham D, Dominiczak AF, Hanson MA, Poston L. Gender-linked hypertension in offspring of lard-fed pregnant rats. Hypertension. 2003; 41:168-175.

79. Chechi K, Cheema SK. Maternal diet rich in saturated fats has deleterious effects on plasma lipids of mice. Exp Clin Cardiol. 2006; 11:129-135.

80. Armitage JA, Gupta S, Wood C, Jensen RI, Samuelsson AM, Fuller W, Shattock MJ, Poston L, Taylor PD. Maternal dietary supplementation with saturated, but not monounsaturated or polyunsaturated fatty acids, leads to tissue-specific inhibition of offspring Na+,K+-ATPase. J Physiol. 2008; 586:5013-5022. 

It is well known that the prevalence of obesity has increased dramatically in the last three decades. Moreover, overweight and obesity are known to be strong risk factors for the development of insulin resistance and type 2 diabetes mellitus (T2DM), non-alcoholic fatty liver disease (NAFLD), and cardiac disease. Fat is mostly stored in adipose tissue, however small amounts of triglycerides are also stored in other tissues. In the overweight and obese state, adipose tissue mass expands, but also fat deposition in non-adipose tissues (so called ectopic sites) increases. The increased fat deposition in non-adipose tissues causes adverse effects (also called lipotoxicity), which is thought to play an important role in the development of the previously mentioned diseases. In the present thesis, we further investigated the relationship between ectopic fat accumulation and cardiac and hepatic tissue function, using noninvasive magnetic resonance techniques.

For the investigation of cardiac metabolism, it is of great importance to use noninvasive in vivo techniques that can be used repeatedly. In Chapter 2 state-ofthe-art Magnetic Resonance methods to assess cardiac metabolism in vivo are reviewed, with a focus on phosphorus $\left({ }^{31} \mathrm{P}\right)$, proton $\left({ }^{1} \mathrm{H}\right)$, and carbon $\left({ }^{13} \mathrm{C}\right)$ hyperpolarized Magnetic Resonance Spectroscopy (MRS). It is concluded that cardiac MRS is an important tool to investigate cardiac metabolism, but that some methodological challenges (such as a long scan time and low signal-to-noise ratio) have be tackled before cardiac MRS can be broadly applied in the clinic.

Since experimental animals are often used to investigate the mechanisms underlying the development of metabolic diseases, quick and reliable methods are required for determination of cardiac function.

To investigate cardiac systolic function, typically multi-slice short-axis cine-MRI of the complete left ventricle (LV) is required. However, this method (which is considered the gold standard for assessment of cardiac systolic function) requires long acquisition as well as postprocessing times. Therefore, in Chapter 3, we evaluated different geometrical models that require only up to three cine-MRI slices to determine cardiac systolic function. We demonstrated that of these models the modified Simpson rule model provided comparable results with the gold standard for all the calculated parameters; LV volumes, stroke volume, and ejection fraction.

Next to methodological development, the aim of this thesis was to investigate the effect of ectopic fat accumulation on the development of metabolic diseases. To this end, we investigated if exposure to a high fat (HF) diet in mice during gestation and lactation would increase the susceptibility to lipotoxic effects of a HF diet consumed later in life. We first reviewed in Chapter 4 literature on mechanisms underlying hepatic and cardiac lipotoxicity through programming 
during early development. We concluded that there is convincing evidence that prenatal exposure to either dietary shortage or overabundance increases the susceptibility for ectopic lipid accumulation in heart and liver. Next, we performed a longitudinal study in mice using various non-invasive MR techniques. As described in Chapter 5, we found that early exposure to a HF diet indeed increased the susceptibility for unfavorable (health) effects, such as increased visceral adipose tissue and cardiac lipid content, and delayed postprandial triglyceride clearance. As postprandial hypertriglyceridemia and visceral fat content are risk factors for cardiovascular disease, the results indicate that early exposure to a HF diet may be an important risk factor for morbidity and mortality later in life.

In contrast to the observed unfavorable (health) effects of early exposure to highfat feeding, it is well known that prolonged exercise training decreases the risk of (cardio-) metabolic diseases by (among others) reducing intrahepatic lipid accumulation. In Chapter 6, we investigated, using ${ }^{1} \mathrm{H}-\mathrm{MRS}$, in overweight middleaged men whether a single bout of acute exercise also leads to decreases in intrahepatic lipid content. In contrast, we found an increase in hepatic lipid content when acute exercise was performed in the fasted state. This increase in hepatic lipid content was not found when acute exercise was performed in the glucose-fed state. When performing exercise in the fasted state, plasma fatty acid levels rise several-fold, to provide the muscle with substrate for oxidation. However when glucose is consumed during exercise, glucose will become the preferred substrate and the rise in plasma FFA levels is blunted. Therefore, we concluded that plasma fatty acid concentrations play an important role in determining intrahepatic lipid content and that a single bout of exercise is not able to lower intrahepatic lipid content.

It is well known that increased hepatic lipid content is strongly associated with the development of T2DM and it has been suggested that impaired hepatic energy metabolism plays an important role in the development of hepatic steatosis. An indicator of hepatic energy metabolism is the cellular ATP concentration. Using ${ }^{31} \mathrm{P}$ MRS, hepatic ATP content can be quantified in absolute concentrations or relative to a reference metabolite. Relative quantification becomes problematic when the concentration of the reference metabolite also changes. In Chapter $\mathbf{7}$ we showed that absolute hepatic $Y$-ATP quantification is feasible using a single phantomreplacement method with correction for small deviations in voxel position by the use of a 3D sensitivity map.

In Chapter 8 the results of this thesis are discussed and put in broader perspective. We conclude that noninvasive Magnetic Resonance techniques are helpful in determining the relationship between ectopic fat accumulation and 
174 | Summary

tissue function, in mice and man. In addition, we conclude that the relationship between ectopic fat accumulation and organ function is complicated and depends amongst others on the organ of interest and the time point at which the measurement is performed. 


Samenvatting

Samenvatting 
Het is algemeen bekend dat de prevalentie van obesitas de laatste 30 jaar dramatisch is toegenomen. Bovendien is bekend dat overgewicht en obesitas sterke risicofactoren vormen voor het ontwikkelen van insuline resistentie en type 2 diabetes mellitus (T2DM), niet-alcoholische leververvetting (NAFLD) en hartziekten. Onder normale omstandigheden wordt het meeste vet opgeslagen in vetweefsel en slechts kleine hoeveelheden vet worden opgeslagen in andere weefsels. In het geval van overgewicht en obesitas neemt het vetweefsel allereerst in omvang toe, maar daarna zal het vet zich ook ophopen in nietvetweefsels (dit wordt ectopische vetstapeling genoemd). De toegenomen vetstapeling in niet-vetweefsel veroorzaakt schadelijke effecten (ook wel lipotoxiciteit genoemd), welke vermoedelijk een belangrijke rol spelen in de ontwikkeling van de eerder genoemde ziekten. In dit proefschrift hebben we verder onderzoek gedaan naar de relatie tussen ectopische vetstapeling en harten leverfunctie, met behulp van niet-invasieve Magnetische Resonantie technieken.

Om het hartmetabolisme te onderzoeken is het van groot belang dat er gebruik gemaakt kan worden van niet-invasieve technieken om herhaaldelijke in vivo metingen mogelijk te maken. In Hoofdstuk $\mathbf{2}$ wordt een overzicht gegeven van de literatuur over de nieuwste en meest geavanceerde Magnetische Resonantie technieken die gebruikt kunnen worden om hartmetabolisme in vivo te meten. Hierbij is voornamelijk gekeken naar fosfor $\left({ }^{31} \mathrm{P}\right)$, waterstof $\left({ }^{1} \mathrm{H}\right)$, en koolstof $\left({ }^{13} \mathrm{C}\right)$ gehyperpolariseerde Magnetische Resonantie Spectroscopie (MRS). Uit de literatuurstudie blijkt dat MRS van het hart een belangrijk hulpmiddel is om hartmetabolisme te onderzoeken, maar ook dat er verschillende methodologische verbeteringen nodig zijn (zoals een vermindering van de totale scantijd en een verbeterde signaal-ruis verhouding) voordat deze techniek op brede schaal toegepast kan worden in de kliniek.

Aangezien proefdieren vaak gebruikt worden om de onderliggende mechanismen van het ontstaan van metabole ziekten te onderzoeken, zijn snelle en betrouwbare technieken vereist voor het bepalen van de hartfunctie.

Om de systolische functie van het hart te onderzoeken, wordt gebruik gemaakt van cine-MRI van het hele linker ventrikel (LV). Deze methode wordt gezien als de 'gouden standaard' om systolische hartfunctie te onderzoeken. Het nadeel van deze methode is dat het veel tijd kost om de cine-MRI van de gehele LV te verkrijgen en te verwerken. Daarom hebben we in Hoofdstuk 3 verschillende geometrische modellen onderzocht waarbij maximaal 3 doorsneden van het LV werden verkregen om de systolische hartfunctie te bepalen. We hebben aangetoond dat alleen het zogenaamde 'modified Simpson rule' model vergelijkbare resultaten gaf als de 'gouden standaard'. 
Naast het ontwikkelen van methoden, werd in dit proefschrift ook onderzoek gedaan naar het effect van ectopische vetstapeling op het ontstaan van metabole ziekten. In één van de studies hebben we in muizen onderzocht of blootstelling aan hoogvet (HF) voeding gedurende de zwangerschap en zoogperiode, leidt tot het ontwikkelen van lipotoxiciteit wanneer deze muizen worden blootgesteld aan $\mathrm{HF}$ voeding na de zoogperiode. In hoofdstuk 4 hebben we de literatuur besproken over de onderliggende mechanismen van lipotoxiciteit in hart en lever onder condities van vroege blootstelling aan overmaat of tekort aan voeding. We conluderen dat er overtuigend bewijs is dat prenatele blootstelling aan een tekort of juist een overvloed aan voeding de gevoeligheid voor ectopische vetstapeling in hart en lever vergroot. Vervolgens hebben we een longitudinale muisstudie uitgevoerd waarbij gebruik gemaakt is van verschillende niet-invasieve MR technieken. Zoals beschreven in Hoofdstuk 5, zagen we dat vroege blootstelling aan HF voeding inderdaad leidt tot ongewenste (gezondheids-) effecten, zoals een toegenomen viscerale vetmassa, toegenomen vetstapeling in het hart en een vertraagde klaring van triglyceride uit het bloedplasma na de maaltijd. Omdat hypertriglyceridemie na de maaltijd en een toegenomen viscerale vetmassa risicofactoren zijn voor het ontwikkelen van cardiovasculaire ziekten, duiden de resultaten van deze studie erop dat vroege blootstelling aan HF voeding een belangrijke risicofactor kan zijn voor het ontstaan van ziekten en mortaliteit later in het leven.

In tegenstelling tot de ongewenste (gezondheids-) effecten van vroege blootstelling aan hoogvet voeding zoals gevonden in Hoofdstuk 5 , is het bekend dat regelmatige lichamelijk inspanning het riscio op (cardio-) metabole ziekten vermindert door (onder andere) het verminderen van vetstapeling in de lever. In Hoofdstuk 6 hebben we met behulp van ${ }^{1} \mathrm{H}$-MRS bij mannen van middelbare leeftijd, met overgewicht onderzocht of twee uur fietsen leidt tot een verlaagd vetgehalte van de lever. We vonden echter een toegenomen vetgehalte in de lever wanneer er twee uur gefietst werd in gevaste toestand, maar deze toename in lever vetgehalte werd niet gevonden wanneer er twee uur werd gefietst terwijl de proefpersonen een glucosedrank mochten consumeren. Wanneer in gevaste toestand inspanning verricht wordt, stijgt de concentratie van de vrije vetzuren in het plasma met als doel de spieren van brandstoffen te voorzien. Wanneer echter tijdens inspanning glucose wordt geconsumeerd, zal glucose de spieren van brandstof voorzien en blijft de plasmaconcentratie van vrije vetzuren laag. Op grond van deze bevindingen hebben we geconcludeerd dat de vrije vetzuurconcentratie in het plasma een belangrijke rol speelt bij de vervetting van de lever en dat één enkele inspanning van twee uur fietsen niet in staat is om het lever vetgehalte te verminderen. 
Het is bekend dat toegenomen lever vetgehalte sterk geassocieerd is met de ontwikkeling van type 2 diabetes en het is gesuggereerd dat een verslechterd energiemetabolisme in de lever een belangrijke rol speelt bij het ontwikkelen van leververvetting. Een indicator voor het energiemetabolisme in de lever is de cellulaire ATP concentratie. Met behulp van ${ }^{31} \mathrm{P}$ MRS kan ATP in de lever in absolute concentraties óf relatief ten opzichte van een referentiemetaboliet gekwantificeerd worden. Relatieve kwantificatie wordt problematisch als de concentratie van het referentiemetaboliet ook verandert. In Hoofdstuk $\mathbf{7}$ hebben we aangetoond dat met een enkele referentiemeting in een zogenaamd 'phantom replacement' experiment absolute ATP kwantificatie in de lever mogelijk is en dat daarbij ook gecorrigeerd kan worden voor kleine afwijkingen in meetpositie door gebruik te maken van een 3D sensitiviteitsmap.

In Hoofdstuk 8 worden de resultaten van dit proefschrift bediscussieerd en in breder perspectief geplaatst. We conluderen dat niet-invasieve Magnetische Resonantie technieken waardevol zijn om de relatie tussen ectopische vetstapeling en weefselfunctie te bepalen, zowel in muizen als mensen. Verder concluderen we dat de relatie tussen ectopische vetstapeling en orgaanfunctie gecompliceerd is en onder andere afhankelijk is van het orgaan waarnaar gekeken wordt en het tijdspunt waarop de meting wordt uitgevoerd. 


Dankwoord

Dankwoord 
Aan het einde van mijn promotietraject, waarvan de onderzoeksresultaten in dit boekje zijn beschreven, wil ik graag iedereen bedanken die mij op welke wijze dan ook gesteund en geholpen heeft.

Als eerste wil ik mijn promotor, prof. dr. Patrick Schrauwen, bedanken. Patrick; ik ben je dankbaar dat je mij de mogelijkheid hebt geboden om aan dit promotietraject te beginnen en het ook te voltooien. Ik wil je bedanken voor je begeleiding; je positief-kritsische houding wanneer ik met mijn onderzoeksresultaten bij je kwam, je geduld, je enthousiasme en je waardevolle adviezen.

Daarnaast wil ik mijn co-promotores, dr. Eline Kooi en dr. Vera SchrauwenHinderling, bedanken. Eline; ik heb je mogen leren kennen als een veelzijdig persoon - bij jou kan je werkelijk met allerlei zaken terecht. Dankjewel voor je luisterend oor en waardevolle adviezen. Vera; door jouw enorme toewijding aan het onderzoek was je altijd bereidt om te helpen waar nodig. Het resultaat daarvan was dat we menig avond samen achter de scanner hebben doorgebracht. Deze avonden zal ik mij herinneren als leerzaam, maar vooral ook gezellig. Eline en Vera; jullie hebben beiden veel expertise op het gebied van MR technieken en ik ben blij dat ik daarom onder jullie begeleiding dit promotietraject mocht doen. Dankjulliewel voor jullie geduld, jullie steun en postieve instelling. Ik heb enorm veel van jullie geleerd en jullie zullen altijd een voorbeeld voor mij blijven.

Tevens wil ik de leden van het PREDICCt project (specifiek workpackage 3), met name prof. dr. Jan Glatz, prof. dr Matthijs Hesselink, prof. dr. Arend Heerschap, prof. dr. Cees Tack, dr. Joost Luiken, dr. Frederic Girard, (dr.) Tineke van de Weijer en (dr.) Patricia Nunes, danken voor de fijne samenwerking en waardevolle overlegmomenten. Jan; helaas kon je geen deel uit maken van mijn promotieteam, maar jouw belangstelling en je suggesties voor het onderzoek waar ik mee bezig was, heb ik altijd erg gewaardeerd. Matthijs; jouw kritische vragen werkten voor mij vaak verhelderend. Ik ben onder de indruk van jouw brede kennis en wil je ook specifiek bedanken voor je waardevolle suggesties met betrekking tot de muisstudies. Tineke; ik heb het fijn gevonden om met jou samen te werken. Je enthousiasme werkt aanstekelijk en ik zal onze gezellige uurtjes bij de scanner niet gauw vergeten. Patricia; thank you for your collaboration, especially during the 'metabolic imprinting' study. Thank you for your support and valuable comments.

Ook andere leden van het PREDICCt project, specifiek dr. Torsten Plösch, dr.Agnes Lendvai en Maurien Pruis, wil ik hartelijk danken voor de discussies en samenwerking met betrekking tot de 'metabolic imprinting' studie en het review. 
In het bijzonder wil ik prof. dr. Joachim Wildberger bedanken. Bedankt dat u mij de mogelijkheid en het vertrouwen hebt gegeven om binnen de afdeling radiologie met verschillende MR-scanners te werken.

Zonder collega's zou werken wel heel saai worden. Daarom wil ik de collega's van de afdeling Humane Biologie, specifiek de SHOCk-groep, en de onderzoeksgroep bij de afdeling Radiologie hartelijk danken voor alle gezelligheid. Naast de vele 'officiele ontmoetingen' (tijdens werktijd), heb ik ook altijd erg genoten van de inofficiele ontmoetingen (buiten werktijd). Dankjulliewel voor alles!

Van de SHOCk-groep wil ik specifiek nog Lena Bilet en Bram Brouwers bedanken voor de fijne samenwerking tijdens de 'acute exercise' studie. In addition, I want to thank Sabina Paglialunga, Anne Gemmink, Joris Hoeks, Johanna Jorgensen, Esther Moonen-Kornips and Gert Schaart for their collaboration, help and valuable suggestions during the 'metabolic imprinting' study. Lucas Lindeboom en Christine Nabuurs; ook jullie wil ik hier specifiek noemen. We hebben dan niet officieel samengewerkt bij een bepaalde studie, maar we hebben wel veel samen gedaan. Ik vond het altijd fijn om met jullie van gedachten te wisselen (bijvoorbeeld tijdens de spectroclub) en soms ook samen te scannen. Ik wens jullie allebei veel succes bij het vervolg van jullie loopbaan.

Van de onderzoeksgroep bij de afdeling Radiologie wil ik nog specifiek Jos Slenter en Martijn Wolters bedanken. Ik ben blij dat jullie mijn paranimfen zijn! Jos; ik heb veel van jou geleerd (niet alleen over de MR-scanner) en ben blij dat je tijdens de openbare verdediging achter mij wil staan. Martijn; je weet enorm veel en daarom heb ik het altijd fijn gevonden om met jou van gedachten te wisselen. Dankjewel dat ook jij tijdens de openbare verdediging achter mij wil staan.

De MR laboranten wil ik hartelijk danken voor de hulp, en de gezelligheid bij het scannen.

Daarnaast wil ik de medewerkers van de CPV bedanken voor hun hulp en advies tijdens de muisstudies.

Verder wil ik de studenten Friso en Kevin danken voor hun hulp bij de verschillende onderzoeken.

Graag wil ik ook de proefpersonen hartelijk danken voor hun deelname aan het onderzoek. Zonder hun medewerking zou de wetenschap niet snel verder komen. Ik dank jullie voor het vertrouwen! 
Ook wil ik een speciaal dankwoord richten tot een aantal mensen uit mijn vrienden- en familiekring.

Petra Smit- van Rijssel; je bent een vriendin door 'dik en dun'. Ook al was de fysieke afstand tussen ons groot, we hielden contact. Een telefoontje met jou, beurde mij soms weer helemaal op. Dankjewel voor wie je bent!

Eline van der Esch; ik denk dat jij in Maastricht op mijn pad geplaatst bent. Wat was en ben ik blij dat we elkaar toen ontmoet hebben en dat we elkaar konden bijstaan in allerlei zaken. Ik hoop dat je een zonnige toekomst tegemoed zal gaan, samen met Petry.

Els De Smet; wat was ik blij dat ik jou ontmoette op de UM aan het begin van ons promotietraject. We hadden dan wel heel verschillende onderwerpen, maar we hadden ook zoveel herkenning. Ik denk dat daardoor onze vriendschap steeds sterker is geworden. Ook ons gedenkwaardige :) uitstapje naar de Ardennen heeft daar zeker aan bijgedragen! Dankjewel voor alles.

Marjanne Marking-van Ittersum; soms vroeg ik me bijna af of je aanvoelde dat ik aan je dacht. Jij was er altijd op de momenten dat het nodig was. Dankjewel!

Familie Heuts; door u voelde ik mij thuis in Maastricht - niet alleen letterlijk, maar ook figuurlijk. Uw hartelijkheid zal ik nooit vergeten.

De mensen van de christengemeenten van Maastricht, Bunde/Meerssen. Hartelijk dank dat ik de zondagen in jullie midden mocht doorbrengen. Hierdoor bleef de zondag voor mij een feestdag! Dankjulliewel voor jullie warmte, hartelijkheid en oprechte meeleven.

Ook de mensen uit mijn thuisgemeente wil ik hartelijk bedanken voor hun meeleven en gebed.

Daarnaast wil ik mijn familie bedanken voor hun trouwe support. Specifiek wil ik mij richtten tot mijn opa en oma, mijn ouders, broer en (schoon)zusje. Opa en oma; ook al snapte u misschien niet helemaal waar ik nu eigenlijk mee bezig was, door uw meeleven en aanmoediging voelde ik mij enorm gesteund. Papa en mama; $u$ heeft mij vanaf de wieg al aangemoedigd om me zo goed mogelijk te ontwikkelen. Door uw steun ben ik gekomen waar ik nu sta. Ik kan onmogelijk mijn enorme dankbaarheid hiervoor in woorden uitdrukken. Niels en Jeanet; dankjulliewel voor jullie trouwe support. Erna en Luuk; ik vind het altijd weer een feest om samen met jullie te genieten van alle kleine en grote dingen. Dankjulliewel voor jullie steun en de nodige afleiding. 
Tenslotte, wil ik mijn hemelse Vader bedanken voor de talenten en mogelijkheden die Hij mij gegeven heeft. Soli Deo Gloria! 

Curriculum Vitea

Curriculum Vitea 
Eline van Ewijk was born in Naarden on the 24th of December 1984. After completing secondary school (Guido de Brès, Amersfoort), she started her study in Medical Natural Sciences (Vrije Universiteit, Amsterdam). During her master specialization she performed two research internships. Under supervision of Prof. dr. ing. M.C.G. Aalders (Academic Medical Centre, Amsterdam) she investigated the use of fluorescence spectroscopy on skin to determine post mortem time. During her minor research internship, which was performed under supervision of Prof. dr. ir. E.J.G. Peterman (Vrije Universiteit, Amsterdam), she worked on automatic particle tracking for directional motion. In 2009 she received her MSc degree and started her PhD project at Maastricht University. Her PhD project was performed under the supervision of Prof. dr. Patrick Schrauwen, Dr. Eline Kooi en Dr. Vera Schrauwen-Hinderling and concerned the use of Magnetic Resonance techniques to study lipotoxicity, which resulted in this thesis. Eline is currently working part-time as a teacher at a vocational school (Hoornbeeck College, Amersfoort). 


List of publications

List of publications 
van de Weijer T, van Ewijk PA, Zandbergen HR, Slenter JM, Kessels AG, Wildberger JE, Hesselink MK, Schrauwen P, Schrauwen-Hinderling VB, Kooi ME. Geometrical models for cardiac MRI in rodents: comparison of quantification of left ventricular volumes and function by various geometrical models with full-volume MRI data set in rodents. Am J Physiol Heart Circ Physiol. 2012 Feb 1;302(3):H709-15.

Pruis MGM, van Ewijk PA, Schrauwen-Hinderling VB, Plösch T. Lipotoxicity and the role of maternal nutrition. Acta Physiol (Oxf). 2013

van Ewijk PA, Schrauwen-Hinderling VB, Bekkers SCAM, Glatz JFC, Wildberger JE, Kooi ME, Magnetic Resonance Spectroscopy: a Noninvasive Window into Cardiac Metabolism. (Submitted)

van Ewijk PA, Paglialunga S, Kooi ME, Nunes PM, Gemmink A, Slenter JM, Kornips E, Jörgensen JA, Hoeks J, Wildberger JE, Hesselink MKC, Glatz JFC, Heerschap A,Kersten S, Schrauwen P, Schrauwen-Hinderling VB, Increased cardiac lipid content and postprandial hypertriglyceridemia after early exposure to high-fat feeding. (Submitted)

Bilet L, Brouwers B, van Ewijk PA, Hesselink MKC, Kooi ME, Schrauwen P, SchrauwenHinderling VB, Hepatic lipid content is unchanged after two hours of cycling exercise in middle-aged overweight men. (Submitted)

van Ewijk PA, Kooi ME, Brouwers B, Bilet L, den Heijer F, van Lieshout $K$, Wildberger JE, Hesselink MKC, Schrauwen P, Schrauwen-Hinderling VB, Absolute quantification of hepatic $\gamma$-ATP concentrations using 31P MR Spectroscopy at a whole body $3 T$ scanner. (In preparation) 

